\title{
Electric and Hybrid Electric Vehicles: A Technology Assessment Based on a Two-Stage Delphi Study
}
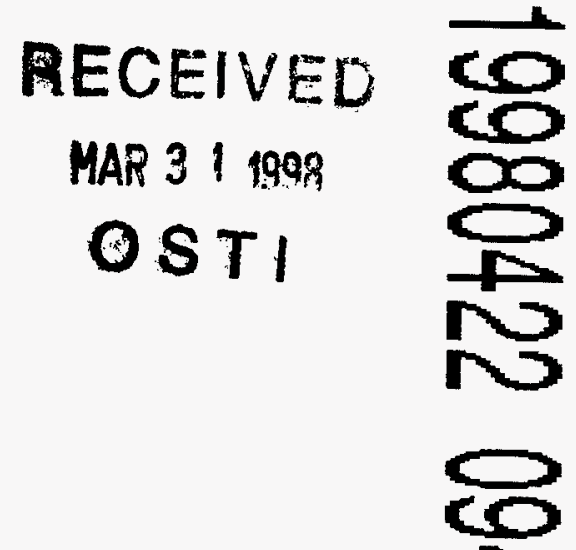

$\rightarrow$

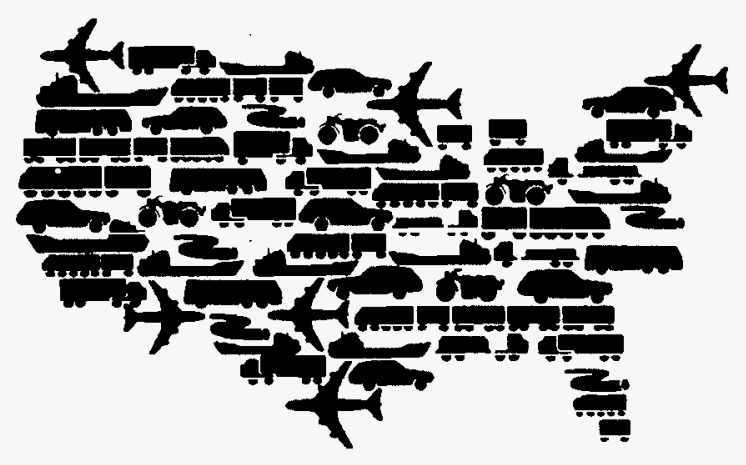

Center for Transportation Research Argonne National Laboratory 


\section{Argonne National Laboratory}

Argonne National Laboratory, with facilities in the states of Illinois and Idaho, is owned by the United States Government, and operated by the University of Chicago under the provisions of a contract with the Department of Energy.

This technical report is a product of Argonne's Energy Systems Division.

For information on the division's scientific and engineering activities, contact:

Director, Energy Systems Division

Argonne National Laboratory

Argonne, Illinois 60439-4815

Telephone (630) 252-3724

Publishing support services were provided by Argonne's Information and Publishing Division (for more information, see IPD's home page: http://www.ipd.anl.gov/).

\section{Disclaimer}

This report was prepared as an account of work sponsored by an agency of the United States Government. Neither the United States Government nor any agency thereof, nor any of their employees, makes any warranty, express or implied, or assumes any legal liability or responsibility for the accuracy, completeness, or usefulness of any information, apparatus, product, or process disciosed, or represents that its use would not infringe privately owned rights. Reference herein to any specific commercial product, process, or service by trade name, trademark, manufacturer, or otherwise, does not necessarily constitute or imply its endorsement, recommendation, or favoring by the United States Government or any agency thereof. The views and opinions of authors expressed herein do not necessarily state or reflect those of the United States Government or any agency thereof.

Available to DOE and DOE contractors from the Office of Scientific and Technical Information, P.O. Box 62, Oak Ridge, TN 37831; prices available from (423) 576-8401.

Available to the public from the National Technical Information Service, U.S. Department of Commerce, 5285 Port Royal Road, Springfield, VA 22161. 


\section{Electric and Hybrid Electric Vehicles: A Technology Assessment Based on a Two-Stage Delphi Study}

by A.D. Vyas, H.K. Ng, D.J. Santini, and J.L. Anderson

Center for Transportation Research, Energy Systems Division,

Argonne National Laboratory, 9700 South Cass Avenue, Argonne, Illinois 60439

DISTRIBUTION OF THS COOUMENT IS UNLIMTED

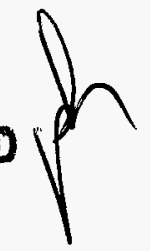

Work sponsored by the United States Department of Energy,

Assistant Secretary for Energy Efficiency and Renewable Energy, Office of Transportation Technologies 


\section{CONTENTS}

ACKNOWLEDGMENTS $\ldots \ldots \ldots \ldots \ldots \ldots \ldots \ldots \ldots \ldots \ldots \ldots \ldots \ldots \ldots$ vii

NOTATION $\ldots \ldots \ldots \ldots \ldots \ldots \ldots \ldots \ldots \ldots \ldots \ldots \ldots \ldots \ldots \ldots \ldots \ldots \ldots \ldots \ldots \ldots$

ABSTRACT $\ldots \ldots \ldots \ldots \ldots \ldots \ldots \ldots \ldots \ldots \ldots \ldots \ldots \ldots \ldots \ldots \ldots \ldots$

1 OVERVIEW $\ldots \ldots \ldots \ldots \ldots \ldots \ldots \ldots \ldots \ldots \ldots \ldots \ldots \ldots \ldots \ldots \ldots \ldots \ldots$

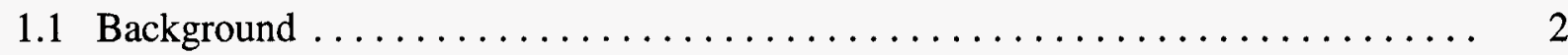

1.2 Electric and Hybrid Electric Vehicle Technologies $\ldots \ldots \ldots \ldots \ldots \ldots \ldots \ldots$

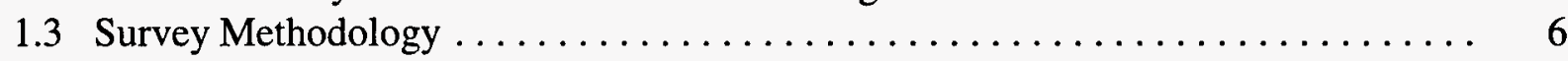

1.4 Survey Response $\ldots \ldots \ldots \ldots \ldots \ldots \ldots \ldots \ldots \ldots \ldots \ldots \ldots \ldots \ldots$

2 SURVEY RESULTS ON ELECTRIC AND HYBRID VEHICLES $\ldots \ldots \ldots \ldots \ldots$

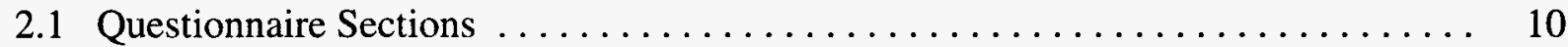

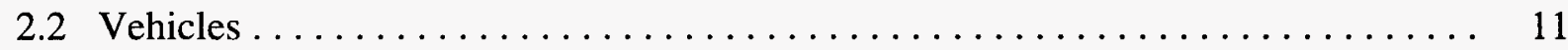

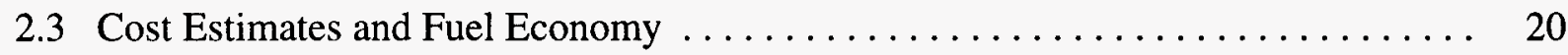

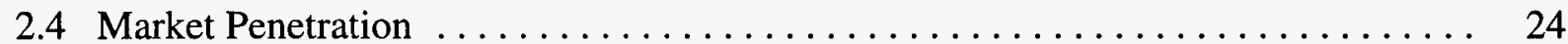

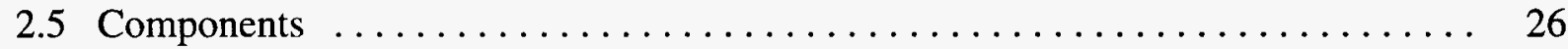

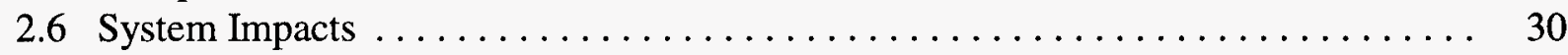

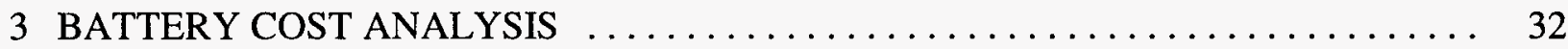

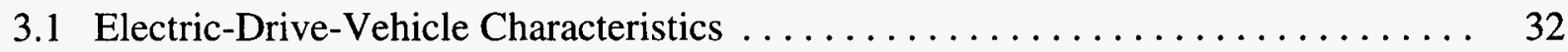

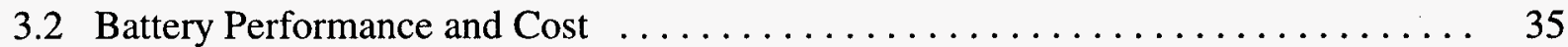

3.3 Variable Operating Costs, Including Battery Replacement $\ldots \ldots \ldots \ldots \ldots \ldots$. . 47

3.4 Comparison with CARB Panel Battery Data $\ldots \ldots \ldots \ldots \ldots \ldots \ldots \ldots \ldots$

3.5 Summary of Battery Cost Analysis $\ldots \ldots \ldots \ldots \ldots \ldots \ldots \ldots \ldots \ldots$

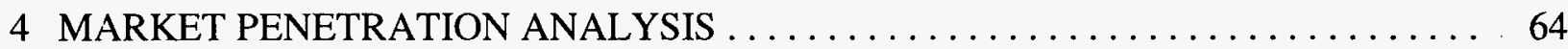

4.1 Modeling the Pattern of Market Penetration . . . . . . . . . . . . . . . . . . 64

4.2 Market Penetration through Consumer Preference Models . . . . . . . . . 67

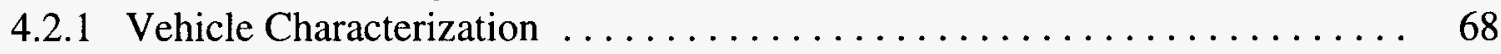

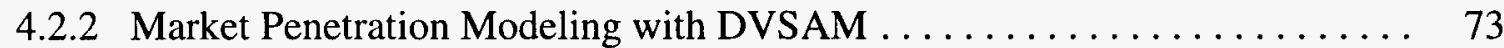

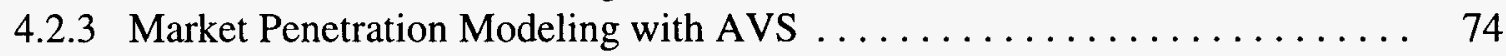

4.3 Summary of Market Penetration Analysis $\ldots \ldots \ldots \ldots \ldots \ldots \ldots \ldots \ldots \ldots$

5 INDUSTRY AND ALL-GROUP COMPARISONS $\ldots \ldots \ldots \ldots \ldots \ldots \ldots \ldots$

5.1 Vehicle-Related Comparisons $\ldots \ldots \ldots \ldots \ldots \ldots \ldots \ldots \ldots \ldots \ldots \ldots \ldots \ldots$

5.2 Costs and Fuel Economy Comparison $\ldots \ldots \ldots \ldots \ldots \ldots \ldots \ldots \ldots \ldots$ 


\section{CONTENTS (Cont.)}

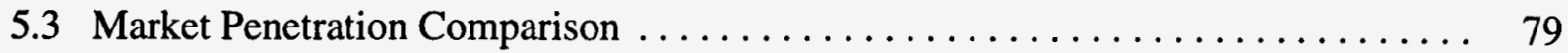

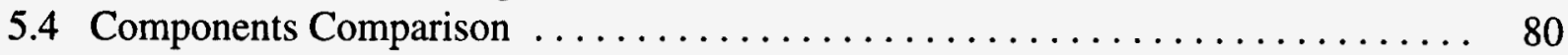

5.5 System Impact Comparison $\ldots \ldots \ldots \ldots \ldots \ldots \ldots \ldots \ldots \ldots \ldots \ldots \ldots \ldots \ldots \ldots$

6 COMPARISON OF STAGE 2 RESULTS WITH STAGE 1 RESULTS $\ldots \ldots \ldots \ldots \ldots \quad 84$

6.1 Comparison of Vehicle-Related Responses $\ldots \ldots \ldots \ldots \ldots \ldots \ldots \ldots \ldots . \ldots 4$

6.2 Cost Comparison ...................................... 88

6.3 Market Penetration Comparison $\ldots \ldots \ldots \ldots \ldots \ldots \ldots \ldots \ldots \ldots \ldots \ldots . \ldots \ldots$

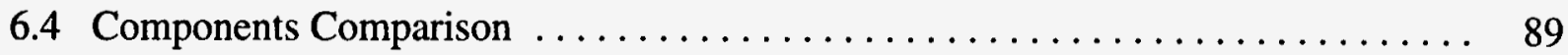

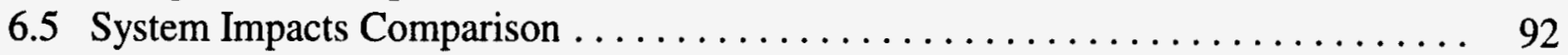

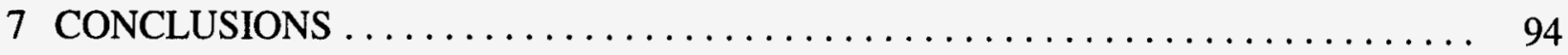

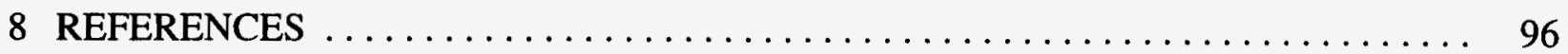

APPENDIX A: First-Stage Results and Second-Stage Questionnaire $\ldots \ldots \ldots \ldots \ldots 101$

APPENDIX B: Comparison of Stage 1 and Stage 2 Questionnaires ............. 127

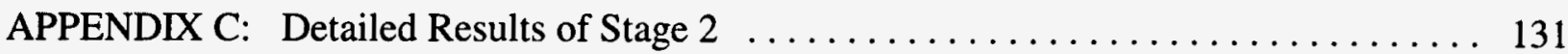

\section{TABLES}

1.1 Organizational Breakdown of Respondents to the Second-Stage

Delphi Questionnaire

2.1 Organizational Breakdown of Respondents by Questionnaire Sections $\ldots \ldots \ldots \ldots \quad 12$

2.2 Forecast Statistics for $11 \mathrm{EV}$ Attributes $\ldots \ldots \ldots \ldots \ldots \ldots \ldots \ldots \ldots \ldots \ldots \ldots \ldots \ldots \ldots \ldots$

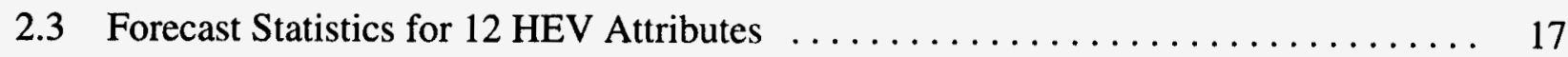

2.4 Forecast Statistics for Vehicle Purchase Price Ratios $\ldots \ldots \ldots \ldots \ldots \ldots \ldots \ldots$

2.5 Forecast Statistics for Fuel Economy Ratios for the Five Technologies $\ldots \ldots \ldots \ldots \quad 23$

2.6 Forecast Statistics for Market Penetration of the Five Technologies ........... 25

2.7 Future Characteristics of the Ten Battery Technologies ................ 27 


\section{TABLES (Cont.)}

3.1 Vehicle Purchase Price for Conventional, Electric, and Hybrid Vehicles ........ 34

3.2 Fuel and Maintenance Costs for Conventional, Electric, and Hybrid Vehicles ...... 34

3.3 Initial EV Battery Pack Power and Mass for the Mean Range $\ldots \ldots \ldots \ldots \ldots \ldots .36$

3.4 Characteristics of Initial EV Battery Pack $\ldots \ldots \ldots \ldots \ldots \ldots \ldots \ldots \ldots \ldots \ldots$

3.5 Characteristics of Initial HEV Battery Pack $\ldots \ldots \ldots \ldots \ldots \ldots \ldots \ldots \ldots \ldots \ldots \ldots$

3.6 Modified CARB Panel Battery Characteristics $\ldots \ldots \ldots \ldots \ldots \ldots \ldots \ldots \ldots . \ldots \ldots$

3.7 Characteristics of the Initial EV Battery Pack, Using the Modified CARB

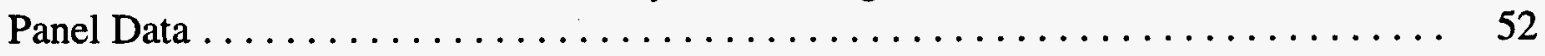

3.8 Characteristics of the Initial HEV Battery Packs, Based on the Modified

CARB Panel Data ................................... 59

4.1 Results of Model Coefficients Estimation $\ldots \ldots \ldots \ldots \ldots \ldots \ldots \ldots \ldots \ldots \ldots \ldots$

4.2 Selected Vehicle Characteristics Used in Vehicle Choice Modeling . . . . . . . . . 70

4.3 Vehicle Attributes Used by the Vehicle Choice Models and Their Sources ....... 72

6.1 Comparison of Vehicle Characteristics Ratings for the Two Stages $\ldots \ldots \ldots \ldots \ldots \quad 85$

\section{FIGURES}

2.1 Mean Importance Ratings for Key EV Attributes $\ldots \ldots \ldots \ldots \ldots \ldots \ldots \ldots \ldots$

2.2 Mean Importance Ratings for Key HEV Attributes $\ldots \ldots \ldots \ldots \ldots \ldots \ldots \ldots \ldots$

2.3 Mean Vehicle Purchase Price for the Five Technologies $\ldots \ldots \ldots \ldots \ldots \ldots \ldots \ldots 21$

2.4 Mean Fuel and Maintenance Cost Ratios for the Five Technologies ........... 22

2.5 Mean Fuel Economy Estimates for the Five Technologies $\ldots \ldots \ldots \ldots \ldots \ldots \ldots$

3.1 EV Range and Battery Cost in Year 2020, Matching Mean Power Requirements . . . 39 


\section{FIGURES (Cont.)}

3.2 EV Battery Replacement Cost and Range Associated with the Mean Power

Requirements

3.3 Analysis of Combined Lead-Acid and Lithium-Polymer Battery Packs

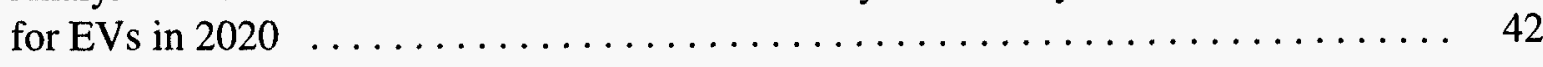

3.4 HEV Battery Replacement Cost and Range Associated with the Mean

Power Requirements ............................... 46

3.5 HEV Battery Replacement Cost and Range Associated with Half the Mean Power

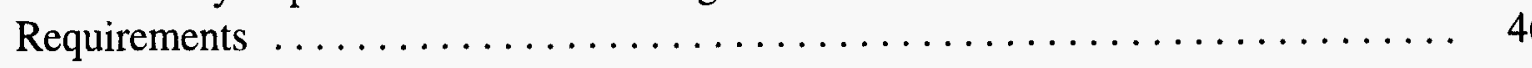

3.6 Variable Operating Costs, Including Battery Replacement Costs and Matching the Mean Range Requirements $\ldots \ldots \ldots \ldots \ldots \ldots \ldots \ldots \ldots \ldots \ldots \ldots \ldots$

3.7 Variable Operating Costs with Less Expensive Battery, Ignoring the Mean Range Requirements

3.8 EV Initial Battery Pack Cost and Range in 2020, from the Modified CARB

Panel Data ....................................... 54

3.9 EV Battery Replacement Cost and Range, from the Modified CARB

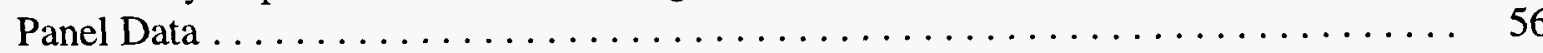

3.10 Analysis of Year 2020 Combined Lead-Acid and Lithium-Polymer Battery

Packs for EVs, Based on the Modified CARB Panel Data .............. 56

3.11 HEV Battery Replacement Cost and Range for the Modified CARB

Panel Data ......................................... 58

4.1 Application of Market Penetration Models to New Technologies ............. 66

4.2 New-Technology Market Shares in 2000, 2010, 2020, and $2030 \ldots \ldots \ldots \ldots \ldots \quad 68$

6.1 Change in Mean Values of EV Attributes Relative to the First Stage .......... 86

6.2 Change in Mean Values of HEV Attributes Relative to the First Stage .......... 86 


\section{ACKNOWLEDGMENTS}

The authors thank Dr. Philip Patterson of the Office of Transportation Technologies, U.S. Department of Energy, for his consistent support and valuable guidance. Thanks are also due to Phillip Mazzotti and Gary Pollak of SAE International for their invaluable help during the planning stage of the study; to SAE's Cooperative Research Program office staff for their participation in refining the questionnaires and for conducting the two-stage survey; and to the experts who devoted their time and effort in responding to the questionnaires - their participation made this study possible. Our technical editor, Floyd Bennett, painstakingly edited this report, the IPD-MED Document Processing and Control Center prepared the manuscript, and Lori Hermes and Laurel Culbert provided graphics support; we are thankful to them. We also thank the technical reviewers whose suggestions improved the quality of this report. This work was supported by the U.S. Department of Energy, Assistant Secretary for Energy Efficiency and Renewable Energy, Office of Transportation Technologies, under contract W-31-109-Eng-38. 


\section{NOTATION: ABBREVIATIONS, ACRONYMS, AND INITIALISMS}

AAMA American Automobile Manufacturers Association

ac

ANL

AVS

CAFE

CARB

CI

CRP

CTR

CV

dc

DOE

DVSAM

EIA

EPA

EV

FC

FC HEV

FTP

GM EV1

GT

GT HEV

$\mathrm{HC}$

HEV

ICE

ICE HEV

LEV

mpg

MY

$\mathrm{NO}_{\mathrm{x}}$

NRC

OTA

OTT

PNGV

R\&D

SAE

SI

SOC

USABC
Alternating current

Argonne National Laboratory

Alternative Vehicle Sales

Corporate Average Fuel Economy

California Air Resources Board

Compression ignition

Cooperative Research Program

Center for Transportation Research

Conventional vehicle

Direct current

U.S. Department of Energy

Disaggregate Vehicle Stock Allocation Model

Energy Information Administration

U.S. Environmental Protection Agency

Electric vehicle

Fuel cell

Fuel-cell-powered hybrid electric vehicle

Federal Test Procedure

General Motors Corporation's Electric Vehicle, Model EVI

Gas turbine

Gas-turbine-powered hybrid electric vehicle

Hydrocarbon(s)

Hybrid electric vehicle

Internal combustion engine

Internal-combustion-engine-powered hybrid electric vehicle

Low emission vehicle

Miles per gallon

Model year

Nitrogen oxides

National Research Council

Office of Technology Assessment

Office of Transportation Technologies

Partnership for a New Generation of Vehicles

Research and development

Society of Automotive Engineers, International

Spark ignition

State of charge

U.S. Advanced Battery Consortium 


\section{NOTATION (Cont.)}

VkmT Vehicle's usage, in kilometers of travel

ZEV Zero emission vehicle 


\title{
ELECTRIC AND HYBRID ELECTRIC VEHICLES: A TECHNOLOGY ASSESSMENT BASED ON A TWO-STAGE DELPHI STUDY
}

by

\author{
A.D. Vyas, H.K. Ng, D.J. Santini, and J.L. Anderson
}

\begin{abstract}
To address the uncertainty regarding future costs and operating attributes of electric and hybrid electric vehicles, a two-stage, worldwide Delphi study was conducted. Expert opinions on vehicle attributes, current state of the technology, possible advancements, costs, and market penetration potential were sought for the years 2000,2010, and 2020. Opinions related to such critical components as batteries, electric drive systems, and hybrid vehicle engines, as well as their respective technical and economic viabilities, were also obtained. This report contains descriptions of the survey methodology, analytical approach, and results of the analysis of survey data, together with a summary of other factors that will influence the degree of market success of electric and hybrid electric vehicle technologies. Responses by industry participants, the largest fraction among all the participating groups, are compared with the overall responses. An evaluation of changes between the two Delphi stages is also summarized. An analysis of battery replacement costs for various types is summarized, and variable operating costs for electric and hybrid vehicles are compared with those of conventional vehicles. A market penetration analysis is summarized, in which projected market shares from the survey are compared with predictions of shares on the basis of two market share projection models that use the cost and physical attributes provided by the survey. Finally, projections of market shares beyond the year 2020 are developed by use of constrained logit models of market shares, statistically fitted to the survey data.
\end{abstract}

\section{OVERVIEW}

The U.S. government actively supports research efforts that seek to contribute to improvement of the nation's security, its foreign trade balance, and thereby, its citizens' well-being. Although many of these efforts are high-risk in nature and the benefits to be derived are far in the future, the government supports them to increase the chances for a prosperous future. Also, when 
the time horizon is long and risks are great, as in most of these research efforts, the private sector tends to under-invest in the development of new technologies, necessitating government support. The government's role is to support research and development (R\&D) to identify, investigate, and enable new technologies that can enhance security, economic competitiveness, and the standard of living and health of its citizens.

\subsection{BACKGROUND}

The Office of Transportation Technologies (OTT) within the U.S. Department of Energy (DOE) funds research that could lead to reduced petroleum consumption through increased vehicle fuel efficiency and/or substitution of alternative fuels. The development of vehicle technologies that are also less harmful to the environment, as required by legislation and stricter new emissions standards early in the next century, is a major secondary goal of the OTT. These efforts will also enhance national security by reducing U.S. dependence on imported petroleum, improving the balance of trade, and assuring a firm foundation for future economic growth.

To ensure that introduction of the technologies being developed is not impeded by future emissions rules, DOE-supported research also provides an impetus to the development of new technologies that can improve air quality, particularly in large urban areas, and alleviate concerns about global warming due to burning of fossil fuels. Air quality in the United States' major urban areas has been slowly improving during the last two decades but, without even stricter emissions rules, the fear is that it will later worsen due to growth in vehicle use. This fear of worsening air quality in major urban areas has caused the federal and state governments to conditionally provide for stricter vehicular emissions standards (Tier II), with some states attempting to implement a California regulation requiring vehicles that will produce "ultra low" and/or zero tailpipe emissions. Consequently, OTT has supported research to make such vehicles possible, in the event they are demanded by numerous states.

\subsection{ELECTRIC AND HYBRID ELECTRIC VEHICLE TECHNOLOGIES}

Electric and hybrid electric vehicles are viewed as solutions to finally achieving urban air quality goals. The air pollution problem that has directed attention to electric vehicles (EVs) is tropospheric (near-ground) ozone, which is the worst in some California urban areas. Tropospheric ozone results primarily from photochemical reaction of air with hydrocarbons (HC) and nitrogen oxides $\left(\mathrm{NO}_{\mathrm{x}}\right.$ ) emissions. Because they will use electricity stored in batteries or other storage devices, such as ultracapacitors and flywheels, EVs have no tailpipe emissions and are classified as zero emission vehicles (ZEVs). However, emissions do result from the operation of the power plants that generate electricity to charge the EVs. Hybrid electric vehicles (HEVs) may be designed to use energy from the electric power grid stored in batteries in the beginning and then use power from a 
conventional or alternative fuel engine once the energy in the batteries has been depleted. Alternatively, an HEV may be designed to run exclusively on onboard electricity, generated through an engine, without ever using energy from the electric grid. Even so, with an adequately large battery pack, such an HEV could be operated in such a way that morning emissions, which undergo the longest photochemical reaction, are significantly reduced. The extent of emissions from an HEV will depend upon its design and the types of fuel and engine used. Many combinations are possible.

Environmental benefits of electric vehicles arise from zero tailpipe emissions, as well as other more complicated and less obvious emissions changes. EVs represent a potential solution to urban ozone problems created in part by gasoline- and diesel-powered vehicles. When emissions from electric power plants are accounted for, electric vehicles not only shift emissions from vehicles to remote places, they also change the composition and timing of emissions. While nearly eliminating carbon monoxide and hydrocarbon emissions, their use may also decrease the emissions of oxides of nitrogen, depending upon the type of power plants supplying electricity (Sperling 1995; Wang and Santini 1993; Wang et al. 1990). The emissions of two criteria pollutants, sulfur oxides and particulates, have been estimated to increase on average in the United States, largely due to coalfired power plants. However, these increased emissions usually will be at power plants that are outside the urban areas, and their estimated magnitudes are small compared to the overall emissions from these two pollutants.

Use of electric vehicles will not simply shift emissions from urban areas to the places where power plants are located. Significant "per vehicle" reduction in "full fuel cycle" emissions will also be obtained for most pollutants, sometimes for nearly all pollutants. The latter opportunity occurs because many urban areas obtain their electricity from hydro-, nuclear-, or natural-gas-powered generating plants that emit very low quantities of criteria pollutants. Also, most of the electric vehicles are likely to be recharged at night. Thus, the contribution of sunlight in the chemistry of pollution formation - especially for ozone — can be reduced drastically. To date, the nature of these changes has not been carefully studied.

Energy benefits of electric vehicles are in reduced petroleum consumption due to substitution and increased efficiency of the electric drive systems. Electric drive systems have very high efficiency, they do not consume energy in idling, and they can be designed to employ regenerative braking to capture the energy usually lost in braking. These advantages are pronounced in urban driving involving repeated braking and idling, but relatively small in highway driving. In urban driving conditions, HEVs also have the potential to be significantly more efficient than gasoline internal combustion engines (ICEs), even when the HEV engine is fueled by gasoline and power from the electric grid is not used (Siegel and Mendler 1996). When power both from the electric grid and the engine is used, the potential to reduce petroleum consumption is significant.

Greenhouse gas benefits of electric vehicles can be highly dependent on the type of primary energy used in generating electricity. Most of the existing fossil-fuel-burning electricity-generating 
plants are 33-35\% efficient. For a typical driving pattern, the present mix of generating technologies would provide only some marginal benefits for EVs with respect to greenhouse gas emissions. However, this generalization has many important exceptions. Some regions in the United States have hydro- or nuclear-power generating plants that would substantially reduce emissions of greenhouse gases for EVs used there (Wang and Marr 1994). The potential for greenhouse gas reduction due to electric vehicles is between 0 and 20\%, depending upon the region (DeLuchi 1991). The EV technology is still under development and may not mature until 2010. By 2010, many fossil-fuelburning electricity-generating plants may be replaced by more efficient plants, thereby providing higher greenhouse gas benefits. Most of the new power plants on order are natural-gas-fired, combined-cycle plants, which have efficiencies well above $40 \%$. Moreover, oxides of nitrogen $\left(\mathrm{NO}_{\mathrm{x}}\right)$ from the power plants might be regulated so that their emissions would also drop sharply.

Another aspect of EVs is that their overall contribution to reduction of air pollution and greenhouse gases may improve over time. A conventional vehicle is designed to meet the emissions standards that are in effect at the time of its manufacture. Experience has shown that its emissions characteristics deteriorate over time (EPA 1994). Also, a conventional vehicle emits more pollutants when operated in modes outside the Federal Test Procedure (FTP) (Ross et al. 1995). This phenomenon of increased emissions outside the FTP is commonly called "off-cycle emissions." In contrast, an EV's contribution to air pollution and greenhouse gases is dependent on electrical generating plants. These plants are usually subject to the current regulations, regardless of their date of commission, and their emissions rates are either stable or declining. Electrical generating plants are often upgraded or retrofitted to make them more energy-efficient and less polluting; motor vehicles are almost never retrofitted to reduce emissions. Thus, the contribution to air pollution and greenhouse gases by an EV could improve during its lifetime, while the contribution by a conventional vehicle would worsen during its lifetime.

Although electric vehicles have the potential to alleviate the urban air quality problem, the technology costs may still exceed the air quality benefits in most locations. Therefore, EVs still can benefit greatly from research and development, both to reduce costs and to determine where their benefits are the highest. Several items related to EVs' acceptance as an alternative to vehicles powered by the internal combustion engine are unresolved. Range, battery pack cost, and useful life are the dominant issues that need to be resolved first. Issues involving passenger comfort and safety through such amenities as heating, defrosting, air conditioning, and audio entertainment also need to be resolved; the amenities, viewed as essential by consumers, will reduce the EV range by a greater proportion than they do in the case of gasoline vehicles. EVs should have acceptable performance characteristics, such as an acceleration rate comparable to that of ICE vehicles and a reasonable top speed. Vehicle size, as defined by interior volume and luggage space, may be compromised if the energy storage system takes considerable space, thereby making an EV less attractive to consumers. 
The range of an electric vehicle is determined by its energy storage system and efficiency. At present, the most viable energy storage system is the battery. Lead-acid batteries are used to provide starting power for ICE vehicles and are available in the market. However, their attributes (such as energy storage potential, cost, and service life) are far from competitive in EV applications. The current lead-acid batteries are expensive and bulky, with low energy density, limited power, and short life when charged/discharged deeply and regularly. Several other battery technologies show promise of technically superior behavior relative to lead-acid batteries, possibly offering more total value per unit cost, while improvements are also possible in the lead-acid technology. Advanced lead-acid and other battery options require intensive research and development efforts. Such R\&D is being conducted under the auspices of the U.S. Advanced Battery Consortium (USABC).

One solution to the range limitation of electric vehicles is to have hybrid electric vehicles. A hybrid electric vehicle uses electrical energy from batteries and power from an onboard system consisting of a gas turbine, a conventional internal combustion engine, or some other candidate "power unit." The batteries may be charged either by energy from the electric grid or from an onboard generator powered by the power unit. A hybrid electric vehicle can be a charge-depleting type in which electrical energy from batteries is used until exhausted and then the power unit is used for the remainder of the trip. A charge-depleting HEV operates primarily as a ZEV while running only on the electricity stored in batteries. Alternatively, as a backup, the vehicle may be powered exclusively by a small power unit. A charge-sustaining hybrid makes use of power supplied from energy previously stored in the batteries for hard acceleration and depends on the power units for cruising and gentle acceleration. The energy previously depleted from the battery by hard accelerations is restored through charging with the power unit during periods of low power demand and through regenerative braking. When used with a conventional ICE, an HEV may produce emissions similar to those of ICE-powered conventional vehicles. When designed for potential universal use, the gasoline-fueled HEV option is attractive more for its high urban fuel economy than for its emissions benefits (in terms of reducing tropospheric ozone precursors in urban areas). It can significantly increase the fuel economy of new vehicles, thereby reducing petroleum consumption and the resulting greenhouse gas emissions. However, its two energy storage and power systems make it complex and expensive. Still, if battery packs remain very expensive, the ability of an HEV to allow substantial reduction in battery pack size may be a major cost benefit for electric drivetrain vehicles.

Electric drive components have evolved to adapt to the existing battery and automotive electric system. The most common electric drive systems use direct current (dc), while most industrial power systems use alternating current (ac). Some recent advancements have made it possible to use ac electric drive systems (Sperling 1995). An ac drive system has the potential to be more energy-efficient. Its regenerative braking system can be designed to capture more energy than is possible with a dc system. 
Research and development in EV and HEV technologies is conducted with public and private funds. Research conducted by the private sector is usually proprietary, providing limited detail. While information is available on some public-sector research, other public/private $R \& D$ efforts are conducted under agreements that results will not be published or will be published after a specified distant date. Because the limited range of an EV is viewed as the chief barrier to its wider acceptance, battery research has attracted considerable attention, but publication of results is limited. The battery also is the largest cost component. Research on electric drive systems is also progressing in both the private and public sectors. These research and development efforts have been under way for some time. Although no vehicle manufacturer has mass-marketed either an EV or an HEV, some fairly large market tests are under way, the most notable of which is the GM EV1.

Due in large part to the absence of public domain data on battery and vehicle research projects, the Center for Transportation Research (CTR) at Argonne National Laboratory (ANL), under OTT sponsorship and with the help of the Society of Automotive Engineers' (SAE) Cooperative Research Program (CRP), undertook a worldwide Delphi study to assess the types of electric and hybrid vehicles that experts expect to be feasible in the next 25 years. The goal of the study was to collect information on various attributes of these vehicles, estimate their performance, and evaluate potential market penetration. Experts in the field were surveyed to collect their opinions on the future characteristics of EVs and HEVs. Study results will help decision makers in government and industry in formulating policy and orienting their research and development efforts properly.

A summary of the Delphi survey, data analysis, and results are presented in this report. The results are summarized for such categories as future vehicles, system components, and system impacts. Opinions related to market shares are compared with other projections. Market penetration expectations are also evaluated by subjecting the vehicle attributes data to a modeling exercise in which conventional and new technology vehicles compete. Results of this modeling exercise are presented. Parts of the work presented here have been published in three conference papers and a journal article (Ng et al. 1995; Ng et al. 1996a, 1996b; and Vyas et al. 1997). This report represents a comprehensive summary of the work performed.

\subsection{SURVEY METHODOLOGY}

One approach to predicting the future is to rely on published research related to potential advancements. This approach has some drawbacks: published research often provides only partial information, is occasionally dominated by a few prolific writers, and often leaves out important items because secrecy has advantages for the developers of new technologies. Also, because of the nearly embryonic state of the EV and HEV technologies, the existing information on them is sporadic, occasionally optimistically speculative, and based on limited analysis. Predicting a realistic state of the technology in the next 25 years from this information is a very difficult task. A wide range of 
projections can be made, depending upon the assumptions about technological advancements and breakthroughs. In order to help OTT overcome some of these difficulties, a modified Delphi survey method has been selected in which the collective judgments of a set of experts are sought through multiple rounds of questionnaires. In the Delphi approach, experts' opinions are pooled through a questionnaire and then the next round is conducted to seek convergence of results by allowing revisions of opinion, given the judgments of other experts. The process gives a respondent an opportunity to review first-round opinions and revise his or her own, thus moving the second-round responses closer to a consensus. An unusual but interesting second-round result can be an agreement to disagree. Bimodal distributions of responses are seen occasionally in some Delphi study results.

This Delphi study is a group process of collecting information necessary for OTT planning and projections and to provide information to the community of scientists and policymakers interested in promoting EVs and HEVs. It employs questionnaires and written responses to pool the judgments of many persons. The mail-out survey process used is appropriate for collecting opinions of experts, users, or administrators who are difficult to gather together physically. Another advantage of the mail-out survey process as set up in this case is that it allows anonymity, avoids hostility among participants, and averts dominance by a few aggressive individuals. Delphi questionnaires in this study were designed to focus upon the problems of technical and cost characteristics of EVs and HEVs and their component parts, and to study the issues underlying the forecasts developed by participants. The questionnaire development process defined the issues and pretested responses. First official and second-round questionnaires were based upon the responses to the pretested questionnaire. Only minor changes were found to be necessary in the second round.

The Delphi technique has characteristically been used for technological forecasting (Helmer 1967; Pyke and North 1969). Ideally, the technique has the advantage of gaining insights from the latest advancements, since published research usually lags behind the current state of the technology. The technique also has some limitations. A Delphi survey provides information on the basis of respondents' knowledge at a fixed point in time. Some respondents may undervalue very recent advancements, while others may overvalue them. Some respondents ignore the new developments and rely on the conventional, prevailing technical paradigms. The overall effects of such respondent behavior are difficult to ascertain, but they are thought to be small. These limitations are described here more to increase a practitioner's understanding than to serve as caveats. The method is very useful in addressing difficult technological forecasting situations, providing an understanding of a problem, and gathering information necessary for decision making. Delphi studies require time and highly skilled participants. Since the quality of the responses is determined by the interest and commitment of the participants, proper selection of a group of experts is critical. The level of participation and quality of results are obviously also positively influenced by clear definition of the problem and proper formulation of the questionnaires.

A modified Delphi approach, in which the process stops after the second questionnaire, was selected for this study. This modification is useful when convergence or a vote on an agreed-to 
divergence is not needed (Delbecq et al. 1975). Responses to the first- and second-stage questionnaires are analyzed and information is reported to the respondents. Usually, the organization conducting the Delphi study works directly with the experts whose opinions are sought. However, because ANL and its DOE sponsor OTT might be perceived to have a conflict of interest arising from participation in several EV and HEV research initiatives, ANL solicited the assistance of the Society of Automotive Engineers. SAE's involvement in selecting Delphi participants was expected to broaden the respondent base and minimize bias. Under the arrangement, SAE-CRP administered the study and provided responses to ANL. This also ensured anonymity of the respondents, because their identities were removed by the SAE-CRP before the data were sent to ANL.

The first-stage questionnaire was designed with valuable help from the SAE Cooperative Research Program. ANL staff drafted a questionnaire, which, after a review by OTT, was subjected to a thorough review by SAE. SAE-CRP then assembled a review committee of 25 persons. Members of this group familiarized themselves with the study objectives and provided useful comments and suggestions to make the questionnaire more effective. Versions of the revised questionnaire were once again reviewed by ANL and DOE staff most familiar with the study. The questionnaire was then pretested. An evaluation of these pretest responses was conducted for their usefulness in this and other research initiatives.

Information on vehicle characteristics, components, and system impacts was collected through the questionnaire. The questionnaire sought opinions on such EV and HEV attributes as range, acceleration time, top speed, the maximum negotiable uphill grade at a sustained speed, seating and luggage capacities, curb weight, power-to-weight ratio, recharging time, and average maintenance interval. Respondents were asked to rate the importance of these attributes and provide expected values in the years 2000, 2010, and 2020. Questions about the importance of amenities, research and development needs, and purchase price and maintenance cost relative to ICE vehicles were included. Opinions on such components as batteries, electric motors, and HEV power plant were also sought. Data from the first-stage questionnaire were analyzed, summarized, and published after first being sent to respondents. Responses showed that EVs and HEVs will have inferior performance and will cost more with respect to ICE vehicles through the year 2000 . They are likely to have approximately $20 \%$ of the new vehicle market by the year 2020 , with costs slightly above conventional ICE vehicles ( $\mathrm{Ng}$ et al. 1995). The second-stage questionnaire also included the firststage results. Both the first- and second-stage questionnaires can be found in Appendixes A and C.

\subsection{SURVEY RESPONSE}

The first-stage questionnaire was sent to 811 persons. This group included persons who associated themselves with the following descriptions: vehicles and components; EV conversions; batteries; mobile source environmental work; transportation policy and economics; and vehicle regulations. SAE-CRP developed a mailing list that was supplemented by names of DOE and ANL 
contacts. Of the 811 names, nearly $90 \%$ were supplied by SAE-CRP. With each questionnaire, SAE sent a letter summarizing the purpose of the survey and guaranteeing anonymity.

We received 191 valid responses to the first-stage questionnaire. A "valid" response was defined as one that was received from the person to whom the questionnaire was sent. Some responses were nearly blank or contained values that were clearly inappropriate. Such responses were also considered invalid. We analyzed the first-stage data and produced descriptive statistics, such as mean, median, and interquartile range. We also produced histograms summarizing the first-stage results. The second-stage questionnaire, which provided a summary of the first-stage results and asked the respondents to specify new values, was sent to the 191 individuals who had responded to the first stage. We received 93 valid responses to the second-stage questionnaire. Table 1.1 summarizes the composition of the second-stage sample in terms of respondent employer. The largest responding group was from industry. The "other" category includes individuals who either did not identify their employers or did not fit in any of the first three categories.

TABLE 1.1 Organizational Breakdown of Respondents to the Second-Stage Delphi Questionnaire

\begin{tabular}{lrr}
\hline Type of Organization & Number & Percent \\
\hline Industry & 44 & 47.3 \\
Automotive OEM & 21 & 22.5 \\
Vehicle/engine & 5 & 5.4 \\
Electric/electronic & 5 & 5.4 \\
Battery & 1 & 1.1 \\
Other & 12 & 12.9 \\
Government & 13 & 14.0 \\
Academic institutions & 9 & 9.7 \\
Other & 27 & 29.0 \\
Total & 93 & 100.0 \\
\hline
\end{tabular}




\section{SURVEY RESULTS ON ELECTRIC AND HYBRID VEHICLES}

The survey questionnaires sought information necessary for DOE's planning and assessment needs. In a two-stage Delphi survey, responses to the second-stage questionnaire represent the final values. The respondents, having reviewed the first-stage results, provided their final answers. In this chapter, we summarize the second-stage results and present a few selected items in detail.

The mean values of all responses are shown separately in Appendix C. Here we present such key statistics as mean and median and the number of responses on which they are based. We also present "mode," the value specified by the maximum number of respondents, and interquartile values. The interquartile values represent values for the first and third quartiles. The first quartile value is the maximum value among the first $25 \%$ of the responses when all the responses are ordered by their values, and the third quartile value is the maximum value among the first $75 \%$ of the responses. These statistical values provide a measure of the degree of agreement among the respondents. A narrower interquartile range indicates a higher degree of agreement. A small difference between mean and median would be consistent with, and possibly indicate, very evenly distributed responses.

We also present optimistic and pessimistic values whenever we have a sufficient number of observations. These values represent means of half the responses either at and below or above the median point. A group's optimistic or pessimistic identity is dependent on the characteristics or attribute. For example, because longer range and lower vehicle curb weight are desirable, the optimistic group for range will be above the median while the optimistic group for curb weight will be at and below the median.

\subsection{QUESTIONNAIRE SECTIONS}

The survey questionnaire contained three main sections, each section seeking opinions on a specific aspect of future EVs and HEVs. The first section (named "vehicles" section) contained questions on expected operating characteristics and attributes of these vehicles. The second section (named "components" section) sought information and opinions on expected characteristics of vehicle components, and the third section (named "system impacts" section) contained questions on environmental and other impacts. Specifically, the first section sought opinions on basic vehicle characteristics, additional amenities, R\&D needs, HEV status and future, vehicle purchase price relative to the present conventional vehicle, vehicle fuel and maintenance cost, vehicle fuel economy, most likely fuel for the HEV, obstacles to commercialization of EVs and HEVs, and market share estimates. The second section sought opinions on operating characteristics of 10 battery types, environmental aspects of individual battery types, electric motors, advanced materials, HEV power 
units, and technologies most beneficial to EVs and HEVs. One drawback of the questionnaire, recognized in retrospect, was a lack of linkage between anticipated battery characteristics and the vehicle type for which the battery was envisioned to be developed. Only one set of battery questions was included. The third section sought opinions on air pollution, global warming, nuclear energy, and factors influencing EV and HEV market success.

The layout of the questionnaire allowed the respondent to go directly to the most familiar section(s) first and consult colleagues about other, less familiar sections. In this two-stage study, a large majority of the respondents did not ask the assistance of a colleague, preferring to leave some of the sections unanswered; probably in some cases, they had no appropriate colleague to consult. This resulted in the components section having significantly fewer answers than the other two sections. An analysis of the responses to the three sections by respondent affiliation was conducted. One representative question was selected from each section and the survey participation rates by respondent affiliation were analyzed. The question on basic vehicle characteristics was selected from the "vehicles" section, the question on battery characteristics was selected from the "components" section, and the question on market success factor was selected from the "system impacts" section.

Table 2.1 shows the number of responses to each section by respondent affiliation. The overall participation rates are $98 \%$ for the "vehicles" section, only $61 \%$ for the "components" section, and 99\% for the "system impacts" section. The industry group remains the largest group, in terms of number of responses, for each section. However, its participation rate for the "components" section is second highest at $64 \%$ and for the "system impacts" sections is third highest at $98 \%$. The academic group has the highest participation rates for the "components" and "systems impacts" sections at $89 \%$, and $100 \%$, respectively. Its participation rate for the "vehicles" section is the lowest at $89 \%$. The government group's participation rates for the three sections are $100 \%$, $53 \%$, and $100 \%$, and the "other" group's participation rates are $96 \%, 52 \%$, and $100 \%$, respectively.

\subsection{VEHICLES}

\section{Basic Characteristics}

The first part of the "vehicles" question asked the respondents to assign importance ratings to $11 \mathrm{EV}$ characteristics. The ratings ranged from 1 ("not important") to 10 ("most important"). Next, the respondents assigned values to the same 11 physical and operating attributes for the years 2000,2010 , and 2020. In the second part of this question, the respondents assigned an importance rating to each of the $12 \mathrm{HEV}$ characteristics. Except for range, the HEV characteristics list was identical to that for EVs. The range for the HEV was split as total (full battery charge and full tank) and engine alone (full tank). Respondents then assigned values to the $12 \mathrm{HEV}$ physical and operating 
TABLE 2.1 Organizational Breakdown of Respondents by Questionnaire Sections

\begin{tabular}{|c|c|c|c|c|c|c|}
\hline \multirow[b]{2}{*}{ Type of Organization } & \multicolumn{2}{|c|}{$\begin{array}{l}\text { Responding to } \\
\text { Vehicle } \\
\text { Characteristics }\end{array}$} & \multicolumn{2}{|c|}{$\begin{array}{l}\text { Responding to } \\
\text { Battery } \\
\text { Characteristics }\end{array}$} & \multicolumn{2}{|c|}{$\begin{array}{l}\text { Responding to } \\
\text { Systems } \\
\text { Impacts }\end{array}$} \\
\hline & No. & $\%$ & No. & $\%$ & No. & $\%$ \\
\hline Industry & 44 & 48.4 & 28 & 49.1 & 43 & 46.8 \\
\hline Automotive OEM & 21 & 23.1 & 17 & 29.7 & 20 & 21.8 \\
\hline Vehicle/engine & 5 & 5.5 & 3 & 5.3 & 5 & 5.4 \\
\hline Electric/electronic & 5 & 5.5 & 2 & 3.5 & 5 & 5.4 \\
\hline Battery & 1 & 1.1 & 1 & 1.8 & 1 & 1.1 \\
\hline Other & 12 & 13.2 & 5 & 8.8 & 12 & 13.0 \\
\hline Government & 13 & 14.3 & 7 & 12.3 & 13 & 14.1 \\
\hline Academic institutions & 8 & 8.8 & 8 & 14.0 & 9 & 9.8 \\
\hline Other & 26 & 28.6 & 14 & 24.6 & 27 & 29.3 \\
\hline Total & 91 & 100.0 & 57 & 100.0 & 92 & 100.0 \\
\hline
\end{tabular}

attributes for the above-mentioned three points in time. For the range, they assigned two values, total and engine alone.

The $11 \mathrm{EV}$ characteristics rated by the respondents (on a scale of 1 through 10) were range, 0-50 kph acceleration time, 50-100 kph acceleration time, top speed, maximum uphill grade for which a 75-kph speed can be maintained, seating capacity, cargo space, unladen vehicle weight (including batteries), power-to-weight ratio, recharging time, and maintenance interval. Most of these vehicle characteristics were chosen to evaluate the importance of input parameters for vehicle choice models used by ANL and DOE/OTT. The final set of 11 characteristics for EVs and 12 for HEVs emerged from the questionnaire review process. Through this question, we tried to identify the vehicle characteristics important to the potential buyers of these vehicles. The vehicle purchase price is not included in this list because the intent of this question was to identify important physical and operational characteristics. Respondents' attitudes concerning the importance of purchase and operational costs are evaluated through a separate question, results for which are summarized in Section 2.6 under "Market Success Factors." Figures 2.1 and 2.2 show the mean importance ratings emerging from the responses.

The five most important EV attributes were (in order of importance): (1) range, (2) maintenance interval, (3) recharging time, (4) 0-50 kph acceleration time, and (5) maximum uphill grade for which a $75-\mathrm{kph}$ speed can be maintained. The three least important attributes were (starting with the least important): (11) top speed, (10) unladen vehicle weight, and (9) cargo space. 

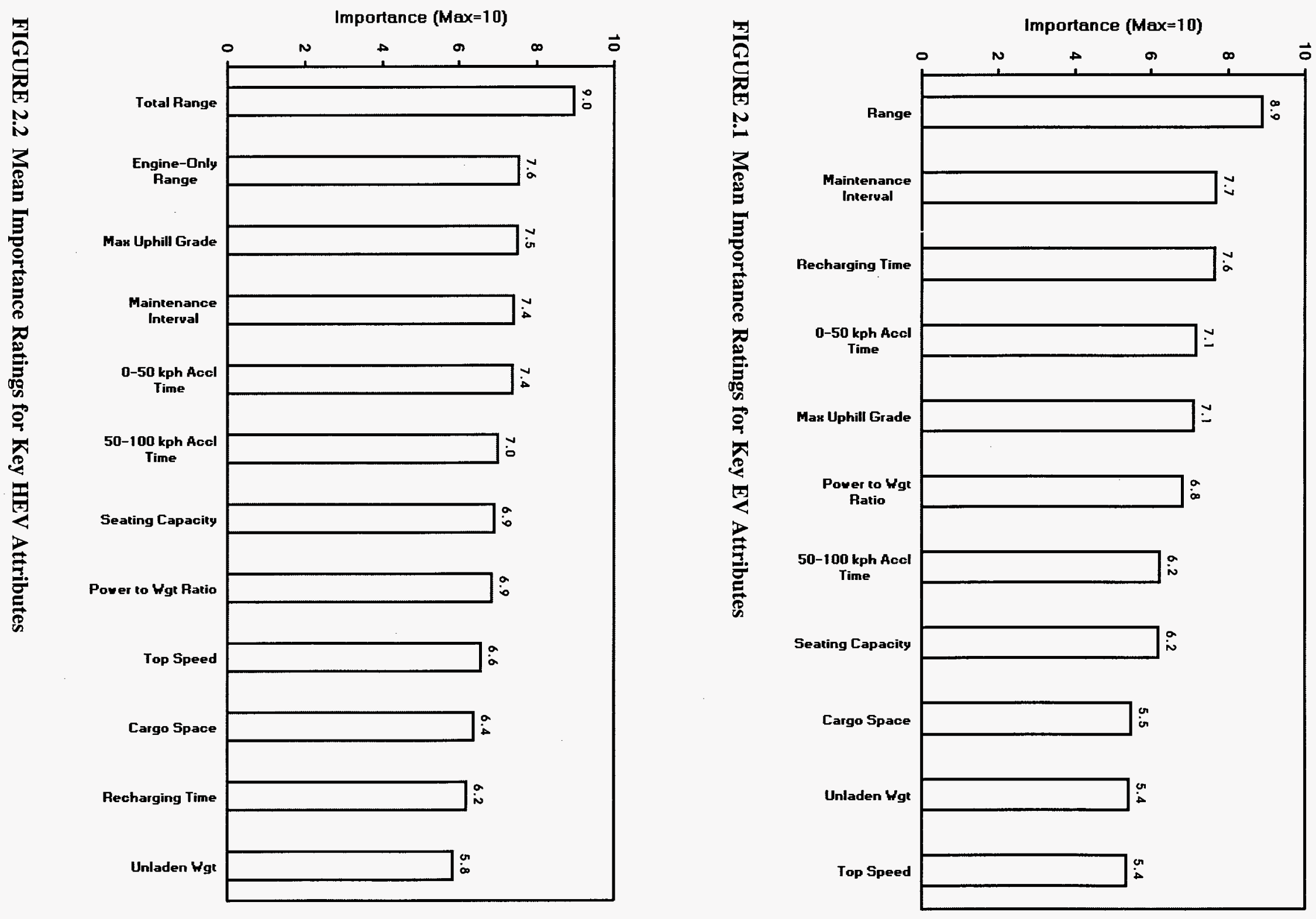
The five most important attributes represent those necessary for meeting daily travel demands and reducing undue burdens on the owner. The respondents seem to view the EV's primary use as a commuting vehicle, because they assigned lower importance to the attributes that make them capable of other uses. This was also apparent when the rankings of attributes for EVs were compared to those for HEVs.

For HEVs, the five most important attributes were (1) total range, (2) engine range, (3) maximum uphill grade for which a 75-kph speed can be maintained, (4) maintenance interval and (5) $0-50 \mathrm{kph}$ acceleration time. The high importance assigned to both ranges (total and engine) and uphill grade probably stems from the desire to have unconstrained mobility (which an HEV would be capable of providing). The concept of power unit (i.e., engine in the questionnaire) is applicable to two of the three HEVs, ICE HEV and gas turbine HEV. A fuel cell vehicle will not have a power unit, but rather some type of fuel handling system. The respondents seem to have specified the rating while assuming that engine range would not depend solely on battery charge.

The three least important HEV attributes were (12) unladen vehicle weight, (11) recharging time, and (10) cargo space. Experts thought recharging time to be very important for the EV, ranking it as the EV's third most important attribute. However, they rated recharging time as the second least important attribute for the HEV. It seems reasonable to speculate that the respondents assumed onboard charging to be the preferred charging scheme for the HEVs. If so, this also implies that they assumed "charge sustaining" HEVs. If an HEV had a small battery pack, it would require frequent charging by the auxiliary power unit (its engine) and would not require or benefit much from charging through the electricity grid. A small (less than $30 \mathrm{~km}$ ) difference between total and enginealone range would indicate such an HEV (running independent of the electric grid). In principle, a response of zero or nearly zero energy storage capacity might be predicting success for a fuel-cell vehicle, because such a vehicle can be designed without an electric-storage system but will use an electric drive-train.

A large majority of the experts specified a $100 \mathrm{~km}$ or greater difference (with means of 145 , 212 , and $244 \mathrm{~km}$ for years 2000, 2010, and 2020, respectively) between total and engine range. These values contradict the low importance given to recharge time, and they are consistent with the specified HEVs being of the "charge-depleting with high all-electric range" type, in which the vehicles can travel some distance (50 km or more) on battery power alone if the batteries are charged. A pure "charge-depleting" HEV would draw energy from the electricity grid to charge its battery, and the engine would take over when the battery energy is depleted. A "charge-depleting" HEV behaves like an EV while running on battery power (i.e., it has no tailpipe emissions). California initially proposed an HEV to have $48 \mathrm{~km}$ or greater all-electric range for it to receive credit under the state's Equivalent Zero Emissions Vehicle (EZEV) regulations. A "chargedepleting" HEV can be designed to be driven as an EV during the initial part of a trip. It is our understanding that the California Air Resources Board (CARB) prefers such an HEV to have a lowpolluting power unit that meets the state's Ultra-Low Emissions Vehicle (ULEV) standards and 
provides broadly acceptable performance once the battery charge is depleted. In the course of normal daily travel, the "power-unit-on" mode would be used as little as possible. This would imply that battery recharging time would be equally important for both EVs and HEVs. However, because of the availability of an auxiliary power unit, the driver of a "charge-depleting" HEV would not be required to wait for battery recharging. The respondents provided mixed indications on likely use of grid battery charging for HEVs by dropping the importance of recharging time from third most important for the EV to second least important for the HEV.

Respondents also assigned values to vehicle characteristics in the years 2000,2010 , and 2020. Forecast statistics for the EV and HEV attributes are tabulated in Tables 2.2 and 2.3. Both EVs and HEVs show substantial improvements between 2000 and 2020. The mean range, power requirement, seating capacity, cargo volume, top speed, uphill grade capability, and maintenance interval increase while acceleration tímes and curb weight decrease.

The mean EV range is $179 \mathrm{~km}$ (111 miles) in 2000, $270 \mathrm{~km}$ (168 miles) in 2010 , and $358 \mathrm{~km}$ ( 222 miles) in 2020. The experts therefore expect the EV range to double between 2000 and 2020. The mean HEV range is $353 \mathrm{~km}$ in $2000,469 \mathrm{~km}$ in 2010 , and $527 \mathrm{~km}$ in 2020 . The mean engine range is $215 \mathrm{~km}$ in 2000, $257 \mathrm{~km}$ in 2010 , and $281 \mathrm{~km}$ in 2020 . We subtracted the engine range from the total range for each response and computed mean battery range. The resulting mean battery range for HEVs is $145 \mathrm{~km}$ in $2000,212 \mathrm{~km}$ in 2010 , and $244 \mathrm{~km}$ in 2020 . As discussed earlier, a large majority (94\%) of the respondents specified the future HEVs to fit a balance of engine and battery ranges consistent with a "range extender" design approach (charge depleting with high all-electric range). These respondents seem to expect the HEVs to be used more for their emissions benefits with their high battery range. However, the high battery range would require larger battery packs, and consequently lower the energy benefits (assuming everything else contributing to energy consumption remains the same). Nevertheless, a high battery range would provide substantial petroleum displacement benefits. A typical urban vehicle is driven $50 \mathrm{~km}$ a day or less on average (NPTS 1991). With battery ranges of 179 and $145 \mathrm{~km}$ in 2000, EVs and HEVs would be able to meet nearly all daily local travel demands of households (and a majority of local travel demands of businesses). However, they would be less suitable for long trips with large party size and luggage, because of their restricted seating capacity and reduced cargo space.

The mean EV power is $66.7 \mathrm{~kW}$ in $2000,86.1 \mathrm{~kW}$ in 2010 , and $99.2 \mathrm{~kW}$ in 2020 . The increase in power is $49 \%$ between 2000 and 2020 , compared to the projected $100 \%$ increase in range. Therefore, the respondents recognize that EV batteries would have to improve their specific energy much more than their specific power. At present, a typical alternating-current (ac) induction motor for EVs is rated at about $66 \mathrm{~kW}$ peak power, and a direct-current (dc) motor around $52 \mathrm{~kW}$ (Cuenca and Gaines 1996). The mean HEV power is projected at $79.6 \mathrm{~kW}$ in $2000,99.1 \mathrm{~kW}$ in 2010 , and $108.6 \mathrm{~kW}$ in 2020 . The responses show a $36 \%$ increase in power between 2000 and 2020 . HEVs are consistently given higher power ratings than EVs, as well as high power-to-mass ratios, indicating better performance expectations for HEVs. 
TABLE 2.2 Forecast Statistics for $11 \mathrm{EV}$ Attributes

\begin{tabular}{|c|c|c|c|c|c|c|c|c|}
\hline Attribute & Year & $\mathrm{n}$ & Mean & Mode & Median & $\begin{array}{c}\text { Interquartile } \\
\text { Values }\end{array}$ & Optimist & Pessimis \\
\hline \multirow[t]{3}{*}{ Range (km) } & 2000 & 92 & 179 & 150 & 150 & $250 / 150$ & 220 & 138 \\
\hline & 2010 & 92 & 270 & 250 & 250 & $350 / 238$ & 341 & 199 \\
\hline & 2020 & 92 & 358 & 250 & 350 & $450 / 250$ & 465 & 250 \\
\hline \multirow{3}{*}{$\begin{array}{l}\text { Maintenance interval } \\
\left(10^{3} \mathrm{~km}\right)\end{array}$} & 2000 & 90 & 20 & 15 & 15 & $30 / 15$ & 31 & 10 \\
\hline & 2010 & 88 & 34 & 30 & 30 & $34 / 15$ & 46 & 21 \\
\hline & 2020 & 88 & 48 & 30 & 50 & $75 / 30$ & 67 & 29 \\
\hline \multirow[t]{3}{*}{ Recharge time (min) } & 2000 & 92 & 233 & 300 & 300 & $120 / 300$ & 160 & 307 \\
\hline & 2010 & 91 & 141 & 120 & 120 & $30 / 300$ & 64 & 217 \\
\hline & 2020 & 92 & 85 & 120 & 45 & $30 / 120$ & 22 & 148 \\
\hline \multirow[t]{3}{*}{$0-50 \mathrm{kph}$ time $(\mathrm{s})$} & 2020 & 90 & 7.4 & 7 & 7 & $7 / 9$ & 6.0 & 8.8 \\
\hline & 2010 & 90 & 5.8 & 5 & 5 & $5 / 7$ & 4.4 & 7.2 \\
\hline & 2020 & 89 & 5.2 & 5 & 5 & $5 / 7$ & 4.0 & 6.3 \\
\hline \multirow[t]{3}{*}{ Max. uphill grade (\%) } & 2000 & 88 & 5.0 & 5 & 5 & $5 / 5$ & 5.9 & 4.2 \\
\hline & 2010 & 87 & 6.7 & 7 & 7 & $7 / 5$ & 7.8 & 5.7 \\
\hline & 2020 & 86 & 7.8 & 7 & 7 & $11 / 7$ & 9.5 & 6.2 \\
\hline \multirow[t]{3}{*}{ Power rating $(\mathrm{kW})$} & 2000 & 91 & 67 & 70 & 70 & $70 / 50$ & 79 & 54 \\
\hline & 2010 & 91 & 86 & 90 & 90 & $90 / 70$ & 100 & 72 \\
\hline & 2020 & 90 & 99 & 110 & 100 & $110 / 90$ & 114 & 84 \\
\hline \multirow[t]{3}{*}{ 50-100 kph time (s) } & 2000 & 89 & 11.6 & 12 & 12 & $10 / 12$ & 10.3 & 12.8 \\
\hline & 2010 & 89 & 9.9 & 10 & 10 & $8 / 10$ & 8.6 & 11.2 \\
\hline & 2020 & 89 & 9.2 & 8 & 10 & $8 / 10$ & 7.5 & 10.8 \\
\hline \multirow[t]{3}{*}{ Number of seats } & 2000 & 91 & 3.4 & 4 & 4 & $4 / 2$ & 4.2 & 2.6 \\
\hline & 2010 & 91 & 4.1 & 4 & 4 & $4 / 4$ & 4.5 & 3.6 \\
\hline & 2020 & 90 & 4.6 & 5 & 4 & $5 / 4$ & 5.3 & 4.0 \\
\hline \multirow{3}{*}{ Cargo space (L) } & 2020 & 86 & 216 & 200 & 200 & $251 / 200$ & 275 & 157 \\
\hline & 2010 & 86 & 289 & 300 & 300 & $300 / 200$ & 352 & 227 \\
\hline & 2020 & 89 & 345 & 300 & 300 & $400 / 300$ & 425 & 262 \\
\hline \multirow[t]{3}{*}{ Curb weight $(\mathrm{kg})$} & 2000 & 88 & 1538 & 1800 & 1400 & $1400 / 1800$ & 1305 & 1771 \\
\hline & 2010 & 88 & 1351 & 1400 & 1400 & $1200 / 1400$ & 1175 & 1527 \\
\hline & 2020 & 88 & 1222 & 1200 & 1200 & $1200 / 1400$ & 1075 & 1370 \\
\hline \multirow[t]{3}{*}{ Top speed (kph) } & 2000 & 91 & 117 & 110 & 110 & $130 / 110$ & 129 & 104 \\
\hline & 2010 & 91 & 131 & 130 & 130 & $140 / 115$ & 143 & 119 \\
\hline & 2020 & 89 & 141 & 130 & 130 & $150 / 130$ & 158 & 123 \\
\hline
\end{tabular}


TABLE 2.3 Forecast Statistics for 12 HEV Attributes

\begin{tabular}{|c|c|c|c|c|c|c|c|c|}
\hline Attribute & Year & $\mathrm{n}$ & Mean & Mode & Median & $\begin{array}{l}\text { Interquartile } \\
\text { Values }\end{array}$ & Optimist & Pessimist \\
\hline \multirow[t]{3}{*}{ Range (km) } & 2000 & 91 & 353 & 350 & 350 & $450 / 250$ & 420 & 286 \\
\hline & 2010 & 91 & 469 & 450 & 450 & $450 / 450$ & 539 & 398 \\
\hline & 2020 & 91 & 527 & 650 & 450 & $650 / 450$ & 628 & 423 \\
\hline \multirow[t]{3}{*}{ Engine-only range $(\mathrm{km})$} & 2000 & 88 & 215 & 300 & 200 & $300 / 150$ & 286 & 144 \\
\hline & 2010 & 88 & 257 & 300 & 209 & $300 / 200$ & 331 & 183 \\
\hline & 2020 & 88 & 281 & 300 & 300 & $300 / 200$ & 345 & 218 \\
\hline \multirow[t]{3}{*}{ Max. uphill grade (\%) } & 2000 & 88 & 5.9 & 5 & 5 & $7 / 5$ & 7.2 & 4.5 \\
\hline & 2010 & 87 & 7.8 & 7 & 7 & $11 / 7$ & 9.3 & 6.2 \\
\hline & 2020 & 88 & 9.3 & 11 & 11 & $11 / 7$ & 11.0 & 7.6 \\
\hline \multirow{3}{*}{$\begin{array}{l}\text { Maintenance interval } \\
\left(10^{3} \mathrm{~km}\right)\end{array}$} & 2000 & 87 & 17 & 15 & 15 & $15 / 15$ & 24 & 10 \\
\hline & 2010 & 86 & 28 & 30 & 30 & $30 / 15$ & 38 & 18 \\
\hline & 2020 & 87 & 38 & 30 & 30 & $50 / 30$ & 53 & 23 \\
\hline \multirow[t]{3}{*}{ 0-50 kph time (s) } & 2020 & 90 & 6.9 & 7 & 7 & $5 / 7$ & 5.7 & 8.2 \\
\hline & 2010 & 89 & 5.5 & 5 & 5 & $5 / 7$ & 4.3 & 6.6 \\
\hline & 2020 & 90 & 4.7 & 5 & 5 & $3 / 5$ & 3.6 & 5.8 \\
\hline \multirow[t]{3}{*}{ 50-100 kph time (s) } & 2000 & 89 & 10.8 & 10 & 10 & $10 / 12$ & 9.3 & 12.1 \\
\hline & 2010 & 89 & 9.1 & 8 & 9 & $8 / 10$ & 7.7 & 10.5 \\
\hline & 2020 & 89 & 8.2 & 8 & 8 & $8 / 10$ & 7.0 & 9.5 \\
\hline \multirow[t]{3}{*}{ Number of seats } & 2000 & 89 & 3.9 & 4 & 4 & $4 / 4$ & 4.3 & 3.4 \\
\hline & 2010 & 89 & 4.5 & 4 & 4 & $5 / 4$ & 5.1 & 3.9 \\
\hline & 2020 & 89 & 5.0 & 5 & 5 & $6 / 4$ & 5.6 & 4.4 \\
\hline \multirow[t]{3}{*}{ Power rating $(\mathrm{kW})$} & 2020 & 87 & 80 & 70 & 70 & $90 / 70$ & 94 & 65 \\
\hline & 2010 & 86 & 99 & 90 & 90 & $110 / 90$ & 113 & 85 \\
\hline & 2020 & 87 & 109 & 110 & 110 & $110 / 90$ & 124 & 94 \\
\hline \multirow[t]{3}{*}{ Top speed (kph) } & 2000 & 90 & 125 & 130 & 130 & $130 / 110$ & 138 & 112 \\
\hline & 2010 & 89 & 139 & 130 & 130 & $150 / 130$ & 154 & 125 \\
\hline & 2020 & 89 & 147 & 150 & 150 & $150 / 130$ & 163 & 131 \\
\hline \multirow[t]{3}{*}{ Cargo space (L) } & 2020 & 81 & 244 & 200 & 200 & $300 / 200$ & 312 & 174 \\
\hline & 2010 & 80 & 317 & 300 & 300 & $400 / 200$ & 393 & 241 \\
\hline & 2020 & 80 & 367 & 400 & 400 & $400 / 300$ & 445 & 290 \\
\hline \multirow[t]{3}{*}{ Recharging time (min) } & 2000 & 88 & 144 & 300 & 120 & $30 / 300$ & 51 & 237 \\
\hline & 2010 & 88 & 62 & 120 & 30 & $10 / 120$ & 17 & 107 \\
\hline & 2020 & 89 & 45 & 30 & 30 & $10 / 60$ & 11 & 79 \\
\hline \multirow[t]{3}{*}{ Curb weight (kg) } & 2000 & 85 & 1556 & 1800 & 1400 & $1400 / 1800$ & 1338 & 1769 \\
\hline & 2010 & 84 & 1382 & 1400 & 1400 & $1200 / 1400$ & 1215 & 1548 \\
\hline & 2020 & 85 & 1265 & 1200 & 1200 & $1200 / 1400$ & 1112 & 1415 \\
\hline
\end{tabular}


By the year 2020, the mean curb weight for both EVs and HEVs is close to $1,250 \mathrm{~kg}$. By comparison, the average curb weight for the 1995 Lumina, Taurus, and Intrepid is $1,525 \mathrm{~kg}$ (Consumer Reports 1995). The year 2000 EVs and HEVs are expected to be heavier than the 1995 mid-size cars, with mean curb weights of 1,538 and $1,556 \mathrm{~kg}$, respectively. Although the future EVs and HEVs have curb weights comparable to those of 1995 mid-size cars, they will not provide the same seating and cargo capacity. The median seating capacity of EVs is estimated at 4 through the year 2020, and HEVs are projected at 4 in 2000 and 2010 and 5 in 2020.

Respondents seem to assume considerable improvement in design and material composition of EV and HEV components between 2000 and 2020. The EV's mean curb weight is reduced by $21 \%$, to $1,222 \mathrm{~kg}$, and the HEV's mean curb weight is reduced by $19 \%$, to $1,265 \mathrm{~kg}$. These reductions are more significant in terms of design, materials, and packaging improvements because cargo and seating capacity are projected to increase in spite of the mass reductions.

\section{Amenities}

Vehicles do not often succeed in the marketplace without additional amenities for occupant comfort, safety, and aesthetics. For the future EVs and HEVs to be accepted by consumers, they must be equipped with such amenities. A question concerning the importance of selected amenities indicated that compartment heating and window defrosting, air conditioning, and premium safety equipment (i.e., air bags, anti-lock brakes) were considered more important than power auxiliaries (i.e. steering, brakes, door locks, windows, seats) and audio entertainment. Respondents rated occupant comfort and safety higher than the items of convenience. Air conditioning and heating would require energy and necessitate larger power units and/or battery packs. These importance ratings are consistent with current consumer preferences; however, the power drain for air conditioning and heating is regarded as a critical problem. The other amenities could more easily be designed into EVs and HEVs without significantly affecting their range.

\section{R\&D Needs}

For EVs and HEVs to be competitive enough to reach the commercialization stage, several of their properties need to be developed beyond their present state. Research and development is progressing in key areas. Battery (energy density, operating temperature, materials) and energy storage technology (ultracapacitors, flywheels); vehicular technology (body, chassis, steering and suspension); and component technology (motor, drive-train, and regenerative or mechanical braking) are the three major concerns in R\&D aimed at commercialization of EVs and HEVs. The respondents were asked to rank these areas in terms of the share of $R \& D$ required before these vehicles can be successfully marketed. Battery/energy storage technology, a most rapidly changing technology area, received the highest ranking from the respondents. Vehicular technology would 
require the lowest $R \& D$ share, according to the respondents. This seems to indicate that most experts are quite confident that present automotive vehicular technology can be readily transferred to EVs and HEVs.

\section{Opinions on Hybrids}

The questionnaire asked the respondents to indicate whether they agreed or disagreed with a set of 11 statements related to HEVs. Eighty-three percent of respondents agreed that HEVs will be commercialized as a viable alternative to gasoline vehicles in the long term (beyond 2005), while 94\% agreed that their operating range will be extended by more than $150 \mathrm{~km}$ compared to EVs. Almost all respondents (98\%) believed that HEVs could meet the U.S. Tier II emissions standards if required for MY2004 and later automobiles. Fewer than one quarter of the respondents expected the HEVs to be cheaper than EVs when commercialized. Only $8 \%$ of respondents agreed that HEVs will never be a viable alternative. Earlier, under the vehicle characteristics questions, a large majority (94\%) of the respondents specified HEV range on battery as $50 \mathrm{~km}$ or longer. This indicated that the respondents had thought HEVs would use electricity from the grid. However, when asked to agree or disagree with the statement that HEVs would not need electricity from the grid, $29 \%$ agreed.

\section{Obstacles to Commercialization}

Numerous recent studies have estimated that EVs and HEVs can cost significantly more than their gasoline counterparts. The respondents to this study ranked two obstacles to commercialization as very important for both EVs and HEVs: (1) sales volume too low for economical production and (2) the high cost and complexities associated with manufacturing the batteries and drive-trains needed to produce attractive vehicles. Nevertheless, government R\&D support for these vehicles was not deemed "inadequate." One obvious obstacle to the commercialization of EVs and HEVs is the lack of refueling infrastructure. Lack of recharging infrastructure away from home is a greater obstacle to EVs because of their limited range. The development of an infrastructure for new fuels is a broad subject, requiring a detailed study by itself. Its importance has been recognized in various studies (Wang et al. 1997). An item related to the need for development of supporting infrastructure was included in Section 2.6 under "Market Success Factors." It rated as the fourth most important factor. 


\subsection{COST ESTIMATES AND FUEL ECONOMY}

\section{Vehicle Purchase Price}

The respondents were asked to provide their estimates of the purchase price ratios for five vehicle types: (1) conventional vehicles (CVs), (2) EVs, (3) hybrid vehicles with internal combustion engines (ICE HEVs), (4) HEVs with a gas turbine, and (5) fuel-cell HEVs. They were asked to specify the ratios relative to the average cost of $\$ 15,000$ for a 19934 -door compact sedan. They were also asked to describe how they arrive at these values. Several respondents provided detailed descriptions of their estimates, while a few admitted that they used professional judgment. The majority of the respondents provided the estimates but gave no description of their cost analysis. In Table 2.4, we have summarized some descriptive statistics for purchase price ratios. Figure 2.3 shows the projected vehicle purchase prices. The mean ratios specified by the respondents are converted to nominal dollars by using the baseline vehicle price of $\$ 15,000$.

The purchase prices of the EVs and HEVs were consistently projected to be higher than the prices for conventional gasoline-fueled baseline passenger vehicles, but the projected values tended to be "flat" for EVs and ICE HEVs. The respondents projected improvements in EV and HEV prices, while projecting the conventional vehicle price to rise throughout the projection period more rapidly than the EVs and HEVs (Figure 2.3). However, only by 2020 would the EVs and ICE HEVs have competitive prices (18 and $26 \%$ higher than conventional vehicles, respectively, based on means). Both the gas-turbine and fuel-cell HEVs were projected to cost two to three times the conventional vehicles in 2000 , but price ratios dropped significantly by 2020 . In spite of these price improvements, the gas-turbine and fuel-cell HEVs would cost substantially more (52 and $97 \%$ more than the conventional vehicle, respectively), making them less attractive to consumers even in 2020. The respondents seem to envision a vehicle price scheme in which EVs would be more expensive than conventional vehicles, while HEVs would be more expensive than EVs, during the projection period.

\section{Fuel and Maintenance Costs}

The respondents also specified fuel and maintenance cost ratios for the five vehicle technologies relative to the 1993 conventional car. The projected fuel and maintenance costs were more favorable to EVs by 2010 and beyond. The year 2000 fuel and maintenance costs for EVs were higher than those for conventional vehicles, indicating that EVs will have to go through the normal product-debugging period. All the HEVs would have fuel and maintenance costs significantly higher than both EVs and conventional vehicles throughout the projection period. Of the three HEV types, the ICE HEVs had the lowest projected fuel and maintenance costs. The fuel and maintenance cost ratios are shown graphically in Figure 2.4. These cost ratios exclude the cost of replacement battery packs. An analysis of battery replacement cost for EVs and HEVs is presented in Chapter 3. 
TABLE 2.4 Forecast Statistics for Vehicle Purchase Price Ratios

\begin{tabular}{|c|c|c|c|c|c|c|c|c|}
\hline \multirow[b]{2}{*}{ Vehicle Type } & \multirow[b]{2}{*}{ Year } & \multirow[b]{2}{*}{$\mathrm{n}$} & \multicolumn{6}{|c|}{ Price Ratio to 1993 Gasoline Vehicle } \\
\hline & & & Mean & Mode & Median & $\begin{array}{c}\text { Interquartile } \\
\text { Value }\end{array}$ & Optimist & Pessimist \\
\hline \multirow{3}{*}{ Conventional ICE vehicle } & 2000 & 87 & 1.26 & 1.2 & 1.2 & $1.10 / 1.31$ & 1.13 & 1.38 \\
\hline & 2010 & 86 & 1.60 & 1.4 & 1.5 & $1.40 / 1.80$ & 1.33 & 1.88 \\
\hline & 2020 & 87 & 2.02 & 2.0 & 2.0 & $1.55 / 2.30$ & 1.53 & 2.51 \\
\hline \multirow[t]{3}{*}{ Electric vehicle } & 2000 & 87 & 2.29 & 2.0 & 2.0 & $2.00 / 2.70$ & 1.78 & 2.78 \\
\hline & 2010 & 86 & 2.31 & 2.0 & 2.2 & $2.00 / 2.50$ & 1.85 & 2.76 \\
\hline & 2020 & 87 & 2.38 & 2.0 & 2.2 & $2.00 / 2.50$ & 1.81 & 2.94 \\
\hline \multirow[t]{3}{*}{ ICE-powered hybrid vehicle } & 2000 & 85 & 2.47 & 2.2 & 2.4 & $2.00 / 2.90$ & 1.87 & 3.06 \\
\hline & 2010 & 84 & 2.44 & 2.5 & 2.4 & $2.00 / 2.66$ & 1.87 & 3.00 \\
\hline & 2020 & 85 & 2.54 & 2.5 & 2.5 & $2.00 / 2.80$ & 1.89 & 3.17 \\
\hline \multirow[t]{3}{*}{ Gas-turbine-powered hybrid } & 2020 & 76 & 3.27 & 3.0 & 3.0 & $2.50 / 4.00$ & 2.33 & 4.22 \\
\hline & 2010 & 84 & 3.04 & 3.0 & 3.0 & $2.46 / 3.11$ & 2.26 & 3.83 \\
\hline & 2020 & 85 & 3.07 & 3.0 & 3.0 & $2.40 / 3.25$ & 2.21 & 3.90 \\
\hline \multirow[t]{3}{*}{ Fuel-cell-powered hybrid } & 2000 & 70 & 5.15 & 4.0 & 4.5 & $3.08 / 5.75$ & 3.13 & 7.16 \\
\hline & 2010 & 81 & 4.36 & 6.0 & 4.0 & $3.00 / 6.00$ & 2.91 & 5.77 \\
\hline & 2020 & 83 & 3.98 & 4.0 & 3.8 & $2.50 / 5.00$ & 2.53 & 5.40 \\
\hline
\end{tabular}

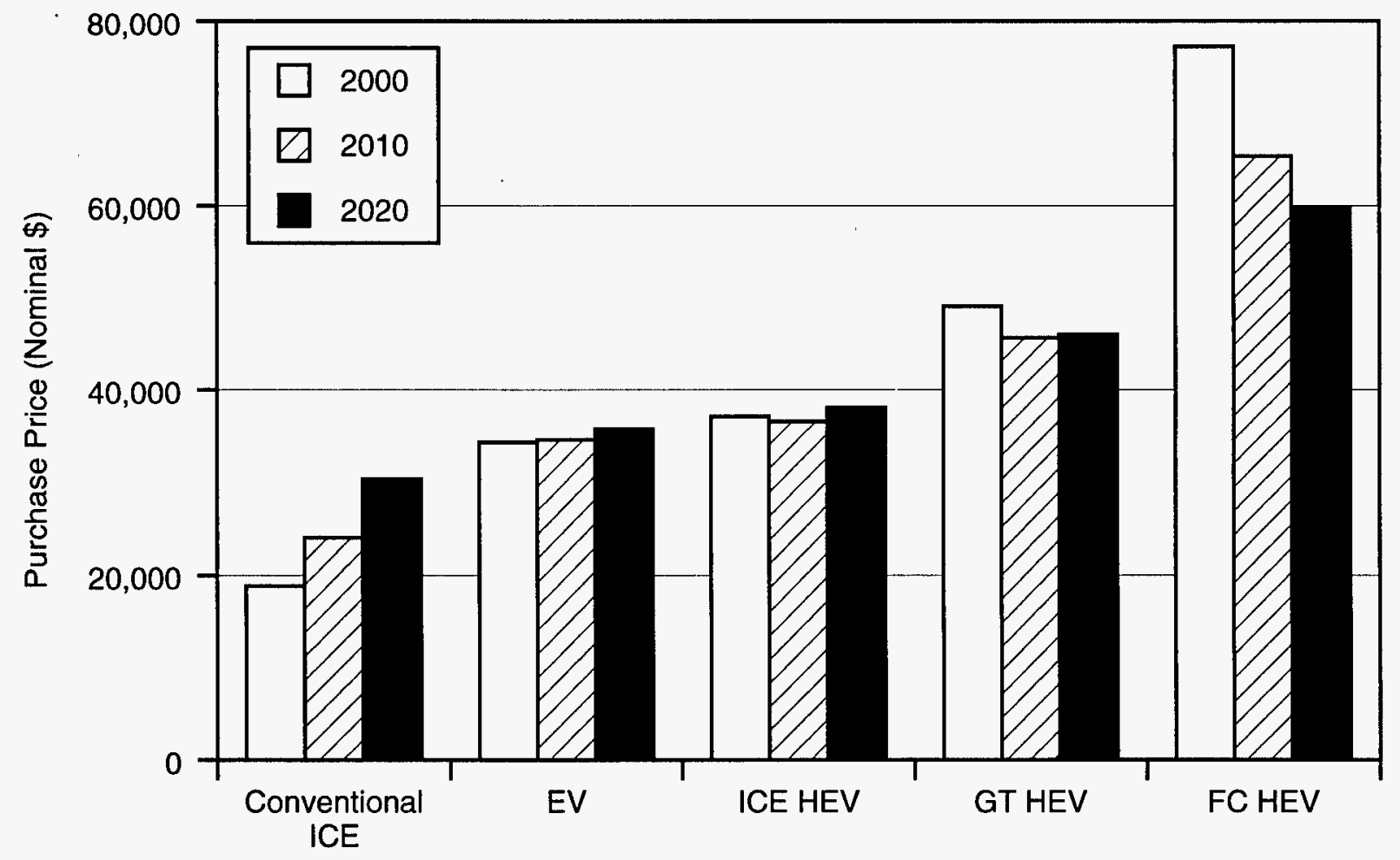

FIGURE 2.3 Mean Vehicle Purchase Price for the Five Technologies 


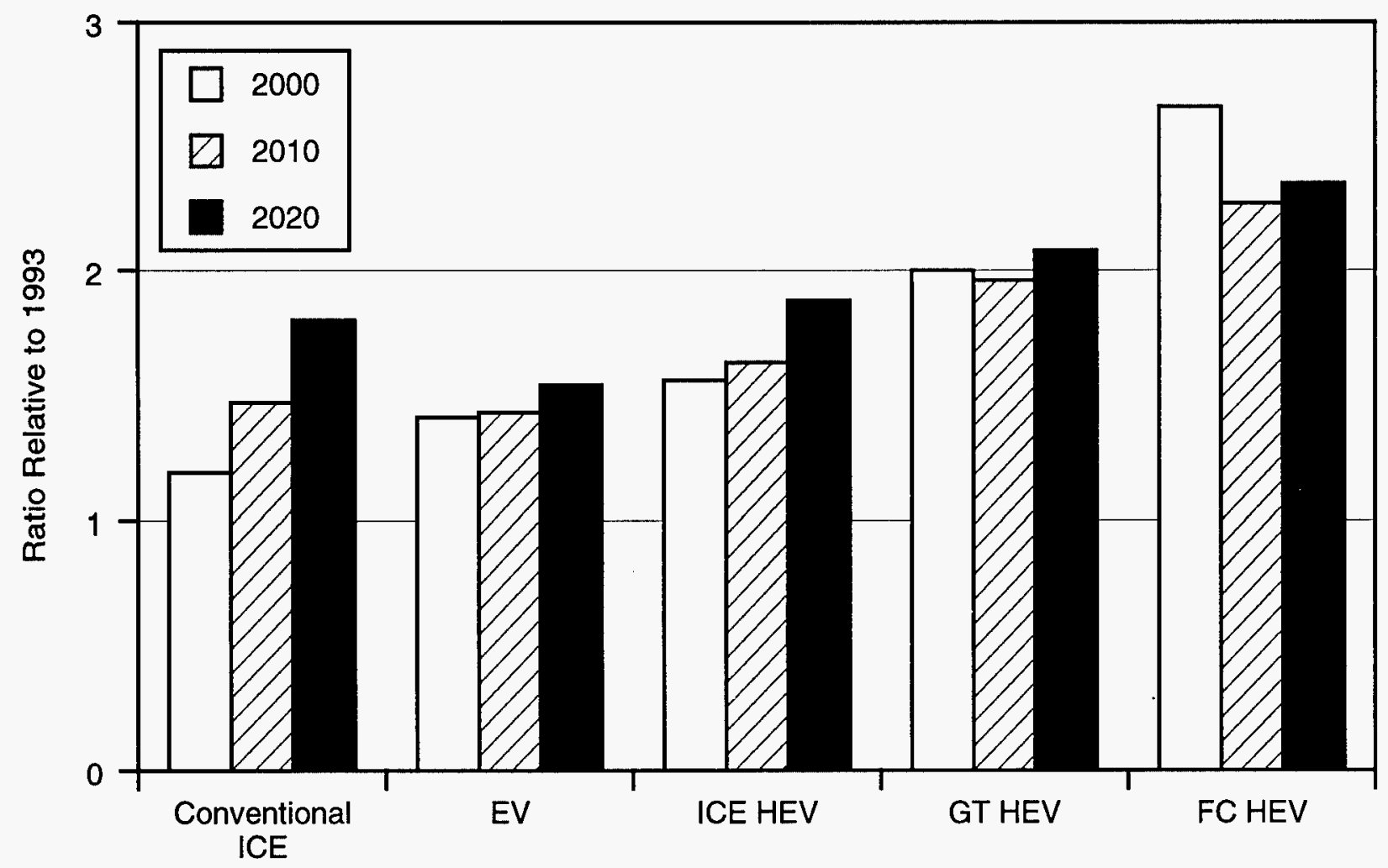

FIGURE 2.4 Mean Fuel and Maintenance Cost Ratios for the Five Technologies

\section{Fuel Economy}

The respondents were asked to project relative fuel economies of CVs, EVs, ICE HEVs, gas-turbine HEVs, and fuel-cell HEVs. They were requested to specify the future fuel economies as ratios to the year 2000 conventional mid-size sedan, which was expected to have a fuel economy of 30 miles per gallon $(12.75 \mathrm{~km} / \mathrm{L})$. Table 2.5 presents summary statistics for the fuel economy ratios for the five vehicle technologies. The mean fuel economy ratios are also converted to miles per gallon (mpg) and shown in Figure 2.5. The experts expect EVs to have the highest fuel economy through the projection period. However, the mean values suggest that $E V$ fuel economy would reach only $50 \mathrm{mpg}$ in 2020, far short of the PNGV (Partnership for a New Generation of Vehicles) goal of $81 \mathrm{mpg}$. Among the hybrids, the fuel cell HEV is projected to have the highest fuel economy at $48 \mathrm{mpg}$ in 2020, based on the mean. The ICE HEV would have the lowest fuel economy among the hybrids, only $21 \%$ higher than the conventional vehicle in 2020 . The respondents do not project very high fuel economies. Even the optimists, as we define them, do not project fuel economies as high as the PNGV goal of $80 \mathrm{mpg}$ for a mid-size vehicle. The optimists project a range of 62 to $77 \mathrm{mpg}$ by 2020 for EVs and HEVs, with the ICE HEV achieving $62 \mathrm{mpg}$ and the EV $77 \mathrm{mpg}$. The pessimists among the experts expect only $20 \mathrm{mpg}$ from the year 2020 fuel-cell HEV. 
TABLE 2.5 Forecast Statistics for Fuel Economy Ratios for the Five Technologies

\begin{tabular}{|c|c|c|c|c|c|c|c|c|}
\hline \multirow[b]{2}{*}{ Vehicle Type } & \multirow[b]{2}{*}{ Year } & \multirow[b]{2}{*}{$\mathrm{n}$} & \multicolumn{6}{|c|}{ Fuel Economy Ratio to 2000 Gasoline Vehicle } \\
\hline & & & Mean & Mode & Median & $\begin{array}{c}\text { Interquartile } \\
\text { Values }\end{array}$ & Optimist & Pessimist \\
\hline \multirow[t]{3}{*}{ Conventional ICE vehicle } & 2000 & 83 & 1.00 & 1.0 & 1.0 & $1.00 / 1.00$ & 1.00 & 1.00 \\
\hline & 2010 & 79 & 1.09 & 1.1 & 1.1 & $1.20 / 0.90$ & 1.23 & 0.94 \\
\hline & 2020 & 79 & 1.16 & 1.2 & 1.2 & $1.33 / 0.83$ & 1.44 & 0.87 \\
\hline \multirow[t]{3}{*}{ Electric vehicle } & 2000 & 63 & 1.41 & 1.0 & 1.0 & $1.50 / 0.80$ & 2.03 & 0.77 \\
\hline & 2010 & 63 & 1.54 & 1.0 & 1.0 & $1.50 / 0.80$ & 2.30 & 0.76 \\
\hline & 2020 & 63 & 1.67 & 1.0 & 1.0 & $1.50 / 0.78$ & 2.58 & 0.72 \\
\hline \multirow[t]{3}{*}{ ICE-powered hybrid vehicle } & 2000 & 64 & 1.18 & 1.1 & 1.1 & $1.35 / 0.80$ & 1.55 & 0.81 \\
\hline & 2010 & 65 & 1.29 & 0.8 & 1.1 & $1.50 / 0.80$ & 1.81 & 0.75 \\
\hline & 2020 & 65 & 1.40 & 0.5 & 1.2 & $1.70 / 0.70$ & 2.08 & 0.69 \\
\hline \multirow[t]{3}{*}{ Gas-turbine-powered hybrid } & 2020 & 60 & 1.22 & 1.2 & 1.2 & $1.50 / 0.90$ & 1.59 & 0.86 \\
\hline & 2010 & 62 & 1.40 & 1.0 & 1.15 & $1.70 / 0.90$ & 1.95 & 0.84 \\
\hline & 2020 & 62 & 1.52 & 1.5 & 1.2 & $1.70 / 0.90$ & 2.24 & 0.81 \\
\hline \multirow[t]{3}{*}{ Fuel-cell-powered hybrid } & 2000 & 53 & 1.27 & 2.0 & 1.1 & $1.80 / 0.70$ & 1.85 & 0.67 \\
\hline & 2010 & 57 & 1.42 & 1.5 & 1.2 & $1.90 / 0.70$ & 2.14 & 0.66 \\
\hline & 2020 & 58 & 1.59 & 1.0 & 1.2 & $2.00 / 0.63$ & 2.53 & 0.65 \\
\hline
\end{tabular}

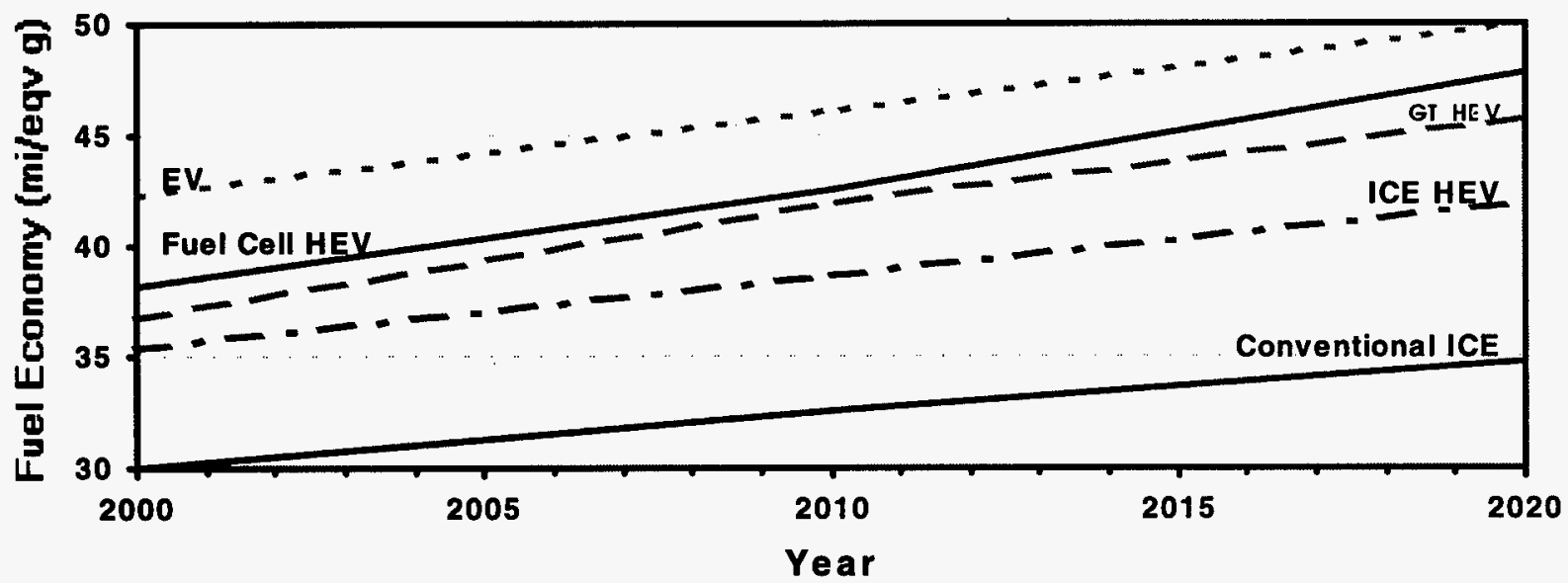

FIGURE 2.5 Mean Fuel Economy Estimates for the Five Technologies 


\section{Fuel for HEVs}

The respondents were also asked to indicate the type of fuel they had assumed for the three types of HEVs. According to the experts, gasoline will be the predominant fuel for the internalcombustion-engine HEVs, while diesel, kerosene, and jet fuel will be the most likely fuels for gas turbine HEVs. For the fuel-cell HEVs, the respondents projected either alcohol or pure hydrogen to be the preferred fuel. These projections, of course, will affect the fuel cost of these hybrid electric vehicles.

\subsection{MARKET PENETRATION}

The respondents were asked to estimate new-vehicle market share for each vehicle type so that the shares total to $100 \%$. Essentially all the experts predicted the $\mathrm{CV}$ to be the dominant vehicle in the new-vehicle market, even in 2020. By any descriptive statistics (mean, median, or mode), such vehicles are projected to have about $80 \%$ of the new-vehicle market. One exceptional respondent felt that conventional vehicles would shrink to a mere $10 \%$ share by 2020 , while fuel-cell HEVs and ICE HEVs would have 20 and $60 \%$ market shares, respectively. Most experts did not express such a view. The statistics for market shares are listed in Table 2.6. We used the respondents' specified market shares to develop models. We also noted the vehicle characteristics emerging from the responses and used them in two market penetration models. The results of this market penetration modeling are summarized in Chapter 4.

Note that the above-mentioned market share estimates are for new vehicles, not for the vehicle fleet, which is made up of vehicles of various vintages. Because a vehicle lasts several years and fleet turnover takes a long time, the new-technology vehicles would only represent a small share of the vehicle fleet even by the year when they achieve a $20 \%$ share of the new-vehicle market (Mintz et al. 1995). The proportion of conventional vehicles in the entire fleet of vehicles held by households, business, and government in 2000, 2010, and 2020 would be greater than that indicated by their new-vehicle shares as presented here.

The experts seem to indicate that EVs would penetrate the market at a rather modest pace, going from a $1 \%$ new-vehicle share in 2000 to $7.5 \%$ by 2020 . Only a few respondents believed that EVs would not make it to the market place, while the majority projected fairly modest penetration. Almost $40 \%$ of the respondents projected that EVs will have better than $10 \%$ market penetration by 2020.

Of the three types of HEVs, the ICE HEV technology was assigned the highest market shares by the respondents. The mean projection by the experts showed ICE HEVs to have almost $8 \%$ market penetration by 2020 , slightly higher than that for the EVs. Almost $30 \%$ of the respondents projected ICE HEVs to have better than $10 \%$ market penetration by 2020 , while $12 \%$ 
TABLE 2.6 Forecast Statistics for Market Penetration of the Five Technologies

\begin{tabular}{|c|c|c|c|c|c|c|c|c|}
\hline \multirow[b]{2}{*}{ Vehicle Type } & \multirow[b]{2}{*}{ Year } & \multirow[b]{2}{*}{$\mathrm{n}$} & \multicolumn{6}{|c|}{ New Light Duty Vehicle Market Share (\%) } \\
\hline & & & Mean & Mode & Median & $\begin{array}{c}\text { Interquartile } \\
\text { Values }\end{array}$ & Optimist & Pessimist \\
\hline \multirow[t]{3}{*}{ Conventional ICE vehicle } & 2000 & 89 & 97.1 & 99 & 98 & $99 / 96$ & 99.2 & 95.0 \\
\hline & 2010 & 88 & 89.7 & 90 & 90 & $96 / 87$ & 95.9 & 83.5 \\
\hline & 2020 & 89 & 77.6 & 80 & 80 & $90 / 70$ & 89.4 & 65.6 \\
\hline \multirow[t]{3}{*}{ Electric vehicle } & 2000 & 89 & 1.3 & 1 & 1 & $2 / 0.5$ & 2.1 & 0.5 \\
\hline & 2010 & 88 & 4.1 & 1 & 4 & $5 / 1.7$ & 6.6 & 1.6 \\
\hline & 2020 & 89 & 7.5 & 10 & 6 & $10 / 3$ & 12.0 & 2.9 \\
\hline \multirow[t]{3}{*}{ ICE-powered hybrid vehicle } & 2020 & 89 & 1.1 & 0 & 0.2 & $1 / 0$ & 2.2 & 0.0 \\
\hline & 2010 & 88 & 4.1 & 1 & 2 & $5 / 1$ & 7.2 & 0.9 \\
\hline & 2020 & 89 & 7.9 & 4 & 5 & $10 / 2$ & 13.4 & 2.3 \\
\hline \multirow[t]{3}{*}{ Gas-turbine-powered hybrid } & 2000 & 89 & 0.2 & 0 & 0 & $0 / 0$ & 0.3 & 0.0 \\
\hline & 2010 & 88 & 0.9 & 0 & 0 & $1 / 0$ & 1.9 & 0.0 \\
\hline & 2020 & 89 & 3.0 & 0 & 1 & $4 / 0$ & 5.7 & 0.2 \\
\hline \multirow[t]{3}{*}{ Fuel-cell-powered hybrid } & 2020 & 89 & 0.2 & 0 & 0 & $0 / 0$ & 0.3 & 0.0 \\
\hline & 2010 & 88 & 0.7 & 0 & 0 & $0.8 / 0$ & 1.4 & 0.0 \\
\hline & 2020 & 89 & 3.0 & 0 & 1 & $4 / 0$ & 5.7 & 0.2 \\
\hline
\end{tabular}

of the respondents had projections of $20 \%$ and higher. This projected market penetration pattern of the ICE HEVs was noticeably different from that for the EVs. The spread of market penetration projections was wider for ICE HEVs compared to the spread for EVs, with ICE HEV optimists more optimistic that EV optimists and ICE HEV pessimists more pessimistic than EV pessimists.

Neither gas-turbine nor fuel-cell HEVs are projected to have any significant market penetration until 2020; even then, the penetration would be about $3 \%$ each, according to the mean estimates of the survey responses. Given that the gas turbine represents a relatively old technology compared with the fuel cell (capturing nearly all of the aircraft market and a significant segment of the electric power generation market), the respondents' estimates of the prospects for fuel-cell HEVs can be interpreted as relatively promising. We speculate that the respondents regard the gas turbine as a mature technology, but think of it as having performance limitations in automotive-scale applications. Almost $40 \%$ of the respondents believed that even by 2020 , neither of these two types of HEVs would be in the market. Only a small fraction, about $10 \%$, of the respondents projected better than a $10 \%$ market penetration for these two types of HEVs, thereby contributing disproportionately to the mean (year 2020) penetration of $3 \%$. 


\subsection{COMPONENTS}

\section{Battery Performance Characteristics}

Relatively fewer survey participants responded to the questions about battery characteristics for 10 battery types. Thus, in comparing the projections for battery characteristics, it is important to note the number of respondents for each battery type. Apparently, the respondents did not wish to make uninformed estimates and confined their responses to those batteries for which they had some expertise and knowledge. However, a far greater response "percentage" was obtained from the second stage of the survey than from the first stage. This higher response percentage could signify that the second-stage respondents, on average, were more familiar with EV/HEV components and had wider expertise. A characteristic of multiple-round mail-out Delphi studies is that the respondents less concerned with the outcome of the survey and/or less certain of the importance of their response will drop out in the later rounds. The possibility exists that some respondents who dropped out might have been in agreement with the first-stage results and, therefore, did not respond to the second-stage questionnaire. Unfortunately, we did not include a simple response form to indicate agreement with the first-stage results. It would be speculative to estimate how many respondents would have returned such a form.

The survey requested information for 10 battery types. The number of responses ranged from a minimum of 19 for the zinc-bromide battery to a maximum of 55 for the lead-acid battery. Five battery types had more than 38 responses: (1) lead-acid, (2) nickel-cadmium, (3) nickel-metal hydride, (4) sodium-sulfur, and (5) lithium-polymer. The first four of these five battery types are used in either commercial EVs or EV prototypes, while the lithium-polymer battery is a long-term technology which the respondents anticipate will improve dramatically. Descriptive statistics for five important characteristics of the 10 battery types are shown in Table 2.7 .

Ongoing research and development in batteries will continue to provide benefits in terms of higher specific energy and specific power, longer shelf and cycle lives, and lower cost. Mean estimates by respondents suggest that by 2020 the lithium-polymer battery would have 3.5 times the specific energy of the lead-acid battery ( $172 \mathrm{vs} .48 \mathrm{Wh} / \mathrm{kg}$ ), nearly twice the shelf life ( 8.2 vs. 4.4 years), $36 \%$ higher cycle life (1,185 vs. 872 charge/discharge cycles), $10 \%$ lower specific power (193 vs. $214 \mathrm{~W} / \mathrm{kg})$, and $61 \%$ higher unit cost ( $\$ 296 \mathrm{vs.} \$ 184 / \mathrm{kWh})$. If these projections materialize, the lithium-polymer battery would be much superior to lead-acid, in terms of life-cycle cost and vehicle performance, and would provide immense benefits to EVs and some (high battery-range) HEV technologies.

By 2020 , four of the five battery types that had high response rates - lithium-polymer, nickel-metal hydride, nickel-cadmium, and lead-acid - would have mean specific power in the 
TABLE 2.7 Future Characteristics of the Ten Battery Technologies

\begin{tabular}{|c|c|c|c|c|c|c|c|c|c|c|c|c|c|c|c|c|c|c|c|c|c|}
\hline \multirow[b]{2}{*}{ Battery } & \multirow[b]{2}{*}{ Year } & \multicolumn{4}{|c|}{ Specific Energy (Wh/kg) } & \multicolumn{4}{|c|}{ Specific Power (W/kg) } & \multicolumn{4}{|c|}{ Shelf life (yr) } & \multicolumn{4}{|c|}{ Life (cycles) } & \multicolumn{4}{|c|}{ Initial cost (\$/KWh) } \\
\hline & & $\mathrm{n}$ & Mean & Median & Quartiles & $\mathrm{n}$ & Mean & Median & Quartiles & $\mathbf{n}$ & Mean & Median & Quartiles & $\mathbf{n}$ & Mean & Median & Quartiles & $\mathbf{n}$ & Mean & Median & Quartiles \\
\hline \multirow{3}{*}{ Lead-acid } & 2000 & 55 & 40 & 40 & $35 / 40$ & 54 & 155 & 130 & $100 / 200$ & 50 & 3.4 & 3 & $3 / 4$ & 55 & 611 & 600 & $500 / 700$ & 54 & 185 & 190 & $150 / 200$ \\
\hline & 2010 & 55 & 44 & 44 & $40 / 50$ & 53 & 190 & 160 & $120 / 200$ & 49 & 4.4 & 4 & $3 / 4.6$ & 53 & 740 & 700 & $550 / 800$ & 54 & 179 & 180 & $150 / 200$ \\
\hline & 2020 & 54 & 48 & 45 & $41 / 51$ & 54 & 214 & 190 & $120 / 200$ & 49 & 4.4 & 4.5 & $3 / 5$ & 53 & 872 & 800 & $600 / 1000$ & 53 & 184 & 180 & $150 / 200$ \\
\hline \multirow{3}{*}{$\mathrm{LiFeS}_{2}$} & 2000 & 24 & 97 & 96 & $80 / 100$ & 22 & 167 & 155 & $150 / 195$ & 21 & 3.5 & 4 & $3 / 4$ & 21 & 512 & 500 & $400 / 600$ & 21 & 853 & 850 & $800 / 1000$ \\
\hline & 2010 & 23 & 116 & 110 & $100 / 130$ & 23 & 209 & 200 & $168 / 235$ & 21 & 4.6 & 5 & $4 / 5$ & 22 & 698 & 725 & $600 / 800$ & 22 & 664 & 700 & $525 / 800$ \\
\hline & 2020 & 32 & 138 & 135 & $119 / 150$ & 32 & 269 & 235 & $200 / 350$ & 29 & 5.7 & 5 & $5 / 6$ & 31 & 884 & 1000 & $800 / 1000$ & 31 & 622 & 600 & $500 / 800$ \\
\hline \multirow[t]{3}{*}{ Li polymer } & 2000 & 39 & 110 & 100 & $100 / 123$ & 38 & 136 & 140 & $120 / 150$ & 35 & 4.8 & 5 & $4 / 5$ & 36 & 577 & 500 & $500 / 600$ & 36 & 592 & 700 & $200 / 800$ \\
\hline & 2010 & 41 & 144 & 150 & $130 / 150$ & 39 & 167 & 160 & $150 / 184$ & 35 & 7.2 & 6 & $5 / 10$ & 37 & 876 & 750 & $700 / 900$ & 37 & 406 & 400 & $150 / 500$ \\
\hline & 2020 & 41 & 172 & 170 & $150 / 200$ & 39 & 193 & 180 & $180 / 209$ & 35 & 8.2 & 7.4 & $6 / 10$ & 37 & 1185 & 1000 & $900 / 1050$ & 37 & 296 & 250 & $125 / 500$ \\
\hline \multirow[t]{3}{*}{$\mathrm{NiCd}$} & 2000 & 45 & 57 & 57 & $55 / 60$ & 43 & 189 & 180 & $175 / 200$ & 38 & 5.7 & 5 & $5 / 5.9$ & 42 & 1254 & 1000 & $1000 / 1300$ & 43 & 575 & 600 & $500 / 600$ \\
\hline & 2010 & 44 & 60 & 60 & $55 / 65$ & 43 & 199 & 190 & $175 / 210$ & 37 & 6.6 & 6 & $5 / 6.6$ & 41 & 1428 & 1300 & $1000 / 1500$ & 43 & 517 & 500 & $400 / 600$ \\
\hline & 2020 & 43 & 62 & 62 & $55 / 66$ & 43 & 209 & 200 & $182 / 222$ & 37 & 7.8 & 7 & $6 / 10$ & 41 & 1546 & 1500 & $1000 / 1800$ & 42 & 492 & 450 & $400 / 588$ \\
\hline \multirow[t]{3}{*}{$\mathrm{NiFe}$} & 2000 & 23 & 51 & 50 & $50 / 55$ & 22 & 125 & 130 & $120 / 131$ & 21 & 8.3 & 9 & $6 / 10$ & 21 & 1055 & 1000 & $1000 / 1127$ & 21 & 529 & 500 & $500 / 550$ \\
\hline & 2010 & 22 & 55 & 55 & $53 / 58$ & 22 & 140 & 135 & $130 / 140$ & 21 & 9.1 & 9.5 & $7 / 10.5$ & 21 & 1294 & 1200 & $1050 / 1482$ & 21 & 482 & 500 & $400 / 500$ \\
\hline & 2020 & 22 & 58 & 58 & $55 / 60$ & 22 & 152 & 150 & $140 / 150$ & 21 & 9.8 & 10 & $8 / 10.9$ & 21 & 1545 & 1350 & $1200 / 1848$ & 21 & 448 & 464 & $400 / 500$ \\
\hline \multirow[t]{3}{*}{$\mathrm{NiMH}$} & 2000 & 43 & 73 & 75 & $70 / 75$ & 41 & 165 & 155 & $150 / 175$ & 37 & 4.6 & 4.7 & $3 / 5$ & 41 & 969 & 1000 & $500 / 1000$ & 43 & 569 & 583 & $350 / 600$ \\
\hline & 2010 & 43 & 83 & 80 & $80 / 85$ & 41 & 184 & 180 & $150 / 200$ & 37 & 6.0 & 5 & $4.7 / 6$ & 41 & 1177 & 1100 & $600 / 1331$ & 43 & 426 & 400 & $200 / 500$ \\
\hline & 2020 & 42 & 89 & 85 & $85 / 95$ & 41 & 203 & 200 & $175 / 220$ & 36 & 6.7 & 6 & $5 / 7$ & 40 & 1312 & 1250 & $750 / 1506$ & 42 & 382 & 300 & $180 / 475$ \\
\hline \multirow[t]{3}{*}{$\mathrm{NiZn}$} & 2000 & 20 & 61 & 60 & $55 / 63$ & 20 & 171 & 161 & $150 / 175$ & 20 & 3.1 & 3 & $3 / 3$ & 20 & 427 & 400 & $375 / 463$ & 20 & 654 & 700 & $500 / 707$ \\
\hline & 2010 & 20 & 68 & 70 & $64 / 70$ & 20 & 192 & 180 & $175 / 200$ & 20 & 4.2 & 3.95 & $3 / 4.6$ & 20 & 570 & 525 & $488 / 603$ & 20 & 587 & 625 & $400 / 681$ \\
\hline & 2020 & 20 & 74 & 75.5 & $67 / 80$ & 20 & 214 & 200 & $198 / 231$ & 20 & 4.8 & 4.5 & $4 / 5$ & 20 & 716 & 650 & $575 / 825$ & 20 & 548 & 600 & $300 / 650$ \\
\hline \multirow[t]{3}{*}{$\mathrm{NaS}$} & 2000 & 41 & 95 & 90 & $80 / 110$ & 40 & 144 & 141.5 & $132 / 150$ & 39 & 4.2 & 4 & $4 / 5$ & 40 & 683 & 700 & $500 / 800$ & 41 & 392 & 400 & $320 / 450$ \\
\hline & 2010 & 40 & 102 & 100 & $90 / 110$ & 40 & 153 & 150 & $148 / 160$ & 38 & 5.4 & 5 & $4.6 / 5$ & 39 & 829 & 850 & $600 / 1000$ & 41 & 339 & 360 & $200 / 400$ \\
\hline & 2020 & 39 & 107 & 110 & $95 / 110$ & 40 & 160 & 150 & $150 / 170$ & 38 & 5.3 & 5 & $5 / 5.5$ & 38 & 910 & 1000 & $625 / 1075$ & 40 & 318 & 333 & $188 / 400$ \\
\hline \multirow[t]{3}{*}{$\mathrm{Zn}$ air } & 2000 & 29 & 116 & 120 & $100 / 120$ & 27 & 91 & 100 & $83 / 100$ & 24 & 3.8 & 3 & $3 / 4$ & 26 & 428 & 350 & $213 / 395$ & 25 & 483 & 500 & $300 / 545$ \\
\hline & 2010 & 28 & 137 & 130 & $120 / 150$ & 27 & 108 & 110 & $100 / 120$ & 24 & 4.9 & 4 & $4 / 4.4$ & 25 & 568 & 450 & $400 / 500$ & 25 & 387 & 400 & $300 / 450$ \\
\hline & 2020 & 27 & 146 & 150 & $130 / 160$ & 26 & 122 & 120 & $113 / 130$ & 24 & 5.3 & 4.5 & $4 / 5$ & 25 & 735 & 600 & $500 / 700$ & 25 & 339 & 350 & $300 / 400$ \\
\hline \multirow[t]{3}{*}{$\mathrm{ZnBr}$} & 2000 & 21 & 69 & 70 & $65 / 70$ & 21 & 94 & 90 & $90 / 100$ & 20 & 3.2 & 3 & $3 / 3.4$ & 20 & 560 & 600 & $500 / 600$ & 20 & 667 & 745 & $600 / 763$ \\
\hline & 2010 & 21 & 75 & 72 & $70 / 75$ & 20 & 110 & 110 & $94 / 124$ & 19 & 4.2 & 4 & $4 / 4.9$ & 20 & 704 & 700 & $600 / 750$ & 20 & 576 & 606 & $500 / 700$ \\
\hline & 2020 & 21 & 79 & 77 & $72 / 80$ & 21 & 124 & 130 & $110 / 140$ & 20 & 5.0 & 5 & $4.8 / 5.1$ & 20 & 840 & 800 & $700 / 900$ & 20 & 523 & 567 & $400 / 600$ \\
\hline
\end{tabular}


range of 193-214 W/kg. Two other battery types, lithium-iron disulfide ( $269 \mathrm{~W} / \mathrm{kg})$ and nickel-zinc $(214 \mathrm{~W} / \mathrm{kg})$, exceed $200 \mathrm{~W} / \mathrm{kg}$, but they are very expensive at $\$ 622$ and $\$ 548 / \mathrm{kWh}$. The year 2020 specific energy of the above four battery types (e.g. lithium-polymer, nickel-metal hydride, nickelcadmium, and lead-acid) range from 48 to $172 \mathrm{Wh} / \mathrm{kg}$, with only one (lithium-polymer) exceeding $100 \mathrm{Wh} / \mathrm{kg}$. The lead-acid battery improves its shelf life by $29 \%$ between 2000 and 2020 , but it still ranks last among the 10 battery types. Its cycle life improves by $43 \%$, and by 2020 the battery ranks seventh among the 10 battery types. By 2020, the lithium-polymer battery ranks very high in each category except specific power; it ranks first in specific energy, sixth in specific power, second (behind nickel-iron) in shelf life, fourth in cycle life, and second (behind lead-acid) in cost.

\section{Battery Recyclability and Environmental Impacts}

The weight of EV battery modules will be in the hundreds of kilograms, or as much as onethird of the vehicle curb weight, indicating a significant materials-disposal problem at the end of the module's life. HEV battery modules would be smaller, but still large enough to pose a materials disposal problem. The respondents were asked to rank recyclability and environmental impacts of the 10 battery types. Lead-acid and nickel-metal hybrid batteries were considered the most recyclable, and zinc-bromide and lithium-iron disulfide were considered the least recyclable. The zinc-air battery was rated as having the least negative environmental impact, while zinc-bromide and nickel-cadmium were considered to have the most negative environmental impact ratings.

\section{Electric Motors}

The match between motor technology and the propulsion battery system will be of great importance to the ultimate success of EVs and HEVs. The respondents were asked to rank three candidate motors - direct-current (dc), alternating-current (ac) induction, and dc brushless - in terms of technology and cost. The ac induction motor was consistently ranked high for technological maturity, but it was considered more expensive than the dc motor until 2020. By 2020, according to the experts, the ac induction motor will have very competitive cost, $2 \%$ lower than the dc motor, the current cost leader. The cost of the dc motor will be as competitive as that of the ac induction motor, but the respondents thought the technology to be behind both the ac induction and dc brushless motors in terms of maturity and motor/battery match for both EV and HEV applications. The motor control technology is also an important element in both EV and HEV technologies. Questions on motor control technology were not included in the survey. Recent progress in control technology warrants future survey attention. 


\section{Materials}

Electric and hybrid vehicle design goals include low vehicle weight, without sacrificing occupant safety. Advanced materials would be good candidates for helping to achieve these goals. Also, there is a possibility that EV and HEV production may stimulate development and accelerate commercialization of some advanced materials. The respondents were requested to rank six candidate materials in terms of environmental benefit, corrosion resistance, crashworthiness, reliability, durability, and cost-effectiveness. The respondents rated high-strength steel as the best material, followed by aluminum, plastics, composite materials, and ceramics, respectively, while powdered metal was rated the lowest. These ratings are based on the combined values for the six attributes, with each attribute assigned equal weight. Individually, high-strength steel rated the highest for all categories except corrosiveness, where plastics rated the highest. Ceramics rated the lowest in crashworthiness, reliability, and cost-effectiveness; composites, in environmental benefits; high-strength steel, in corrosion; and powdered metal, in durability.

\section{HEV Power Units}

The future hybrids will be powered by onboard units deploying different technologies. The respondents were asked to rank five power unit technologies in terms of technological maturity, suitability for hybrid use and safety, and cost-effectiveness. The five technologies were (1) 2-stroke Otto (SI) engine, (2) 4-stroke Otto (SI) engine, (3) diesel (CI) engine, (4) gas turbine, and (5) fuel cell. For technological maturity and cost-effectiveness, the respondents assigned the highest rating to the 4-stroke Otto engine through the projection period, with the diesel engine finishing second. The 4-stroke Otto engine also rated the highest for suitability and safety through the year 2010, with the diesel engine second. By 2020, the diesel engine was rated the highest, with the 4-stroke Otto engine dropping to second.

\section{Other Concepts}

Several advanced technologies and concepts could be used by EVs and HEVs. These concepts would make both EVs and HEVs more viable, but their higher cost is a detriment. Respondents were asked to rate five advanced concepts for their technological viability and cost. The five concepts are (1) advanced electronics; (2) very light, high-tensile-strength materials; (3) extended-life batteries; (4) solar conversion devices; and (5) ultracapacitor. The respondents rated the five concepts in the above order for both technological viability and cost, with one exception, ultracapacitors, rated ahead of solar conversion devices. The relative ratings were the same through the projection period. 


\subsection{SYSTEM IMPACTS}

\section{Air Pollution}

The experts were asked whether they agreed or disagreed with a set of statements relating to air pollution and global warming. Most (93\%) of the experts had the opinion that EVs will help reduce urban ozone levels, due to the displacement of gasoline combustion and storage by fuels or energy production techniques with lower ozone-forming potential. More that $90 \%$ of the experts believed that most EV charging will use overnight base load capacity, resulting in little net increase in daytime power-plant emissions. Close to $90 \%$ agreed that EVs will be environmentally beneficial because of the displacement of emissions from urban areas to remote power plants and from daytime to nighttime. Moreover, any increase in power-plant emissions due to EV use will be offset at the local level by decreases in on-road emissions. About one-half expected coal to be the predominant power-plant fuel. Less than (but close to) half expected that electricity will be generated from natural gas, low-carbon-per-kW fuels, and nuclear sources.

\section{Global Warming}

Less than one-half (44\%) of the respondents believed that EVs and HEVs will reduce the potential for global warming by 2020 , even if these vehicles have a market share of only $33 \%$ (study mean projection, $21 \%$ ). More than $80 \%$ of the experts had the opinion that the complexity of global warming as a scientific issue requires that many more studies must be undertaken before any key policy decisions are made, but they also agreed that mitigation of global warming potential could have significant socioeconomic benefits. Only $16 \%$ of the respondents felt that global warming is unimportant and future decisions on transportation policy should not have to consider it.

\section{Nuclear Power}

The respondents were asked to rank the possible reasons that nuclear power is more popular in Europe and Asia compared to the United States. Most respondents strongly agreed that nuclear energy has a negative public image due to accidents or near accidents in the United States. The next ranking reason was the lack of perception about the relative costs and environmental benefits of nuclear, fossil, and renewable plant technologies, including the costs of residuals disposal. The relative abundance of coal and that of natural gas ranked third and fourth, respectively. 


\section{Market Success Factors}

At the end of the questionnaire, the respondents were asked to assign importance rankings to 12 statements indicating what is most important for the EVs and HEVs to succeed in the market. Indirectly, the rankings are a form of expression of the context for their estimates of the technical, cost, and market penetration for EVs and HEVs. This might also have caused the respondents to review their answers to the questions in other sections, especially by the second round. The top three statements ranked as highly important are (1) these vehicles must have lower acquisition and operating costs, (2) they must be as reliable as conventional vehicles, and (3) there must be enough R\&D to ensure excellent products. The three lowest-ranked statements are (12) a new oil crisis would have to occur, (11) large direct incentives to the buyers are necessary, and (10) consumer education and overall promotion of EVs and HEVs must increase. Supporting infrastructure, public perception of urban air pollution as a severe problem, and key technology implementation prior to market introduction were all ranked as important, but slightly less so than the top three. 


\section{BATTERY COST ANALYSIS}

In Chapter 2, we presented a summary of basic vehicle characteristics and battery performance data emerging from the Delphi study. Characteristics for EVs and HEVs and for 10 battery technologies were evaluated for the years 2000,2010, and 2020. The battery replacement costs were analyzed separately; the results are presented in this chapter. The battery cost methodology described in this chapter uses the basic characteristics of EVs and HEVs summarized in Chapter 2.

\subsection{ELECTRIC-DRIVE-VEHICLE CHARACTERISTICS}

The survey questionnaire contained sections on vehicles, components, and system impacts. A set of questions within the vehicles section sought experts' opinions on such vehicle attributes as range, acceleration, highest acceptable uphill grade, seating capacity, cargo capacity, curb weight, power, battery recharging time, and maintenance interval. For the HEV, an additional question was asked concerning the engine range. In estimating the HEV battery replacement cost, we use the implied battery-only range, which is computed by subtracting engine range from the total HEV range. Experts also provided opinions on EV and HEV price and fuel and maintenance costs, which are used in the analysis presented here. Within the components section of the questionnaire, they responded to questions about 10 battery technologies. In this chapter, we analyze the responses to all these questions to arrive at two separate estimates of EV and HEV characteristics, primary (i.e., resulting from respondents' vehicle opinions) and secondary (i.e., resulting from respondents' battery opinions). For most of the analysis presented here, we have used mean values of the responses.

\section{Basic Vehicle Characteristics}

The basic vehicle characteristics for EVs and HEVs are power, curb weight, seating capacity, and range. These characteristics are summarized in Chapter 2 (see Tables 2.2 and 2.3). As can be seen from the number of observations, most respondents answered the basic vehicle characteristics questions. They projected consistent improvements in both the EVs and the HEVs.

Table 2.2 in Chapter 2 shows the projected attributes of an EV. The projected mean EV range is $179 \mathrm{~km}$ in the year 2000, increasing to $270 \mathrm{~km}$ by 2010 (a $51 \%$ increase) and to $358 \mathrm{~km}$ by 2020 (a 100\% increase). The projected mean EV power is $66.7 \mathrm{~kW}$ in the year $2000,86.1 \mathrm{~kW}$ in 2010 (a $29 \%$ increase), and $99.2 \mathrm{~kW}$ in 2020 (a 49\% increase over 2000). An EV is projected to have a mean curb weight of $1,538 \mathrm{~kg}$ in $2000,1,351 \mathrm{~kg}$ in 2010 (a 12\% reduction), and $1,222 \mathrm{~kg}$ in 2020 (a $21 \%$ reduction). The projected improvements in power, range, and curb weight pose substantial challenges to EV manufacturers. Lightweight materials, such as aluminum and carbon polymer, have 
the potential to reduce the curb weight, but vehicles that use such materials will cost more. To illustrate, an aluminum-intensive mid-size conventional car would weigh $31 \%$ less when power per unit mass is held constant; however, such a car would cost $\$ 1,200$ (1990 dollars) more (Stodolsky, Vyas, and Cuenca 1995).

Table 2.3 in Chapter 2 shows the projected attributes of an HEV. Its mean power is projected to be $79.6 \mathrm{~kW}$ in $2000,99.1 \mathrm{~kW}$ in 2010 (a $24 \%$ increase), and $108.6 \mathrm{~kW}$ in 2020 (a $36 \%$ increase). Two HEV range values, total and engine-only, are summarized in the table. A large majority (94\%) of the respondents expected the future HEV to be of the "range extender" type (that is, vehicles with significant all-electric range). A small battery range indicates that the respondent did not expect the HEV to be a "range extender," because it would not be charged through the electric grid. Only 7 respondents in the year 2000 and 5 respondents each in 2010 and 2020 projected very small battery-only ranges.

The mean total range of an HEV is projected to be $353 \mathrm{~km}$ in $2000,469 \mathrm{~km}$ in 2010 (a 33\% increase), and $527 \mathrm{~km}$ in 2020 (a $49 \%$ increase). The total range is less than the range of a conventional vehicle (500-550 km) until 2020, which indicates that the respondents did not see HEVs being used for vacations and long trips until after 2010. The mean engine range is $215 \mathrm{~km}$ in $2000,257 \mathrm{~km}$ in 2010 (a 20\% increase), and $281 \mathrm{~km}$ in 2020 (a $31 \%$ increase). The engine range does not increase as much as the total range. The respondents saw the battery supplying more of the HEV range, increasing from 39\% of the total range in 2000 to $47 \%$ in 2020.

The mean curb weight of an HEV is $1,556 \mathrm{~kg}$ in $2000,1,382 \mathrm{~kg}$ in 2010 (a $11 \%$ reduction), and $1,265 \mathrm{~kg}$ in 2020 (a 19\% reduction). The rate of weight reduction is slightly lower than the rate for an EV (see above). The respondents saw an HEV as being slightly heavier than an EV.

\section{Vehicle Costs}

Vehicle purchase prices are summarized in Table 3.1, and fuel and maintenance costs are summarized in Table 3.2. The respondents projected the conventional vehicle to cost $26 \%$ more by $2000,60 \%$ more by 2010 , and $102 \%$ more by 2020 . The respondents expected both EVs and HEVs to cost more than the conventional vehicle through the projection period (2000-2020), although they projected minimal increases in EV and HEV prices during the period (4\% and 3\%, respectively). With the projected $61 \%$ increase in the conventional vehicle price between 2000 and 2020 and the above-mentioned minimal increases in EV and HEV prices, the price gaps between conventional and new technology vehicles would narrow over time. An EV is projected to cost $82 \%$ more than a conventional vehicle in the year $2000,44 \%$ more in 2010 , and $18 \%$ more in 2020 . The least expensive HEV, an ICE-powered version, would cost $97 \%$ more than a conventional vehicle in 2000 , $52 \%$ more in 2010, and $25 \%$ more in 2020. A fuel-cell HEV is projected to be the most expensive 
TABLE 3.1 Vehicle Purchase Price (in nominal dollars) for Conventional, Electric, and Hybrid Vehicles

\begin{tabular}{lccccccccc}
\hline Vehicle Technology & Year & Obs & Mean & Mode & Median & Quartile-1 & Quartile-3 & Optimist & Pessimist \\
\hline \multirow{2}{*}{ Conventional ICE } & 2000 & 87 & 18,862 & 18,000 & 18,000 & 16,500 & 19,650 & 16,999 & 20,952 \\
& 2010 & 86 & 24,052 & 21,000 & 22,500 & 21,000 & 27,000 & 20,090 & 28,401 \\
& 2020 & 87 & 30,336 & 30,000 & 30,000 & 23,250 & 34,500 & 24,361 & 40,114 \\
& & & & & & & & & \\
& 2000 & 87 & 34,300 & 30,000 & 30,000 & 30,000 & 40,500 & 26,870 & 42,261 \\
Electric vehicle & 2010 & 86 & 34,594 & 30,000 & 33,000 & 30,000 & 37,500 & 28,909 & 44,681 \\
& 2020 & 87 & 35,703 & 30,000 & 33,000 & 30,000 & 37,500 & 28,188 & 46,869 \\
& & & & & & & & & \\
& 2000 & 85 & 37,082 & 33,000 & 35,250 & 30,000 & 43,500 & 28,193 & 46,182 \\
ICE-powered hybrid & 2010 & 84 & 36,552 & 37,500 & 36,000 & 30,000 & 39,825 & 28,800 & 45,936 \\
& 2020 & 85 & 38,051 & 37,500 & 37,500 & 30,000 & 42,000 & 30,101 & 50,577 \\
Gas-turbine- & & & & & & & & & \\
powered hybrid & 2000 & 76 & 49,089 & 45,000 & 45,000 & 37,500 & 60,000 & 36,077 & 66,045 \\
& 2010 & 84 & 45,655 & 45,000 & 45,000 & 36,863 & 46,688 & 37,335 & 67,722 \\
& 2020 & 85 & 46,016 & 45,000 & 45,000 & 36,000 & 48,750 & 36,605 & 67,373 \\
Fuel-cell-powered & 2000 & 70 & 77,231 & 60,000 & 67,500 & 46,125 & 86,250 & 49,123 & 112,592 \\
hybrid & 2010 & 81 & 65,344 & 90,000 & 60,000 & 45,000 & 90,000 & 45,796 & 91,037 \\
& 2020 & 83 & 59,770 & 60,000 & 57,000 & 37,500 & 75,000 & 38,421 & 81,640 \\
\hline
\end{tabular}

TABLE 3.2 Fuel and Maintenance Costs (in nominal cent/km) for Conventional, Electric, and Hybrid Vehicles ${ }^{\mathrm{a}}$

\begin{tabular}{|c|c|c|c|c|c|c|c|c|c|}
\hline Vehicle Technology & Year & Obs & Mean & Mode & Median & Quartile-1 & Quartile-3 & Optimist & Pessimist \\
\hline \multirow[t]{3}{*}{ Conventional ICE } & 2000 & 85 & 6.9 & 6.4 & 6.9 & 6.4 & 7.5 & 6.4 & 7.7 \\
\hline & 2010 & 84 & 8.5 & 8.1 & 8.1 & 7.5 & 9.2 & 7.3 & 10.0 \\
\hline & 2020 & 83 & 10.4 & 8.7 & 9.2 & 8.4 & 11.6 & 8.0 & 13.1 \\
\hline \multirow[t]{3}{*}{ Electric vehicle } & 2000 & 84 & 8.2 & 7.5 & 7.5 & 6.4 & 8.7 & 6.4 & 11.0 \\
\hline & 2010 & 83 & 8.3 & 6.9 & 7.5 & 6.9 & 8.7 & 6.3 & 10.7 \\
\hline & 2020 & 83 & 8.9 & 8.7 & 7.5 & 6.2 & 10.4 & 5.9 & 12.2 \\
\hline \multirow[t]{3}{*}{ ICE-powered hybrid } & 2000 & 79 & 9.0 & 8.7 & 8.7 & 7.5 & 9.8 & 7.5 & 11.2 \\
\hline & 2010 & 79 & 9.4 & 8.1 & 8.7 & 8.1 & 10.4 & 7.6 & 11.7 \\
\hline & 2020 & 79 & 10.9 & 11.0 & 10.4 & 8.4 & 11.6 & 8.1 & 13.7 \\
\hline \multirow{3}{*}{$\begin{array}{l}\text { Gas-turbine-powered } \\
\text { hybrid }\end{array}$} & 2000 & 79 & 11.6 & 8.7 & 10.4 & 8.7 & 11.6 & 8.8 & 15.3 \\
\hline & 2010 & 80 & 11.3 & 10.4 & 10.4 & 8.7 & 11.6 & 9.0 & 15.6 \\
\hline & 2020 & 80 & 12.0 & 10.4 & 10.4 & 8.7 & 12.7 & 9.1 & 16.2 \\
\hline \multirow{3}{*}{$\begin{array}{l}\text { Fuel-cell-powered } \\
\text { hybrid }\end{array}$} & 2000 & 73 & 15.4 & 11.6 & 12.1 & 11.6 & 17.3 & 9.8 & 21.1 \\
\hline & 2010 & 76 & 13.1 & 11.6 & 11.6 & 9.8 & 14.4 & 10.0 & 17.7 \\
\hline & 2020 & 77 & 13.6 & 11.6 & 11.6 & 9.8 & 14.4 & 9.5 & 19.3 \\
\hline
\end{tabular}

a Excludes battery cost for electric and hybrid vehicles. 
of the four electric-drive vehicles, costing 309\% more than a conventional vehicle in 2000 and $97 \%$ more in 2020. The interquartile ranges are wider for the gas-turbine-powered and fuel-cell-powered HEVs.

Fuel and maintenance costs in Table 3.2 are computed by multiplying the respondentspecified ratios by 5.8 cents. This base value of 5.8 cents $/ \mathrm{km}$ represents the average fuel, lubrication, tire, and maintenance cost for a conventional car in 1993, according to the American Automobile Manufacturers Association (AAMA 1996). Battery replacement costs are excluded for the EV and the three HEVs. The conventional ICE is expected to have a fuel and maintenance cost advantage in 2000 . The EV will have a slight advantage over the conventional vehicle by 2010 and a $14 \%$ ( 1.5 cents) advantage by 2020 . HEV technologies are projected to have higher fuel and maintenance costs than the conventional vehicle through the year 2020. Only the ICE-powered HEV will come within $5 \%$ of the conventional vehicle cost by 2020 .

\subsection{BATTERY PERFORMANCE AND COST}

\section{Basic Performance Characteristics}

Respondents were asked to provide achievable values for key characteristics of 10 promising battery technologies. They provided estimates for five characteristics: specific energy $(\mathrm{Wh} / \mathrm{kg}$ ), specific power $(\mathrm{W} / \mathrm{kg}$ ), shelf life (year), life in charge/discharge cycles, and initial cost $(\$ / \mathrm{kWh})$. Table 2.7 in Chapter 2 shows a summary of the responses on battery characteristics. Many respondents chose not to respond to the battery technology questions, citing their lack of expertise in the area. Compared with the participation rate of nearly $98 \%$ for basic vehicle characteristics, the battery technology participation rate was low. Lead-acid technology had the highest participation rate, nearly $60 \%$. Four technologies, lithium-polymer, nickel-cadmium, nickel-metal hydride, and sodium-sulfur, had participation rates in the range of $42-48 \%$.

Lithium-polymer, zinc-air, lithium-iron disulfide, and sodium-sulfur batteries have high specific energy, while the lead-acid battery has the lowest. Lithium-iron disulfide, nickel-zinc, leadacid, and nickel-cadmium batteries have high specific power, while zinc-air and zinc-bromide batteries have low specific power. Nickel-iron, lithium-polymer, nickel-cadmium, and nickel-metal hydride batteries have longer shelf lives, while nickel-zinc and lead-acid batteries have shorter shelf lives. The sodium-sulfur battery showed a plateau in shelf life, with nearly constant mean shelf life between 2010 and 2020. Nickel-cadmium, nickel-iron, and nickel-metal hydride batteries are projected as being able to go through a high number of charge and discharge cycles. The lead-acid battery has the lowest initial cost, while the lithium-iron disulfide battery has the highest. The battery characteristics indicate that no one battery technology is superior in all respects. 


\section{Initial Battery Pack Characteristics for the EV}

An EV may be characterized to match a desired power level (acceleration capability), a desired range, or a specified minimum for both. Because the currently available batteries are energylimited, range may be a good criterion for characterizing an EV in the near term. However, the Delphi study used in our analysis is intended to project a long-term outlook, and therefore either mean power or mean range requirements may be used to characterize an EV. We first evaluated the initial battery pack characteristics on the basis of mean range requirements. Table 3.3 lists estimated power and battery pack mass necessary to meet the mean range requirements for the 10 battery technologies. Under this approach, a few battery technologies provide more power than required and have very high mass. Also, some battery technologies provide less than the mean power required and thus would not meet the performance (acceleration) capabilities predicted by the respondents. Battery technologies that have low specific power and high specific energy show low power (inability to meet the acceleration predictions), while those with high specific power and low specific energy have very high mass when sized to meet projected range (incompatibility with the overall vehicle mass estimates). After this examination of use of range as a design constraint, it was concluded that the initial battery pack characteristics for an EV should be evaluated on the basis of mean power requirements (listed in Table 2.2 in Chapter 2). The EV thus characterized will meet the acceleration requirements (will be road-worthy) and can be evaluated for other characteristics, such as range, mass, and cost.

TABLE 3.3 Initial EV Battery Pack Power and Mass for the Mean Range ${ }^{a}$

\begin{tabular}{|c|c|c|c|c|c|c|}
\hline \multirow[b]{2}{*}{ Battery Technology } & \multicolumn{3}{|c|}{ EV Power (kW) } & \multicolumn{3}{|c|}{ Battery Pack Mass (kg) } \\
\hline & 2000 & 2010 & 2020 & 2000 & 2010 & 2020 \\
\hline Lead-acid & 153 & 306 & 485 & 989 & 1,610 & 2,265 \\
\hline Lithium-iron disulfide & 44 & 75 & 109 & 266 & 358 & 404 \\
\hline Lithium-polymer & 31 & 46 & 61 & 230 & 276 & 314 \\
\hline Nickel-cadmium & 103 & 185 & 290 & 545 & 930 & 1,391 \\
\hline Nickel-iron & 82 & 156 & 255 & 656 & 1,115 & 1,675 \\
\hline Nickel-metal hydride & 64 & 104 & 156 & 387 & 568 & 765 \\
\hline Nickel-zinc & 84 & 147 & 222 & 494 & 764 & 1,036 \\
\hline Sodium-sulfur & 40 & 67 & 98 & 277 & 438 & 613 \\
\hline Zinc-air & 21 & 34 & 51 & 225 & 312 & 417 \\
\hline Zinc-bromide & 42 & 81 & 126 & 450 & 732 & 1,014 \\
\hline
\end{tabular}

a The mean range requirements are $179 \mathrm{~km}$ in $2000,270 \mathrm{~km}$ in 2010 , and $358 \mathrm{~km}$ in 2020. 
Table 3.4 lists the estimated initial battery pack characteristics for each battery technology for the three future years. Battery mass, energy, and initial cost are computed from the mean of responses to match the mean power requirements. EV range and battery life (in $\mathrm{km}$ ) are computed by using information from related studies (Marr 1994; Wang 1994). We used a set of baseline EV energy demand values (from the battery pack) and corresponding battery mass estimates by Marr to compute range. We applied a $3.3 \%$ rate of change in energy consumption per $10 \%$ change in battery mass. (Note that battery mass represents a fraction of the vehicle mass.) This $3.3 \%$ rate of change in energy consumption is half the rate of change used for total vehicle mass for conventional vehicles, according to the congressional Office of Technology Assessment (OTA 1991). Lifetime distance (distance traveled by the vehicle during the battery's lifetime) in kilometers represents the shorter of two distances: (a) shelf life times annual travel $(17,600 \mathrm{~km})$ or (b) number of cycles times half the range.

The initial battery pack characteristics estimated in this fashion for EVs do not match well with the basic vehicle characteristics specified by respondents in Table 2.2 in Chapter 2 . Nearly all respondents, 92 of 93 , answered the EV range question. They projected high range $(179 \mathrm{~km}$ in 2000 , increasing to $358 \mathrm{~km}$ in 2020) and nearly stable purchase price. Six of the 10 battery technologies can provide a $179-\mathrm{km}$ range in 2000 . The least expensive of these six batteries, nickel-metal hydride, would cost $\$ 16,750$. Subtracting this initial battery cost from the mean $E V$ purchase price of $\$ 34,300$ (see Table 3.1) leaves $\$ 17,550$ for the remaining components, including an expensive controller (Cuenca and Gaines 1996). Respondents viewed three battery technologies as capable of providing a range of $358 \mathrm{~km}$ or more in 2020 . The sodium-sulfur battery is the least expensive of these three at $\$ 21,120$. The mean predicted vehicle price in 2020 is $\$ 35,700$, leaving $\$ 14,580$ for the remaining components.

The battery technology would be a fairly mature technology by the year 2020. Delphi estimates for 2020 would indicate the extent of such maturity. We computed range and cost for each battery type for the mean power requirements in the year 2020. The results are shown graphically in Figure 3.1. The mean range from basic vehicle characteristics is shown by a vertical line, and the target battery cost (one-third of the vehicle price) is shown by a horizontal line. Since higher range and lower cost are desirable, the desired region is shown in the figure within which the acceptable battery types would fall. None of the ten battery types fall within the desired region. Even when the region is expanded by reducing the range expectations to $250 \mathrm{~km}$ and increasing the cost expectations to $45 \%$ of the vehicle price $(\$ 16,070)$, all battery types remain outside the desired region. The closest battery types are nickel-metal hydride, with a $260-\mathrm{km}$ range and $\$ 16,670(47 \%$ of EV price) cost, and sodium-sulfur, with a 360-km range and $\$ 21,120$ (59\% of EV price) cost.

EVs are projected to become lighter over time. Their mean curb weight is $1,538 \mathrm{~kg}$ in 2000 , dropping to $1,222 \mathrm{~kg}$ in 2020 (Table 2.2 in Chapter 2). On the other hand, the initial battery pack weight increases from $410 \mathrm{~kg}$ (nickel-metal hydride) in 2000 to $620 \mathrm{~kg}$ (sodium-sulfur) in 2020 . Some inconsistency between basic vehicle characteristics and battery characteristics appears to exist 
TABLE 3.4 Characteristics of Initial EV Battery Pack ${ }^{\mathrm{a}, \mathrm{b}}$

\begin{tabular}{|c|c|c|c|c|c|c|}
\hline Battery Technology & Year & $\begin{array}{c}\text { Mass } \\
(\mathrm{kg})\end{array}$ & $\begin{array}{l}\text { Energy } \\
\text { (Wh) }\end{array}$ & $\begin{array}{c}\text { Initial } \\
\text { Cost }(\$)\end{array}$ & $\begin{array}{l}\text { Range } \\
(\mathrm{km})\end{array}$ & $\begin{array}{l}\text { Life } \\
(\mathrm{km})\end{array}$ \\
\hline Lead-acid & $\begin{array}{l}2000 \\
2010 \\
2020\end{array}$ & $\begin{array}{l}430 \\
450 \\
460\end{array}$ & $\begin{array}{l}17,040 \\
20,030 \\
22,340\end{array}$ & $\begin{array}{l}3,150 \\
3,590 \\
4,120\end{array}$ & $\begin{array}{l}110 \\
120 \\
140\end{array}$ & $\begin{array}{l}32,100 \\
45,200 \\
59,400\end{array}$ \\
\hline Lithium-iron disulfide & $\begin{array}{l}2000 \\
2010 \\
2020\end{array}$ & $\begin{array}{l}400 \\
410 \\
370\end{array}$ & $\begin{array}{l}38,700 \\
47,610 \\
50,630\end{array}$ & $\begin{array}{l}33,010 \\
31,610 \\
31,480\end{array}$ & $\begin{array}{l}250 \\
300 \\
330\end{array}$ & $\begin{array}{r}61,500 \\
81,800 \\
101,300\end{array}$ \\
\hline Lithium-polymer & $\begin{array}{l}2000 \\
2010 \\
2020\end{array}$ & $\begin{array}{l}490 \\
520 \\
510\end{array}$ & $\begin{array}{l}53,900 \\
74,290 \\
88,100\end{array}$ & $\begin{array}{l}31,900 \\
30,170 \\
26,040\end{array}$ & $\begin{array}{l}320 \\
430 \\
520\end{array}$ & $\begin{array}{r}84,800 \\
127,700 \\
145,000\end{array}$ \\
\hline Nickel-cadmium & $\begin{array}{l}2000 \\
2010 \\
2020\end{array}$ & $\begin{array}{l}350 \\
430 \\
480\end{array}$ & $\begin{array}{l}20,020 \\
25,930 \\
29,660\end{array}$ & $\begin{array}{l}11,520 \\
13,410 \\
14,600\end{array}$ & $\begin{array}{l}130 \\
160 \\
180\end{array}$ & $\begin{array}{r}82,600 \\
114,900 \\
138,300\end{array}$ \\
\hline Nickel-iron & $\begin{array}{l}2000 \\
2010 \\
2020\end{array}$ & $\begin{array}{l}530 \\
610 \\
650\end{array}$ & $\begin{array}{l}27,240 \\
33,820 \\
37,510\end{array}$ & $\begin{array}{l}14,400 \\
16,310 \\
16,800\end{array}$ & $\begin{array}{l}160 \\
180 \\
200\end{array}$ & $\begin{array}{r}81,900 \\
118,400 \\
153,800\end{array}$ \\
\hline Nickel-metal hydride & $\begin{array}{l}2000 \\
2010 \\
2020\end{array}$ & $\begin{array}{l}410 \\
470 \\
490\end{array}$ & $\begin{array}{l}29,440 \\
38,930 \\
43,570\end{array}$ & $\begin{array}{l}16,750 \\
16,590 \\
16,670\end{array}$ & $\begin{array}{l}190 \\
230 \\
260\end{array}$ & $\begin{array}{r}82,000 \\
106,100 \\
117,700\end{array}$ \\
\hline Nickel-zinc & $\begin{array}{l}2000 \\
2010 \\
2020\end{array}$ & $\begin{array}{l}390 \\
450 \\
460\end{array}$ & $\begin{array}{l}23,670 \\
30,410 \\
34,050\end{array}$ & $\begin{array}{l}15,480 \\
17,850 \\
18,660\end{array}$ & $\begin{array}{l}150 \\
190 \\
210\end{array}$ & $\begin{array}{l}32,200 \\
53,100 \\
74,300\end{array}$ \\
\hline Sodium-sulfur & $\begin{array}{l}2000 \\
2010 \\
2020\end{array}$ & $\begin{array}{l}460 \\
560 \\
620\end{array}$ & $\begin{array}{l}44,040 \\
57,510 \\
66,340\end{array}$ & $\begin{array}{l}17,250 \\
19,520 \\
21,120\end{array}$ & $\begin{array}{l}260 \\
320 \\
360\end{array}$ & $\begin{array}{l}74,800 \\
94,900 \\
93,100\end{array}$ \\
\hline Zinc-air & $\begin{array}{l}2000 \\
2010 \\
2020\end{array}$ & $\begin{array}{l}730 \\
800 \\
810\end{array}$ & $\begin{array}{r}85,110 \\
109,170 \\
118,960\end{array}$ & $\begin{array}{l}41,120 \\
42,220 \\
40,350\end{array}$ & $\begin{array}{l}420 \\
520 \\
570\end{array}$ & $\begin{array}{l}66,500 \\
87,200 \\
94,300\end{array}$ \\
\hline Zinc-bromide & $\begin{array}{l}2000 \\
2010 \\
2020\end{array}$ & $\begin{array}{l}710 \\
780 \\
800\end{array}$ & $\begin{array}{l}48,740 \\
58,090 \\
63,410\end{array}$ & $\begin{array}{l}32,510 \\
33,440 \\
33,160\end{array}$ & $\begin{array}{l}250 \\
280 \\
310\end{array}$ & $\begin{array}{l}56,500 \\
74,600 \\
87,800\end{array}$ \\
\hline
\end{tabular}

a For the mean power requirements of $66.7 \mathrm{~kW}$ in $2000,86.1 \mathrm{~kW}$ in 2010 , and $99.2 \mathrm{~kW}$ in 2020 .

b Values are rounded to the nearest ten or hundred. 


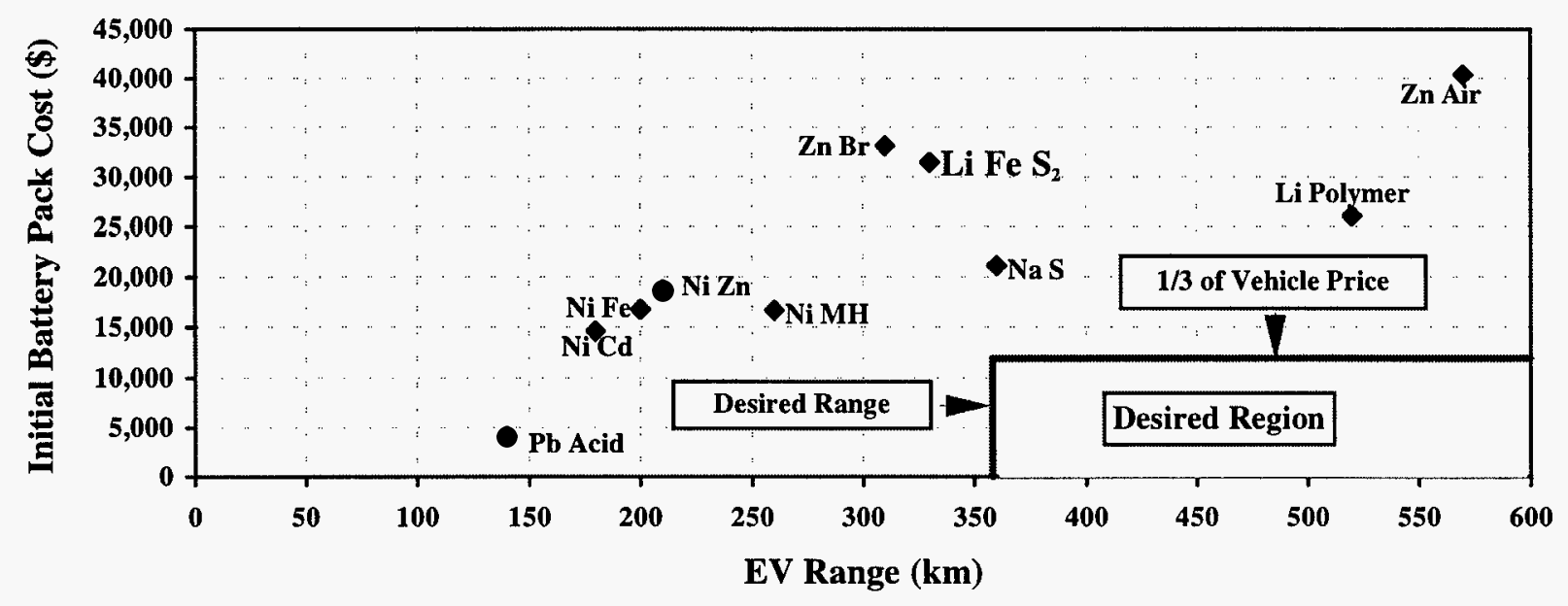

FIGURE 3.1 EV Range and Battery Cost in Year 2020, Matching Mean Power Requirements

in the responses. However, almost all respondents provided information on the desired EV characteristics, while only those familiar with the battery technologies responded to the battery questions. The mean basic vehicle characteristics appear to have been influenced by many respondents willing to predict the vehicle characteristics, but not the battery technologies needed to make those characteristics feasible.

\section{EV Battery Replacement Costs}

On average, a conventional vehicle lasts $12-15$ years and travels $170,000-210,000 \mathrm{~km}$ (Davis 1995; Mintz, Tompkins, and Camp 1994). Because an EV does not idle while stopped and has fewer parts that are subjected to continuous wear and tear, we assumed an EV to be in use for $195,000-240,000 \mathrm{~km}, 15 \%$ longer. Since the initial battery pack has a shorter life than this, one or more replacement packs will be needed.

We computed battery replacement costs by using a sequential procedure. First, we computed intermediate values for battery specific energy, specific power, shelf life, cycles, and initial cost through linear interpolation. Next, we computed battery pack mass, energy, and cost for each of the 15 years an EV is in use for the mean power rating of the year of manufacture (viz., 2000, 2010, or 2020). Next, we computed range and useable life in kilometers over a battery's shelf life and cycle life; then we computed battery replacement cost over both shelf and cycle lives and discounted it at $4 \%$ (real). Since battery technologies improve over time, the replacement batteries will have improved characteristics. For example, a year $2000 \mathrm{EV}$ will require one or more replacement battery pack(s) over its life time (during the period 2003-2015). The projected improvements in battery characteristics will offer the buyer of a replacement battery pack two alternatives: (1) buy a battery pack that delivers enough power to match the motor's rating or (2) buy as big a battery pack as fits in the space available. The second alternative will cost more, but it will 
provide greater range because of improvements in the battery's specific energy. We assumed that the motor's power rating will be the constraining factor when purchasing a replacement battery (i.e., to keep costs down, an EV owner will not buy a battery pack with more power, even though doing so would increase the vehicle range). Finally, we summed the discounted replacement costs, distributed them over the respective lives (i.e., shelf life or cycles), and selected the higher of the two costs. Thus, the cost is for the shortest predicted life, in terms of distance, of the battery. (Note that a battery can only be used until its life ends.) The methodology uses the shorter of the two predictions. The procedure excludes the cost of the initial battery pack because the Delphi questionnaire asked the respondents to include it in the vehicle purchase price.

Figure 3.2 shows battery replacement cost and initial pack range for the 10 technologies. Three points are plotted for each technology, representing values for EVs produced in 2000, 2010, and 2020. In general, the replacement cost declined over time and the range increased. One exception is the sodium-sulfur battery, for which the replacement cost is not projected to drop after 2010 (though range increases, a bigger battery pack is necessary to match the higher power rating in 2020). The changes in replacement cost are remarkable because they are visible even with the increases in mean power requirements. Only two batteries, lead-acid and nickel-cadmium, are projected to have their replacement costs under 6 cents $/ \mathrm{km}$ in 2000. The nickel-iron battery will join them in 2010 and nickel-metal hydride in 2020. The respondents have high expectations for the lithium-polymer battery. Its replacement cost dropped from 12 cents $/ \mathrm{km}$ in 2000 to 6.8 cents $/ \mathrm{km}$ in 2020 , and it has nearly twice the range of the nickel-metal hydride battery.

Results of the replacement cost analysis show the nickel-metal hydride battery as capable of meeting the year 2000 mean-range requirement of $179 \mathrm{~km}$ at a cost of $7.5 \mathrm{cents} / \mathrm{km}$. The nickelcadmium battery has a lower cost, 6 cents $/ \mathrm{km}$, but provides only a $130-\mathrm{km}$ range. The lithiumpolymer battery improves its replacement cost by $50 \%$ between 2000 and 2010 . The lithium-polymer battery can also meet the mean-range requirements for 2010 and 2020, at the cost of 7.1 and 6.8 cents $/ \mathrm{km}$, respectively.

As explained earlier, each battery pack in Table 3.4 and Figure 3.2 is characterized to meet the mean power requirements emerging from the Delphi data. The Delphi respondents specified higher vehicle power requirements in 2010 and 2020, thereby implicitly requiring bigger battery packs if the battery technologies that have low specific power are to be used. A nickel-metal hydride battery pack with $66.7 \mathrm{~kW}$ of power in 2000 will weigh $410 \mathrm{~kg}$, contributing an estimated $26 \%$ of the EV curb weight. A nickel-cadmium battery pack with a shorter range $(130 \mathrm{~km})$ will weigh $350 \mathrm{~kg}$ and contribute $23 \%$ of the EV curb weight. Lithium-polymer battery packs are estimated to be heavier, in the range of $500-520 \mathrm{~kg}$; the increased mass results from the lower specific power rating of the technology. If the range expectations are lowered to $260 \mathrm{~km}$ or less, the nickel-metal hydride battery can meet them at costs lower than those of the lithium-polymer battery. Even the nickel-metal 


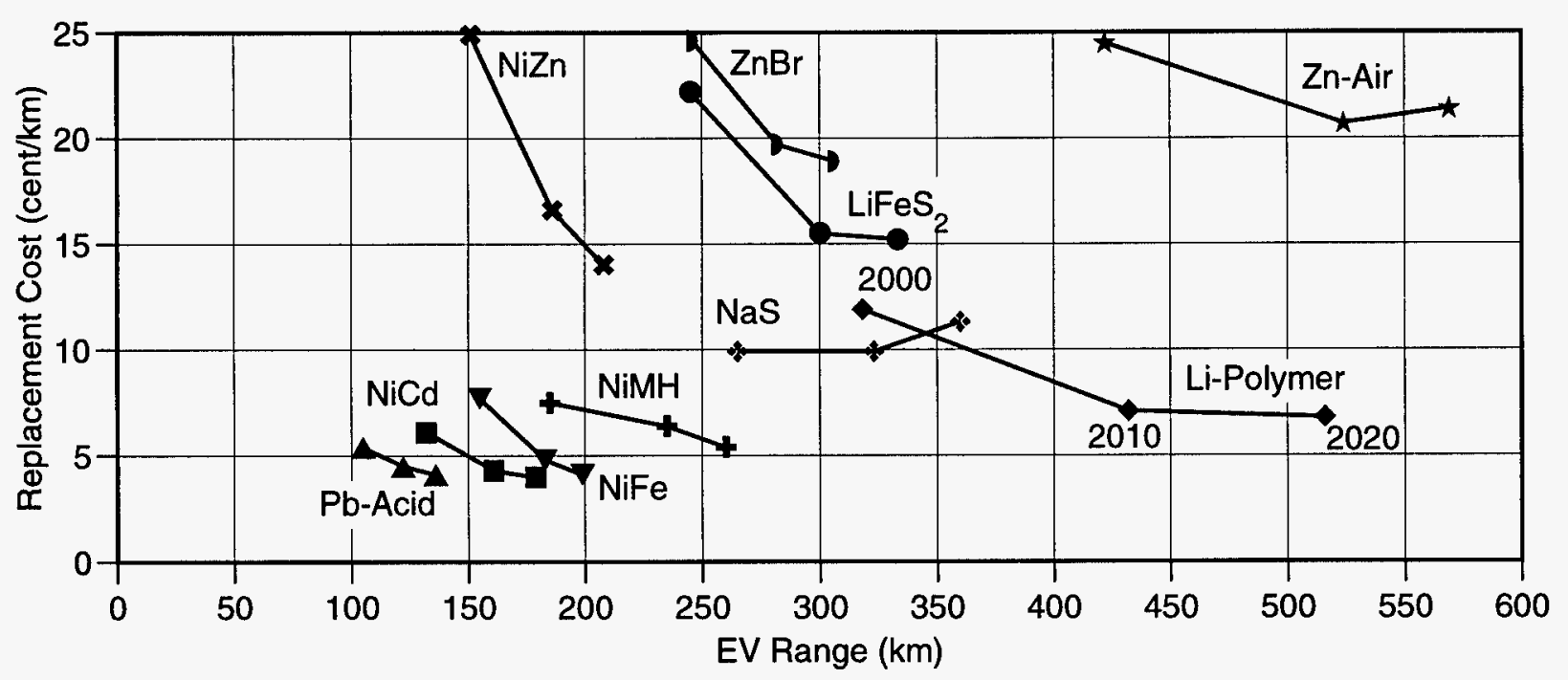

FIGURE 3.2 EV Battery Replacement Cost and Range Associated with the Mean Power Requirements

hydride battery packs will weigh more (see Table 3.4 ) because of increases in the mean power requirements.

Mean power requirements of $66.7,86.1$, and $99.2 \mathrm{~kW}$ and mean curb weights of 1,538 , 1,351 , and $1,222 \mathrm{~kg}$ for the three future years were obtained from the basic vehicle characteristics responses. These numbers translate to $0.043,0.064$, and $0.081 \mathrm{~kW} / \mathrm{kg}$, compared with the current desirable power-to-mass ratio of $0.074 \mathrm{~kW} / \mathrm{kg}(0.045 \mathrm{hp} / \mathrm{lb})$ for the conventional ICE. Cars had average power-to-mass ratios of $0.053 \mathrm{~kW} / \mathrm{kg}(0.032 \mathrm{hp} / \mathrm{lb}$ ) in 1981 and 1982 (Heavenrich and Hellman 1996). Individual models with even lower power-to-mass ratios were acceptable during the past energy price shocks. For example, the 1982 four-door Chevrolet Chevette equipped with a diesel engine had a power-to-mass ratio of $0.037 \mathrm{~kW} / \mathrm{kg}$ (Automotive News 1982). Thus, although future EVs appear to be underpowered through 2010, their power-to-mass ratios are not unrealistic.

Among the battery technologies that have replacement costs under 10 cents $/ \mathrm{km}$, lead-acid is the least expensive, with very limited range, and lithium-polymer is the most expensive, but with high range (see Figure 3.2). For a better balance between power and range, a combination battery pack of lead-acid and lithium-polymer batteries is the best combination. Advances in battery monitoring technology are predicted to make such mixing and matching of batteries feasible in portable computing (McCormick 1996). We analyzed hypothetical combination battery packs, in which both lead-acid and lithium-polymer batteries would power an EV in the year 2020. The cost objective worked consistently, but power was low. We lowered the power requirement to $85 \mathrm{~kW}$, assuming that the better speed-torque relationship of an electric motor would not require as high a power-to-mass ratio as an ICE. The results of the analysis are shown in Figure 3.3. Two curves, 


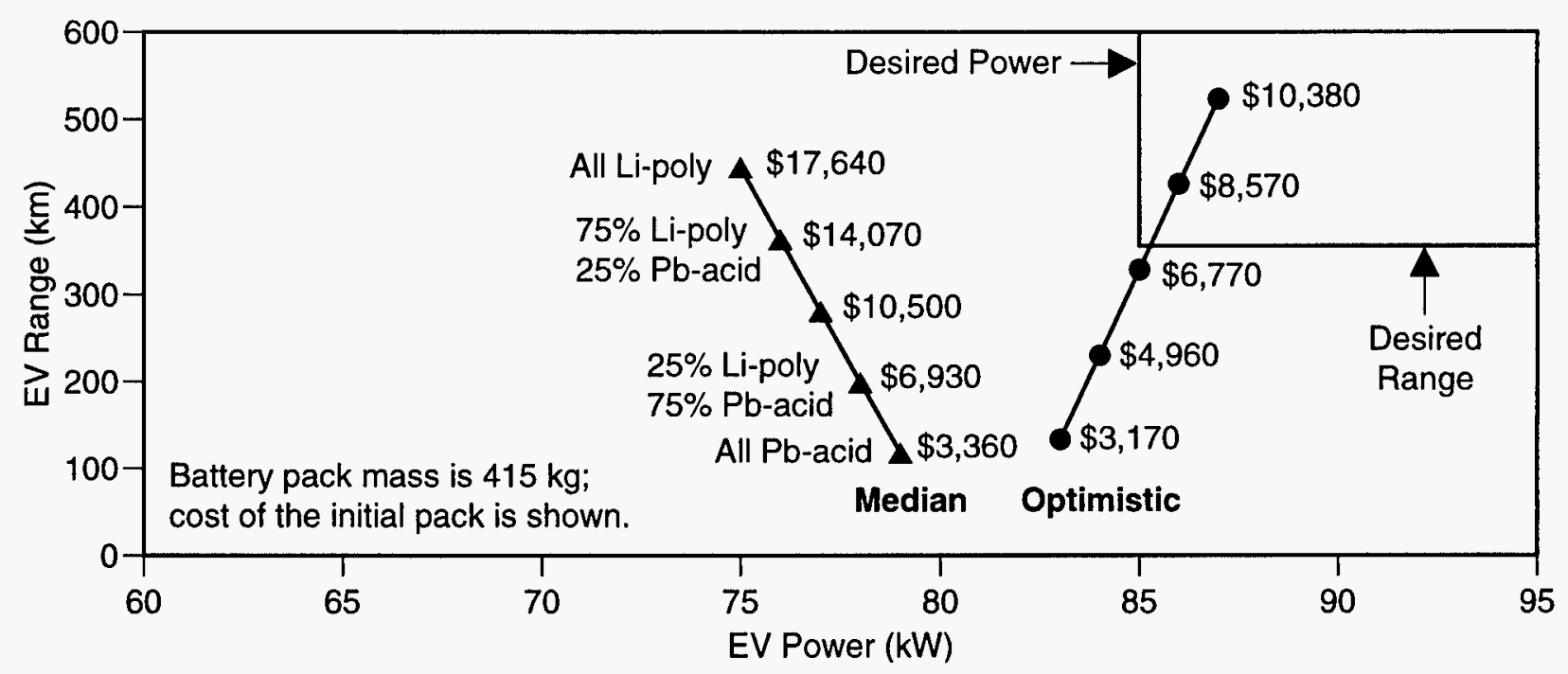

FIGURE 3.3 Analysis of Combined Lead-Acid and Lithium-Polymer Battery Packs for EVs in 2020

median and optimistic, are shown. The median curve shows results with the median values of Delphi responses, while the optimistic curve shows results with optimistic values for specific power, specific energy, and cost. The median responses show power increasing and range declining with increased share of the battery pack by lead-acid batteries. The optimistic group for the lithiumpolymer battery expected higher specific power for it than did the optimists for the lead-acid battery. This led to reductions in both power and range when the lead-acid battery share increased. In both cases, the cost of the battery pack was reduced when the lead-acid battery share increased.

\section{Initial Battery Pack Characteristics for the HEV}

As discussed earlier, most respondents appear to assume that all hybrids are of the "range extender" type. A "range extender" HEV should provide the specified peak vehicle power while running on batteries. The battery packs will have $79.6 \mathrm{~kW}$ of power in $2000,99.1 \mathrm{~kW}$ in 2010 , and $108.6 \mathrm{~kW}$ in 2020 . The resulting power-to-mass ratios (computed by using data from Table 2.3 in Chapter 2) are $0.051-0.086 \mathrm{~kW} / \mathrm{kg}$. Table 3.5 summarizes the estimated characteristics of the initial HEV battery packs for the 10 battery technologies. The estimates in the table are based on mean values of survey responses for such battery attributes as specific power, specific energy, and initial costs. For computing the range, we modified the baseline estimates by Marr (Marr 1994). We assumed that an HEV would consume the same amount of energy per kilometer as an EV and that its baseline battery pack mass would be similar to the baseline EV battery pack mass. Here, too, we used a $3.3 \%$ rate of change in energy consumption per $10 \%$ change in the battery pack mass. 
An important caveat about and shortcoming of the Delphi questionnaire is that in seeking experts' opinions on the future characteristics of batteries for use in both EVs and HEVs, it requested only one set of responses to battery questions. Thus, even though it is possible to design batteries for specific end uses (such as higher specific energy for EVs and higher specific power for HEVs), all respondents had to provide only one set of values for both EVs and HEVs. We therefore found it necessary to use the same battery characteristics for both vehicle types.

Figure 3.4 shows the computed battery replacement costs for the 10 technologies. The leadacid technology has the lowest replacement costs for 2000. The nickel-cadmium battery is ranked next, with estimated replacement cost at a fraction of a cent higher. The nickel-metal hydride technology provides a longer battery range, but it costs more (at least one and a half cents more per kilometer than nickel-cadmium in 2020). As observed previously, the lithium-polymer technology is projected to improve dramatically between 2000 and 2020 .

All battery technologies except lead-acid can provide a range of $140 \mathrm{~km}$ or longer for 2000; the nickel-cadmium battery has the lowest replacement cost, $6.3 \mathrm{cents} / \mathrm{km}$, for this period. The nickel-metal hydride battery would be the battery of choice from 2010 onward, to meet the desired range of $210 \mathrm{~km}$ and higher; its estimated replacement cost is 7.3 cents $/ \mathrm{km}$ in 2010 and 5.9 cents $/ \mathrm{km}$ in 2020. If replacement cost were the controlling factor, the lead-acid battery would be preferred through 2020, with a replacement cost ranging from 5.8 cents $/ \mathrm{km}$ in 2000 to 4.1 cents $/ \mathrm{km}$ in 2020 . The lead-acid battery is projected to have a range of $118-144 \mathrm{~km}$ through 2020 . A majority of urban vehicles travel 45-48 km/day (Wang 1994; NPTS 1991); the lead-acid battery would be able to supply the necessary energy for that distance.

The U.S. government and the automotive industry have developed a partnership, the Partnership for a New Generation of Vehicles, to develop high-fuel-economy vehicles. The need for such a vehicle arises from concerns about global warming and the fear of excessive reliance of the U.S. economy on imported oil. One of the technological options under consideration by the PNGV is the development of a low all-electric range and low battery-power (or battery and/or ultracapacitor power) hybrid electric vehicle. Such a vehicle will not be designed for, or expected to use, electricity from the electric grid. Any all-electric operation would be limited to low-speed (and lowacceleration) local driving and cruising. Separately, we analyzed battery replacement costs for a lowbattery-power hybrid, assuming its batteries to have power equal to half the mean power specified by the Delphi respondents. We applied the same methodology as before, and the resulting battery replacement costs are shown in Figure 3.5. The pattern of battery replacement costs is similar to that of "range extender" HEVs described above. Since the battery power range is not a constraining factor for these HEVs, lead-acid emerges as the least-cost battery technology, with nickel-cadmium as the next near-term alternative. The lithium-polymer battery was estimated by this method to be a lowcost alternative in the long term. 


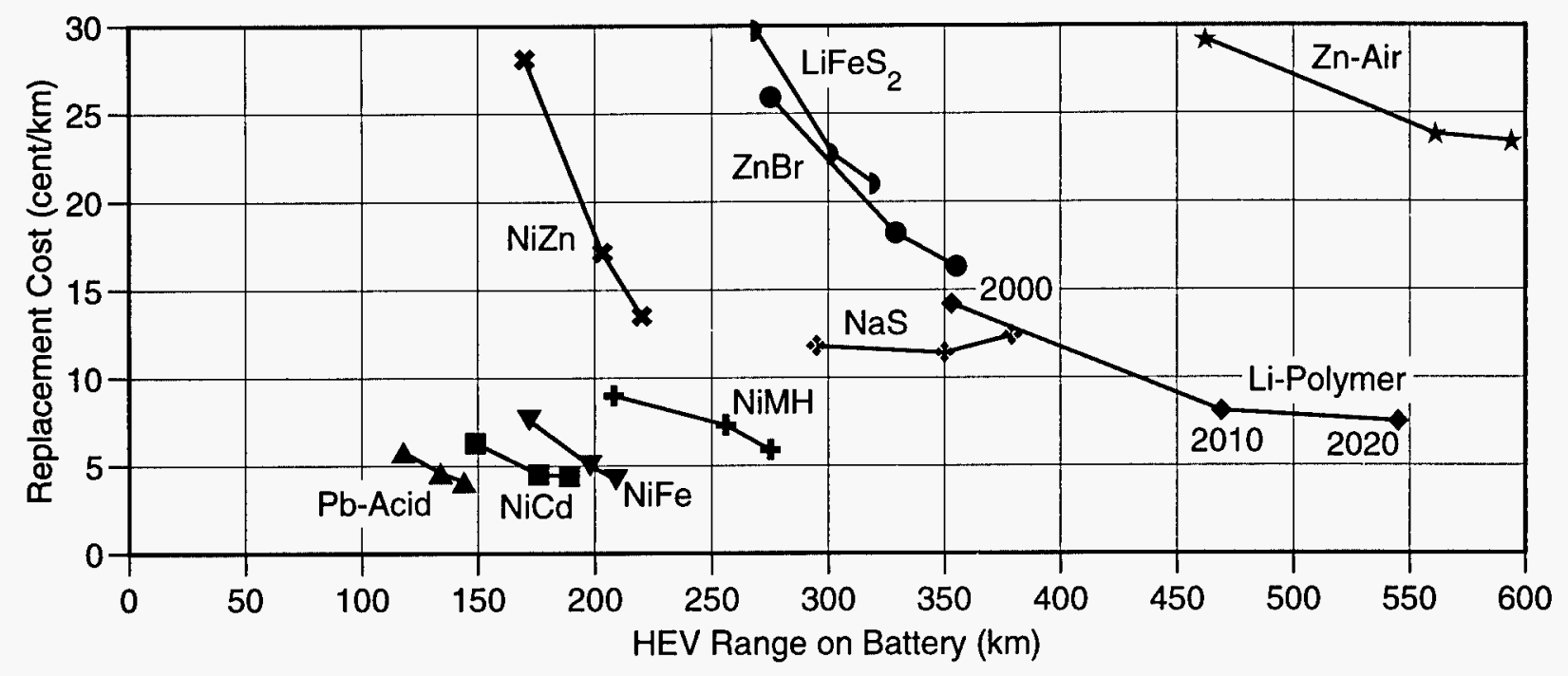

FIGURE 3.4 HEV Battery Replacement Cost and Range Associated with the Mean Power Requirements

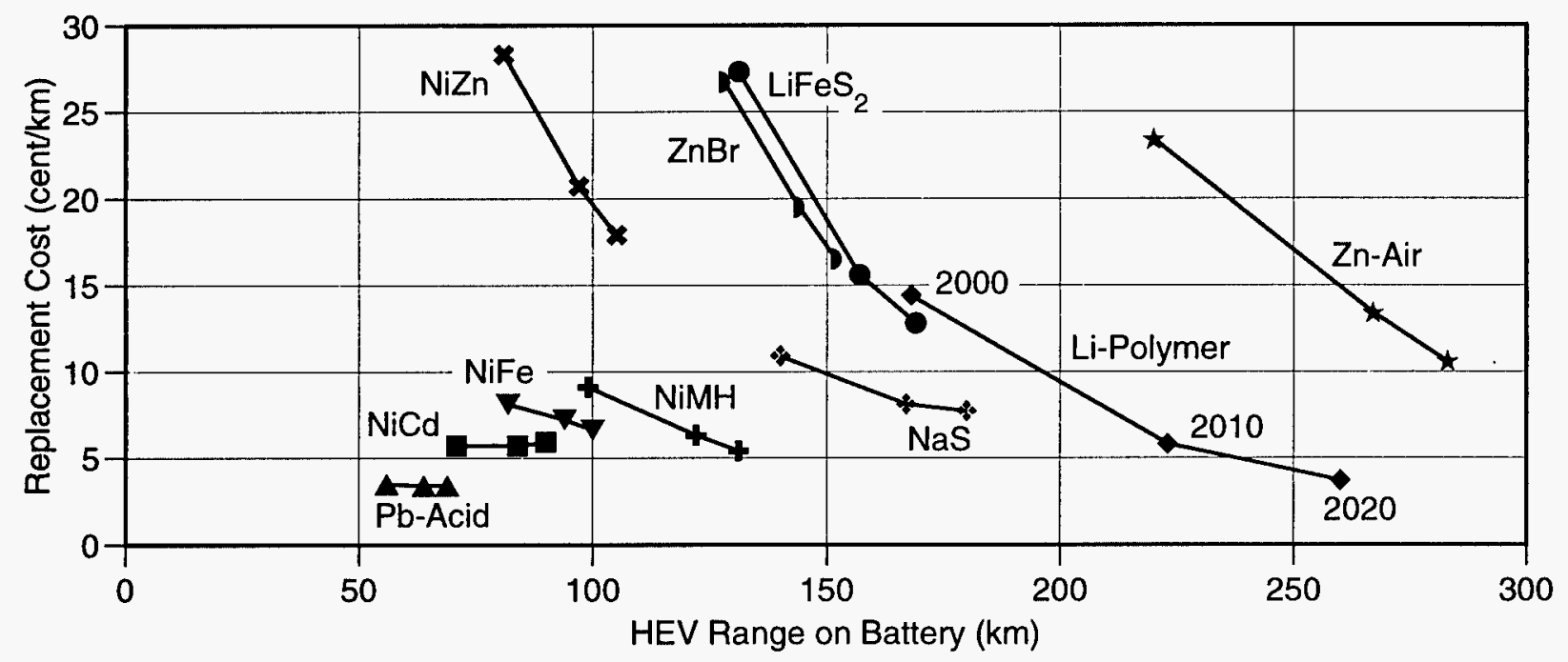

FIGURE 3.5 HEV Battery Replacement Cost and Range Associated with Half the Mean Power 
It appears possible, in retrospect, that the survey questionnaire's structure guided respondents to think in terms of "range extender" HEVs rather than PNGV-type HEVs. The absence of separate battery questions for EVs and HEVs, and the nature of the cycle life question, would have promoted this type of response. The cycle life question asked for cycle life to 50\% state of charge (SOC). A question valid for a PNGV-type HEV might have asked for cycle life if the battery were operated from 80 to $60 \%$ SOC. Since such a question was not asked, it is not appropriate to estimate the pattern of battery replacement costs for a PNGV-type HEV with this Delphi study's results. (Note that relatively few battery responses were obtained, so any increased complexity of the questionnaire might have been unproductive in any case.)

\subsection{VARIABLE OPERATING COSTS, INCLUDING BATTERY REPLACEMENT}

Earlier, we analyzed fuel and maintenance cost responses with respect to electric-drivevehicle characteristics. The mean fuel maintenance costs for EVs and HEVs did not include battery replacement costs. Among the three HEV technologies, the fuel-cell-powered HEV is not expected to have a large battery pack. We added the above-discussed battery replacement costs to the EV and the other two HEV technologies and compared the results with those for conventional ICE vehicles.

First, we computed total variable operating cost for an EV or HEV when the battery technology of choice meets the mean range requirements. Figure 3.6 shows the results of this comparison. In 2000 , the EV is powered by a nickel-metal hydride battery pack and the two HEVs are powered by nickel-cadmium battery packs. Lithium-polymer is the battery of choice for EVs from 2010 onward, while nickel-metal hydride is the battery of choice for HEVs from 2010 onward. The conventional ICE has the decided advantage of low variable operating cost. The EV has a slightly higher operating cost than the ICE-powered HEV for 2000 and lower operating costs thereafter. The gas-turbine-powered HEV has the highest operating cost through the analysis period. The respondents projected lower variable operating cost for the fuel-cell-powered HEVs compared to the EV and other two HEVs.

We also computed total variable operating costs with reduced all-electric range expectations. We selected the nickel-cadmium battery for the EV and the lead-acid battery for HEVs, for all years. Although lead-acid is the least expensive battery for the EV in 2000, we did not select it because of its limited range. The results are shown graphically in Figure 3.7. Total variable costs dropped, making the EV more attractive than the two HEVs. However, the conventional vehicle still has an estimated cost advantage. Only if consumers viewed emission reduction and energy independence advantages as more important than these cost differences could the new-technology vehicles gain significant market shares. 


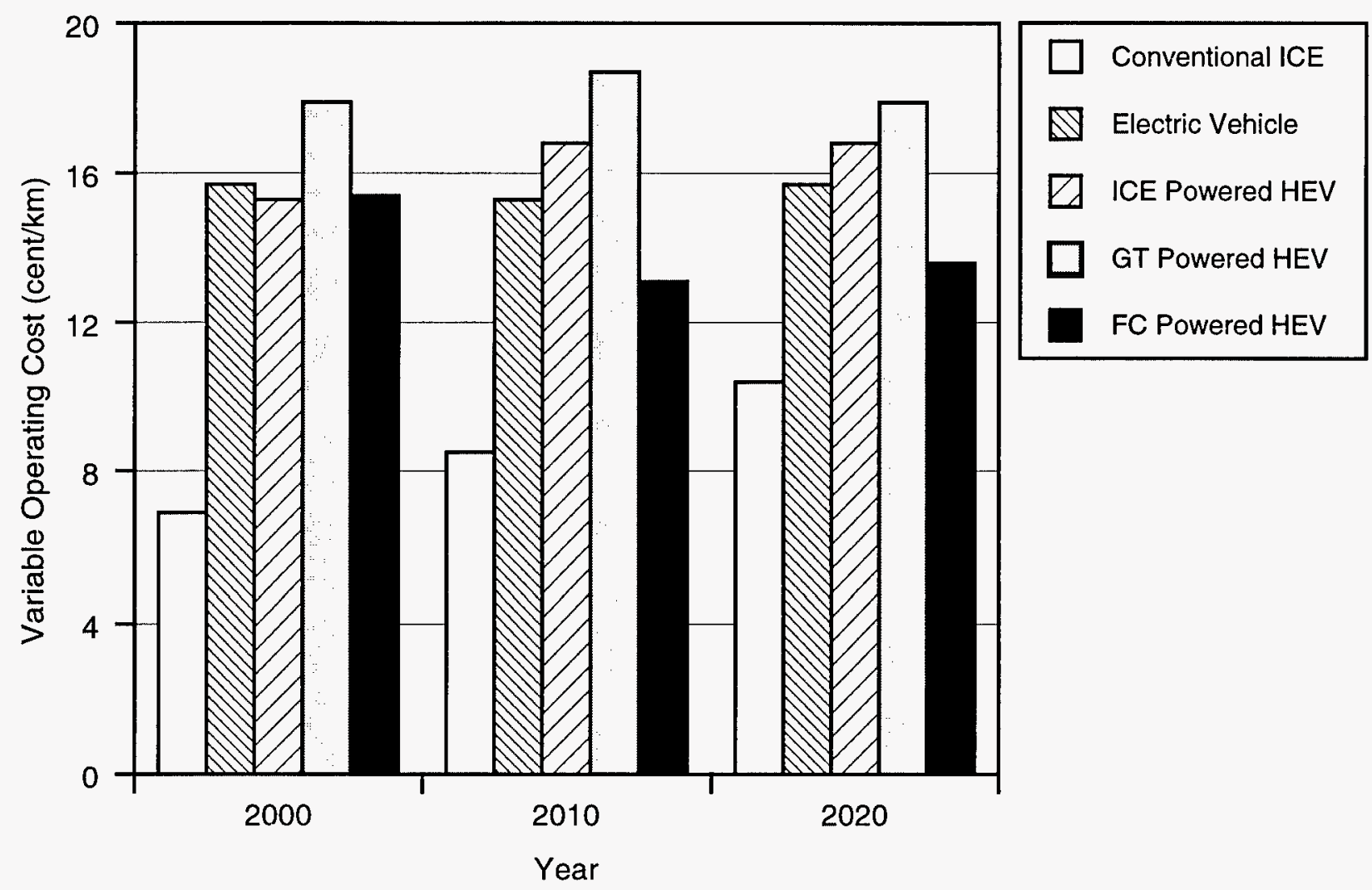

FIGURE 3.6 Variable Operating Costs, Including Battery Replacement Costs and Matching the Mean Range Requirements

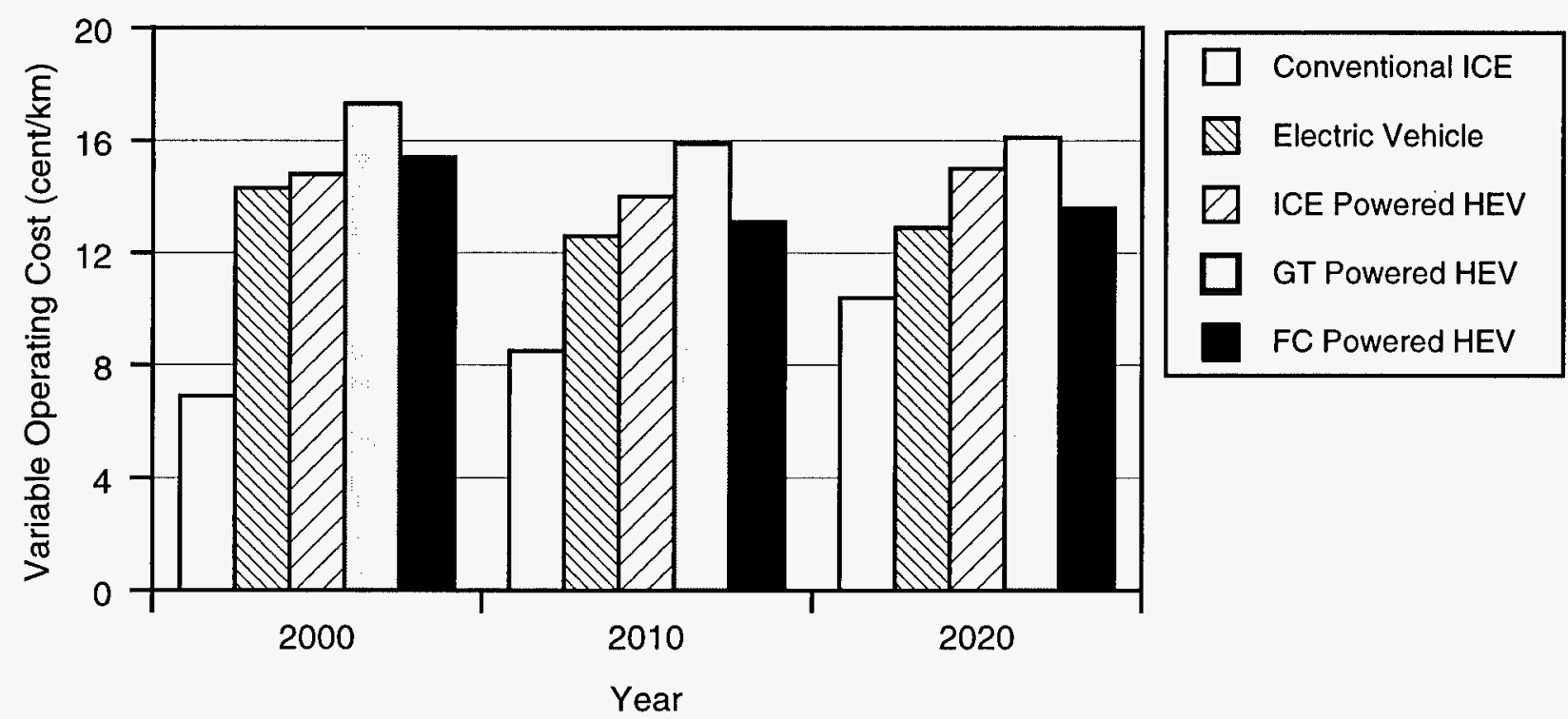

FIGURE 3.7 Variable Operating Costs with Less Expensive Battery, Ignoring the Mean Range Requirements 


\subsection{COMPARISON WITH CARB PANEL BATTERY DATA}

Persistently poor air quality in its major urban areas prompted the State of California to pass regulations requiring vehicle manufacturers to offer zero emission vehicles (ZEVs) by 1998. Because they have no tailpipe emissions, EVs are classified as ZEVs. Currently, a few after-market conversion companies produce EVs for those who order them. These converted EVs - each one produced by purchasing a conventional vehicle, removing the internal combustion engine, transmission, and fuel system, and then installing a battery pack and electric drive system - are expensive. Following the adoption of the ZEV mandate by California, most of the automobile and light truck manufacturers initiated programs to eventually produce and market EVs. However, the manufacturers view the high costs and poor performance characteristics of the current battery technologies as major barriers to widespread acceptance of EVs. Since the passing of California's ZEV regulations, General Motors and Honda have attempted limited introduction of EVs in California.

\section{CARB Battery Panel Study}

A 1995 study by a panel of experts, commissioned by the California Air Resources Board (CARB), provides a snapshot assessment of the expected performance of batteries for electric vehicles (Kalhammer et al. 1995). The study methodology involved assembling and analyzing the battery performance information through questionnaires and visits to organizations engaged in EV battery development and/or manufacture. The study concluded that improved lead-acid and nickelcadmium batteries will be available by 1998 , the original year during which the ZEV requirements were to become effective. Other battery technologies were at various stages of research and development at the time of the study. The report presents a summary of the possible performance improvements for these technologies with continued research and development. It also presents data on expected cost reductions as production increases. Aside from lead-acid and nickel-cadmium batteries, the study covered nickel-metal hydride, lithium-ion, lithium-polymer, sodium-sulfur, and sodium-nickel chloride batteries. The panel considered the technical status of the zinc-air battery technology as rather uncertain and therefore investigated it less thoroughly.

The primary focus of the CARB panel study was an assessment of battery performance characteristics and cost for the 1998-2003 time frame, a period in which the original ZEV sales requirements were to ramp up from $2 \%$ share of the new light duty vehicles (autos and light trucks up to $3,750 \mathrm{lb}$ ) to $10 \%$. The ZEV regulations have since been amended to strike the sales requirements during the period 1998-2002, keeping the 10\% ZEV sales requirements in 2003 and subsequent model years intact. CARB has also entered into a separate memorandum of agreement (MOA) with each of the seven large light duty vehicle manufacturers. The MOAs make ZEV introduction during the 1998-2002 period voluntary, but they require continued investment in ZEV development, demonstration, and commercialization. 


\section{Modification of Panel Projections}

We reviewed the CARB battery panel report and compiled battery performance and cost data for lead-acid, nickel-cadmium, nickel-metal hydride, lithium-ion, lithium-polymer, sodiumsulfur, sodium-nickel chloride, and zinc-air batteries. Because the ZEV mandates have been relaxed, the points in time at which higher performance characteristics and cost reductions would be achieved were changed. For mature battery technologies, such as lead-acid and nickel-cadmium, five years were added to the panel's projections. For other batteries, the projected best performance and cost characteristics were assumed to be achieved between 2010 and 2020. Table 3.6 lists the modified battery characteristics.

Data in Table 3.6 are based on the information in Section III and Appendix D of the CARB panel report. The panel data are generally comparable to the optimistic (i.e. first quartile for cost and third quartile for all other) values in the Delphi survey (see Table 2.7). One exception is that the panel projected lower specific power for the nickel-cadmium battery, compared even to the mean values in the Delphi survey.

The CARB panel report does not provide information about the shelf (or calendar) life. These values were estimated by using the upper-quartile values of the Delphi data. Exceptions were made for sodium-sulfur and zinc-air batteries. The third-quartile shelf lives for them are lower in Table 2.7 than the values shown above. CARB panel data for these two battery types were much more optimistic for all other characteristics (specific energy, specific power, cycle life, and cost), compared to the optimistic values in the Delphi data. Their shelf lives were increased similarly. Two battery technologies, lithium-ion and sodium-nickel chloride, were not included in the Delphi survey. We assigned lithium-polymer's shelf life to lithium-ion and sodium-sulfur's shelf life to sodium-nickel chloride. Because our methodology for computing battery replacement cost selects the higher of the two costs, based on shelf and cycle lives, we took care to assign higher shelf lives. Assignment of lower shelf lives could result in higher battery replacement costs.

\section{Initial Battery Pack Characteristics for the EV with Respect to CARB Data}

The characteristics of the initial EV battery packs for each of the eight battery technologies were developed for the three forecast years. The battery packs were characterized to meet the respective mean power requirements in the Delphi study. The characteristics are summarized in Table 3.7.

The initial battery pack characteristics in the year 2000 are comparable to the year 2000 characteristics based on the Delphi data (see Table 3.4). The panel data show considerable improvements in specific energy, specific power, cycle life, and cost by 2010 . Consequently, the 
TABLE 3.6 Modified CARB Panel Battery Characteristics

\begin{tabular}{|c|c|c|c|c|c|c|}
\hline Battery & Year & $\begin{array}{c}\text { Specific } \\
\text { Energy } \\
(\mathrm{Wh} / \mathrm{kg})\end{array}$ & $\begin{array}{c}\text { Specific } \\
\text { Power } \\
(\mathrm{W} / \mathrm{kg})\end{array}$ & $\begin{array}{l}\text { Shelf Life } \\
(\mathrm{yr})\end{array}$ & $\begin{array}{l}\text { Cycle Life } \\
\text { (cycles) }\end{array}$ & $\begin{array}{c}\text { Cost } \\
(\$ / \mathrm{kWh})\end{array}$ \\
\hline \multirow[t]{3}{*}{ Lead-acid } & 2000 & 44 & 160 & 4.0 & 600 & 150 \\
\hline & 2010 & 50 & 300 & 5.0 & 900 & 120 \\
\hline & 2020 & 50 & 300 & 6.0 & 1,000 & 120 \\
\hline \multirow[t]{3}{*}{ Lithium-ion $^{\mathrm{a}}$} & 2000 & 90 & 200 & 5.0 & 800 & 1,000 \\
\hline & 2010 & 140 & 260 & 7.5 & 1,200 & 300 \\
\hline & 2020 & 150 & 300 & 10.0 & 1,200 & 180 \\
\hline \multirow[t]{3}{*}{ Lithium-polymer } & 2000 & 120 & 160 & 5.0 & 600 & 750 \\
\hline & 2010 & 185 & 210 & 7.5 & 900 & 300 \\
\hline & 2020 & 225 & 240 & 10.0 & 1,200 & 175 \\
\hline \multirow[t]{3}{*}{ Nickel-cadmium } & 2000 & 60 & 160 & 6.0 & 1,200 & 500 \\
\hline & 2010 & 60 & 180 & 7.0 & 2,000 & 350 \\
\hline & 2020 & 62 & 180 & 9.0 & 2,000 & 300 \\
\hline \multirow[t]{3}{*}{ Nickel-metal hydride } & 2000 & 80 & 220 & 5.0 & 800 & 550 \\
\hline & 2010 & 120 & 300 & 6.5 & 1,500 & 350 \\
\hline & 2020 & 130 & 300 & 8.0 & 2,000 & 250 \\
\hline \multirow[t]{3}{*}{ Sodium-nickel chloride ${ }^{\mathrm{a}}$} & 2000 & 80 & 130 & 4.5 & 1,000 & 800 \\
\hline & 2010 & 100 & 150 & 6.0 & 1,400 & 230 \\
\hline & 2020 & 100 & 150 & 7.0 & 1,500 & 175 \\
\hline \multirow[t]{3}{*}{ Sodium-sulfur } & 2000 & 110 & 200 & 4.5 & 700 & 1,000 \\
\hline & 2010 & 140 & 300 & 6.0 & 1,500 & 250 \\
\hline & 2020 & 230 & 400 & 7.0 & 1,500 & 150 \\
\hline \multirow[t]{3}{*}{ Zinc-air } & 2000 & 120 & 100 & 4.0 & 450 & 350 \\
\hline & 2010 & 230 & 150 & 5.5 & 600 & 200 \\
\hline & 2020 & 325 & 200 & 7.0 & 800 & 125 \\
\hline
\end{tabular}

a These technologies were not included in the Delphi study. 
TABLE 3.7 Characteristics of the Initial EV Battery Pack, Using the Modified CARB Panel Data ${ }^{a, b}$

\begin{tabular}{|c|c|c|c|c|c|c|}
\hline Battery Technology & Year & $\begin{array}{c}\text { Mass } \\
(\mathrm{kg})\end{array}$ & $\begin{array}{c}\text { Energy } \\
\text { (Wh) }\end{array}$ & $\begin{array}{c}\text { Initial } \\
\text { Cost }(\$)\end{array}$ & $\begin{array}{c}\text { Range } \\
(\mathrm{km})\end{array}$ & $\begin{array}{l}\text { Life } \\
(\mathrm{km})\end{array}$ \\
\hline \multirow[t]{3}{*}{ Lead-acid } & 2000 & 420 & 18,340 & 2,750 & 110 & 34,300 \\
\hline & 2010 & 290 & 14,350 & 1,720 & 100 & 45,400 \\
\hline & 2020 & 330 & 16,530 & 1,980 & 110 & 56,200 \\
\hline \multirow[t]{3}{*}{ Lithium-ion $^{\mathrm{c}}$} & 2000 & 330 & 30,020 & 30,020 & 200 & 80,400 \\
\hline & 2010 & 330 & 46,360 & 13,910 & 310 & 132,700 \\
\hline & 2020 & 330 & 49,600 & 8,930 & 340 & 177,000 \\
\hline \multirow[t]{3}{*}{ Lithium-polymer } & 2000 & 420 & 50,030 & 37,520 & 310 & 88,500 \\
\hline & 2010 & 410 & 75,850 & 22,760 & 480 & 132,700 \\
\hline & 2020 & 410 & 93,000 & 16,280 & 590 & 177,000 \\
\hline \multirow[t]{3}{*}{ Nickel-cadmium } & 2000 & 420 & 25,010 & 12,510 & 160 & 93,600 \\
\hline & 2010 & 480 & 28,700 & 10,050 & 170 & 123,900 \\
\hline & 2020 & 550 & 34,170 & 10,250 & 190 & 159,300 \\
\hline \multirow[t]{3}{*}{ Nickel-metal hydride } & 2000 & 300 & 24,250 & 13,340 & 170 & 66,700 \\
\hline & 2010 & 290 & 34,440 & 12,050 & 240 & 115,000 \\
\hline & 2020 & 330 & 42,990 & 10,750 & 290 & 141,600 \\
\hline \multirow[t]{3}{*}{ Sodium-nickel chloride ${ }^{c}$} & 2000 & 510 & 41,050 & 32,840 & 240 & 79,600 \\
\hline & 2010 & 570 & 57,400 & 13,200 & 320 & 106,200 \\
\hline & 2020 & 660 & 66,130 & 11,570 & 350 & 123,900 \\
\hline \multirow[t]{3}{*}{ Sodium-sulfur } & 2000 & 330 & 36,690 & 36,690 & 250 & 79,600 \\
\hline & 2010 & 290 & 40,180 & 10,050 & 280 & 106,200 \\
\hline & 2020 & 250 & 57,040 & 8,560 & 420 & 123,900 \\
\hline \multirow[t]{3}{*}{ Zinc-air } & 2000 & 670 & 80,040 & 28,010 & 410 & 70,800 \\
\hline & 2010 & 570 & 132,020 & 26,400 & 740 & 97,300 \\
\hline & 2020 & 500 & 161,200 & 20,150 & 960 & 123,900 \\
\hline
\end{tabular}

a For the mean power requirements of $66.7 \mathrm{~kW}$ in $2000,86.1 \mathrm{~kW}$ in 2010 , and $99.2 \mathrm{~kW}$ in 2020.

b Values are rounded to the nearest ten or hundred.

c These technologies were not included in the Delphi study. 
initial battery packs in Table 3.7 have lower mass, equal or higher energy capacity, lower cost, equal or longer range, and equal or longer lifetime distance compared to the initial battery packs characterized with the Delphi data.

The panel data appear optimistic for the battery technologies that are under research and development. The data reflect the enthusiasm of the organizations conducting research. The panel data showed very optimistic values for the sodium-sulfur technology, one and a half times to twice the values of the optimistic quartile in the Delphi survey. The research and development on this technology was conducted by Silent Power GmbH (Germany) and Silent Power Limited (UK), subsidiaries of RWE Energy AG. The parent company has since discontinued the research and development efforts, citing the high financial risk associated with the successful development of the sodium-sulfur technology for EV use (Kalhammer et al. 1995).

The characteristics of the two technologies considered ready by the panel, lead-acid and nickel-cadmium, also differ between the panel and Delphi data. The panel data for the lead-acid battery are similar to the optimistic quartile in the Delphi survey, except for specific power and cost. The Delphi data show a very narrow band between the mean and the optimistic quartile for the leadacid battery. The optimistic value for specific power in the Delphi survey is $200 \mathrm{~W} / \mathrm{kg}$ for each of the three projection years (see Table 2.7). The panel data show $300 \mathrm{~W} / \mathrm{kg}$ as an achievable value, which we assigned to the years 2010 and 2020. The optimistic Delphi value for cost is $\$ 150 / \mathrm{kWh}$ for each of the three projection years. The panel report provides a range of $\$ 120-150 / \mathrm{kWh}$. We assigned $\$ 150 / \mathrm{kWh}$ to the year 2000 and $\$ 120 / \mathrm{kWh}$ to both 2010 and 2020 . The resulting initial lead-acid battery packs are lighter and less expensive. Since the battery pack size is determined by its power, the range and the lifetime distance are slightly lower for 2010 and 2020. The nickelcadmium battery packs also show a few dissimilarities. As mentioned earlier, specific power values in the panel report are lower than the mean specific power in the Delphi survey. The panel report's values for specific energy are comparable to the mean Delphi survey values. The panel report projects the battery cost range at $\$ 300-350 / \mathrm{kWh}$, lower than Delphi optimistic values. The resulting battery packs are heavier, but less expensive. Even though the nickel-cadmium battery packs are heavier, they have comparable range and lifetime distances.

The costs and ranges of the initial EV battery pack in 2020 are plotted in Figure 3.8. Each battery technology is shown by a symbol. Two lines denoting the year 2020 mean range and onethird of the year 2020 vehicle price from the Delphi survey are shown as "desired range" and "desired cost." This figure is patterned after Figure 3.1. The range of the initial battery pack cost is narrower in Figure 3.8, $\$ 2,000-20,000$, compared with $\$ 4,000-40,000$ in Figure 3.1. The panel report cited the cost estimates provided by the battery developers. The developers are optimistic that the material and production costs will drop substantially with increased production, over 100,000 battery packs a year. 


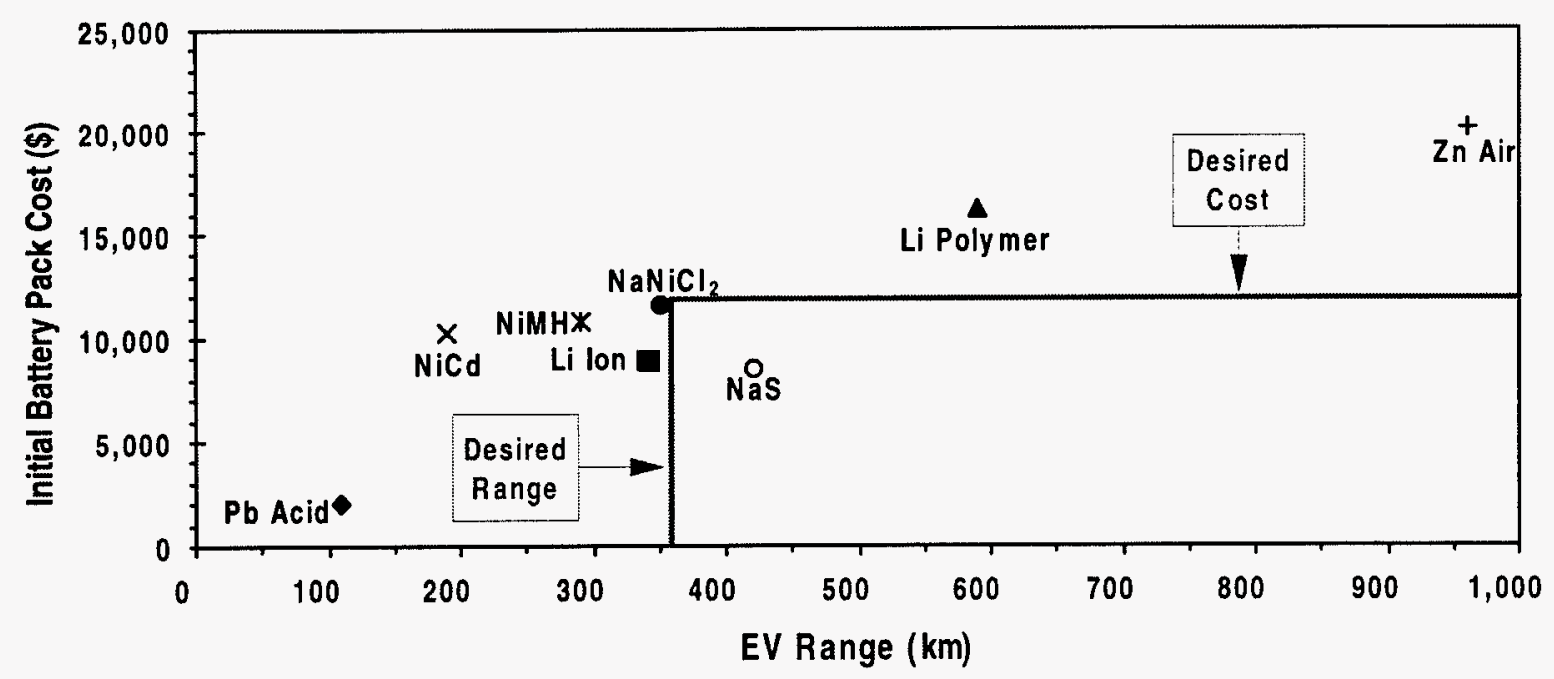

FIGURE 3.8 EV Initial Battery Pack Cost and Range in 2020, from the Modified CARB Panel Data

Only one battery technology, sodium-sulfur, falls within the price and range region that would be considered the desired region on the basis of Delphi responses. However, research and development efforts on the sodium-sulfur battery technology have been discontinued because of high financial risks. Sodium-nickel chloride and lithium-ion battery technologies have slightly shorter range, but their battery pack costs are less than one-third the vehicle price. Of these two battery technologies, sodium-nickel chloride operates at $270-350^{\circ} \mathrm{C}$; it is being developed by AEG Anglo Batteries in Europe. The developers have indicated that the cost reduction (as shown in the figure) can be achieved when production reaches 100,000 battery packs a year. The lithium-ion battery is projected to provide a slightly shorter range, $340 \mathrm{~km}$ compared to the Delphi mean of $358 \mathrm{~km}$, with a cost approaching $25 \%$ of the year $2020 \mathrm{EV}$ price. Research on the lithium-ion technology is being conducted in the United States, Europe, and Japan. Though used in several consumer products (mostly in nonrechargeable form), rechargeable lithium-ion batteries for EV use have several hurdles to clear. The reports of fire in smaller, four-cell lithium-ion batteries in lap-top computers have heightened concerns about the safety aspects of this technology (Kalhammer et al. 1995). A third battery technology, nickel-metal hydride, would provide a shorter $(290 \mathrm{~km})$ range at a cost slightly over $30 \%$ of the year $2020 \mathrm{EV}$ price. These cost estimates for nickel-metal hydride are based on the development of advanced electrode materials at low cost. The development efforts were at the laboratory stage at the time of the panel's investigation. The ability of the advanced materials to resist corrosion, to withstand hydrogen absorption and desorption with extended cycling, to be chemically and structurally stable under overcharge and over-discharge, to have charge acceptance capability and stability at high temperatures, and to withstand high rates of charge and discharge would have to be proven for this technology to achieve these cost and performance levels. Moreover, the advanced materials would have to have low cost and be amenable to low-cost production methods. 


\section{EV Battery Replacement Costs with Respect to CARB Panel Data}

The earlier-described procedure for computing battery replacement cost was used with the modified CARB panel data. The results are shown graphically in Figure 3.9. The replacement costs are projected to be lower on the basis of the panel data, compared to the Delphi values in Figure 3.2. The battery developers' optimism concerning performance characteristics and costs is reflected here. In general, the battery replacement cost declined between 2000 and 2020, and range increased. The only exception is the lead-acid battery, for which cost declined without any increase in range. The lead-acid technology is considered to be ready by 2000 and is not likely to show any dramatic improvements. The nickel-cadmium technology, the other technology considered to be ready by 2000 , shows limited improvements in range (25\%) and replacement cost (35\%) between 2000 and 2020. The lithium-ion technology shows the same range potential as the sodium-nickel chloride technology, but it has nearly half the replacement cost by 2010 . By 2020 , lithium-ion's replacement cost is $15 \%$ lower than the replacement cost for lead-acid, and it has three times the range. The sodium-sulfur technology shows substantial improvements in replacement cost and range, but research and development on it has been discontinued (Kalhammer et al. 1995). As was the case with the Delphi data, the lithium-polymer technology shows a very high rate of improvement and provides very high range at a reasonable cost. Because the CARB panel considered this technology to be at the conceptual stage, we did not assign it the lowest possible cost in 2020.

All battery technologies in Figure 3.9, except zinc-air, have year 2020 replacement costs under 4 cents per kilometer. As explained earlier, the cost of the initial battery pack is not included in the replacement cost, but its lifetime distance is. The cost of the initial battery pack is included in the vehicle price. Even though these replacement costs are low, an EV's marketability would be significantly affected by the cost of the initial battery pack. Among the seven technologies that have the year 2020 replacement cost under 4 cents $/ \mathrm{km}$, lead-acid has the least expensive initial battery pack, with the shortest range, and lithium-polymer has the most expensive initial battery pack, with the longest range (see Figure 3.8). These two technologies showed similar extreme characteristics in the Delphi data, too. As was done with the Delphi data, three hypothetical combination battery packs were analyzed to verify if lower cost and higher range objectives can be satisfied with mixing and matching of these two batteries. The results are shown in Figure 3.10. The 25 to $75 \%$ shares in the figure are determined by the technology's contribution to the total battery mass, which is held constant at $415 \mathrm{~kg}$. As was done with the Delphi data (see Figure 3.3), two lines are drawn that show the desired range and power in 2020 . Any points falling within the upper-right-hand box would meet the requirements. Two mixed battery packs (and the all-lithium-polymer battery pack) meet both the power and range objectives. Compared to the optimistic group in the Delphi survey, the initial battery pack costs are higher. However, very high power of each battery pack indicates that a lighter (less than $415 \mathrm{~kg}$ in mass) and different combination battery pack would meet both the power $(85 \mathrm{~kW})$ and range $(358 \mathrm{~km})$ requirements. The range and power line for such a lighter battery pack would be parallel to the line shown in Figure 3.10 and would pass close to the point 


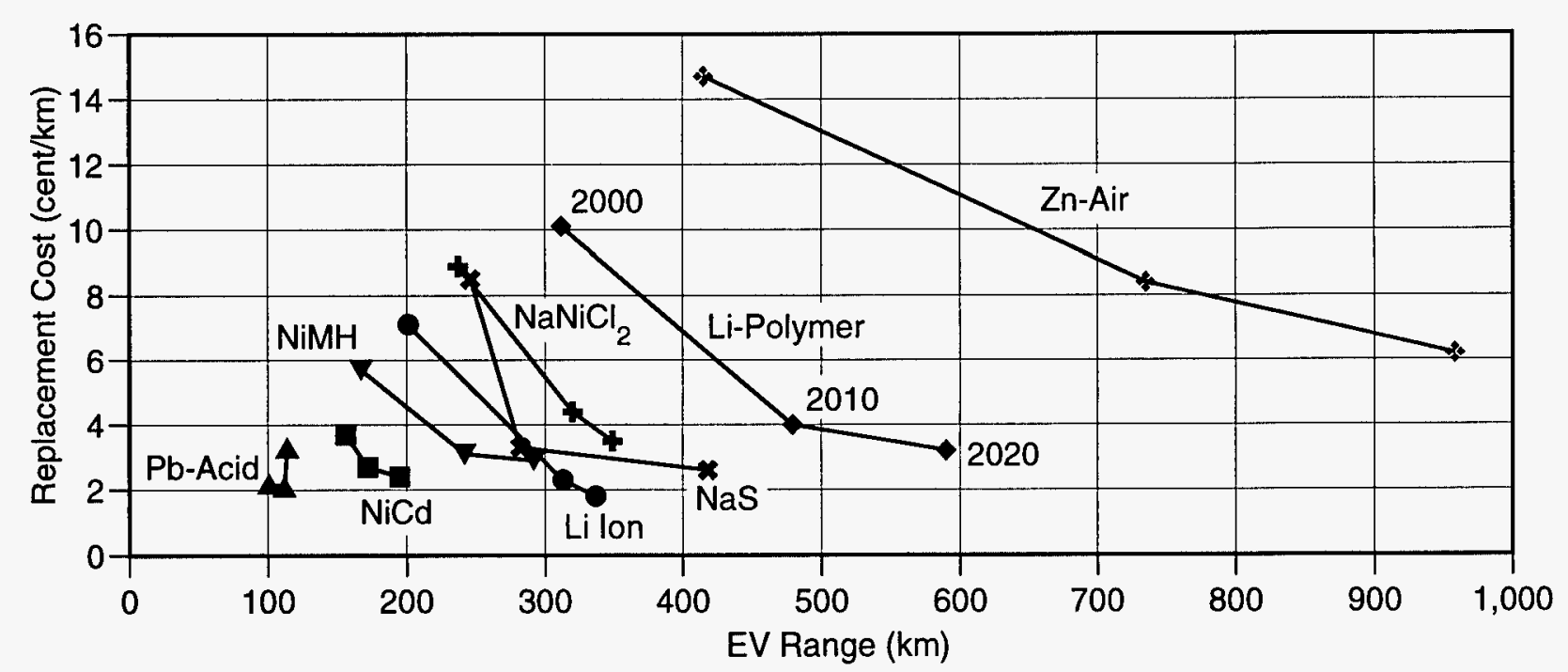

FIGURE 3.9 EV Battery Replacement Cost and Range, from the Modified CARB Panel Data

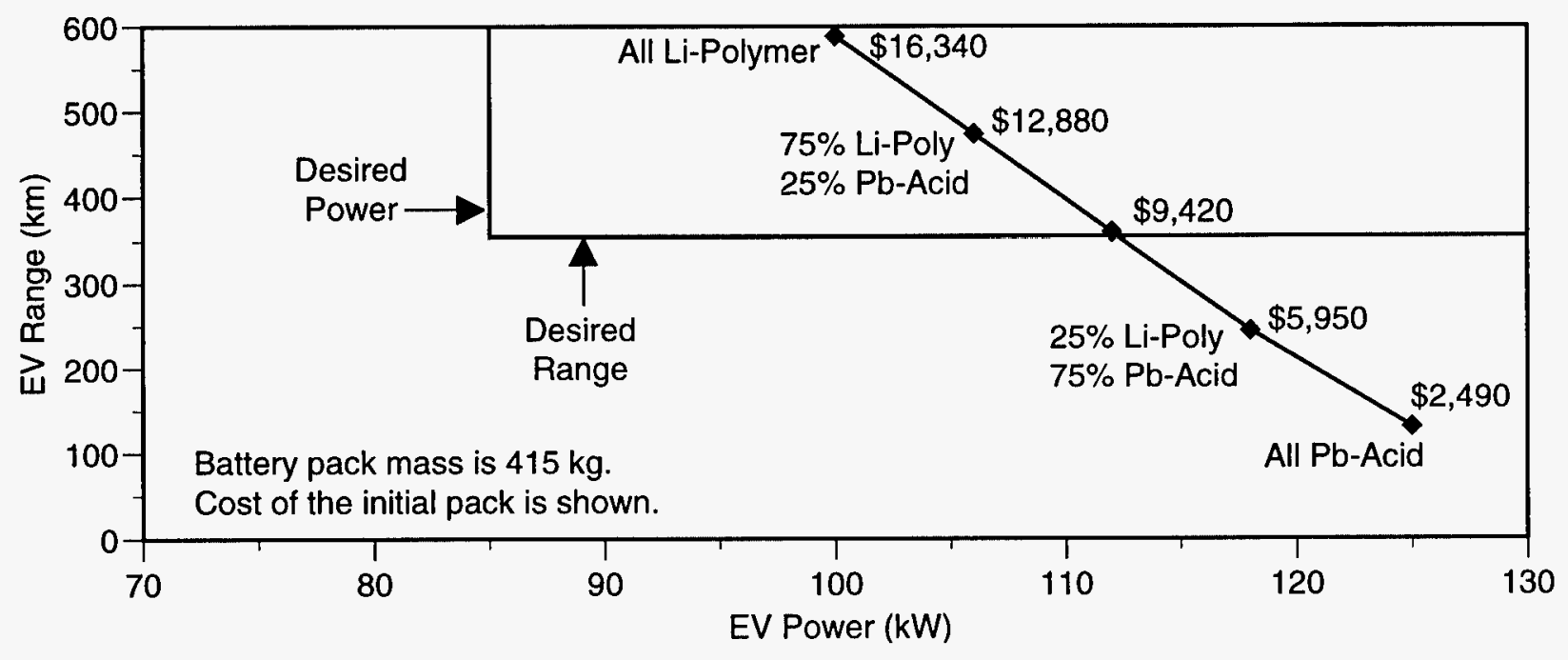

FIGURE 3.10 Analysis of Year 2020 Combined Lead-Acid and Lithium-Polymer Battery Packs for EVs, Based on the Modified CARB Panel Data 
designated by the $85 \mathrm{~kW}$ power and $358 \mathrm{~km}$ range. Our analysis indicates that such a mixed battery pack would have a $60 \%$ lithium-polymer content by weight, a total mass of $325 \mathrm{~kg}$, and a cost of $\$ 8,460$.

\section{Initial Battery Pack Characteristics for the HEV with Respect to CARB Data}

Initial battery packs for the $\mathrm{HEV}$ were characterized to match the mean power requirements of Delphi results. Their characteristics are summarized in Table 3.8. As was observed in the case of EV battery packs, the initial battery packs are lighter and less expensive compared to those characterized with the Delphi data. The only exception is the nickel-cadmium technology. Range and lifetime distance values of the battery packs in Table 3.8 are comparable to the Delphi values in 2000 , slightly higher in 2010 , and substantially higher in 2020 . The only exception is the leadacid technology.

The analysis of the initial HEV battery packs shows lead-acid as the least expensive technology, with a cost range of $\$ 1,980-3,280$ through the projection period. However, its allelectric range is limited at $110-130 \mathrm{~km}$. A majority of vehicles in the United States are driven $50 \mathrm{~km}$ or less a day (NPTS 1991), a demand that can easily be satisfied by the lead-acid battery packs. The lead-acid battery pack's mass of $500 \mathrm{~kg}$ in 2000 accounts for $32 \%$ of the mean HEV curb weight. The nickel-metal hydride battery pack is projected to have a mass of $360 \mathrm{~kg}$ (23\% of the HEV curb weight) and an all-electric range of $190 \mathrm{~km}$ in 2000 ; it would cost $\$ 14,930$, four and a half times the cost of $\$ 3,280$ for lead-acid. Nickel-cadmium, the only other technology that would be commercially available in 2000 , does not provide any mass or range advantages over nickel-metal hydride, and only a $\$ 1,000$ cost advantage. In 2010 , the lead-acid battery pack would cost $\$ 1,980$, weigh $330 \mathrm{~kg}$, and have a range of $110 \mathrm{~km}$; the nickel-metal hydride battery pack would cost $\$ 13,870$, weigh $330 \mathrm{~kg}$, and have a range of $270 \mathrm{~km}$; and the lithium-ion battery pack would cost $\$ 16,010$, weigh $380 \mathrm{~kg}$, and have a range of $350 \mathrm{~km}$. The HEV technology is still at the research and development stage and is most likely to enter the market between 2005 and 2010. If the projections by the panel materialize, these three battery technologies would be the leading candidates for HEV use. By 2020 , the initial battery packs for lead-acid, lithium-ion, and nickel-metal hydride technologies would have the same mass of $360 \mathrm{~kg}$. The lead-acid battery pack would be the least expensive of these three at $\$ 2,170$, lithium-ion the second least expensive at $\$ 9,770$, and nickelmetal hydride the most expensive at $\$ 11,770$. In the above discussion, we have not included the sodium-sulfur technology, even though its battery packs have competitive mass, cost, and range characteristics, in Table 3.8 because of the reasons stated earlier. 


\section{HEV Battery Replacement Costs with CARB Panel Data}

HEV battery replacement costs were computed by using the procedure described earlier. The results are shown in Figure 3.11. As was observed in the case of EVs, the replacement costs are lower with the panel data compared to those computed with the Delphi data. The rates of improvement in the replacement costs are nearly the same as those for the EV. The year 2000 replacement costs with the panel data are nearly $60-66 \%$ of the costs computed with the Delphi data. The replacement costs for two technologies that would be still at the development stage in 2000, sodium-sulfur and lithium-polymer, are very close to those computed with the Delphi data. Because of the projected high rates of improvements between 2000 and 2020, the year 2020 replacement costs with the panel data are nearly $45-60 \%$ of the costs computed with the Delphi data. The panel data indicate very high rates of improvements for sodium-sulfur and zinc-air technologies. Though the sodium-sulfur technology has very low replacement costs (associated with long all-electric range), we neglect it for previously stated reasons. The zinc-air technology shows substantial improvement between 2000 and 2020, but its replacement costs are still higher than those of other technologies.

\subsection{SUMMARY OF BATTERY COST ANALYSIS}

We have presented an analysis of battery costs for EVs and HEVs by using data from ANL's two-stage Delphi study and the CARB battery panel report. Expected vehicle characteristics (from the Delphi study) and the future characteristics of battery technologies (from both the Delphi study and the CARB panel report) were summarized. We evaluated initial battery pack costs and also analyzed replacement battery costs.

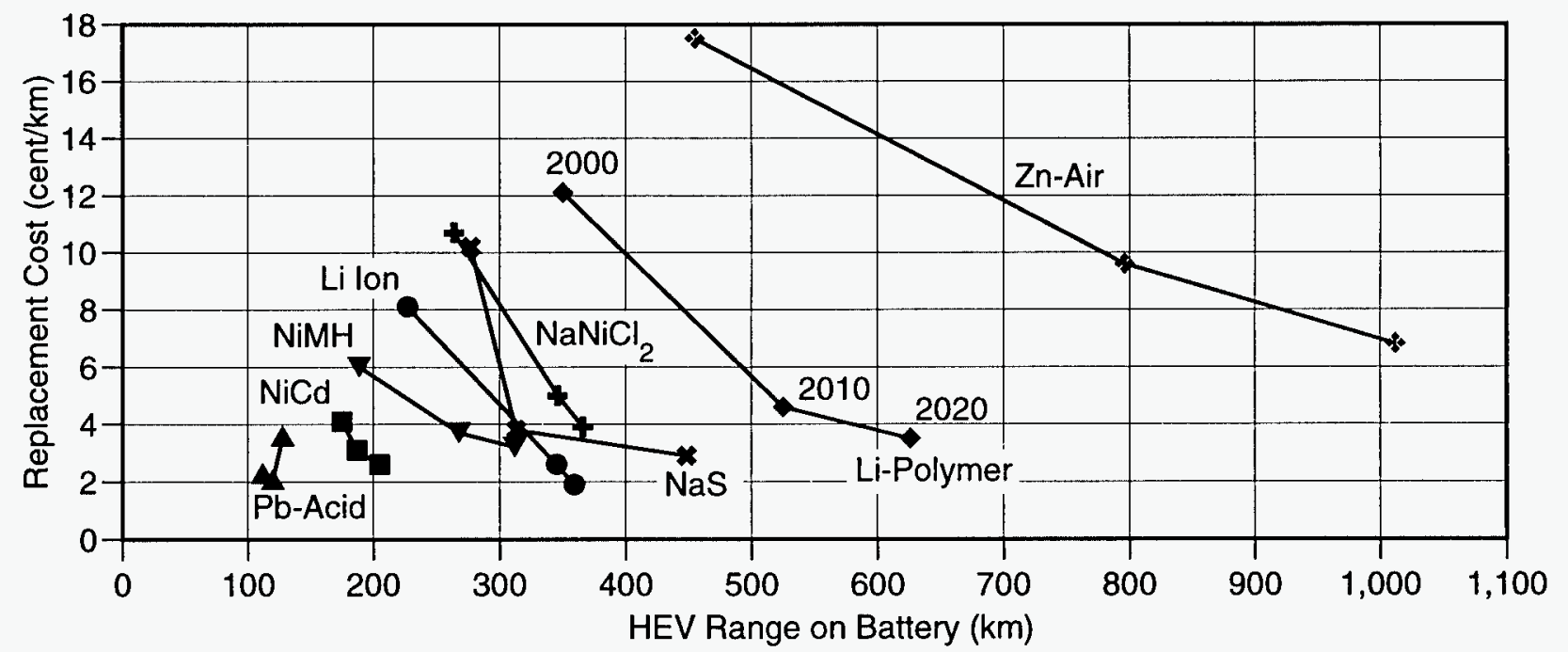

FIGURE 3.11 HEV Battery Replacement Cost and Range, from the Modified CARB Panel Data 
TABLE 3.8 Characteristics of the Initial HEV Battery Packs, Based on the Modified CARB Panel Data ${ }^{a, b}$

\begin{tabular}{|c|c|c|c|c|c|c|}
\hline Battery Technology & Year & $\begin{array}{c}\text { Mass } \\
(\mathrm{kg})\end{array}$ & $\begin{array}{c}\text { Energy } \\
(W h)\end{array}$ & $\begin{array}{c}\text { Initial } \\
\text { Cost }(\$)\end{array}$ & $\begin{array}{r}\text { Range } \\
(\mathrm{km})\end{array}$ & $\begin{array}{l}\text { Life } \\
(\mathrm{km})\end{array}$ \\
\hline \multirow[t]{3}{*}{ Lead-acid } & 2000 & 500 & 21,890 & 3,280 & 130 & 38,400 \\
\hline & 2010 & 330 & 16,520 & 1,980 & 110 & 50,200 \\
\hline & 2020 & 360 & 18,100 & 2,170 & 120 & 59,900 \\
\hline \multirow[t]{3}{*}{ Lithium-ion $^{c}$} & 2000 & 400 & 35,820 & 35,820 & 230 & 88,500 \\
\hline & 2010 & 380 & 53,360 & 16,010 & 350 & 132,700 \\
\hline & 2020 & 360 & 54,300 & 9,770 & 360 & 177,000 \\
\hline \multirow[t]{3}{*}{ Lithium-polymer } & 2000 & 500 & 59,700 & 44,780 & 350 & 88,500 \\
\hline & 2010 & 470 & 87,300 & 26,190 & 520 & 132,700 \\
\hline & 2020 & 450 & 101,810 & 17,820 & 630 & 177,000 \\
\hline \multirow[t]{3}{*}{ Nickel-cadmium } & 2000 & 500 & 29,850 & 14,930 & 170 & 104,900 \\
\hline & 2010 & 550 & 33,030 & 11,560 & 190 & 123,900 \\
\hline & 2020 & 600 & 37,410 & 11,220 & 210 & 159,300 \\
\hline \multirow[t]{3}{*}{ Nickel-metal hydride } & 2000 & 360 & 28,950 & 15,920 & 190 & 75,600 \\
\hline & 2010 & 330 & 39,640 & 13,870 & 270 & 115,000 \\
\hline & 2020 & 360 & 47,060 & 11,770 & 310 & 141,600 \\
\hline \multirow[t]{3}{*}{ Sodium-nickel chloride ${ }^{\mathrm{c}}$} & 2000 & 610 & 48,980 & 39,190 & 260 & 79,600 \\
\hline & 2010 & 660 & 66,070 & 15,200 & 350 & 106,200 \\
\hline & 2020 & 720 & 72,400 & 12,670 & 370 & 123,900 \\
\hline \multirow[t]{3}{*}{ Sodium-sulfur } & 2000 & 400 & 43,780 & 43,780 & 280 & 79,600 \\
\hline & 2010 & 330 & 46,250 & 11,560 & 310 & 106,200 \\
\hline & 2020 & 270 & 62,450 & 9,370 & 450 & 123,900 \\
\hline \multirow[t]{3}{*}{ Zinc-air } & 2000 & 800 & 95,520 & 33,430 & 460 & 70,800 \\
\hline & 2010 & 660 & 151,950 & 30,390 & 800 & 97,300 \\
\hline & 2020 & 540 & 176,480 & 22,060 & 1,010 & 123,900 \\
\hline
\end{tabular}

a For the mean power requirements of $79.6 \mathrm{~kW}$ in $2000,99.1 \mathrm{~kW}$ in 2010 , and $108.6 \mathrm{~kW}$ in 2020.

b Values are rounded to the nearest ten or hundred.

c These technologies were not included in the Delphi study. 
The results of the analysis of the Delphi study data can be summarized as follows:

1. A large majority, $91-98 \%$, of the 93 respondents to the second-stage Delphi questionnaire gave opinions on basic vehicle characteristics for EVs and HEVs. These characteristics include power, range, curb weight, seating capacity, and other attributes, as described in Chapter 2.

a. Respondents projected a $49 \%$ increase in mean EV power capability and a 36\% increase in mean HEV power capability between 2000 and 2020 .

b. They projected a $100 \%$ increase in mean EV range between 2000 and 2020. For the HEV, they projected a $49 \%$ increase in total range and a $31 \%$ increase in the engine range between 2000 and 2020 . The estimated battery-only range is $39 \%$ of the total in 2000 and $47 \%$ of the total in 2020. The high battery ranges imply to us that the candidate HEVs are seen by respondents as "range extenders."

c. Respondents projected a $21 \%$ reduction in the mean EV curb weight and a 19\% reduction in the mean HEV curb weight between 2000 and 2020.

2. A slightly lower number of respondents, $75-93 \%$, gave opinions on vehicle purchase price and variable operating cost, excluding batteries.

a. Respondents projected a $102 \%$ increase in the conventional vehicle price by 2020 compared to that for 1993 . They projected that both the EV and the HEV would have higher initial prices than the conventional vehicle through 2020.

b. They projected that the conventional vehicle would have an advantage in terms of variable operating cost in 2000, even when the battery replacement cost was excluded. An EV would have a variable cost advantage beginning in 2010. Through 2020, all three HEV technologies would have higher variable costs compared with the conventional vehicles. 
3. A smaller number of respondents, $22-59 \%$, gave opinions on 10 battery technologies. They provided input on such future battery characteristics as specific energy, specific power, shelf life, number of charge/discharge cycles, and initial cost.

a. Respondents projected that almost all battery technologies would improve over time. The rate of improvement varies among technologies. No one battery technology is superior in all respects.

b. The high mean-range requirements for EVs and HEVs will necessitate expensive battery packs, given the battery characteristics projected by respondents. The price of the initial battery pack will therefore make purchase price predictions very difficult to achieve. The mass of the initial battery is also expected to be high, making the mean curb weight predictions difficult to achieve.

4. We developed a procedure to compute battery replacement costs and computed these costs for both the EV and the HEV.

a. Almost all battery technologies were projected to reduce their cost over time. The lithium-polymer battery showed the highest rate of improvement.

b. If the mean-range requirements are to be met, the battery replacement cost will be 6.8 cents $/ \mathrm{km}$ or higher for EVs and 5.9 cents $/ \mathrm{km}$ or higher for HEVs.

c. If the EV range requirements are moderated as $130 \mathrm{~km}$ in $2000,160 \mathrm{~km}$ in 2010 , and $180 \mathrm{~km}$ in 2020 , then low battery replacement costs ( 6 cents $/ \mathrm{km}$ or lower) are projected.

d. HEV battery pack replacement costs can be reduced substantially with the use of lead-acid batteries. The battery-only range will be limited to $115-145 \mathrm{~km}$, but the battery replacement cost will be reduced to $4.1-5.8 \mathrm{cents} / \mathrm{km}$.

e. When battery replacement costs are added to variable operating costs, the respondents' battery characteristics predictions imply that the conventional vehicle would have a substantial operating cost advantage. Both EVs and HEVs reduce their total variable costs when the mean battery range 
requirement predictions are ignored and the least expensive battery is selected.

We modified the projected battery characteristics in the CARB panel report and supplemented the data with shelf (calendar) life information. The panel compiled the battery characteristics information by sending questionnaires to various developers and manufacturers as well as through plant visits. The optimism of the developers and manufacturers is reflected in the data. Except for the nickel-cadmium, sodium-sulfur, and zinc-air batteries, the performance characteristics in the panel report are comparable to the corresponding optimistic quartile in the Delphi study. The results of the analysis with the CARB panel data can be summarized as follows:

1. Two battery technologies, lead-acid and nickel-cadmium, are ready and will be available in improved forms when EVs are introduced.

a. The lead-acid technology is projected to have much higher (50\%) specific power, higher cycle life (20\%), slightly higher specific energy (12\%), and lower $(20 \%)$ cost compared to the Delphi means by 2010 .

b. The nickel-cadmium technology is projected to have higher (30\%) cycle life, lower (12\%) specific power, and lower (33\%) cost compared to the Delphi means by 2010 .

2. Six battery technologies are likely to be available between 2000 and 2010 if current R\&D efforts are successful. These battery technologies are lithiumion, lithium-polymer, nickel-metal hydride, sodium-nickel chloride, sodiumsulfur, and zinc-air.

a. The sodium-sulfur technology is projected to have much higher specific energy (115\%), specific power (150\%), and cycle life (65\%) compared to the Delphi means. It will also have much lower cost (53\%). The R\&D efforts on this technology have since been discontinued by the developer who supplied the information.

b. The panel considered the technical status of the zinc-air technology rather uncertain. If the present $\mathrm{R} \& \mathrm{D}$ efforts are successful, the technology was projected to have much higher specific energy and specific power, compared to the Delphi means. Its cost projections are very low, while its cycle life projections are similar to the Delphi means.

c. The panel's projections for the lithium-polymer technology are comparable to the optimistic quartile in the Delphi study. The panel 
provided very sparse data on lithium-polymer technology because it is at an early stage of development.

d. The performance characteristics for the nickel-metal hydride technology in the panel report are better than the third (optimistic) quartile in the Delphi study, while its cost projections fall between the second and the first (optimistic) quartiles. The panel projections are based on successful development of advanced electrode materials that would provide very high specific energy and specific power.

3. We characterized initial battery packs for EVs and HEVs to match the mean power predictions of the Delphi study. The battery packs for both the EV and HEV were lighter in mass and less expensive. We evaluated some combination EV battery packs that would be less expensive and would provide longer range. We also computed battery replacement costs that were much lower than the replacement costs computed with the Delphi data.

a. Two technologies that are considered ready by the panel, lead-acid and nickel-cadmium, would have replacement costs at $50-60 \%$ of the cost computed with the Delphi data. The range expectations are similar for lead-acid, while they improve slightly for nickel-cadmium.

b. The nickel-metal hydride technology would provide longer range and lower replacement cost (45-50\%), compared to the Delphi study predictions.

c. By 2020 , the lithium-ion technology would have the lowest replacement cost, on a cost-per-kilometer basis. Its range would be slightly lower than the Delphi mean for EVs and higher than the Delphi mean for HEVs. 


\section{MARKET PENETRATION ANALYSIS}

The Delphi questionnaire sought opinions on potential market shares for conventional and new-technology vehicles. Experts were asked to provide market share estimates at three points in time, for the years 2000, 2010, and 2020. Among new technologies, EVs, HEVs powered by conventional (gasoline or diesel) reciprocating engines, HEVs with gas turbines, and HEVs with fuel cells were included. An additional category allowed respondents to specify shares for any other technology vehicles.

We conducted two types of market penetration analysis pertaining to the above market shares. In one analysis, we developed mathematical models that best represented the pattern of market penetration emerging from the Delphi data. These models, developed by using the mean survey responses, could then be used for computing future market shares. In the other analysis, we used the Delphi survey data to develop profiles of the future vehicles. The profiles consist of such vehicle attributes as purchase price, seating capacity, fuel cost per mile, other operating and maintenance cost per mile, curb weight, performance in terms of power or acceleration, and emissions. We used these profiles as inputs to two vehicle choice models to project future market shares. One of the vehicle choice models used in this analysis was developed from past consumer purchase decisions (a "revealed preference" model), while the other model was developed from a "stated preference" survey in which respondents evaluated hypothetical future vehicles.

\subsection{MODELING THE PATTERN OF MARKET PENETRATION}

The Delphi respondents predicted market shares for three future years, 2000, 2010, and 2020. These predicted shares varied between respondents and technologies. Mean values of these points represent aggregate opinions and may not conform to a classical market penetration pattern. Also, a mathematical model would be useful to estimate market penetration during the intermediate years, as well as to project market penetration further into the future. OTT planning exercises ("Quality Metrics") involve projecting new-technology market shares to 2030.

Marketing professionals frequently use models of technology substitution. Research has shown that such market penetration follows an S-shaped curve (Mansfield 1961; Blackman 1974; Paul 1979; Teotia and Raju 1986). We used a formulation in which functions $F_{0}\{t\}$ and $F_{n}\{t\}$ define market shares of old and new technologies at time t. Note that $F_{o}\{t\}$ equals $1-F_{n}\{t\}$. We used the following logistic function, also used previously by Santini (1989):

$$
t=\delta+\beta \ln [F\{t\} /(1-F\{t\})]+\mu,
$$


where $\delta$ and $\beta$ are coefficients that become scalar factors determining the shape of the market penetration curve and $\mu$ is the error term. The term $\delta$ defines the midpoint in time for the symmetric logit curve represented by equation (1), and $\beta$ determines the rate at which the market would be penetrated.

Initially, we estimated coefficients $\delta$ and $\beta$ by using mean values of the three data points specified by the respondents. However, three data points did not provide an adequate statistical "anchor" for the market share estimates. When models developed with three data points were used to project the technologies that are likely to be introduced after the year 2000 , the results were poor. We therefore used interpolation to expand the number of data points to overcome this deficiency. Intermediate values obtained through linear interpolation provided additional market penetration points for each survey respondent. We assumed that the respondents had a smooth market share profile in mind, and imputation of values for intermediate years would be consistent with their opinions. The expanded data set had more points but still reflected mean values of experts' opinions when all responses were taken into account. (Although the method provided a smooth transition between the years, it did not lead to a set of smooth mean values for intermediate years.) We used mean values for each of the 21 years, 2000 through 2020, to obtain revised estimates of $\delta$ and $\beta$. Model coefficients were estimated by using the nonlinear regression procedure within the SHAZAM econometrics software (McGraw-Hill 1993). Additional data points within the expanded data set provided a better fit for all models, which led to plausible results for all technologies. The results of the final model estimation, based on 21 data points, are summarized in Table 4.1. The t-statistics show that coefficient values are significant for each technology and the goodness of fit is high, as shown by the R-square values.

Each model in Table 4.1 was estimated independently of others. When a number of market share models of this type are estimated independently and then combined, the sum of market shares will exceed $100 \%$ at some point. The sum of market shares must then be normalized to $100 \%$. We found that the sum of projected market shares will require such an adjustment after 2026. As new technologies penetrate the market, the conventional ICE share of the market will decline. Both conventional ICE and the combined total share for all new technologies would reach 50\% market share at the same point in time, 2033, as shown by the value of parameter $\delta$ for the conventional ICE. However, because the sum of individual model projections exceeded $100 \%$ by the year 2027 , the $50 \%$ point was reached in 2030 .

Figure 4.1 shows the predictions of the individual models, except for the conventional ICE, extended through 2030. Symbols show the estimated annual means developed from the survey responses, while solid lines show the model fit from 2000 to 2020 and projections to 2030 . We applied the above estimated models to compute the market shares for conventional ICEs, EVs, ICE HEVs, gas-turbine HEVs, fuel-cell HEVs, and "other technologies." The values shown by solid lines in the figure are the normalized market shares for the new technologies. 
TABLE 4.1 Results of Model Coefficients Estimation

\begin{tabular}{lccc}
\hline \multicolumn{1}{c}{ Technology } & $\delta$ & $\beta$ & R-square \\
\hline \multirow{2}{*}{ Conventional ICE } & 33.1 & -10.2 & 0.99 \\
& $(81.6)^{\mathrm{a}}$ & $(-44.9)$ & \\
Electric vehicle & 53.7 & 13.3 & 0.98 \\
& $(42.8)$ & $(30.8)$ & \\
ICE HEV & 50.4 & 12.3 & 0.98 \\
& $(43.3)$ & $(30.3)$ & \\
Gas-turbine HEV & 50.6 & 8.7 & 0.99 \\
& $(48.2)$ & $(31.7)$ & \\
Fuel-cell HEV & 47.5 & 7.7 & 0.99 \\
& $(50.4)$ & $(32.1)$ & \\
Other new technologies & 66.9 & 10.4 & 0.99 \\
& $(44.8)$ & $(33.9)$ & \\
\hline
\end{tabular}

${ }^{\text {a }}$ Numbers in parentheses show t-statistics.

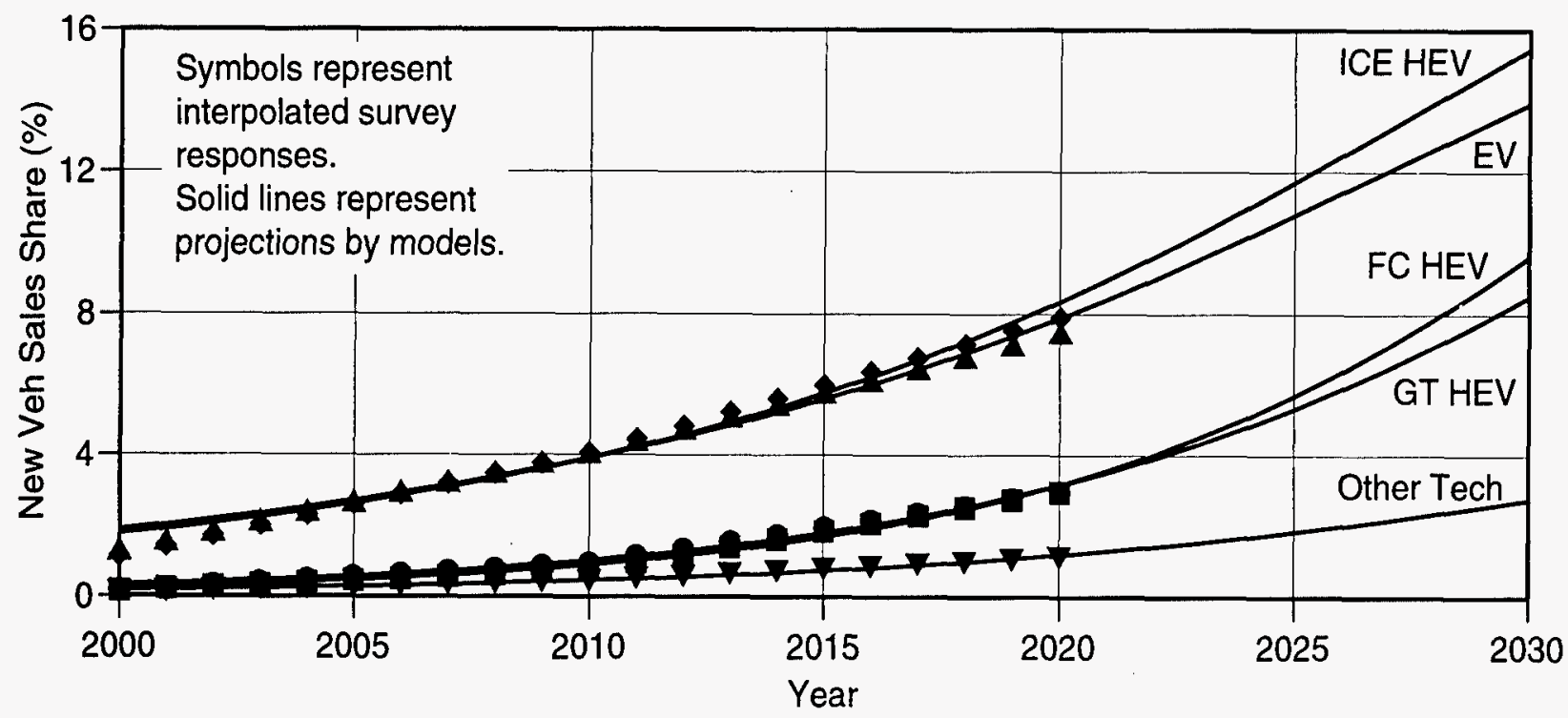

FIGURE 4.1 Application of Market Penetration Models to New Technologies 
Figure 4.1 does not show the share of conventional ICE vehicles. This technology's share is nearly $100 \%$ during the early years, while the highest share for any of the new technologies does not exceed $16 \%$. New-technology shares would be difficult to differentiate visually if they were shown in the same graph with the conventional ICE technology. The projected conventional ICE technology market share is $50 \%$ of the new-vehicle market in 2030 . Thus, the experts considered that various superior attributes of the conventional ICE technology will restrain the growth of the new technologies for a long time to come.

Using the one standard market share model in the fashion used here, the model projections imply that electric drive-train vehicles will begin to "take off' in the market place between 2020 and 2030. When the model projections are extended beyond those shown in Figure 4.1 , only $20 \%$ of the new vehicles are estimated to be conventional ICEs in 2040. Figure 4.2 shows survey mean and statistically projected market shares for new technologies for the years 2000, 2010, 2020, and 2030. The number at the top of each bar represents the sum of new-technology market shares. Subtracting each value from 100 percent provides conventional ICE market share estimates.

This market share analysis indicates that if the current research and development efforts are continued, EVs and ICE HEVs will penetrate the market first, at about the same time. ICE HEVs will penetrate the market at a faster rate, surpassing EVs after 2010. Gas-turbine- and fuel-cell-powered HEVs are projected to start much later, but they exhibit more rapid rates of market penetration than EVs and ICE HEVs once they become technically and economically competitive.

\subsection{MARKET PENETRATION THROUGH CONSUMER PREFERENCE MODELS}

Light duty vehicles are used predominantly for passenger transportation. Household-owned vehicles dominate this sector, so an evaluation of the household's purchase decision process is desirable to estimate the market potential of any new technology. The household vehicle purchase decision process is influenced by several demographic, economic, and geographical factors aside from vehicle characteristics. The demographic attributes of a household, which change over time, define its needs, while vehicle characteristics represent a technology's ability to meet these needs. We have selected and applied two vehicle choice models in this analysis. These models attempt, through analysis of surveys and construction of computer models, to mimic the household vehicle purchase decision process.

The Disaggregate Vehicle Stock Allocation Model (DVSAM) and the Alternative Vehicle Sales (AVS) model were used in this consumer-preference-based analysis. Both these models evaluate household and vehicle characteristics in computing market shares. DVSAM is based on past consumer purchases of gasoline vehicles in the 1970s (Vyas, Mintz, and Gur 1989) and uses disaggregate household characteristics. AVS is based on stated preferences of consumers for 


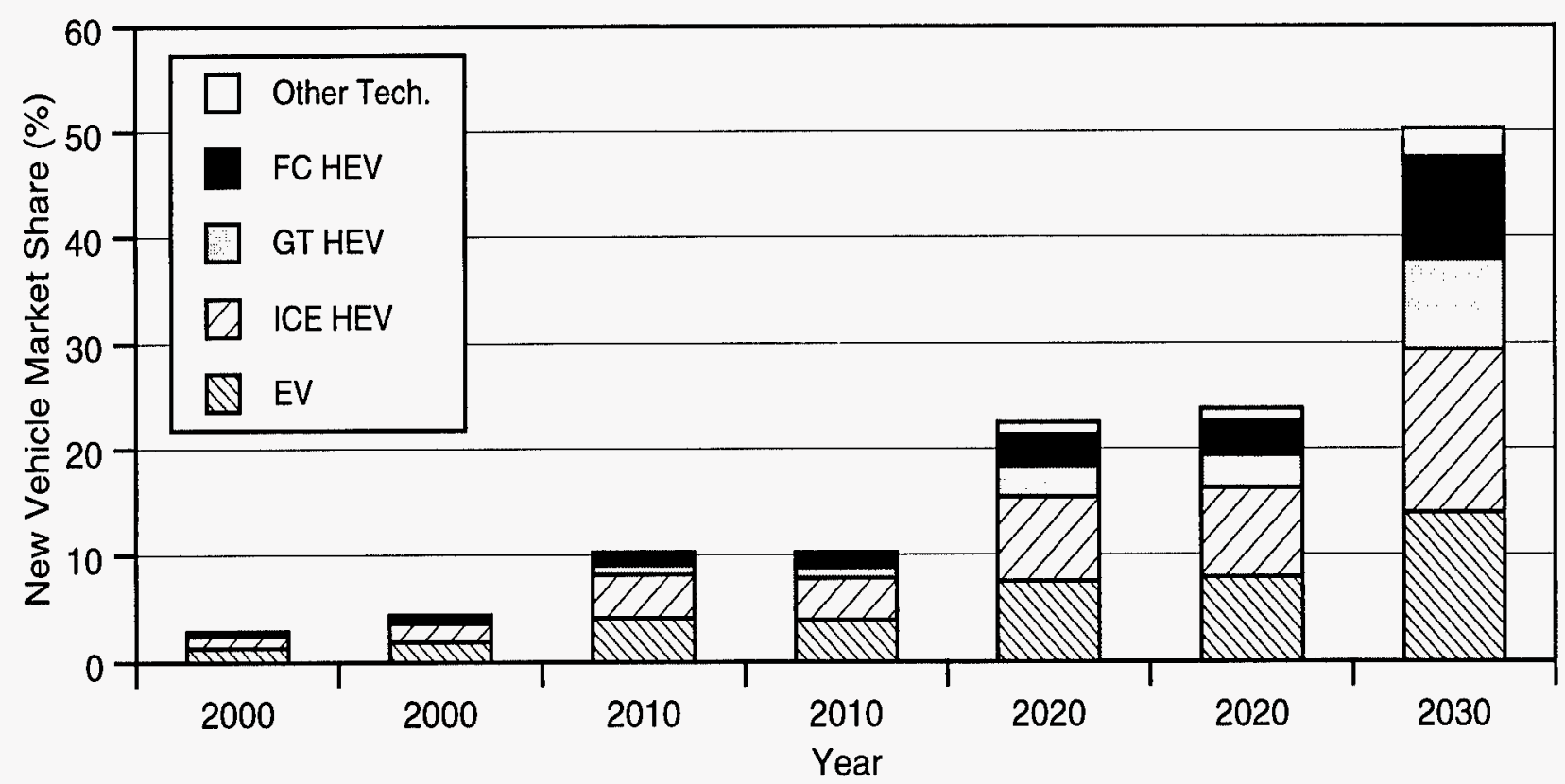

FIGURE 4.2 New-Technology Market Shares in 2000, 2010, 2020, and 2030

hypothetical future alternative-fueled vehicles in comparison to gasoline vehicles (Fulton 1994; Bunch et al. 1993) and uses aggregate demographic information.

\subsubsection{Vehicle Characterization}

We prepared profiles of five vehicle types - the conventional ICE, EV, ICE-powered $\mathrm{HEV}$, gas-turbine-powered HEV, and fuel-cell-powered HEV - and used them as input to the above two vehicle choice models to project market shares. In contrast with the earlier analysis, in which we fitted a curve to the market share data, this analysis will estimate market shares that could be expected if the vehicles have the attributes specified by the respondents and are offered to hypothetical consumers having the preferences simulated by the two vehicle choice models. The results will relate the market share estimates of the Delphi study respondents to those developed by using the vehicle attributes predicted by the respondents. Though the vehicle choice model results reflect previously measured consumer preferences, the comparison will be a form of "consistency check."

The Delphi study questionnaire (see Appendix A) included several questions related to the most realistic characteristics of the future EVs and HEVs in 2000, 2010, and 2020. Questions I-(A) and $\mathrm{I}-(\mathrm{B})$ asked the respondents to specify vehicle characteristics, such as range, acceleration, seating capacity, cargo space, curb weight, power, recharging time, and maintenance interval. Question I-(F) asked about vehicle cost compared with the conventional ICE-powered vehicle, and question I-(G) 
asked the respondents to provide fuel and maintenance cost ratios relative to an average 1993 conventional car. Question II-(A) asked the respondents to provide future characteristics of 10 battery technologies. We supplemented these data with historical purchase price and operating cost information and developed a set of plausible characteristics for each of the vehicle types.

We used the mean of responses to question I-(F) and the 1993 conventional vehicle cost of $\$ 15,000$ to arrive at future purchase prices. The resulting conventional vehicle prices for the years 2000,2010 , and 2020 were $\$ 18,900, \$ 24,000$, and $\$ 30,300$, respectively (see Table 4.2 ). While requesting opinions on operating cost ratios, the questionnaire stated that the conventional vehicle operating cost was $18 \mathrm{cent} / \mathrm{km}$ ( $29 \mathrm{cent} / \mathrm{mi})$ in 1993. This cost includes fixed costs, such as insurance, license, registration, and taxes. One of the two vehicle choice models we employed requires that we specify only the variable operating costs, such as fuel, lubricants, tires, battery replacement if applicable, and maintenance. We therefore used a 1993 variable operating cost of $5.8 \mathrm{cent} / \mathrm{km}(9.3 \mathrm{cent} / \mathrm{mi})$ for the conventional vehicle in our analysis (AAMA 1995). We applied the mean maintenance and fuel cost ratios to the above value in computing the costs in 2000,2010, and 2020. The resulting conventional vehicle costs were $6.9 \mathrm{cent} / \mathrm{km}(11.1 \mathrm{cent} / \mathrm{mi})$ in 2000 , $8.5 \mathrm{cent} / \mathrm{km}(13.7 \mathrm{cent} / \mathrm{mi})$ in 2010 , and $10.4 \mathrm{cent} / \mathrm{km}(16.7 \mathrm{cent} / \mathrm{mi})$ in 2020 . We used the mean of responses to questions I-(A) and I-(B) for curb weight, power, acceleration, and number of seats (see Table 4.2).

As described in Chapter 3, we analyzed the Delphi responses concerning 10 battery technologies and also developed a procedure for estimating battery replacement costs for EVs and HEVs. The procedure computes battery pack attributes and replacement costs for a desired power rating. Battery replacement costs are computed for shelf and cycle lives and are discounted. Within the procedure, mean power requirements for EVs and HEVs are used to compute the corresponding required battery pack mass and energy given mean battery characteristics. A related ANL analysis provided expected energy consumption per mile at the electric outlet in years 2000, 2010, and 2020 and the associated battery pack mass (Marr 1994). We assumed that vehicle energy consumption would change at a rate of $3.3 \%$ with each $10 \%$ change in the battery pack mass while computing the range on full charge. This response to mass is lower than for conventional ICE vehicles, both because of an absence of idling (related to power and engine displacement in a conventional vehicle) and benefits of regenerative braking in EVs and HEVs.

In computing $\mathrm{EV}$ battery replacement costs, we used the mean power requirements of 66.7, 86.1 , and $99.2 \mathrm{~kW}$ in 2000,2010 , and 2020 , respectively. Through interpolation, we derived a mean power value of $76.4 \mathrm{~kW}$ in 2005 . We included the year 2005 in our market penetration analysis because it appears to be the year when EVs would be marketed in respectable numbers. The battery replacement costs for the year 2005 were computed by interpolating each battery attribute and applying the methodology described in Chapter 3 . Mean specific power was the binding requirement for battery pack mass, and mean specific energy then determined its energy storage capacity. We used the above-mentioned energy consumption rates, corrected for the battery pack mass, to compute 
TABLE 4.2 Selected Vehicle Characteristics Used in Vehicle Choice Modeling

\begin{tabular}{|c|c|c|c|c|c|c|c|}
\hline Attribute & Source & Year & $\begin{array}{l}\text { Conventional } \\
\text { ICE }\end{array}$ & $\begin{array}{l}\text { Electric } \\
\text { Vehicle }\end{array}$ & $\begin{array}{l}\text { HEV with } \\
\text { ICE }\end{array}$ & $\begin{array}{c}\text { HEV with } \\
\text { Gas Turbine }\end{array}$ & $\begin{array}{l}\text { HEV with } \\
\text { Fuel Cell }\end{array}$ \\
\hline \multirow[t]{4}{*}{ Price $(1993 \$)$} & \multirow[t]{4}{*}{ Q I-F } & 2000 & 18,900 & 34,350 & 37,050 & 49,050 & 77,250 \\
\hline & & 2005 & 21,300 & 34,500 & 36,850 & 47,300 & 71,100 \\
\hline & & 2010 & 24,000 & 34,650 & 36,600 & 45,600 & 65,400 \\
\hline & & 2020 & 30,300 & 35,700 & 38,100 & 46,050 & 59,700 \\
\hline \multirow{4}{*}{$\begin{array}{l}\text { Fuel and maintenance } \\
\text { cost }(1993 \not / \mathrm{mi})\end{array}$} & \multirow[t]{4}{*}{$Q \mathrm{I}-\mathrm{G}^{\mathrm{a}}$} & 2000 & 11.1 & 13.1 & 14.5 & 18.6 & 24.7 \\
\hline & & 2005 & 12.4 & 13.2 & 14.8 & 18.4 & 22.9 \\
\hline & & 2010 & 13.7 & 13.3 & 15.2 & 18.2 & 21.1 \\
\hline & & 2020 & 16.7 & 14.3 & 17.5 & 19.3 & 21.9 \\
\hline \multirow[t]{4}{*}{ Curb weight (lb) } & \multirow[t]{4}{*}{ Q I-A \& I-B } & 2000 & 2,894 & 3,391 & 3,430 & 3,430 & 3,430 \\
\hline & & 2005 & 2,821 & 3,178 & 3,233 & 3,233 & 3,233 \\
\hline & & 2010 & 2,750 & 2,978 & 3,047 & 3,047 & 3,047 \\
\hline & & 2020 & 2,612 & 2,694 & 2,789 & 2,789 & 2,789 \\
\hline \multirow[t]{4}{*}{ Power (HP) } & \multirow[t]{4}{*}{ Q I-A \& I-B ${ }^{b}$} & 2000 & 130 & 89 & 107 & 107 & 107 \\
\hline & & 2005 & 127 & 102 & 119 & 119 & 119 \\
\hline & & 2010 & 125 & 115 & 133 & 133 & 133 \\
\hline & & 2020 & 120 & 133 & 146 & 146 & 146 \\
\hline \multirow{4}{*}{$\begin{array}{l}\text { Fuel economy } \\
\text { (mi/gasoline gal eqv.) }\end{array}$} & \multirow[t]{4}{*}{ Q I-G } & 2000 & 30.0 & 42.3 & 35.4 & 36.6 & 38.1 \\
\hline & & 2005 & 31.4 & 44.3 & 37.1 & 39.3 & 40.4 \\
\hline & & 2010 & 32.7 & 46.2 & 38.7 & 42.0 & 42.6 \\
\hline & & 2020 & 34.8 & 50.1 & 42.0 & 45.6 & 47.7 \\
\hline \multirow{4}{*}{$\begin{array}{l}\text { Battery replacement } \\
\text { cost }(1993 \not / \mathrm{mi})\end{array}$} & \multirow[t]{4}{*}{$Q-I I-A^{c}$} & 2000 & $\mathrm{~N} / \mathrm{A}$ & 9.6 & 9.3 & 9.3 & N/A \\
\hline & & 2005 & N/A & 10.9 & 8.0 & 8.0 & N/A \\
\hline & & 2010 & $\mathrm{~N} / \mathrm{A}$ & 11.4 & 7.3 & 7.3 & $\mathrm{~N} / \mathrm{A}$ \\
\hline & & 2020 & $\mathrm{~N} / \mathrm{A}$ & 11.0 & 6.5 & 6.5 & N/A \\
\hline \multirow[t]{4}{*}{ Range (mi) } & \multirow[t]{4}{*}{$\mathrm{ANL}^{\mathrm{d}}$} & 2000 & 350 & 85 & $\begin{array}{r}220 \\
(73)^{\mathrm{e}}\end{array}$ & $\begin{array}{r}220 \\
(73)\end{array}$ & 220 \\
\hline & & 2005 & 350 & 130 & $\begin{array}{l}255 \\
(78)\end{array}$ & $\begin{array}{r}255 \\
(78)\end{array}$ & 255 \\
\hline & & 2010 & 350 & 260 & $\begin{array}{l}290 \\
(83)\end{array}$ & $\begin{array}{r}290 \\
(83)\end{array}$ & 290 \\
\hline & & 2020 & 350 & 310 & $\begin{array}{r}335 \\
(90) \\
\end{array}$ & $\begin{array}{r}335 \\
(90)\end{array}$ & 335 \\
\hline
\end{tabular}

a Based on 1993 cost of 9.3 cent/mi from AAMA Motor Vehicle Facts \& Figures (1995).

b Values for conventional vehicle are derived from a related ANL study (Stodolsky, Vyas, and Cuenca 1995).

c EV battery costs are computed for the mean power requirements (Q I-A). The selected EV batteries are $\mathrm{Ni}-\mathrm{Cd}$ in 2000 , $\mathrm{Ni}-\mathrm{MH}$ in 2005, and Li-poly. thereafter. HEV costs are for half the mean power requirements (Q I-B) supplied by lead-acid batteries.

d EV range values for 2000 and 2005 are from ANL battery replacement cost analysis, while ranges for 2010 and 2020 are the means of Q I-A responses. HEV range values are the means of Q I-B responses.

e Values in parentheses show the battery-only range. 
vehicle range. Since battery technologies improve over time, the replacement batteries will usually have higher specific power and specific energy. We assumed that the electric motor and drive-train will last through the life of an EV and that future battery packs will be purchased to match the motor's power rating. (The owner will not buy more power than the motor's rating even though doing so would increase the range.) An EV purchased in 2000 may require a replacement battery pack before 2010. We therefore needed attributes of each battery technology for the intervening years. We assumed a linear rate of improvement in computing specific power, specific energy, shelf life, cycle life, and cost for the intervening years.

An EV owner will replace the battery pack either at the end of its shelf life or its cycle life, whichever comes first. The procedure computes two replacement costs for each technology, one based on its shelf life and the other based on its cycle life, and selects the higher of the two values. The future battery costs are converted to present worth and their sum is distributed over the vehicle's lifetime usage $(\mathrm{VkmT})$. Since the Delphi questionnaire asked respondents to include the first battery pack cost in the purchase price, we excluded the cost but included its VkmT. For annual usage (i.e., $\mathrm{VkmT}$ ), we used the lower of the following two values: one-half of the range times 365 days, or $17,700 \mathrm{~km}(11,000 \mathrm{mi})$. The battery cycle life is converted to its lifetime usage by multiplying the number of cycles by one-half the range. This procedure was followed because the respondents were asked to specify cycle life for each battery technology for recharging at 50\% depth of discharge.

HEV battery replacement costs were also computed by using the above procedure. Costs in Table 4.2 are computed for the cheapest battery technology that can provide the mean vehicle power requirements. In order to be attractive to consumers, an HEV battery pack should be significantly lighter and cheaper than that for an EV, because the vehicle carries two power systems. Based on this logic, we selected the cheapest battery technology, lead-acid, for the vehicle choice analysis and ignored the mean battery range requirements. This is consistent with several analysts' conclusions about HEV batteries. The HEVs we characterized with lead-acid batteries will have ranges of $118,126,134$, and $144 \mathrm{~km}(73,78,83$, and $90 \mathrm{mi})$ in 2000, 2005, 2010, and 2020, respectively (well below the Delphi responses).

Both DVSAM and AVS use several vehicle attributes. Because it simulates past purchase decisions, DVSAM uses more attributes related to the physical and economic aspects of the vehicles. The AVS model simulates a hypothetical selection process in which such attributes as fuel availability and emission reduction potential are included. The Delphi data did not provide values for all attributes used by the two models. We supplemented the data with information from related ANL and DOE studies where necessary. Table 4.3 lists the attributes used by the two models and indicates how they were derived. 
TABLE 4.3 Vehicle Attributes Used by the Vehicle Choice Models and Their Sources

\begin{tabular}{|c|c|c|c|c|c|c|c|}
\hline \multirow[b]{2}{*}{ Study Attribute } & \multirow[b]{2}{*}{ Vehicle } & \multicolumn{3}{|c|}{ DVSAM } & \multicolumn{3}{|c|}{ AVS } \\
\hline & & $\begin{array}{c}\text { Delphi } \\
\text { Responses }\end{array}$ & $\begin{array}{c}\text { ANL } \\
\text { Analysis } \\
\text { of Delphi }\end{array}$ & $\begin{array}{l}\text { Exogenous } \\
\text { Data }\end{array}$ & $\begin{array}{c}\text { Delphi } \\
\text { Responses }\end{array}$ & $\begin{array}{c}\text { ANL } \\
\text { Analysis } \\
\text { of Delphi }\end{array}$ & $\begin{array}{c}\text { Exogenous } \\
\text { Data }\end{array}$ \\
\hline \multirow[t]{5}{*}{ Vehicle price } & Conventional ICE & All & & & All & & \\
\hline & Electric vehicle & All & & & All & & \\
\hline & HEV with ICE & All & & & All & & \\
\hline & Gas-turbine HEV & All & & & All & & \\
\hline & Fuel-cell HEV & All & & & All & & \\
\hline \multirow[t]{5}{*}{ Range } & Conventional ICE & & & All & & & All \\
\hline & Electric vehicle & $2010-20$ & $2000-05$ & & $2010-20$ & $2000-05$ & \\
\hline & HEV with ICE & & All & & & All & \\
\hline & Gas-turbine HEV & & All & & & All & \\
\hline & Fuel-cell HEV & & All & & & All & \\
\hline \multirow[t]{5}{*}{ Power } & Conventional ICE & & & All & & & \\
\hline & Electric vehicle & All & & & & & \\
\hline & HEV with ICE & All & & & & & \\
\hline & Gas-turbine HEV & All & & & & & \\
\hline & Fuel-cell HEV & All & & & & & \\
\hline \multirow[t]{5}{*}{ Curb weight } & Conventional ICE & & & All & & & \\
\hline & Electric vehicle & All & & & & & \\
\hline & HEV with ICE & Ail & & & & & \\
\hline & Gas turbine HEV & All & & & & & \\
\hline & Fuel-cell HEV & All & & & & & \\
\hline \multirow[t]{5}{*}{ Seating capacity } & Conventional ICE & & & All & & & \\
\hline & Electric vehicle & All & & & & & \\
\hline & HEV with ICE & All & & & & & \\
\hline & Gas-turbine HEV & All & & & & & \\
\hline & Fuel-cell HEV & All & & & & & \\
\hline \multirow{5}{*}{$\begin{array}{l}\text { Fuel and maintenance } \\
\text { cost }\end{array}$} & Conventional ICE & All & & & & $\mathbf{a}$ & \\
\hline & Electric vehicle & All & & & & $\mathbf{a}$ & \\
\hline & HEV with ICE & All & & & & $\mathbf{a}$ & \\
\hline & Gas-turbine HEV & All & & & & $\mathbf{a}$ & \\
\hline & Fuel-cell HEV & All & & & & $\mathbf{a}$ & \\
\hline \multirow{5}{*}{$\begin{array}{l}\text { Battery replacement } \\
\text { cost }\end{array}$} & Conventional ICE & & b & & & & \\
\hline & Electric vehicle & & All & & & & \\
\hline & HEV with ICE & & All & & & & \\
\hline & Gas-turbine HEV & & All & & & & \\
\hline & Fuel-cell HEV & & All & & & & \\
\hline \multirow[t]{5}{*}{ Fuel price } & Conventional ICE & & c & & & & All \\
\hline & Electric vehicle & & c & & & & All \\
\hline & HEV with ICE & & c & & & & All \\
\hline & Gas-turbine HEV & & c & & & & All \\
\hline & Fuel-cell HEV & & c & & & & All \\
\hline
\end{tabular}


TABLE 4.3 (Cont.)

\begin{tabular}{|c|c|c|c|c|c|c|c|}
\hline \multirow[b]{2}{*}{ Study Attribute } & \multirow[b]{2}{*}{ Vehicle } & \multicolumn{3}{|c|}{ DVSAM } & \multicolumn{3}{|c|}{ AVS } \\
\hline & & $\begin{array}{c}\text { Delphi } \\
\text { Responses }\end{array}$ & $\begin{array}{c}\text { ANL } \\
\text { Analysis } \\
\text { of Delphi }\end{array}$ & $\begin{array}{c}\text { Exogenous } \\
\text { Data }\end{array}$ & $\begin{array}{c}\text { Delphi } \\
\text { Responses }\end{array}$ & $\begin{array}{c}\text { ANL } \\
\text { Analysis } \\
\text { of Delphi }\end{array}$ & $\begin{array}{c}\text { Exogenous } \\
\text { Data }\end{array}$ \\
\hline \multirow[t]{5}{*}{ Fuel economy } & Conventional ICE & & c & & All & & \\
\hline & Electric vehicle & & c & & All & & \\
\hline & HEV with ICE & & c & & All & & \\
\hline & Gas-turbine HEV & & c & & All & & \\
\hline & Fuel-cell HEV & & c & & All & & \\
\hline \multirow[t]{5}{*}{ Emissions factor } & Conventional ICE & & & & & & All \\
\hline & Electric vehicle & & & & & & All \\
\hline & HEV with ICE & & & & & & All \\
\hline & Gas-turbine HEV & & & & & & All \\
\hline & Fuel-cell HEV & & & & & & All \\
\hline \multirow[t]{5}{*}{ Fuel availability } & Conventional ICE & & & & & & All \\
\hline & Electric vehicle & & & & & & All \\
\hline & HEV with ICE & & & & & & All \\
\hline & Gas-turbine HEV & & & & & & All \\
\hline & Fuel cell HEV & & & & & & All \\
\hline \multirow{5}{*}{$\begin{array}{l}\text { Number of makes } \\
\text { and models }\end{array}$} & Conventional ICE & & & & & & All \\
\hline & Electric vehicle & & & & & & All \\
\hline & HEV with ICE & & & & & & All \\
\hline & Gas-turbine HEV & & & & & & All \\
\hline & Fuel-cell HEV & & & & & & All \\
\hline
\end{tabular}

a AVS uses fuel price and fuel economy to compute fuel cost per mile.

b Not applicable.

c DVSAM uses variable operating cost per mile. Fuel cost is included in fuel and maintenance cost.

\subsubsection{Market Penetration Modeling with DVSAM}

Vehicle characteristics used by the DVSAM model are price, operating cost, seating capacity, curb weight, and power. We executed the model for the years 2000, 2005, 2010, and 2020 and projected market shares for five vehicles in each year. We characterized five vehicles: (1) conventional vehicles, (2) EVs, (3) HEVs with an ICE, (4) HEVs with a gas turbine, and (5) HEVs with a fuel cell. Vehicle characteristics summarized in Table 4.2 were used. DVSAM uses household information through a matrix of household counts. Households are disaggregated by six attributes: (1) location (central city, suburb, rural); (2) income ( $<15 \mathrm{k}, 15-35 \mathrm{k}, 35-55 \mathrm{k}$, and $>55 \mathrm{k}$; 1993 dollars); (3) age of householder (<35, 35-44, 45-64, >64); (4) household size (1, 2, 3-4, >4); (5) number of drivers $(0,1,2,>2)$; and (6) number of vehicles $(0,1,2,>2)$. A baseline household matrix is updated to match an exogenously generated set of target vectors for these six attributes. Data from the Bureau of the Census and macroeconomic forecasts are used to generate these target 
vectors. We used the household files created for an earlier ANL study (Stodolsky, Vyas, and Cuenca 1995).

The model predicted the four new electric-drive technologies would gain a negligible market share of $0.1 \%$ in 2000 . Their share than increases to $0.7 \%$ by $2005,4.0 \%$ by 2010 , and $6.4 \%$ by 2020 . These projected shares are very small compared with the mean market shares specified by the respondents (as shown in Figure 4.2). DVSAM projects only a quarter of the year 2020 mean market share $(23 \%)$ projected by study respondents. This implies that (1) vehicles will have to be better than projected by Delphi respondents to obtain their predicted shares, (2) the Delphi market share estimates are too optimistic, or (3) the new-technology vehicles will have to be subsidized substantially.

The above analysis shows that new-technology vehicles must offer very distinct advantages to gain consumer acceptance. These vehicles (see Table 4.2) cost consistently more than conventional vehicles, and their operating costs are at least $50 \%$ higher. The EV has very short range in 2000 and 2005 , costs at least $70 \%$ more, and has nearly twice the operating cost compared with the conventional ICE. Respondents did not give much fuel and maintenance cost advantage to the EV. Battery replacement costs more than offset the small fuel and maintenance cost advantages given in 2010 and 2020. We executed DVSAM with two different EV battery scenarios, one involving the cheapest battery and the other involving batteries with higher range, but the projected market shares did not change much. When we increased the EV range in 2000 and 2005 (the ranges in 2010 and 2020 are already more than $400 \mathrm{~km}$, or $250 \mathrm{mi}$ ) by using more expensive batteries, the market shares remained unchanged. Use of the cheapest battery resulted in substantial loss of EV shares because of limited range. Another run involving a $\$ 5,400$ subsidy (to bring the EV cost equal to the conventional vehicle cost in 2020) was tried. Lower purchase price caused high relative increases in the EV market shares in 2010 and 2020, but small absolute changes in shares. The EVs' share increased from 0.4 to $0.6 \%$ in 2010 and from 1.5 to $2.5 \%$ in 2020 .

The analysis with DVSAM predicted that EVs and HEVs cannot compete with the conventional ICE vehicle if they have the attributes specified by the respondents. This could be attributed to the fact that DVSAM computes market shares on the basis of demographic data, costs, and performance attributes, but it does not take into account air quality benefits, environmental regulations, and changes in consumer preferences. Alternatively, it may have predicted valid shares.

\subsubsection{Market Penetration Modeling with AVS}

AVS uses such vehicle characteristics as price, fuel cost, change in tailpipe emissions of criteria pollutants, change in total energy cycle greenhouse gas emissions, vehicle range, fuel availability (compared with gasoline), and number of makes and models being marketed. We used price and range data from Table 4.2. We used mean fuel economy ratios (question I-G) and fuel price 
(EIA 1996) to compute fuel cost per mile, and we obtained emissions, fuel availability, and make and model information from a related DOE study (OTT 1996). The AVS model uses average attributes of new vehicle buyers. They are disaggregated as having high or low education; owning $<2,2$, or $>2$ vehicles; having high or low income; and being located in NAAQS attainment or nonattainment areas.

AVS projected the four new electric-drive technologies to have market shares of 2.5, 2.7, 7.5 , and $23.6 \%$ in $2000,2005,2010$, and 2020 , respectively. These shares are closer to the mean market shares of $2.9,6.6,10.3$, and $22.5 \%$ specified by the respondents. The AVS model's treatment of emissions and range appears to have contributed to these increased shares. However, AVS does not include operating and battery replacement costs, vehicle mass, and performance (in terms of acceleration or horsepower per unit mass), while DVSAM does include coefficients for predicting consumer response to these attributes.

\subsection{SUMMARY OF MARKET PENETRATION ANALYSIS}

Expert opinions on future market shares were analyzed by using two techniques. Under the first technique, we developed classical technology substitution models. Under the second technique, we executed two vehicle choice models with the vehicle attributes emerging from the Delphi responses. We projected market shares under both techniques. The following observations can be made as a result of this analysis:

- Respondents appear to have included their perceptions of urban air quality and energy security issues while responding to the market share questions. They projected that the new technologies (i.e., EV, ICE-powered HEV, gas-turbinepowered HEV, and fuel-cell-powered HEV) would have nearly $23 \%$ of the new-vehicle sales by the year 2020 . The respondents projected these vehicles would have significant all-electric range, a capability that can reduce vehicle tailpipe emissions and petroleum use.

- The market penetration patterns emerging from the Delphi responses are similar to the classical technology substitution patterns used by marketing professionals. The mathematical formulation used in the analysis would be useful for projecting new-technology shares beyond the year 2020. The four new-technologies would gain a 50\% share of the new vehicle market in 2030 if the projections are extended beyond 2020 .

- When a "revealed preference" vehicle choice model based on past vehicle purchases (DVSAM) was applied, it predicted very small shares for the four 
new technologies. However, respondents' perception of changing consumer preferences and emission reduction benefits were not included in this analysis.

While preparing vehicle characteristics for DVSAM, estimates of battery replacement costs and vehicle range became necessary. The Delphi data on 10 battery technologies provided high battery replacement costs through 2020 and low range through 2005. Respondents specified high initial purchase price and higher operating and maintenance cost (including battery replacement cost) for the new technologies. Given the consumer preference characteristics simulated by DVSAM, this resulted in very low market share predictions.

- When a vehicle choice model based on a stated preference survey (AVS) was applied, it predicted market shares very similar to the mean of responses. Emissions reduction benefits were modeled in this analysis. However, battery replacement costs and performance attributes, acceleration and top speed, were not included.

- Two of the three techniques used here imply a significant jump in market share of electric-drive vehicles from 2010 to 2030, while one does not. 


\section{INDUSTRY AND ALL-GROUP COMPARISONS}

A majority of the responses in both the Delphi stages were provided by persons affiliated with industry. Respondents were identified by their employment and were assigned to groups. Because the industry group was the largest, it is pertinent to look at the responses within it and compare them to the total group. If the industry experts have opinions vastly different from the whole sample, it would indicate that the other (non-industry) experts have a different view of EV and HEV issues than do those involved in vehicle manufacturing. In order to check whether the industry group differed by a wide margin, we compared the means of responses by the industry group with those for the entire sample. The results of the comparative analysis are presented in this chapter.

\subsection{VEHICLE-RELATED COMPARISONS}

\section{Basic EV/HEV Characteristics}

In assigning ratings to the $11 \mathrm{EV}$ attributes, both the industry respondents and the total group provided similar rankings, with three exceptions. Cargo space was ranked ninth by all respondents vs. eleventh (or last) by the industry group. Since the ranking by the whole group was higher for cargo space, non-industry respondents must have given it much higher rating. The difference in its mean rating was only $6.3 \%$, but because the bottom three attributes were so closely rated, that much difference was enough to drop cargo space by two ranks. Thus, the concern about losing storage space to the bulky batteries seems to be more prevalent among the non-industry respondents. With regard to the other two exceptions, the industry group ranked recharging time as the second most important attribute, up one notch, and power-to-weight ratio as the fifth most important attribute, ahead of uphill grade capability.

The mean estimates of the $11 \mathrm{EV}$ attributes for the forecast years 2000, 2010, and 2020 were very similar for both groups, with a few exceptions. The industry group means for cargo space and maintenance interval for the year 2000 were lower by $10.4 \%$ and $13.5 \%$, respectively. The industry group also assigned lower values to cargo space for 2010 and 2020. The mean cargo space value for the industry group was lower by $10.8 \%$ in 2010 and by $7.7 \%$ in 2020 .

The rankings resulting from ratings of the $12 \mathrm{HEV}$ attributes were slightly different. The industry group assigned a higher rating to $0-50 \mathrm{kph}$ acceleration time, thereby moving it up two notches, from fifth to third most important. The industry group also rated power-to-weight ratio ahead of seating capacity and recharging time ahead of cargo space. 
In assigning values to the $12 \mathrm{HEV}$ attributes, the industry group assigned lower values to cargo space in all three years. The industry group mean cargo space value was lower by $6.4 \%$ in $2000,9.2 \%$ in 2010 , and $7.2 \%$ in 2020 . The mean value for recharging time was higher for the industry group by $17.5 \%$ in $2000,11.1 \%$ in 2010 , and $12.4 \%$ in 2020 . The industry group also provided a $15 \%$ lower maintenance interval in 2000.

\section{Amenities}

The industry group ranked the five amenities in the same order as the whole sample. The group's mean importance rating for audio entertainment was $5.7 \%$ higher, and all other mean ratings were within $3 \%$ of those of the whole sample.

\section{R\&D Needs}

The three $R \& D$ areas were ranked in the same order by both groups. The industry group assigned a slightly lower (by $4.7 \%$ ) importance to vehicular technology.

\section{Opinions on Hybrids}

When the 11 statements involving hybrid vehicles were ranked by the percent of respondents agreeing, the industry group differed from the whole sample in a few items. More industry respondents (93\% vs. $88 \%$ ) agreed that component manufacturing and servicing infrastructure for HEVs is lacking. The industry group ranking of the statement was third, compared to fourth by the whole group. The whole group was more optimistic, based on percent agreeing, on the HEV's cost being less than the EV's when commercialized. Although only $23 \%$ of all respondents agreed, they were $29 \%$ more than the industry group, in which only $16 \%$ agreed. Only $14 \%$ of the industry respondents agreed that most components needed by HEVs are market-ready today, compared to $27 \%$ of all respondents. Some $11 \%$ of the industry group agreed that HEVs will never be a viable alternative, compared to $8 \%$ for the whole sample.

\subsection{COSTS AND FUEL ECONOMY COMPARISON}

\section{Vehicle Purchase Price}

The mean values of cost ratios for the three future years $(2000,2010$, and 2020) for conventional vehicles were almost identical for the two groups, differing by less than $4 \%$. The 
groups were in greater agreement for the $\mathrm{EV}$, having mean cost ratios within $1 \%$ of each other. With

regard to HEVs, the industry group was a little more pessimistic than the whole sample, particularly for the fuel-cell HEVs. The mean cost ratios for fuel-cell vehicles were about $10 \%$ higher for the industry group, compared to the whole group. The industry group also had higher means for ICEpowered HEVs (by 7\%) and gas-turbine-powered HEVs (by 5\%) for the year 2000.

\section{Fuel and Maintenance Cost}

Both groups were in close agreement on fuel and maintenance $(\mathrm{F} \& \mathrm{M})$ cost ratios, differing by $3 \%$ or less for most of the responses. Only three estimates differed by a slightly bigger margin of $4-5 \%$. The year $2000 \mathrm{~F} \& \mathrm{M}$ cost for the gas-turbine-powered HEV was $5 \%$ lower for the industry group, the year $2020 \mathrm{~F} \& \mathrm{M}$ cost ratio for the ICE-powered HEV was $4 \%$ higher, and the $2020 \mathrm{~F} \& \mathrm{M}$ cost ratio for the fuel-cell-powered HEV was $4 \%$ lower.

\section{Fuel Economy}

The industry group provided lower estimates of fuel economy, especially for the EV. The mean fuel economy ratio for the EV was lower by $11 \%$ in $2000,20 \%$ in 2010 , and $26 \%$ in 2020 . The fuel economy ratio for the ICE-powered HEV was lower by 5\% in 2010 and $9 \%$ in 2020, that for the gas-turbine-powered HEV was lower by $5 \%$ in 2010 and $10 \%$ in 2020, and that for the fuel-cell HEV was lower by $11 \%$ in 2010 and $16 \%$ in 2020 .

\subsection{MARKET PENETRATION COMPARISON}

\section{Obstacles to Commercialization}

The mean rating of six perceived obstacles to EV and HEV commercialization differed by $5 \%$ or less for all except two obstacles. The industry group assigned a 7\% higher rating to insufficient CAFE (Corporate Average Fuel Economy) credits for EVs and a $6 \%$ higher rating to cost and complexities in the manufacture of battery and drive-train for HEVs. When ranked by mean rating, only the EV CAFE credits ranked a notch higher (ahead of failure to include intangible environmental benefits in life-cycle analysis) for the industry group; all other obstacles ranked in the same order. 


\section{Market Penetration}

The mean market share estimates (of new vehicles) were significantly different between the groups, with the industry group consistently assigning higher market shares to the conventional vehicle. Though the increases in the $\mathrm{CV}$ market shares were small, ranging from $0.3 \%$ in 2000 to $7.1 \%$ in 2020, the large absolute market shares of CVs caused losses in the range of 10-38\% for the new-technology vehicles. There were exceptions in 2000 , where the industry group assigned $0.2 \%$ and $0.3 \%$ shares to gas-turbine-powered and fuel-cell-powered HEVs, respectively. The whole sample had very low shares for these two vehicle types in 2000 , and the industry shares are higher by $29 \%$ and $63 \%$, respectively. These exceptions were created by a few overly optimistic experts from the industry who assigned much higher market shares to the two HEV types. The industry group assigned lower shares to EVs, by $11 \%$ in 2010 and $9 \%$ in 2020 . The industry group's estimates for the ICE-powered HEV were lower by $30 \%$ in 2000 and 38\% each in 2010 and 2020 . The group also assigned a 38\% lower 2010 share to gas-turbine-powered HEVs and a 26\% lower 2020 share. The fuel-cell market share estimates by the industry group were lower by $21 \%$ in 2010 and $33 \%$ in 2020. In general, the industry group was not very optimistic about the new-technology vehicles. According to the industry group, only by 2020 would the EVs and HEVs capture respectable market shares (i.e., greater than $5 \%$ ).

\subsection{COMPONENTS COMPARISON}

\section{Battery Characteristics}

The battery specific energy estimates given by the two groups were almost identical for the three forecast years, differing by less than $5 \%$. There were a few exceptions. The industry group's estimate of lithium-polymer specific energy in 2000 was $11 \%$ lower than the whole sample. The industry group's mean of specific energy for the zinc-air battery was $8 \%$ lower in 2020 . The group also had a $6 \%$ lower specific energy estimate for the nickel-zinc battery and a $6 \%$ higher estimate for the sodium-sulfur battery, both in 2000 .

The mean specific power estimates differed more between the two groups. The industry group estimate of lead-acid specific energy was $18 \%$ higher in 2000 and $8 \%$ higher in 2010 . The industry group also estimated an $8 \%$ higher specific power for the lithium-iron disulfide battery in 2020 and an $8 \%$ lower specific power in 2010 . The industry group assigned lower specific power to nickel-iron by $8 \%$ in $2000,6 \%$ in 2010 , and $5 \%$ in 2020 . The nickel-zinc battery had $7 \%$ lower specific power in 2000 and $5 \%$ lower each in 2010 and 2020, within the industry group. The group had 7\% lower specific power estimates for the lithium-polymer battery in both 2010 and 2020. The industry group also assigned lower specific power to the zinc-air battery, 7\% in 2010 and 5\% each in 2000 and 2020. 
The estimates for battery shelf life and cycle life differed significantly between the groups. The industry group estimate of nickel-iron shelf life was $25 \%$ higher in 2000, $21 \%$ higher in 2010, and $19 \%$ higher in 2020 . The group also estimated a $15 \%$ longer shelf life for the lithium-iron disulfide battery in 2000 and a $10 \%$ longer shelf life in 2010 . The industry group had an $11 \%$ shorter shelf life in 2000 for the nickel-metal hydride battery and a $12 \%$ shorter shelf life in 2020 . The zincair battery was assigned an $11 \%$ shorter shelf life in 2000 by the industry group, and $19 \%$ shorter each in 2010 and 2020 . The industry group also assigned shorter shelf life to the nickel-zinc battery, by $9 \%$ in $2000,19 \%$ in 2010 , and $18 \%$ in 2020 . The largest differences in cycle life were nickel-iron battery with a $21 \%$ increase in 2000 and a $9 \%$ increase in 2010 ; lithium-iron disulfide battery with a $12 \%$ increase in 2000 , a $9 \%$ increase in 2010 , and a $12 \%$ increase in 2020; zinc-air battery with a $13 \%$ decrease in 2000 and a $25 \%$ decrease each in 2010 and 2020; nickel-zinc battery with an 11\% decrease in 2000 , a $14 \%$ decrease in 2010 , and a $19 \%$ decrease in 2020 ; sodium-sulfur battery with an $8 \%$ decrease in 2010 and an $18 \%$ decrease in 2020 ; and lead-acid battery with a $10 \%$ decrease in 2010 and an $11 \%$ decrease in 2020.

The industry group provided lower initial cost estimates for some batteries and higher estimates for others. The batteries that had initial costs differing by more than 5\% compared to the whole sample include sodium-sulfur with a $22 \%$ lower cost in 2000 , an $18 \%$ lower cost in 2010 , and a $10 \%$ lower cost in 2020; lithium-polymer with a $13 \%$ lower cost in 2000 , an $8 \%$ lower cost in 2010 , and a $7 \%$ lower cost in 2020; nickel-metal hydride with a $14 \%$ lower cost in 2000 and a $10 \%$ lower cost in 2010; lithium-iron disulfide with an $8 \%$ lower cost in 2000 and a $9 \%$ higher cost in 2020; nickel-iron with a 9\% lower cost in 2000 and an $11 \%$ higher cost in 2020; zinc-air with a $7 \%$ lower cost in 2000, a 10\% higher cost in 2010, and a 19\% higher cost in 2020; and zinc-bromide with a $10 \%$ higher cost in 2010 and a $16 \%$ higher cost in 2020 .

\section{Battery Environmental Considerations}

The ratings of battery recyclability were very similar between the two groups, with two exceptions. The nickel-cadmium and sodium-sulfur batteries each had an $11 \%$ increase in their recyclability rating. The increases moved these batteries two notches up, ahead of nickel-iron and nickel-zinc. The two groups also differed somewhat while rating the environmental impact of the batteries. Zinc-air, which was rated by the whole group as having the least negative impact, was rated third by the industry group. Nickel-metal hydride and lithium-polymer batteries each moved one notch up as the top two with the least environmental impact for the industry group. The lithium-iron disulfide battery was ranked the fifth (in the middle) by the industry group, compared to its eighth rank by the whole group. The nickel-zinc and nickel-iron batteries each moved two ranks down, from fifth in the whole sample to seventh within the industry group and from sixth to eighth, respectively. 


\section{Electric Motors}

The technological rankings of the three motors were identical between the two groups for all forecast years. Cost ratios, although providing nearly similar rankings, were slightly higher for the whole group. The industry group projected nearly identical cost ratios for the dc and dc brushless motors in 2020 , while the whole group had a $15 \%$ higher cost ratio for the dc brushless motor compared to the dc motor.

\section{Materials}

The rankings of the six advanced materials by six use-related attributes were almost identical between the two groups. The only exception was in the ranking of materials for durability, where the industry group believed aluminum to be superior to high-strength steel. The whole group had ranked aluminum second to the high-strength steel. The mean values of ratings differed by less than 5\%, except for the durability ratings of aluminum (up 5\%) and high-strength steel (down 5\%).

\section{HEV Power Units}

The technological maturity rankings of the five candidate HEV power units were identical between the two groups for all three forecast years. The industry group assigned a $12 \%$ higher rating to the gas turbine than did the whole group in 2020 , indicating greater maturity, but its ranking did not change. In rating the five power units for suitability/safety, the industry group ranked diesel at the top, ahead of the 4-stroke gasoline engine, in 2010, while the whole group had ranked the 4stroke gasoline engine at the top. The industry group ranked the 2-stroke engine at the bottom in 2020 , compared to the whole group ranking of fourth, ahead of the fuel cell. The cost-effectiveness ranking of the five power units was similar in each forecast year between the two groups. However, the industry group assigned a $13 \%$ higher rating to diesel in 2020, bringing it within $1.5 \%$ of the 4stroke gasoline engine. The whole group had a $10 \%$ rating difference between diesel and the 4-stroke gasoline engine, with diesel considered less cost-effective.

\section{Advanced Concepts}

The five advanced concepts were ranked in the same order, for technological viability, by the two groups through the three forecast years. The industry group assigned slightly higher ratings to the solar devices and lower ratings to the ultracapacitor, but the overall rankings did not change. The two groups provided nearly identical cost ranking for the five advanced concepts, with one exception. The industry group considered the solar devices more cost-effective than the ultracapacitor in 2000 . 


\subsection{SYSTEM IMPACT COMPARISON}

\section{Air Pollution and Global Warming}

The industry group's perception of eight statements relating to air pollution, measured in terms of percent agreeing, was slightly different than the whole group's. Fewer industry experts (88\%) compared to the whole sample (92\%) agreed that most EV charging will use overnight base load capacity. Nearly equal percentages of industry experts $(89 \%)$ and the whole sample $(87 \%)$ agreed that any increase in power-plant emissions due to EV use will be offset at the local level by a decrease in on-road emissions. These two differences combined to change the rankings of the eight air-pollution-related statements between the two groups. The statement about an increase in powerplant emissions being offset by a decrease in on-road emissions was ranked second by the industry group and fourth by the whole sample. Although the other statements were ranked identically for both groups, a higher percentage of the industry group (84\%) compared to the whole sample (71\%) agreed that total emissions of carbon dioxide and, possibly, oxides of nitrogen and sulfur will increase because the electricity for EVs and HEVs will be generated predominantly from coal.

Fewer industry experts (37\%) than the whole sample (44\%) agreed that EVs and HEVs will reduce global warming potential by 2020 , even if they have a market share of $33 \%$. More industry experts $(67 \%)$ than the whole sample (59\%) agreed that policies with significant implications for global warming potential will be implemented by governments no later than the year 2000 .

\section{Nuclear Power}

Both groups ranked the six statements related to the equivocal state of nuclear power in the United States identically. However, the industry group assigned an $11 \%$ lower rating to the statement about the perceived superiority of U.S. fossil fuel power-plant technology and a $9 \%$ lower rating to the statement indicating lack of perception or education relating to relative costs and benefits.

\section{Market Success Factors}

The industry group rating of the statement "large direct incentives to buyer are necessary" was $11 \%$ higher than the rating by the whole group. The higher rating moved the statement's rank from eleventh for the whole sample to seventh for the industry group. The industry group assigned a $6 \%$ higher rating to the statement "supporting infrastructure must be developed," moving it one rank up from fourth. The industry group also assigned a 5\% lower rating to the statement "commitment by original equipment maker must be greater," moving it down to eleventh from its ninth rank for the whole sample. 


\section{COMPARISON OF STAGE 2 RESULTS WITH STAGE 1 RESULTS}

In this chapter, we compare the results of the second stage of the survey with the first. The intent is to shed some light on the process of convergence of opinions. The study might have been an educational experience for some participants who, for the first time, were required to specify values for a series of EV/HEV items. Also, between the two stages of the survey, some political and regulatory changes either took place or were likely to take place, which could have influenced the second-stage results.

The first-stage data collection was finished near the end of August 1994, and the secondstage data collection was completed by July 1995 . During the intervening time of almost a year, several incidents that could significantly affect the development of EVs/HEVs took place. Some notable incidents were the fire in a sodium-sulfur-battery-powered EV, which had received quite a bit of publicity; the indications that the California Air Resources Board (CARB) would either repeal or postpone the zero emissions mandate; and the election of a Republican majority in the United States Congress. In addition, PNGV, the joint government-industry initiative to triple the light duty vehicle fuel economy, started to take shape (NRC 1994). Moreover, advances were made in battery, motor, and vehicle technologies, although complete information on these advances is not available due to their proprietary nature. Collectively, these items could have affected the information collected through the second stage. We present the changes in the mean ranking and/or rating of some items and also present the percent changes.

\subsection{COMPARISON OF VEHICLE-RELATED RESPONSES}

\section{Basic Vehicle Characteristics}

The respondents ranked $11 \mathrm{EV}$ and $12 \mathrm{HEV}$ attributes in terms of their importance. The HEV has one more attribute because the vehicle range was subdivided as total and engine-only range. The attribute rankings and mean importance ratings for the two stages are tabulated in Table 6.1.

Vehicle range was ranked first for EVs in both the stages. Maintenance interval and recharging time were second and third, but they switched their ranks between the two stages. Top speed was ranked the last in the second stage, two ranks lower than in the first stage. Most of the remaining attributes did not change their individual rank by more than one place.

For the HEV, total range was assigned the highest rating in both the stages. HEV range on engine-alone moved from its sixth rank in the first stage to the second rank in the second stage. This 
TABLE 6.1 Comparison of Vehicle Characteristics Ratings for the Two Stages

\begin{tabular}{|c|c|c|c|c|c|c|c|c|}
\hline \multicolumn{4}{|c|}{ Electric Vehicle } & \multirow[b]{3}{*}{ Vehicle Attribute } & \multicolumn{4}{|c|}{ Hybrid Electric Vehicle } \\
\hline \multicolumn{2}{|c|}{ Second Stage } & \multicolumn{2}{|c|}{ First Stage } & & \multicolumn{2}{|c|}{ Second Stage } & \multicolumn{2}{|c|}{ First Stage } \\
\hline $\begin{array}{l}\text { Mean } \\
\text { Rating }\end{array}$ & Rank & $\begin{array}{l}\text { Mean } \\
\text { Rating }\end{array}$ & Rank & & $\begin{array}{l}\text { Mean } \\
\text { Rating }\end{array}$ & Rank & $\begin{array}{l}\text { Mean } \\
\text { Rating }\end{array}$ & Rank \\
\hline 8.86 & 1 & 8.49 & 1 & $\begin{array}{l}\text { EV range (as appropriate to market } \\
\text { niche/mission) }\end{array}$ & & & & \\
\hline 7.14 & 4 & 7.13 & 4 & 0 to $50 \mathrm{kph}(31 \mathrm{mph})$ acceleration time & 7.38 & 5 & 7.33 & 4 \\
\hline 6.21 & 7 & 6.35 & 8 & $\begin{array}{l}50 \text { to } 100 \mathrm{kph}(62 \mathrm{mph}) \text { acceleration } \\
\text { (i.e., passing power) }\end{array}$ & 7.00 & 6 & 7.27 & 5 \\
\hline 5.35 & 11 & 5.84 & 9 & Top speed & 6.57 & 9 & 6.66 & 9 \\
\hline 7.09 & 5 & 7.03 & 5 & $\begin{array}{l}\text { Maximum uphill grade }(\%) \text { that will allow } \\
\text { sustained speed of } 75 \mathrm{kph}(45 \mathrm{mph})\end{array}$ & 7.49 & 3 & 7.48 & 2 \\
\hline 6.18 & 8 & 6.37 & 7 & Seating capacity & 6.90 & 7 & 6.92 & 7 \\
\hline 5.48 & 9 & 5.81 & 10 & Cargo space & 6.37 & 10 & 6.46 & 11 \\
\hline 5.41 & 10 & 5.67 & 11 & Unladen vehicle weight (including batteries) & 5.82 & 12 & 5.81 & 12 \\
\hline 6.80 & 6 & 6.69 & 6 & Power-to-weight ratio & 6.85 & 8 & 6.84 & 8 \\
\hline 7.63 & 3 & 7.58 & 2 & Recharging time & 6.19 & 11 & 6.54 & 10 \\
\hline \multirow[t]{3}{*}{7.67} & 2 & 7.56 & 3 & Maintenance interval & 7.42 & 4 & 7.45 & 3 \\
\hline & & & & HEV range (on full battery charge and fuel) & 8.96 & 1 & 8.65 & 1 \\
\hline & & & & HEV range on engine alone & 7.55 & 2 & 7.02 & 6 \\
\hline
\end{tabular}

was the most dramatic change between the two stages. The attributes that were ranked second through fifth in the first stage moved a rank down as a consequence of this high rating assigned to the engine-alone range. The rest of the attributes did not change in rank by more than one place. One may speculate that many of the respondents moved in the direction of the idea of a PNGV-type HEV, which relies more on the engine. However, the values assigned to the total and engine-alone ranges in the second part of this question do not indicate too large a shift of opinion. By elevating the engine-alone range from sixth to second, the respondents seem to have valued dependable total range capability much more. They may have lowered their expectations of breakthroughs in batteries and charger technologies.

Figures 6.1 and 6.2 show the percent change in mean values of EV and HEV attributes from the first stage. Each value in the figures is computed as second-stage value as a percent of the firststage value minus 100 . Generally, the second-stage vehicle attribute values were pessimistic compared to the first stage. The respondents seem to have moderated their opinions about future technical and economic improvements in EVs and HEVs.

The mean values of $5 \mathrm{EV}$ attributes, ranked as the top five, changed by more than $20 \%$. Range, recharging time, $0-50 \mathrm{kph}$ acceleration time, and maximum uphill grade showed more 


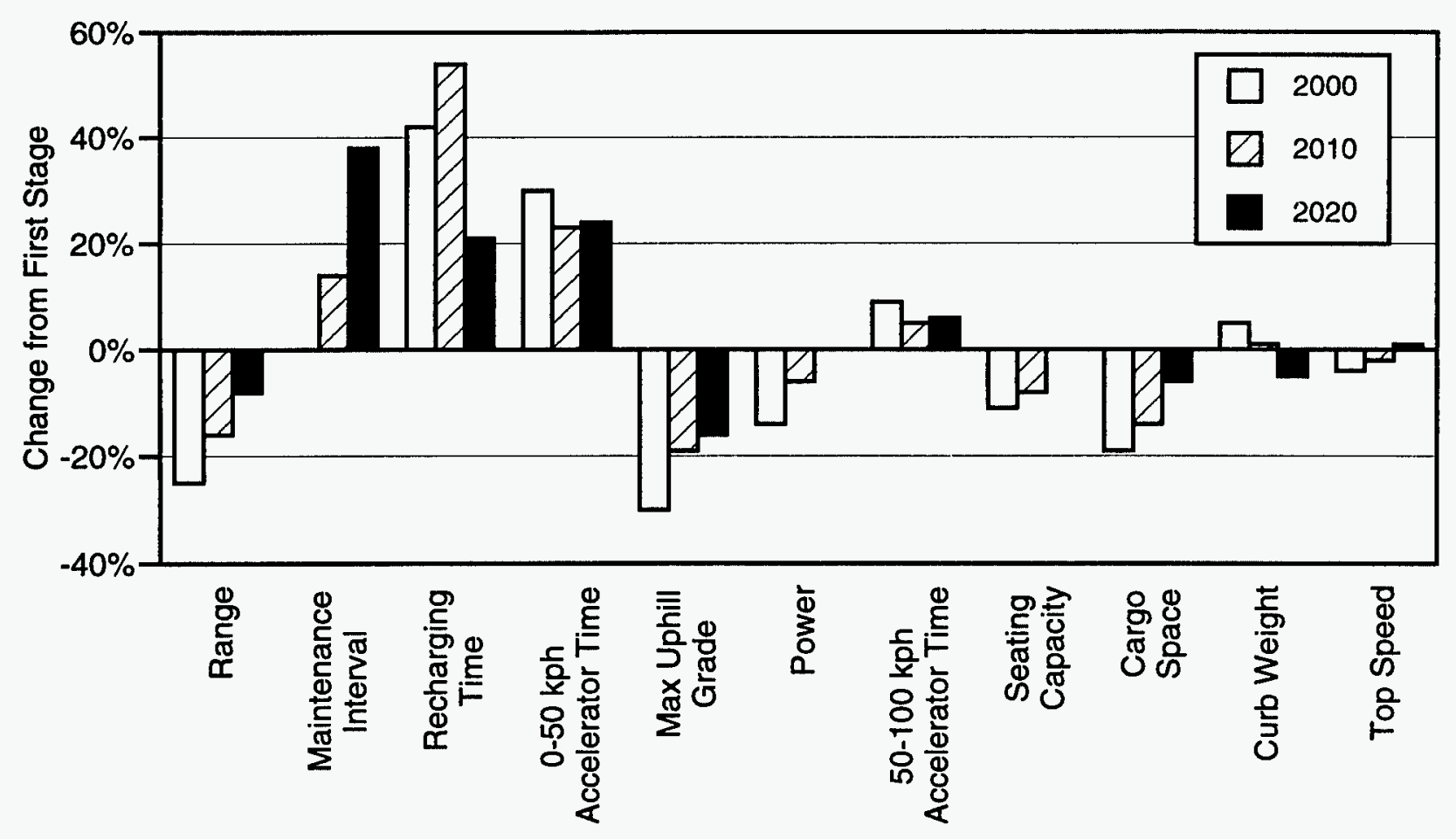

FIGURE 6.1 Change in Mean Values of EV Attributes Relative to the First Stage

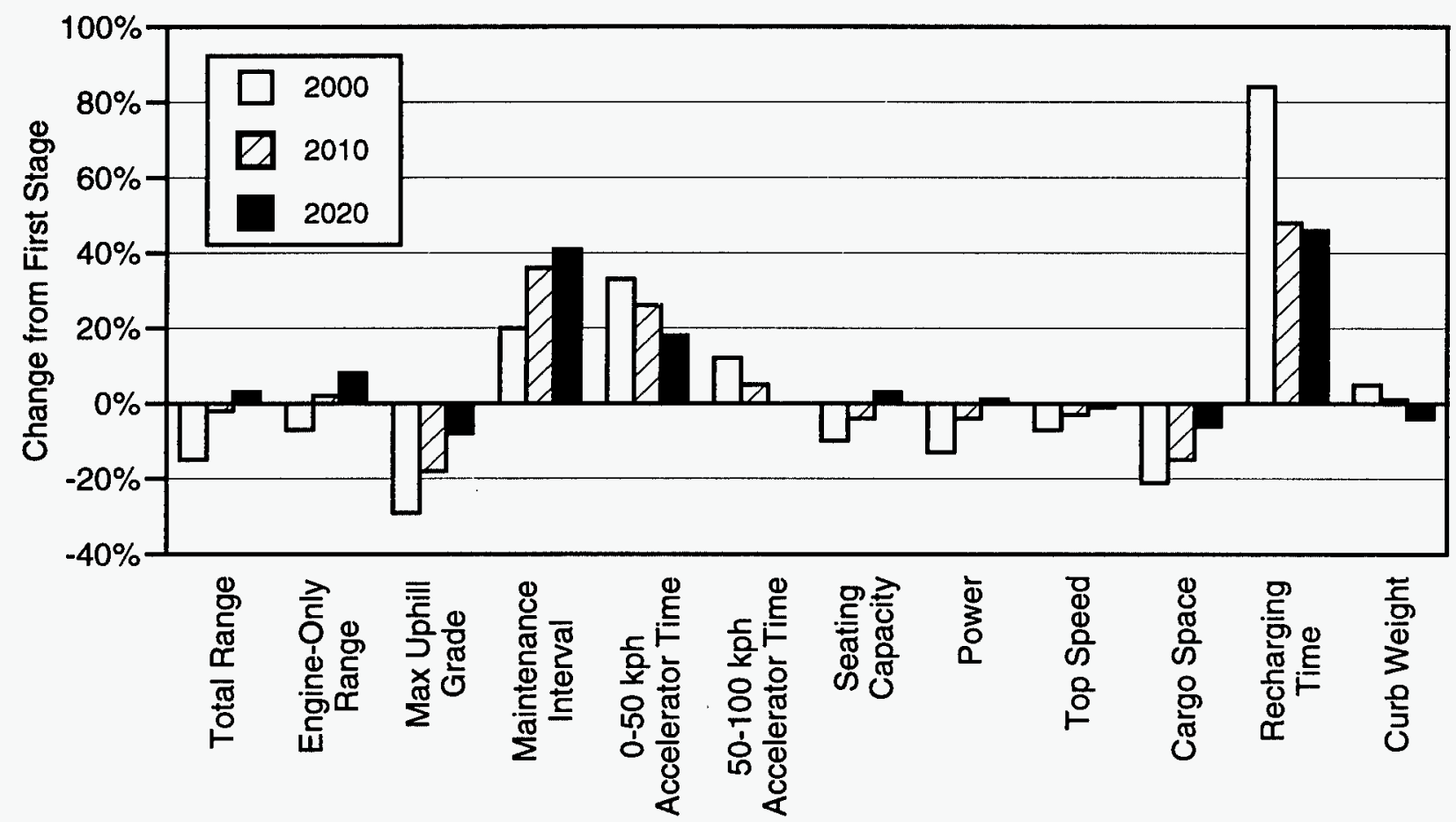

FIGURE 6.2 Change in Mean Values of HEV Attributes Relative to the First Stage 
pessimistic values, while maintenance interval improved. The recharging time changed the most, with its mean values for the three forecast years increasing by 42,54 , and $21 \%$, respectively. The mean value of $0-50 \mathrm{kph}$ acceleration time increased by 30,23 , and $24 \%$, respectively, for the three years. The range showed a $25 \%$ decline in $2000,16 \%$ in 2010 , and $8 \%$ in 2020 . The maximum uphill grade capability was lowered by $30 \%$ in $2000,19 \%$ in 2010 , and $16 \%$ in 2020 . However, the maintenance interval increased by $14 \%$ in 2010 and $38 \%$ in 2020 .

The mean values of second-stage HEV attributes were also more pessimistic than in the first stage. Here, too, five attributes changed by more than $20 \%$; however, only three of these five were ranked among the top five in overall importance. The other two were ranked at the bottom, as tenth and eleventh. Recharge time, ranked eleventh, increased by 83,48 , and $46 \%$ for the three forecast years. The mean values for $0-50 \mathrm{kph}$ acceleration time increased by 33,26 , and $18 \%$, respectively, for the three forecast years. The mean value of uphill grade capability was lower by $29 \%$ in 2000 , $18 \%$ in 2010 , and $8 \%$ in 2020 . The mean cargo space, ranked tenth, decreased by $21 \%$ in $2000,15 \%$ in 2010 , and $6 \%$ in 2020 . As in the case of EVs, maintenance interval showed improvements. Its mean value showed the highest change among the top five attributes, increasing by $20 \%$ in 2000 , $36 \%$ in 2010 , and $41 \%$ in 2020 . The total range and engine range, the top two attributes, differed only by a few percentage points between the two stages. The total range was $15 \%$ lower in $2000,2 \%$ lower in 2010 , and $3 \%$ higher in 2020 . The engine-alone range was $7 \%$ lower in $2000,2 \%$ higher in 2010 , and $8 \%$ higher in 2020.

\section{Amenities}

Responses to the question concerning the importance of amenities in EVs and HEVs had identical ranking for both stages. The mean rating for compartment heating and window defrost (to comfort level in 5 minutes) was higher (by 11\%) in the second stage, while mean ratings for both the power auxiliaries and audio entertainment were lower (by 16 and 12\%, respectively) in the second stage.

\section{R\&D Needs}

The three areas of R\&D needs, battery and energy storage technologies, vehicular technology, and component technology, were ranked in the same order in both the stages. Even though the R\&D needs for the battery/energy storage, vehicular, and component technologies had the same ranking for the two stages, the battery/energy storage technology mean rating became more significant at 2.85 out of 3 (increasing by $11 \%$ from the first stage). The rating for vehicular technology dropped by $21 \%$ and that for component technology dropped by $5 \%$. The experts seem to suggest that $R \& D$ for battery/energy storage technology should increase relative to that for vehicle technology. 


\section{Opinions on Hybrids}

When asked to agree or disagree with 11 statements about HEVs, the respondents in both stages gave nearly identical answers. Almost all (98\%), in both stages, believed that HEV performance can be improved. Only $8 \%$ of the second-stage respondents felt that HEVs will never be a viable alternative, compared to $14 \%$ of the first-stage respondents. A greater share of respondents in the second stage $(83 \%)$ than the first stage $(72 \%)$ agreed that HEVs will be commercialized as a viable alternative to conventional vehicles in the long term.

\subsection{COST COMPARISON}

\section{Vehicle Purchase Price}

The mean purchase price ratios for four of the five vehicle technologies differed by only a few percent between the two stages. The only exception was the fuel-cell HEV, where the mean cost ratios for the three forecast years were higher by 13,26 , and $26 \%$, respectively, for the three years in the second stage. The mean cost ratios for the conventional vehicle declined by $9 \%$ in 2000 and by $6 \%$ each in 2010 and 2020 . The mean cost ratios for EVs and gas-turbine HEVs showed identical patterns of increases in the second stage. The ratio for EVs increased by $1 \%$ in 2000 and $9 \%$ in both 2010 and 2020 , while the ratio for gas-turbine HEVs increased by $2 \%$ in 2000 and $8 \%$ in both 2010 and 2020 . The mean cost ratios for hybrids with the conventional ICE also increased, by $5 \%$ in $2000,12 \%$ in 2010 , and $8 \%$ in 2020 .

\section{Fuel and Maintenance Costs}

The fuel and maintenance $(F \& M)$ cost ratios were significantly different between the two stages. The second-stage F\&M cost ratios were lower for the conventional vehicles but higher for all other vehicle technologies. The mean F\&M cost ratio for fuel-cell HEVs was $36 \%$ higher in 2000 , $21 \%$ higher in 2010 , and $36 \%$ higher in 2020 . The mean F\&M cost ratios for the gas-turbine hybrids increased by $20 \%$ in $2000,15 \%$ in 2010 , and $16 \%$ in 2020. 


\subsection{MARKET PENETRATION COMPARISON}

\section{Obstacles to Commercialization}

The respondents were asked to rank six potential obstacles to EV and HEV commercialization. The six obstacles were ranked in the same order in both the stages. The top two obstacles, too low sales volume for economical production and cost and complexities in manufacturing of battery and drive-train, were assigned greater importance (11\% higher) in the second stage.

\section{Market Penetration}

The second-stage market penetration forecasts for the CV were slightly (2-8\%) higher than the first stage. Because the CV market share (of new vehicles) was already high (72-96\%) in the first stage, the small increases had substantial effects on EV and HEV market shares. The mean market share for EVs dropped by $32 \%$ in $2000,22 \%$ in 2010 , and $19 \%$ in 2020 . The absolute market share for EVs ranged from $1.3 \%$ in 2000 to $7.5 \%$ in 2020 , compared to $1.9 \%$ to $9.2 \%$ in the first stage. The most popular version of the hybrids, ICE HEV, was also assigned lower market shares in 2000 (19\% lower) and 2010 (22\% lower), but its 2020 market share remained unchanged. Two hybrid technologies, gas turbine and fuel cell, were assigned less than $1 \%$ market shares through 2010 in the second stage, compared to greater than $1 \%$ market shares by 2010 in the first stage. Their year 2020 market shares were $3 \%$ each in the second stage, compared to $4 \%$ for the gas turbine and $5 \%$ for the fuel cell in the first stage.

\subsection{COMPONENTS COMPARISON}

\section{Battery Characteristics}

The respondents projected future values of five performance characteristics for 10 battery types. The five characteristics were specific energy, specific power, shelf life, cycle life, and initial cost. The ten battery types were lead-acid, lithium-iron disulfide, lithium-polymer, nickel-cadmium, nickel-iron, nickel-metal hydride, nickel-zinc, sodium-sulfur, zinc-air, and zinc-bromide.

The mean values of specific energy did not change much between the two stages, except for a few. The year 2000 specific energy for the lithium-polymer battery was $17 \%$ lower in the second stage, but its mean specific energy for 2010 and 2020 did not change much. The 
sodium-sulfur and zinc-air batteries showed $10 \%$ declines in the year 2020 mean specific energy. The mean values for all other batteries deviated by $5 \%$ or less.

The mean estimates of specific power showed only a few differences between the two stages. The year 2020 specific power for the lithium-iron disulfide battery was $18 \%$ higher in the second stage, while the values for the years 2000 and 2010 were within $6 \%$ of the first stage. The mean specific power for lead-acid was higher in the second stage by 11,9 , and $6 \%$, respectively, for the three forecast years. Lithium-polymer showed an 11\% decline for both 2010 and 2020, while zinc-bromide showed the same (11\%) decline in 2020. Both zinc-air and zinc-bromide showed a $9 \%$ decline in the year 2010. All other second-stage responses were within a few percent of the first stage.

The zinc-air battery had the highest increases in shelf life estimates, about $22 \%$, for all survey years. The mean shelf life of the lithium-polymer battery showed increases of $15 \%$ and $11 \%$ for the years 2010 and 2020, respectively. The mean shelf life of nickel-iron declined by $9 \%$ in 2000 , $13 \%$ in 2010 , and $11 \%$ in 2020 . The zinc-bromide battery showed an $11 \%$ decline in mean shelf life in 2010 and a $10 \%$ decline in 2020 . The lead-acid battery showed an $11 \%$ decline in 2020 , and lithium-iron disulfide showed a $13 \%$ decline in 2000 .

The mean cycle life estimates were consistently lower in the second stage, except for the zinc-air battery. The zinc-air battery showed moderate increases of 13,5 , and $7 \%$ for the three forecast years. The sodium-sulfur battery showed declines of 14,17 , and $28 \%$, and lithium-iron disulfide showed declines of 18,29 , and $12 \%$ for the three years. The mean cycle life for the nickeliron battery declined $13 \%$ in 2010 and $11 \%$ in 2020 , while that for the nickel-metal hydride battery declined $12 \%$ in 2010 and $14 \%$ in 2020 . The mean cycle life for the lead-acid battery declined $9 \%$ in $2000,13 \%$ in 2010 , and $9 \%$ in 2020 ; that for lithium-polymer declined $5 \%$ in $2000,8 \%$ in 2010 , and $14 \%$ in 2020; and that for zinc-bromide declined $11 \%$ in $2000,8 \%$ in 2010 , and $9 \%$ in 2020.

Thus, overall, the technical performance predictions for batteries worsened in the second round, but the cost predictions improved.

The mean initial costs were lower for all batteries except for lithium-iron disulfide, which showed an $8 \%$ increase in 2010 and a $10 \%$ increase in 2020 . The mean cost for the lithium-polymer battery declined by $24 \%$ in the year 2000 , while showing practically no change for the other two years. The mean initial cost for the zinc-air battery declined by $11 \%$ in $2000,8 \%$ in 2010 , and $10 \%$ in 2020 ; that for the nickel-zinc battery declined by $7 \%$ in $2000,11 \%$ in 2010 , and $10 \%$ in 2020; that for the zinc-bromide battery declined by $10 \%$ in $2000,5 \%$ in 2010 , and $8 \%$ in 2020 ; and that for the sodium-sulfur battery declined by $9 \%$ in $2000,7 \%$ in 2010 , and $5 \%$ in 2020 . 


\section{Electric Motors}

The technological maturity and motor/battery system match rankings of three motors, direct current, ac induction, and dc brushless, were nearly identical for the two stages. The only exception was in 2000 , where the dc brushless motor was ranked the lowest among the three motors in the second stage, while that ranking was assigned to the dc motor in the first stage. The ac induction motor remained the top-ranked motor for all three years in both the stages. The mean value of the ranking was higher for the ac induction motor and lower for the dc brushless motor in the second stage.

The mean cost ratios to the $1993 \mathrm{dc}$ motor put the costs for the three motors in the same order in both stages. The dc motor had the lowest ratios in 2000 and 2010, followed by the ac induction motor. The highest cost ratios were assigned to the dc brushless motor in both the stages for all the survey years. The ac induction motor had the lowest year 2020 cost ratios, but barely $2 \%$ lower than the dc motor in the second stage vs. $8 \%$ lower in the first stage. The mean cost ratio for the dc brushless motor was higher by $17 \%$ in the year 2000 and $12 \%$ in the year 2010 in the second stage. The mean cost ratio for the ac induction motor was higher by $13 \%$ in 2000 and $9 \%$ in 2010 . The year 2020 estimates for the three motors changed only by a few percentage points. The increases in ac induction motor and dc brushless motor cost ratios for the years 2000 and 2010 indicate that the experts view these motor technologies as expensive for adaptation to EV/HEV use during the next two decades. They do not anticipate any cost breakthroughs.

\section{Materials}

Six potential advanced materials for use in EVs and HEVs were assigned ratings by the respondents. These materials were evaluated for six attributes: environmental benefit, corrosion resistance, crash worthiness, reliability, durability, and cost-effectiveness. The six materials were composites, powder metal, plastics, ceramics, aluminum, and high-strength steel. On the basis of a combined rating (i.e., sum of all ratings), the six materials were rated in the same order in both the stages. For environmental benefits, high-strength steel was rated the highest, followed by aluminum, in the second stage, while aluminum was rated ahead of high-strength steel in the first stage. Composites were rated the lowest in both stages, with powder metal the fifth in the second stage, while plastics were rated fifth in the first stage. For corrosion resistance, plastics were rated the highest, followed by composites, in the second stage, while ceramics were assigned the highest rating, followed by plastics, in the first stage. Steel ranked the lowest and powder metal fifth in both stages. For crashworthiness, steel rated the highest in both stages. Aluminum rated second in the second stage, while composites rated second in the first stage. Ceramics and powder metal were ranked the lowest and the fifth in both stages. The reliability ratings were the same for both stages. For durability, steel was ranked the highest in both stages. The second rank was given to aluminum in the second stage and to composites in the first stage. Powder metal rated the lowest, with ceramics 
the fifth, in the second stage, while ceramics were rated the lowest, with powder metal the fifth, in the first stage. There were no changes in the ratings for cost-effectiveness between the two stages.

\section{HEV Power Units}

Five types of power units were ranked for technological maturity, suitability and safety, and cost-effectiveness. The technological rankings had the same order for the two stages, but the mean values for gas turbine and fuel cell were much lower in the second stage. The suitability and safety rankings were in the same order for years 2000 and 2020 between the two stages. In 2010, the 2 -stroke (SI) engine was ranked fourth (behind the gas turbine) in the second stage, while it was ranked third (ahead of the gas turbine) in the first stage. For cost-effectiveness, the diesel engine and 2-stroke (SI) engine switched places between the two stages. The diesel engine was ranked second (ahead of the 2-stroke engine) in the second stage, while the 2-stroke engine was ranked second in the first stage.

\section{Other Concepts}

The five advanced concepts were ranked nearly in the same order in both stages. The only exception was the year 2020 rank switch between very-light, high-tensile-strength material and extended life batteries. The extended life batteries were ranked third in the second stage and second in the first stage. The mean values changed, particularly for the ultracapacitors and solar conversion devices, showing pessimism on the part of the respondents for these two concepts.

\subsection{SYSTEM IMPACTS COMPARISON}

\section{Air Pollution, Global Warming, and Nuclear Energy}

The respondents were asked a total of 19 questions grouped into three sections: air pollution, global warming, and nuclear energy. The rankings for these questions were identical within each section for both the stages.

In reply to the questions concerning air pollution, a greater share of respondents in the second stage (93\% vs. $82 \%$ ) agreed that EVs will help reduce urban ozone levels. A greater majority in the second stage (92\% vs. $77 \%$ ) agreed that most EV charging will use overnight base load capacity, resulting in fewer daytime power-plant emissions. Similarly, a greater majority in the second stage (89\% vs. $77 \%$ ) agreed that EVs will be environmentally beneficial due to their displacement of emissions from urban areas to remote power plants and from daytime to nighttime. 
On global warming, a larger share of the respondents in the second stage (84\% vs. $74 \%$ ) agreed that the complexity of global warming as a scientific issue requires that many more studies must be undertaken before key policy decisions are made. Also, a larger share of respondents in the second stage $(81 \%$ vs. $72 \%)$ agreed that mitigation of global warming potential could have significant socioeconomic benefits.

The six possible causes for the difference in the United States' position on nuclear power compared to that of Europe and Asia were ranked in the same order in both the stages. A 13\% increase in the mean ranking was given to the top cause, negative public opinion due to accidents or near-accidents in the United States, in the second stage. A 9\% higher mean ranking was assigned to the third ranking cause, relative abundance of coal in the United States, in the second stage.

\section{Market Success Factors}

The questions pertaining to market success factors had nearly identical rankings for the two stages. However, there were some changes. The statement "acquisition and ownership costs must be reduced" was ranked the highest in the second stage, and second in the first stage. The statement "EVs/HEVs must be as reliable as gasoline vehicles" was ranked second in the second stage vs. first in the first stage. The second-stage respondents ranked the statement "public policy must sufficiently incorporate environmental imperative" higher than the first stage ( 8 vs. 9), while the second-stage respondents ranked the statement "commitment by original equipment manufacturers must be greater" one notch lower than in the first stage (9 vs. 8). 


\section{CONCLUSIONS}

We have presented a summary of a Delphi study on the anticipated state of electric and hybrid electric vehicles through 2020 . The study provides some insights into experts' judgment on key issues and also provides some valuable data. We have used the data in conducting some cost and market penetration analyses. The following conclusions can be reached from the study:

1. Delphi respondents seemed to assume stable economic conditions, with relatively small increases in energy prices. They projected moderate improvements in vehicle technologies. They did not consider the PNGV's Goal 3 (tripling fuel economy of mid-sized vehicles, consistent with "constant dollar" life-cycle ownership cost that does not exceed the cost of today's mid-sized vehicle).

2. The Energy Policy Act (EPACT) of 1992 goal of substituting 30\% nonpetroleum alternative and replacement fuels by 2010 will not be accomplished by the introduction of electric drive-train vehicles, even if those vehicles use electricity from the grid (nearly completely non-petroleum) to the maximum extent possible. Projections of new-vehicle market share for the EVs and HEVs are far too low to meet the EPACT goal in this manner.

3. Respondents appeared to be convinced that the purpose of introducing EVs and HEVs is to reduce emissions and that most HEVs will be designed to use electricity from the grid.

4. Respondents were optimistic that battery storage technology consistent with most long-term goals of the U.S. Advanced Battery Consortium is possible. They also believed that future HEVs will have considerable all-electric range capability, providing the potential to use electricity rather than petroleumbased fuels for nearly all urban driving.

5. Respondents anticipated that, throughout the study period, petroleum-based fuels (gasoline, diesel, kerosene, and jet fuel) will be the dominant fuels for HEVs when powered by their power units. However, depending upon assumptions external to the study, the results can be interpreted to imply that a very large amount of petroleum fuels could be displaced by electric power used by EVs and HEVs.

6. The second stage of the study followed the first stage by almost a year; in the meantime, the respondents had become slightly pessimistic on the prospects 
of both EVs and HEVs. On a question-by-question basis, the differences were mostly minor.

7. The industry experts as a group did not have opinions distinctly different from the total group of respondents.

8. Battery costs and technology would need much further improvement in order to make EVs and HEVs widely acceptable. Our battery cost analysis showed that with the battery replacement costs added to the fuel and maintenance costs, the conventional ICE vehicle would have a clear cost advantage over electric-drive vehicles through the year 2020.

9. Respondents projected EVs and HEVs to have nearly a $23 \%$ share of the new-vehicle market by 2020 . The year-by-year market penetration profile emerging from the responses followed the classical technology substitution pattern used by marketing professionals. A mathematical formulation used to fit this pattern showed that EVs and HEVs could capture a $50 \%$ share of the new-vehicle market in 2030.

10. When the Delphi study vehicle characteristics were used with a "revealed preference" vehicle choice model, the model predicted much smaller market shares for EVs and HEVs. A "stated preference" vehicle choice model predicted market shares very similar to the mean of the Delphi study responses. 


\section{REFERENCES}

AAMA (1995), Motor Vehicle Facts \& Figures, American Automobile Manufacturers Association, Detroit, Mich.

AAMA (1996), Motor Vehicle Facts \& Figures '95, American Automobile Manufacturers Association, Detroit, Mich.

Automotive News (1982), 1982 Market Data Book Issue, Detroit, Mich.

Blackman, A.W. (1974), The Market Dynamics of Technological Substitutions, Technological Forecasting and Social Change, Vol. 6, pp. 41-63.

Bunch, D.S., et al. (1993), Demand for Clean-Fuel Personal Vehicles in California: A DiscreteChoice Stated Preference Study, Transportation Research, 27A: 237-253.

Consumer Reports (1995), Mid-Priced Sedans, Vol. 60, No. 1, pp. 20-26, Jan.

Cuenca, R.M., and L.L. Gaines (1996), Estimates of Electric Vehicle Production Cost, Argonne National Laboratory, Argonne, Ill., unpublished information.

Davis, S.C. (1995), Transportation Energy Data Book: Edition 15, Oak Ridge National Laboratory Report ORNL-6856, Oak Ridge, Tenn.

Delbecq, A.L., A.H. Van de Ven, and D.H. Gustafson (1975), Group Techniques for Program Planning, A Guide to Nominal Group and Delphi Processes, Scott, Foresman and Co., Glenview, Ill.

DeLuchi, M.A. (1991), Emissions of Greenhouse Gases from the Use of Transportation Fuels and Electricity, Argonne National Laboratory Report ANL/ESD/TM-22, Argonne, Ill.

EIA (1996), Annual Energy Outlook 1996, U.S. Department of Energy, Energy Information Administration Report DOE/EIA-0383(96), Washington, D.C.

EPA (1994), Users Guide to MOBILE5 (Mobile Source Emission Factor Model), Office of Mobile Sources, U.S. Environmental Protection Agency, Ann Arbor, Mich.

Fulton, L.M. (1994), Alternative-Fuel Vehicles and the Energy Policy Act: A Case Study in Technology Policy, University of Pennsylvania, Philadelphia, Pa. 
Heavenrich, R.M., and K.H. Hellman (1996), Light-Duty Automotive Technology and Fuel Economy Trends through 1996, U.S. Environmental Protection Agency Report EPA/AA/TDSG/96-01, Ann Arbor, Mich.

Helmer, O. (1967), Analysis of the Future: The Delphi Method, Rand Corporation, Santa Monica, Calif.

Kalhammer, F.R, A. Kozawa, C.B. Moyer, and B.B. Owens (1995), Performance and Availability of Batteries for Electric Vehicles: A Report of the Battery Technical Advisory Panel, California Air Resources Board, El Monte, Calif.

Mansfield, E. (1961), Technical Change and the Rate of Imitation, Econometrica, Vol. 29, pp. 741765 .

Marr, W.W. (1994), Estimates of Energy Consumption of Electric and Conventional Vehicles, Argonne National Laboratory, Argonne, Ill., unpublished information.

McCormick, J. (1996), The Battle between Lithium-Ion and Zinc-Air Batteries Has Begun, Government Computer News/State \& Local, Silver Springs, Md.

McGraw-Hill (1993), SHAZAM Econometrics Computer Program: User's Reference Manual, Version 7.0.

Mintz, M.M., M.M. Tompkins, and J. Camp (1994), The IMPACTT Model: Structure and Technical Description, Argonne National Laboratory Report ANL/ESD/TM-93, Argonne, Ill.

Ng, H.K., J.L. Anderson, and D.J. Santini (1995), The Prospects for Electric/Hybrid Vehicles, 20002020: First-Stage Results of a Two-Stage Delphi Study, in Electric and Hybrid Vehicles Implementation of Technology, SAE International Report SP-1105, pp 123-135, Warrendale, Pa.

Ng, H.K., J.L. Anderson, and D.J. Santini (1996a), Electric and Hybrid Vehicles: A 25-Year Forecast, Automotive Engineering, 104:2, pp. 66-70, Warrendale, Pa.

Ng, H.K., J.L. Anderson, D.J. Santini, and A.D. Vyas (1996b), Prospects for Electric and Hybrid Electric Vehicles: Second-Stage Results of a Two-Stage Delphi Study, in Technical Solutions to Alternative Transportation Problems, SAE International Report SP-1189, pp. 111-130, Warrendale, $\mathrm{Pa}$.

NPTS (1991), 1990 Nationwide Personal Transportation Survey: User's Guide for the Public Use Tapes, Federal Highway Administration, U.S. Department of Transportation, Washington, D.C. 
NRC (1994), Review of the Research Program of the Partnership for a New Generation of Vehicles, National Research Council, published by National Academy Press, Washington, D.C.

OTA (1991), Improving Automobile Fuel Economy: New Standards, New Approaches, Office of Technology Assessment, U.S. Congress Report OTA-E-504, Washington, D.C.

OTT (1996), Program Analysis Methodology for the Office of Transportation Technologies, U.S. Department of Energy, Office of Transportation Technologies, Washington, D.C.

Paul, R.A. (1979), The Impact of Future Diesel Emissions on the Air Quality of Large Cities, U.S. Environmental Protection Agency Report EPA-450/5-79-005, Research Triangle Park, N.C.

Pyke, D., and H. North (1969), Technological Forecasting to Aid Research and Development Planning, Research Management, XII, 4.

Ross, M., R. Goodwin, R. Watkins, M.Q. Wang, and T. Wenzel (1995), Real-World Emissions from Model Year 1993, 2000, and 2010 Passenger Cars, American Council for an Energy Efficient Economy, Washington, D.C.

Santini, D.J. (1989), Interactions among Transportation Fuel Substitution, Vehicle Quantity Growth, and National Economic Growth, Transportation Research Part A, Vol. 23, No. 3, pp. 183-207.

Siegel, W., and C. Mendler (1996), The Technological Opportunities of Hybrid Electric Vehicles, Symposium for the Promotion of Low Emissions Vehicles, Tokyo, Japan.

Sperling, D. (1995), Future Drive, Electric Vehicles and Sustainable Transportation, Island Press, Washington, D.C.

Stodolsky, F., A. Vyas, and R. Cuenca (1995), Lightweight Materials in the Light-Duty Passenger Vehicle Market: Their Market Penetration Potential and Impacts, Proc. Second World Car Conference, University of California at Riverside, Riverside, Calif.

Teotia, A.P.S., and P.S. Raju (1986), Forecasting the Market Penetration of New Technologies Using a Combination of Economic Cost and Diffusion Models, Journal of Product Innovation and Management, Vol. 4, pp. 225-237.

Vyas, A.D., H.K. Ng, D.J. Santini, and J.L. Anderson (1997), Batteries for Electric Drive Vehicles: Evaluation of Future Characteristics and Costs through a Delphi Study, in State of Alternative Fuel Technologies - 1997, SAE International Report SP-1274, pp. 13-34, Warrendale, Pa. 
Vyas, A.D., M. Mintz, and Y. Gur (1989), Modeling the Size and Composition of the U.S. Personal Vehicle Fleet, Proc. International Association of Science and Technology for Development (IASTED) International Symposium on Applied Simulation and Modeling, pp. 74-78, Santa Barbara, Calif.

Wang, M.Q., et al. (1990), Emissions Impacts of Electric Vehicles, Journal of Air and Waste Management Association, 40-9, pp. 1275-1284, Pittsburgh, Pa.

Wang, M.Q., and D. Santini (1993), Magnitude and Value of Emissions Reductions for Six Driving Cycles in Four U.S. Cities with Varying Air Quality Problems, Transportation Research Record No. 1416, pp. 33-42, Transportation Research Board, Washington, D.C.

Wang, M.Q. (1994), Vehicle Travel Patterns in the Four Studied Areas and Driving Cycle Selection for Simulating EV Energy Consumption and CV Energy Consumption and Emissions, Argonne National Laboratory, Argonne, Ill., unpublished information.

Wang, M.Q., and W.W. Marr (1994), Greenhouse Gas Emission Impacts of Electric Vehicles under Varying Driving Cycles in Various Countries and U.S. Cities, World Resource Review, 6-3, pp. 316-335, Woodridge, Ill.

Wang, M., K. Stork, A. Vyas, M. Mintz, M. Singh, and L. Johnson (1997), Assessment of PNGV Fuels Infrastructure, Phase 1 Report: Additional Capital Needs and Fuel-Cycle Energy and Emissions Impacts, Argonne National Laboratory Report ANL/ESD-TM-140, Argonne, Ill. 
APPENDIX A:

FIRST-STAGE RESULTS AND SECOND-STAGE QUESTIONNAIRE 


\section{Electric/Hybrid \\ Vehicle Study \\ Book One}

First Stage Results and Second Stage Questionnaire

Argonne National Laboratory

Center for Transportation Research 
If you have a specific concept of the likely market(s) for electric vehicles in the U.S. transportation system (for example, commercial fleet vehicle only, commuter car, "city car," rental/lease vehicle only) please indicate what that market or markets will be before proceeding with the questionnaire:

\section{VEHICLES - Basic Characteristics of Electric Passenger Vehicles (EVs)}

(A) Please rate below the importance of these vehicular attributes from 1 (not important) to 10 (most important), based on your assessment of the most likely EV market as entered above, and also identify on the accompanying charts the most realistic specifications and characteristics of EVs for each of the years 2000, 2010, and 2020.

YOUR SECOND STAGE RESPONSE

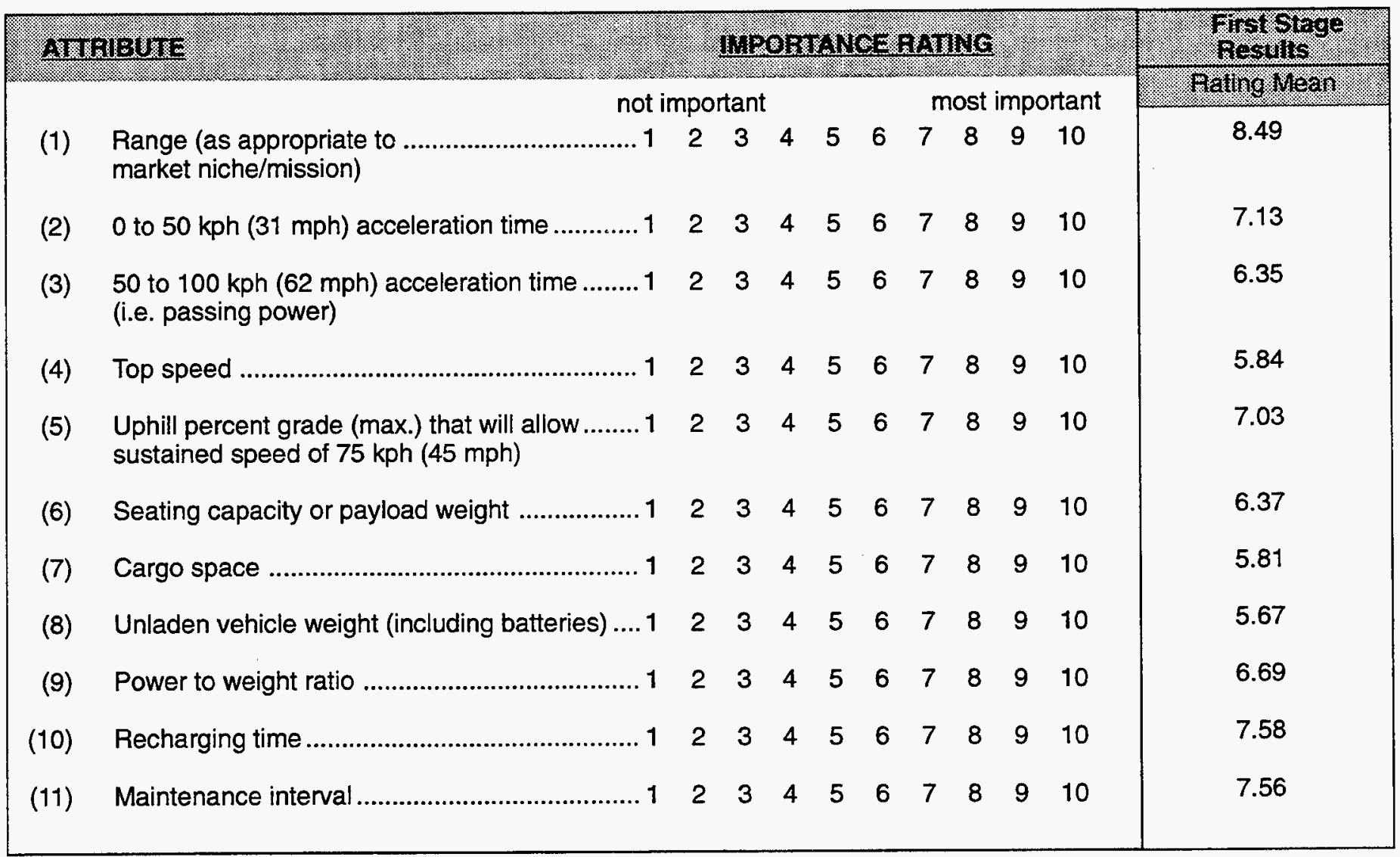


Please mark appropriate box for EVs for each projection year.

YOUR SECOND STAGE RESPONSE

\begin{tabular}{|l|l|l|l|}
\hline & \multicolumn{3}{|c|}{ I. } \\
\hline KM (MI.) & 2000 & 2010 & 2020 \\
\hline $650(404)$ & & & \\
\hline $450(280)$ & & & \\
\hline $350(217)$ & & & \\
\hline $250(155)$ & & & \\
\hline $150(93)$ & & & \\
\hline
\end{tabular}

\begin{tabular}{|c|c|c|c|}
\hline \multicolumn{4}{|c|}{ 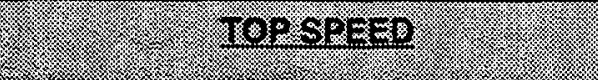 } \\
\hline KPH (MPH) & 2000 & 2010 & 2020 \\
\hline $190(118)$ & & & \\
\hline $150(93)$ & & & \\
\hline $130(81)$ & & & \\
\hline $110(68)$ & & & \\
\hline $90(56)$ & & & \\
\hline
\end{tabular}

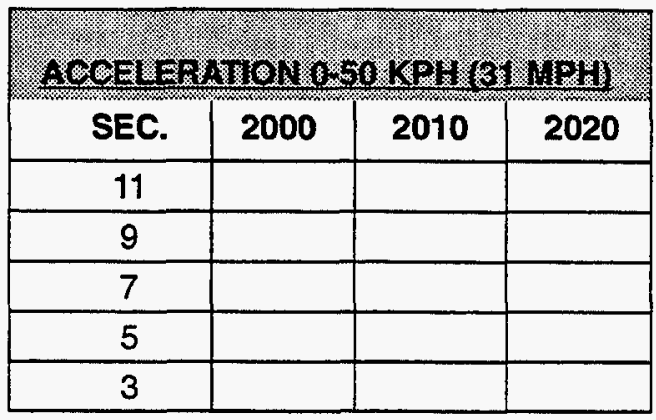

\begin{tabular}{|c|c|c|c|}
\hline \multicolumn{4}{|c|}{ 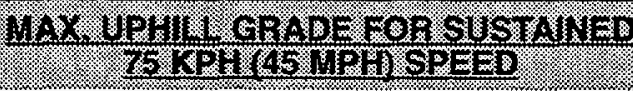 } \\
\hline$\%$ GRADE & 2000 & 2010 & 2020 \\
\hline 11 & & & \\
\hline 7 & & & \\
\hline 5 & & & \\
\hline 3 & & & \\
\hline 1 & & & \\
\hline
\end{tabular}

\begin{tabular}{|c|c|c|c|}
\hline SEC. & 2000 & 2010 & 2020 \\
\hline 14 & & & \\
\hline 12 & & & \\
\hline 10 & & & \\
\hline 8 & & & \\
\hline 6 & & & \\
\hline
\end{tabular}

\begin{tabular}{|c|c|c|c|}
\hline \multicolumn{4}{|c|}{ SEAMUG Daphom } \\
\hline PERSONS & 2000 & 2010 & 2020 \\
\hline 6 & & & \\
\hline 5 & & & \\
\hline 4 & & & \\
\hline 3 & & & \\
\hline 2 & & & \\
\hline
\end{tabular}

If you disagree with the range of values provided along the $y$-axis for any of these characteristics, please supplement or replace them by entering your preferred values in the appropriate cells.

\begin{tabular}{|c|c|c|c|c|}
\hline 8 & \multicolumn{3}{|c|}{ IIIST STHEE RESULTS UE AN } & \\
\hline (1) $Y E A A=$ & 1995 & 2000 & 2010 & 2020 \\
\hline Range, $\mathrm{Km}$ & 170 & 238 & 321 & 388 \\
\hline 0-50 KPH, Sec & 6.89 & 5.69 & 4.71 & 4.21 \\
\hline $50-100 \mathrm{KPH}, \mathrm{Sec}$ & 11.99 & 10.63 & 9.38 & 8.65 \\
\hline Top Speed, KPH & 111 & 122 & 133 & 139 \\
\hline Up Hill, \% & 5.64 & 7.15 & 8.38 & 9.35 \\
\hline Seating, Person & 3.12 & 3.82 & 4.41 & 4.63 \\
\hline
\end{tabular}


Please mark appropriate box for EVs for each projection year.

YOUR SECOND STAGE RESPONSE

\begin{tabular}{|c|c|c|c|}
\hline LITERS (ft3) & 2000 & 2010 & 2020 \\
\hline \multicolumn{4}{|l|}{$600(21)$} \\
\hline \multicolumn{4}{|l|}{$400(14)$} \\
\hline \multicolumn{4}{|l|}{$300(11)$} \\
\hline \multicolumn{4}{|l|}{$200(7)$} \\
\hline $100(4)$ & & & \\
\hline
\end{tabular}

\begin{tabular}{|c|c|c|c|}
\hline MINUTES & 2000 & 2010 & 2020 \\
\hline \multicolumn{4}{|l|}{300} \\
\hline \multicolumn{4}{|l|}{120} \\
\hline \multicolumn{4}{|l|}{30} \\
\hline \multicolumn{4}{|l|}{10} \\
\hline 5 & & & \\
\hline
\end{tabular}

\begin{tabular}{|c|c|c|c|}
\hline \multicolumn{4}{|c|}{ CUra valeur } \\
\hline KG (LB) & 2000 & 2010 & 2020 \\
\hline 1800 (3968) & & & \\
\hline $1400(3086)$ & & & \\
\hline $1200(2646)$ & & & \\
\hline $1000(2205)$ & & & \\
\hline $800(1764)$ & & & \\
\hline
\end{tabular}

\begin{tabular}{|c|c|c|c|}
\hline \multicolumn{4}{|c|}{ 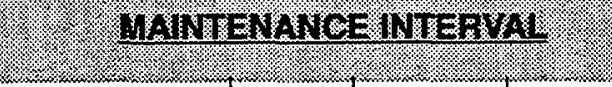 } \\
\hline KM (MI) & 2000 & 2010 & 2020 \\
\hline $75000(46603)$ & & & \\
\hline $50000(31069)$ & & & \\
\hline $30000(18641)$ & & & \\
\hline $15000(9321)$ & & & \\
\hline $5000(3107)$ & & & \\
\hline
\end{tabular}

\begin{tabular}{|c|c|c|c|}
\hline \multicolumn{4}{|c|}{ POWEA RAMU⿴囗十 } \\
\hline kW (hp) & 2000 & 2010 & 2020 \\
\hline $150(201)$ & & & \\
\hline $110(148)$ & & & \\
\hline $90(121)$ & & & \\
\hline $70(94)$ & & & \\
\hline $50(67)$ & & & \\
\hline
\end{tabular}

If you disagree with the range of values provided along the $y$-axis for any of these characteristics, please supplement or replace them by entering your preferred values in the appropriate cells.

\begin{tabular}{|c|c|c|c|c|}
\hline \multicolumn{5}{|c|}{ FIRST STAEE RESULY IS MEAT } \\
\hline$Y=4 \%$ & 1095 & 2000 & 2010 & 2020 \\
\hline Cargo, Liter & 222 & 268 & 337 & 365 \\
\hline Curb Weight, $\mathrm{Kg}$ & 1547 & 1464 & 1344 & 1286 \\
\hline Power, Kw & 66.1 & 77.8 & 91.3 & 99.6 \\
\hline Recharging, Min & 251 & 164 & 92 & 70 \\
\hline Maintenance, $\mathrm{Km}$ & 13970 & 20257 & 29538 & 34593 \\
\hline
\end{tabular}


If you have a specific concept of the likely market(s) for hybrid electric vehicles in the U.S. transportation system (for example, commercial fleet vehicle only, commuter car, "city car", rental/lease vehicle only) please indicate what that market or markets will be before proceeding:

\section{VEHICLES - Basic Characteristics of Hybrid Electric Passenger Vehicles (HEVs)}

(B) Please rate below the importance of these vehicular attributes from 1 (not important) to 10 (most important), based on your assessment of the most likely HEV market(s), and also identify on the accompanying charts the most realistic specifications and characteristics of HEVs (battery plus engine) for each of years 2000, 2010, and 2020.

YOUR SECOND STAGE RESPONSE

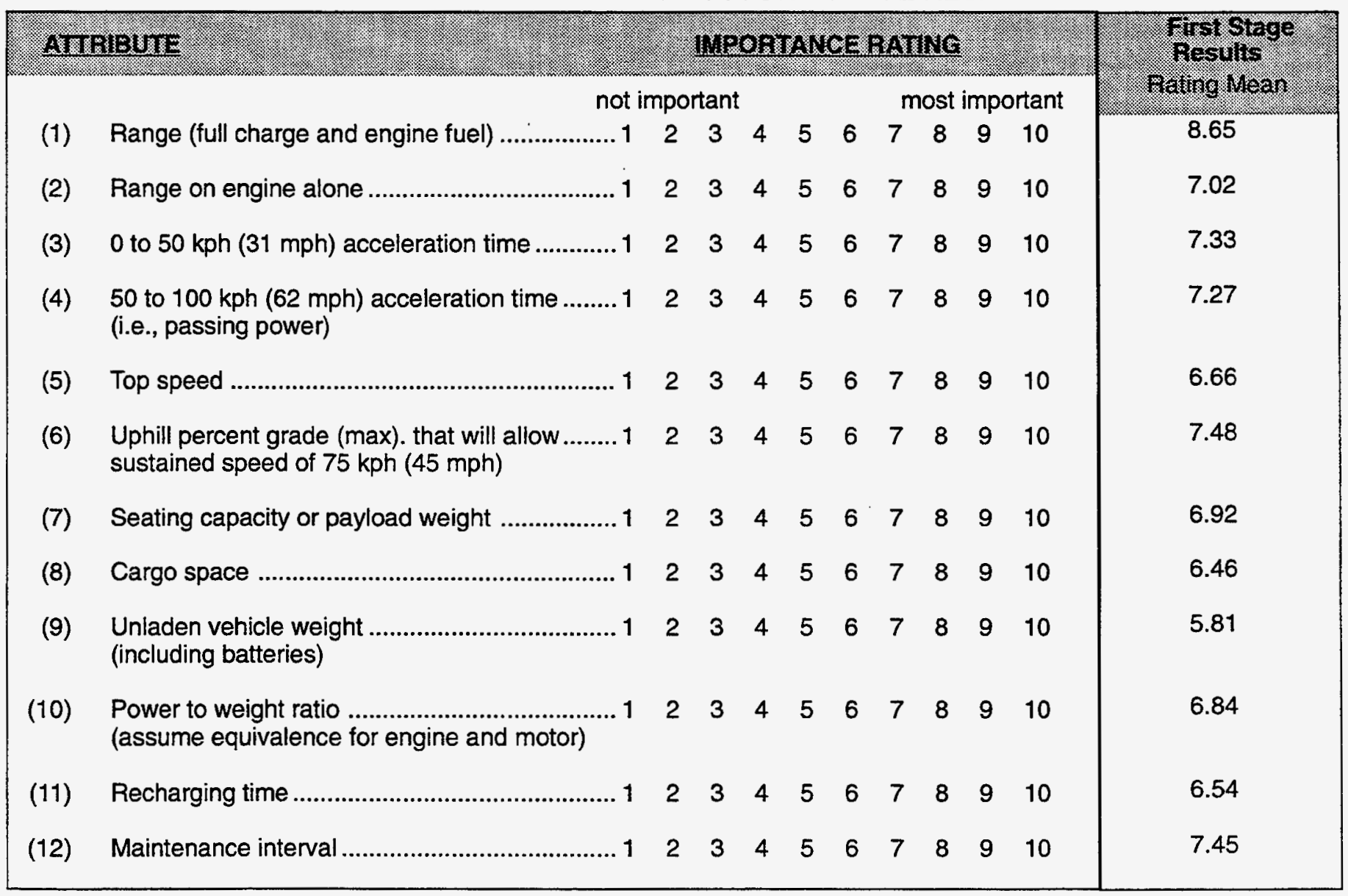


Please mark appropriate box for HEVs for each projection year.

\section{YOUR SECOND STAGE RESPONSE}

\begin{tabular}{|c|c|c|c|}
\hline \multicolumn{4}{|c|}{ sen:me } \\
\hline KM (MI.) & 2000 & 2010 & 2020 \\
\hline $650(404)$ & & & \\
\hline $450(280)$ & & & \\
\hline $350(217)$ & & & \\
\hline $250(155)$ & & & \\
\hline $150(93)$ & & & \\
\hline
\end{tabular}

\begin{tabular}{|c|c|c|c|}
\hline \multicolumn{4}{|c|}{ 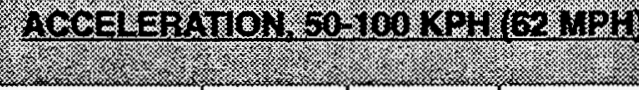 } \\
\hline SEC. & 2000 & 2010 & 2020 \\
\hline 14 & & & \\
\hline 12 & & & \\
\hline 10 & & & \\
\hline 8 & & & \\
\hline 6 & & & \\
\hline
\end{tabular}

\begin{tabular}{l}
\hline \multicolumn{4}{|c|}{ RAMGE OFENGIME AU. BWE } \\
\begin{tabular}{|c|c|c|c|}
\hline KM (MI.) & 2000 & 2010 & 2020 \\
\hline $300(186)$ & & & \\
\hline $200(124)$ & & & \\
\hline $150(93)$ & & & \\
\hline $100(62)$ & & & \\
\hline $50(31)$ & & & \\
\hline
\end{tabular}
\end{tabular}

\begin{tabular}{|c|c|c|c|}
\hline \multicolumn{4}{|c|}{ TOP SPEEED } \\
\hline KPH (MPH) & 2000 & 2010 & 2020 \\
\hline $190(118)$ & & & \\
\hline $150(93)$ & & & \\
\hline $130(81)$ & & & \\
\hline $110(68)$ & & & \\
\hline $90(56)$ & & & \\
\hline
\end{tabular}

\begin{tabular}{|c|c|c|c|}
\hline \multicolumn{4}{|c|}{ 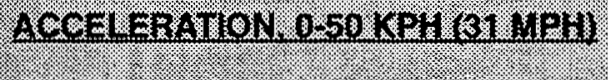 } \\
\hline SEC. & 2000 & 2010 & 2020 \\
\hline 11 & & & \\
\hline 9 & & & \\
\hline 7 & & & \\
\hline 5 & & & \\
\hline 3 & & & \\
\hline
\end{tabular}

\begin{tabular}{|c|c|c|c|}
\hline \multicolumn{4}{|c|}{ 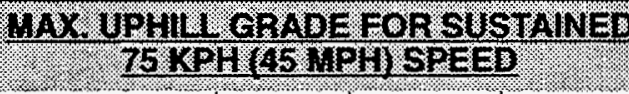 } \\
\hline$\%$ GRADE & 2000 & 2010 & 2020 \\
\hline \multicolumn{4}{|l|}{11} \\
\hline \multicolumn{4}{|l|}{7} \\
\hline \multicolumn{4}{|l|}{5} \\
\hline \multicolumn{4}{|l|}{3} \\
\hline 1 & & & \\
\hline
\end{tabular}

If you disagree with the range of values provided along the $y$-axis for any of these characteristics, please supplement or replace them by entering your preferred values in the appropriate cells.

\begin{tabular}{|c|c|c|c|c|}
\hline & \multicolumn{4}{c|}{ FIRST STAGE RESULTS MEAN } \\
\hline YEAR & 1995 & 2000 & 2010 & 2020 \\
\hline Range, Km & 350 & 415 & 481 & 510 \\
\hline Engine Range, Km & 199 & 230 & 253 & 260 \\
\hline 0-50 KPH, Sec & 6.17 & 5.22 & 4.34 & 4.00 \\
\hline $50-100 \mathrm{KPH}$, Sec & 10.59 & 9.58 & 8.64 & 8.19 \\
\hline Top Speed, KPH & 122 & 134 & 144 & 148 \\
\hline Up Hill, \% & 6.73 & 8.30 & 9.52 & 10.10 \\
\hline
\end{tabular}


Please mark appropriate box for HEVs for each projection year.

\section{YOUR SECOND STAGE RESPONSE}

\begin{tabular}{|c|c|c|c|}
\hline \multicolumn{4}{|c|}{ - s-amac capagna } \\
\hline PERSONS & 2000 & 2010 & 2020 \\
\hline 6 & & & \\
\hline 5 & & & \\
\hline 4 & & & \\
\hline 3 & & & \\
\hline 2 & & & \\
\hline
\end{tabular}

\begin{tabular}{|c|c|c|c|}
\hline kW (hp) & 2000 & 2010 & 2020 \\
\hline $150(201)$ & & & \\
\hline $110(148)$ & & & \\
\hline $90(121)$ & & & \\
\hline $70(94)$ & & & \\
\hline $50(67)$ & & & \\
\hline
\end{tabular}

\begin{tabular}{|c|c|c|c|}
\hline CARGO SRAGE & \\
LITERS (ft3) & 2000 & 2010 & 2020 \\
\hline $600(21)$ & & & \\
\hline $400(14)$ & & & \\
\hline $300(11)$ & & & \\
\hline $200(7)$ & & & \\
\hline $100(4)$ & & & \\
\hline
\end{tabular}

\begin{tabular}{|c|c|c|c|}
\hline \multicolumn{4}{|c|}{ 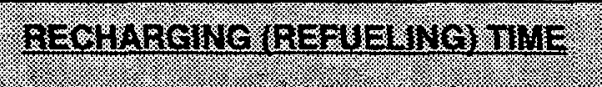 } \\
\hline MINUTES & 2000 & 2010 & 2020 \\
\hline 300 & & & \\
\hline 120 & & & \\
\hline 30 & & & \\
\hline 10 & & & \\
\hline 5 & & & \\
\hline
\end{tabular}

\begin{tabular}{|c|c|c|c|}
\hline \multicolumn{4}{|c|}{ II: } \\
\hline$K G(L B)$ & 2000 & 2010 & 2020 \\
\hline $1800(3968)$ & & & \\
\hline $1400(3086)$ & & & \\
\hline $1200(2646)$ & & & \\
\hline $1000(2205)$ & & & \\
\hline $800(1764)$ & & & \\
\hline
\end{tabular}

\begin{tabular}{|c|c|c|c|}
\hline MAMTIE & Uanc & MER & \\
\hline KM (MI) & 2000 & 2010 & 2020 \\
\hline $75000(46603)$ & & & \\
\hline $50000(31069)$ & & & \\
\hline $30000(18641)$ & & & \\
\hline $15000(9321)$ & & & \\
\hline $5000(3107)$ & & & \\
\hline
\end{tabular}

If you disagree with the range of values provided along the $y$-axis for any of these characteristics, please supplement or replace them by entering your preferred values in the appropriate cells.

\begin{tabular}{|c|c|c|c|c|}
\hline & FRST STAGE RESULTS MEAN & \\
\hline YEAF & 1995 & 2000 & 2010 & 2020 \\
\hline Seating, Person & 3.75 & 4.28 & 4.68 & 4.84 \\
\hline Cargo, Liter & 262 & 310 & 372 & 392 \\
\hline Curb Weight, Kg & 1576 & 1481 & 1374 & 1315 \\
\hline Power, kW & 79 & 92 & 103 & 107 \\
\hline Recharging, Min & 126 & 78 & 42 & 31 \\
\hline Maintenance, KM & 10809 & 14356 & 20933 & 27016 \\
\hline
\end{tabular}




\section{VEHICLES - Amenities}

(C) Cars often do not succeed in the marketplace without additional amenities for occupant comfort and aesthetics. If applied to EVs and HEVs, some of these component amenities may have to be re-designed or even newly-developed. In your view, how important are the following amenities to the eventual success of EVs and HEVs? Please rank from 1 (least important) to 5 (most important).

\begin{tabular}{|c|c|c|}
\hline $\begin{array}{l}\text { Trust Stage: } \\
\text { Mesulks }\end{array}$ & \multirow{2}{*}{\multicolumn{2}{|c|}{$\begin{array}{l}\text { YOUR SECOND STAGE RESPONSE } \\
\text { RANK } \mathbf{1 - 5}\end{array}$}} \\
\hline (2) & & \\
\hline 3.63 & & Air conditioning \\
\hline 4.08 & & Compartment heating and window defrost (to comfort level in 5 minutes) \\
\hline 2.69 & & Power auxiliaries (windows, doors, seats, brakes, steering) \\
\hline 2.80 & & Audio entertainment \\
\hline 3.43 & 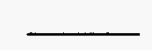 & Premium safety equipment (i.e., air bags, anti-lock brakes) \\
\hline
\end{tabular}

\section{VEHICLES - Research and Development Needs}

(D) Battery (energy density, operating temperature, materials) and energy storage technology (ultracapacitors, flywheels); vehicular technology (body, chassis, steering and suspension); and component technology (motor, drive train, and regenerative or mechanical braking) are the three major concerns in R \& D aimed at commercialization of EVs and HEVs. In your opinion, which areas of concern will require the greatest share of $\mathrm{R} \& \mathrm{D}$ before these vehicles can be successfully marketed? Please rank the three areas from 1 (least important) to 3 (most important).

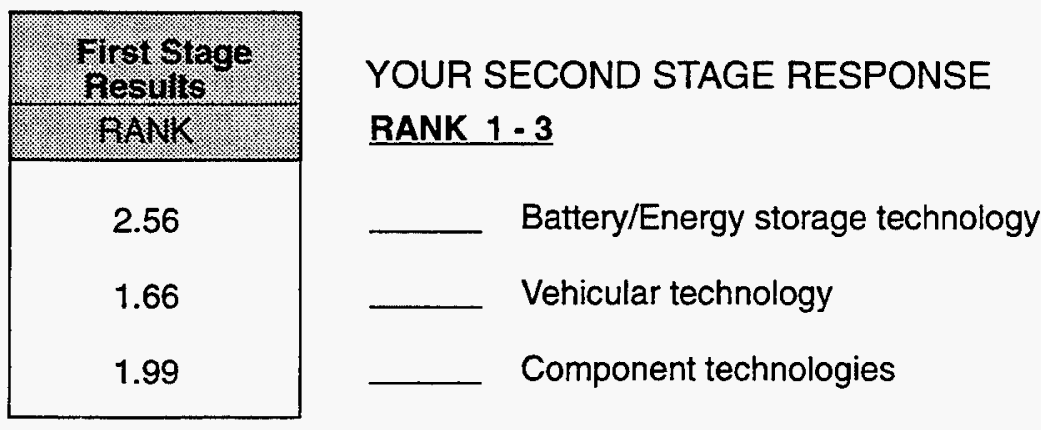




\section{VEHICLES - Hybrids}

(E) Hybrid electric vehicles (HEVs) have been considered an alternative to gasoline passenger vehicles because they may combine the best aspects of internal combustion (IC) engine-powered and battery-powered propulsion. Please indicate with an " $x$ " whether you agree or disagree with the following statements about HEVs. Assume that the IC engine is fueled by either gasoline or a non-petroleum fuel; if your answer would differ based on what the IC engine fuel is, please so indicate.

\section{YOUR SECOND STAGE RESPONSE AGREE DISAGREE}

(1) HEVs will be commercialized as a viable alternative to gasoline vehicles in the intermediate term (2000-2005)

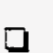

(2) HEVs will be commercialized as a viable alternative to gasoline vehicles in the longer term (2005-2020)

(3) HEVs will never be a viable alternative .

(4) Most components needed by HEVs are market-ready today ............

(5) New R \& D requirements for HEVs are minimal

(6) Operating range of HEVs will be extended by more than $150 \mathrm{~km}$ (93 miles) compared to EVs.

(7) Component manufacturing and servicing infrastructure for HEVs is lacking.

(8) HEVs will cost less than EVs when commercialized

(9) HEVs could meet U.S. Tier Il emissions standards if required for MY2004 and later automobiles

(10) Performance of HEVs can be improved

(11) Hybrid vehicies will not need electricity from the grid

\begin{tabular}{|c|}
\hline 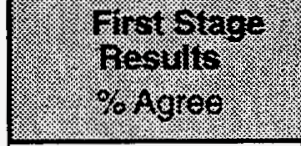 \\
\hline 45 \\
\hline 72 \\
\hline 14 \\
\hline 36 \\
\hline 28 \\
\hline 94 \\
\hline 77 \\
\hline 28 \\
\hline 95 \\
\hline 98 \\
\hline 34 \\
\hline
\end{tabular}




\section{VEHICLES - Cost Ratios}

(F) Using a conventional gasoline-fueled compact 4-door sedan as the baseline [1993 US $\$ 15000$ as index value (1.0)], please provide your estimate of the purchase price ratio for each of the five types of vehicles listed below in each of 3 future years. The cost of the initial battery pack should be included but not the replacement battery cost in your estimate.

\section{YOUR SECOND STAGE RESPONSE \\ YEAR $\quad 2000 \quad 2010 \quad 2020$}

(1) Conventional (piston) engines

(2) Electric

(3) Hybrid with conventional (piston) engine

(4) Hybrid with gas turbine

(5) Hybrid with fuel cell.

Please describe below how you arrived at these values (a list of assumptions about the type and size of battery pack that you assume for vehicles 2-5 would be very helpful)

\begin{tabular}{|c|c|c|c|c|c|}
\hline \multicolumn{6}{|c|}{ FIRST STAGE RESUHTS UEAU } \\
\hline & (1):0. & 1905. & 2000 & 2010 & 2820 \\
\hline (1) & 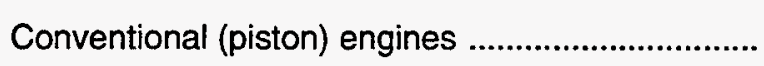 & 1.2 & 1.38 & 1.70 & 2.14 \\
\hline (2) & Electric.. & 2.63 & 2.26 & 2.12 & 2.19 \\
\hline (3) & Hybrid with conventional (piston) engine ............... & 2.80 & 2.35 & 2.18 & 2.36 \\
\hline$(4)$ & Hybrid with gas turbine & 3.52 & 3.20 & 2.81 & 2.83 \\
\hline$(5)$ & 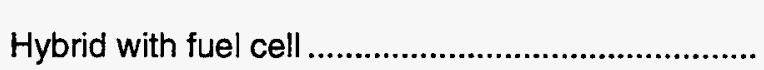 & 5.37 & 4.56 & 3.47 & 3.15 \\
\hline
\end{tabular}




\section{VEHICLES - Fuel and Maintenance Cost Ratios}

(G) Part 1

Using a conventional gasoline-fueled mid-size sedan with fuel and maintenance cost of 1993 US $\$ 0.18 / \mathrm{km}$ (\$0.29/ mile) as the baseline, please provide your estimate of the fuel and maintenance cost ratio for each of the five types of vehicles listed below in each of 3 future years. Do not include replacement cost for the propulsion battery pack in your estimate.

\section{YOUR SECOND STAGE RESPONSE \\ YEAR $2000 \quad 2010 \quad 2020$}

(1) Conventional (piston) engines

(2) Electric

(3) Hybrid with conventional (piston) engine

(4) Hybrid with gas turbine

(5) Hybrid with fuel cell

Please describe below how you arrived at these values

\begin{tabular}{|c|c|c|c|c|c|}
\hline & (2.) & E1950 & Tate & SULT & EAN \\
\hline & YEAR & 1995 & 2000 & 2010 & 2020 \\
\hline$(1)$ & Conventional (piston) engines ................. & 1.1 & 1.27 & 1.56 & 1.97 \\
\hline (2) & Electric... & 1.22 & 1.21 & 1.26 & 1.39 \\
\hline (3) & Hybrid with conventional (piston) engine .. & 1.42 & 1.46 & 1.52 & 1.65 \\
\hline (4) & Hybrid with gas turbine & 1.77 & 1.67 & 1.71 & 1.80 \\
\hline (5) & Hybrid with fuel cell . & 2.18 & 1.95 & 1.87 & 1.73 \\
\hline
\end{tabular}




\section{VEHICLES - Fuel and Maintenance Cost Ratios}

(G) Part 2

Using a conventional gasoline-fueled mid-size sedan with an estimated year 2000 fuel economy of 30 miles/gallon $(12.75 \mathrm{~km} / \mathrm{L})$ as the baseline, please provide your estimate of the fuel economy ratio for each of the 5 types of vehicles listed below for each of the 3 future years.

YEAR $\quad 2000 \quad 2010 \quad 2020$

(1) Conventional (piston) engines

1.0

(2) Electric

(3) Hybrid with conventional (piston) engine

(4) Hybrid with gas turbine

(5) Hybrid with fuel cell

(G) Part 3

Please indicate the type of fuel that you have assumed for the three types of hybrid electric vehicles in each of 3 future years.

\section{YEAR}

2000

2010

2020

(1) Hybrid with conventional (piston) engine

(2) Hybrid with gas turbine

(3) Hybrid with fuel cell 


\section{VEHICLES - Obstacles to Commercialization}

(H) Recent studies have estimated that EVs and HEVs could cost significantly more than their gasoline counterparts. Please rank from 1 (least important) to 6 (most important) the following six issues according to your belief in their potential to be obstacles to EV and HEV commercialization; use cost as the primary criterion.

YOUR SECOND STAGE RESPONSE

EVs HEVs

RANK 1-6 RANK 1-6

Materials scarcity
Cost and complexities in manufacture of battery and drivetrain
needed to produce an attractive vehicle
Sales volume too low for economical production
Inadequate government $R$ \& D support

\section{IITST STAGE RESULTU RUTK WEAT}

EVS 10 UEVS

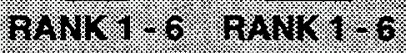

\begin{tabular}{|c|c|c|}
\hline 2.49 & 2.35 & Materials scarcity \\
\hline 4.33 & 4.29 & $\begin{array}{l}\text { Cost and complexities in manufacture of battery and drivetrain } \\
\text { needed to produce an attractive vehicle }\end{array}$ \\
\hline 4.60 & 4.48 & Sales volume too low for economical production \\
\hline 2.92 & 3.12 & Inadequate government $R$ \& D support \\
\hline 3.32 & 3.45 & $\begin{array}{l}\text { Insufficient Corporate Average Fuel Economy (CAFE) credits to } \\
\text { offset costs of } R \& D \text { and vehicles }\end{array}$ \\
\hline 3.60 & 3.53 & $\begin{array}{l}\text { Failure of life cycle costing to include intangible environmental } \\
\text { benefits needed to offset } R \& D \text { and vehicle costs }\end{array}$ \\
\hline
\end{tabular}




\section{VEHICLES - Market Penetration}

(I) Please estimate the market (U.S.) share in percent for each of the six vehicle types listed below in each of three future years. Make sure the shares total to $100 \%$ in each column. Estimate the share of new light duty vehicle (passenger cars and light trucks) sales.

\section{YOUR SECOND STAGE RESPONSE YEAR $20002010 \quad 2020$}

(1) Conventional (piston) engines

(2) Electric

(3) Hybrid with conventional (piston) engine

(4) Hybrid with gas turbine

(5) Hybrid with fuel cell

(6) Other technology not named above (please stipulate)

TOTALS $\quad 100 \% \quad 100 \% \quad 100 \%$

\begin{tabular}{|c|c|c|c|c|c|}
\hline & : : Iflist sty & 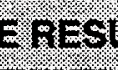 & 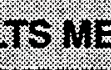 & INOA & 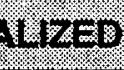 \\
\hline & 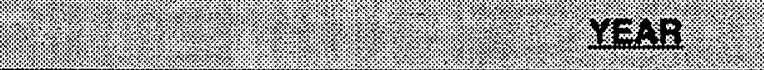 & 1905 & 2001 & 2010 & $20 \%$ \\
\hline (1) & 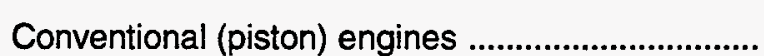 & 99.20 & 95.58 & 85.00 & 72.03 \\
\hline (2) & Electric & .39 & 1.93 & 5.29 & 9.20 \\
\hline (3) & Hybrid with conventional (piston) engine ................ & .16 & 1.40 & 5.24 & 7.89 \\
\hline (4) & Hybrid with gas turbine... & .04 & .50 & 1.90 & 4.18 \\
\hline$(5)$ & Hybrid with fuel cell... & .04 & .19 & 1.40 & 4.73 \\
\hline \multirow[t]{2}{*}{ (6) } & $\begin{array}{l}\text { Other technology not named above } \\
\text { (please stipulate) }\end{array}$ & .17 & .40 & 1.17 & 1.97 \\
\hline & TOTALS & $100 \%$ & $100 \%$ & $100 \%$ & $100 \%$ \\
\hline
\end{tabular}




\section{COMPONENTS - Battery Characteristics}

(A) Battery technology is important to both electric and hybrid electric vehicles (EVs and HEVs). For each of the years 2000,2010 , and 2020 , please estimate achievable characteristics of as many of the ten types of batteries listed in the next page with which you are familiar. Please feel free to ask your colleagues to assist you in responding to this question.

\section{YOUR SECOND STAGE RESPONSE}

Please provide your estimate of battery characteristics using the same units as the current batteries.

\begin{tabular}{|c|c|c|c|c|c|c|c|c|c|c|c|c|c|c|}
\hline 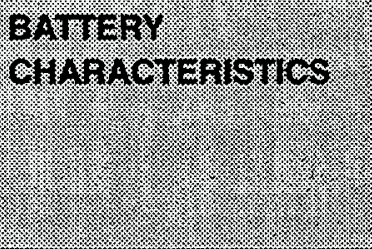 & \multicolumn{3}{|c|}{ Somerici: } & \multicolumn{3}{|c|}{ 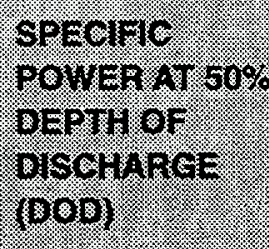 } & \multicolumn{3}{|c|}{$\begin{array}{l}\text { suelf: } \\
\text { lare }\end{array}$} & \multicolumn{3}{|c|}{ 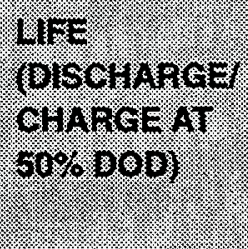 } & \multicolumn{2}{|c|}{ mosm } \\
\hline $\begin{array}{l}\text { Current lead acid } \\
\text { Current nickel cadmium } \\
\text { Current sodium sulfur }\end{array}$ & \multicolumn{3}{|c|}{$30 \mathrm{Wh} / \mathrm{kg}$} & \multicolumn{3}{|l|}{$\begin{array}{l}175 \\
130\end{array}$} & \multicolumn{3}{|c|}{$\begin{array}{l}3 \text { Years } \\
5 \\
4\end{array}$} & \multicolumn{3}{|c|}{$\begin{array}{l}500 \text { Cycles } \\
1000 \\
700\end{array}$} & \multicolumn{2}{|c|}{$\begin{array}{l}\text { US \$200/KWh } \\
700 \\
400\end{array}$} \\
\hline YEAR & ষ্ণ & $\frac{0}{8}$ & ్ㅗㅇ & \& & $\frac{0}{8}$ & ণ্ণ & ๕ & & & ᄋ్ & 웅 & ণ্ণ & 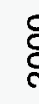 & ষ্ণ \\
\hline \multicolumn{15}{|l|}{ Lead acid } \\
\hline \multicolumn{15}{|l|}{ Lithium iron disulfide } \\
\hline \multicolumn{15}{|l|}{ Lithium polymer } \\
\hline \multicolumn{15}{|l|}{ Nickel cadmium } \\
\hline \multicolumn{15}{|l|}{ Nickel iron } \\
\hline \multicolumn{15}{|l|}{ Nickel metal hydride } \\
\hline \multicolumn{15}{|l|}{ Nickel zinc } \\
\hline \multicolumn{15}{|l|}{ Sodium sulfur } \\
\hline \multicolumn{15}{|l|}{ Zinc air } \\
\hline Zinc bromide & & & & & & & & & & & & & & \\
\hline
\end{tabular}




\section{COMPONENTS - Battery Characteristics}

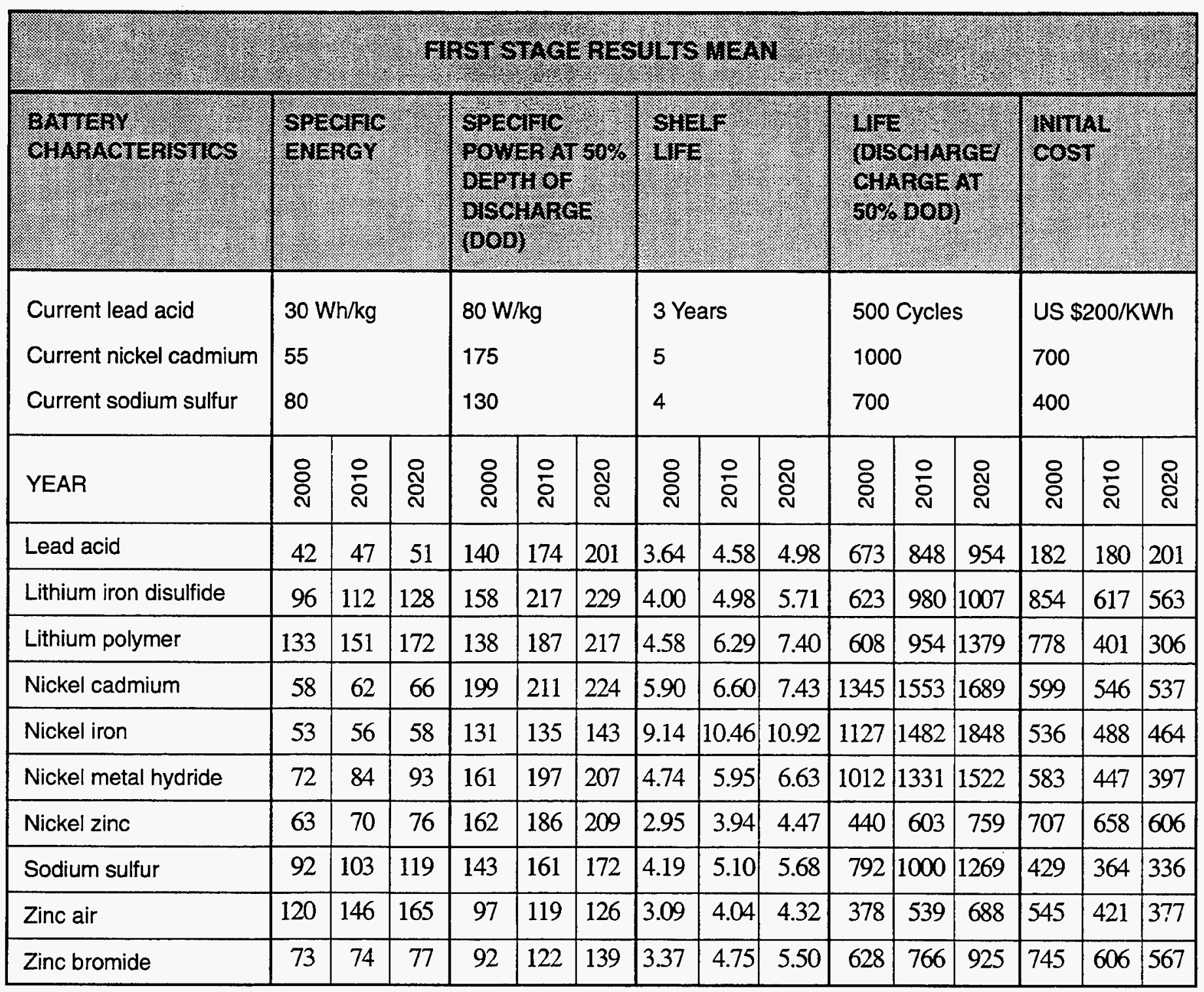




\section{COMPONENTS - Environmental Impact}

(B) The weight of vehicular propulsion battery modules will be in the hundreds of kilograms, or as much as one-third of vehicle curb weight, indicating a significant materials disposal problem at the end of the module's life. How would you rate the following battery types with respect to their (a) recyclability and (b) overall environmental impact with respect to residuals of manufacture, use, and disposal? Please use a scale of 1 (least recyclable, most negative environmental impact) to 10 (most recyclable, least negative environmental impact).

YOUR SECOND STAGE RESPONSE

\begin{tabular}{|c|c|c|c|c|c|c|c|c|c|c|c|c|c|c|c|c|c|c|c|c|}
\hline & s: : : & & & a & & 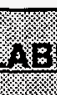 & & & & & : & & & we & ME & $\pi T$ & 11 & PA & & \\
\hline & wo & rst & & & & & & & & est & wo & & & & & & & & & best \\
\hline (1) & Lead acid ................ 1 & 2 & 3 & 4 & 5 & 6 & 7 & 8 & 9 & 10 & ............. 1 & 2 & 3 & 4 & 5 & 6 & 7 & 8 & 9 & 10 \\
\hline (2) & $\begin{array}{l}\text { Lithium iron ............. } 1 \\
\text { disulfide }\end{array}$ & 2 & 3 & 4 & 5 & 6 & 7 & 8 & 9 & 10 & ........... 1 & 2 & 3 & 4 & 5 & 6 & 7 & 8 & 9 & 10 \\
\hline (3) & Lithium polymer ..... 1 & 2 & 3 & 4 & 5 & 6 & 7 & 8 & 9 & 10 & ............. 1 & 2 & 3 & 4 & 5 & 6 & 7 & 8 & 9 & 10 \\
\hline (4) & Nickel cadmium ..... 1 & 2 & 3 & 4 & 5 & 6 & 7 & 8 & 9 & 10 &. .1 & 2 & 3 & 4 & 5 & 6 & 7 & 8 & 9 & 10 \\
\hline (5) & Nickel iron .............. 1 & 2 & 3 & 4 & 5 & 6 & 7 & 8 & 9 & 10 & ............ 1 & 2 & 3 & 4 & 5 & 6 & 7 & 8 & 9 & 10 \\
\hline (6) & $\begin{array}{l}\text { Nickel metal ........... } 1 \\
\text { hydride }\end{array}$ & 2 & 3 & 4 & 5 & 6 & 7 & 8 & 9 & 10 & $\ldots 1$ & 2 & 3 & 4 & 5 & 6 & 7 & 8 & 9 & 10 \\
\hline$(7)$ & Nickel zinc ............. 1 & 2 & 3 & 4 & 5 & 6 & 7 & 8 & 9 & 10 &. .1 & 2 & 3 & 4 & 5 & 6 & 7 & 8 & 9 & 10 \\
\hline$(8)$ & Sodium sulfur ........ 1 & 2 & 3 & 4 & 5 & 6 & 7 & 8 & 9 & 10 & ....... 1 & 2 & 3 & 4 & 5 & 6 & 7 & 8 & 9 & 10 \\
\hline (9) & Zinc air ................... 1 & 2 & 3 & 4 & 5 & 6 & 7 & 8 & 9 & 10 & ............. 1 & 2 & 3 & 4 & 5 & 6 & 7 & 8 & 9 & 10 \\
\hline$(10)$ & Zinc bromide .......... 1 & 2 & 3 & 4 & 5 & 6 & 7 & 8 & 9 & 10 & & 2 & 3 & 4 & 5 & 6 & 7 & 8 & 9 & 10 \\
\hline
\end{tabular}

FIRST STAEE RESULTS RATING MEAN

\begin{tabular}{|c|c|c|}
\hline 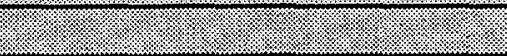 & 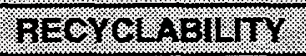 & EMVIFONMENTA MPACT \\
\hline (1) Lead acid & 8.19 & 6.24 \\
\hline (2) Lithium iron disulfide & 5.34 & 5.58 \\
\hline (3) Lithium polymer & 5.61 & 6.21 \\
\hline (4) Nickel cadmium & 5.53 & 3.59 \\
\hline (5) Nickel iron & 7.05 & 6.13 \\
\hline (6) Nickel metal hydride & 7.04 & 6.47 \\
\hline (7) Nickel zinc & 6.93 & 6.33 \\
\hline (8) Sodium sulfur & 5.61 & 5.53 \\
\hline (9) Zinc air & 7.35 & 7.17 \\
\hline (10) Zinc bromide & 4.56 & 4.03 \\
\hline
\end{tabular}




\section{COMPONENTS - Motors}

(C) The match between motor technology and propulsion battery system will be of great importance to the ultimate success of EVs and HEVs. Three candidate motor technology types are given below. For each of the projection years shown, please indicate your ranking of these three candidates from 1 (least likely) to 3 (most likely) with respect to your estimate of technological maturity and appropriateness of motor/battery system match in that year. Also please give your estimate of what each of these systems will cost, using as your index value (1.0) the cost of a 1993 DC motor and assuming amortization of necessary research, development, and demonstration. Assume equal production volumes for all candidates.

\section{YOUR SECOND STAGE RESPONSE}
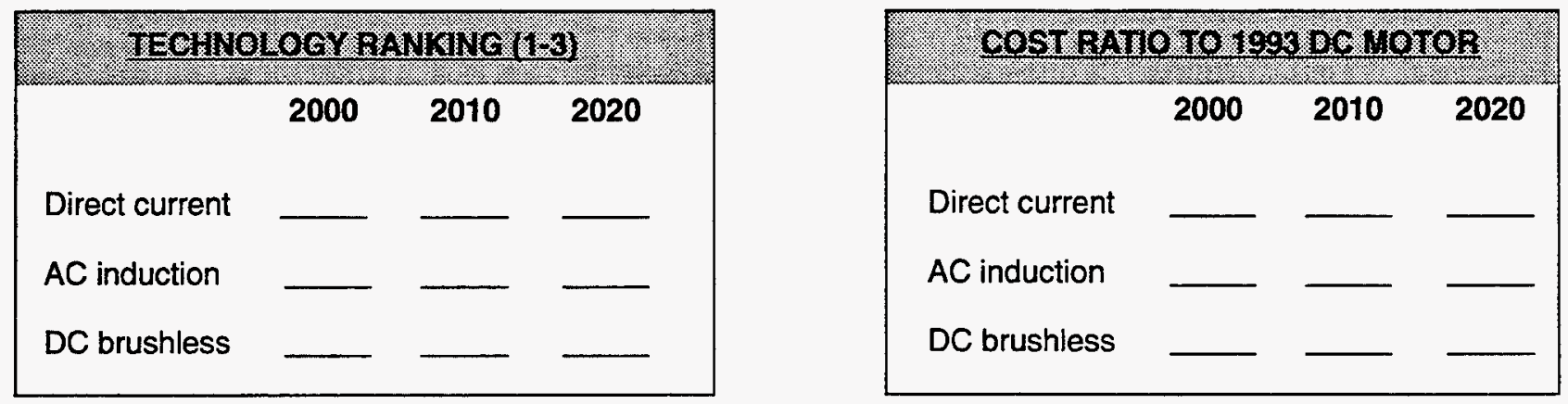

Please describe how you developed the cost ratios

\begin{tabular}{|c|c|c|c|c|c|c|c|c|}
\hline \multicolumn{9}{|c|}{ FIRST STAGE RESULTS RANK MEAN } \\
\hline & \multicolumn{4}{|c|}{ 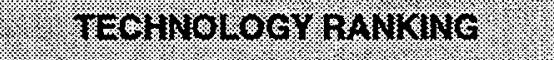 } & \multicolumn{4}{|c|}{ COST RATIO ro 1998 De Motor } \\
\hline Year & 1995 & 2000 & 2010 & 2020 & 1995 & 2000 & 2010 & 2020 \\
\hline Direct current & 1.91 & 1.66 & 1.57 & 1.61 & 1.18 & 1.19 & 1.34 & 1.56 \\
\hline$A C$ induction & 2.09 & 2.25 & 2.31 & 2.25 & 1.96 & 1.54 & 1.37 & 1.44 \\
\hline DC brushless & 1.86 & 2.05 & 2.20 & 2.21 & 3.06 & 2.10 & 1.70 & 1.65 \\
\hline
\end{tabular}




\section{COMPONENTS - Advanced Materials}

(D) Electric and hybrid vehicle design goals include low vehicle weight without sacrifice in occupant safety. Advanced materials may be good candidates for helping to achieve these goals, and EV production may in turn stimulate development and accelerate commercialization of advanced materials. A selection of materials likely to be used in EV/HEV production applications is given below. Please rate each with respect to the attributes shown, using a scale of 1 (poor performance on this attribute) to 5 (excellent performance on this attribute).

\section{YOUR SECOND STAGE RESPONSE}

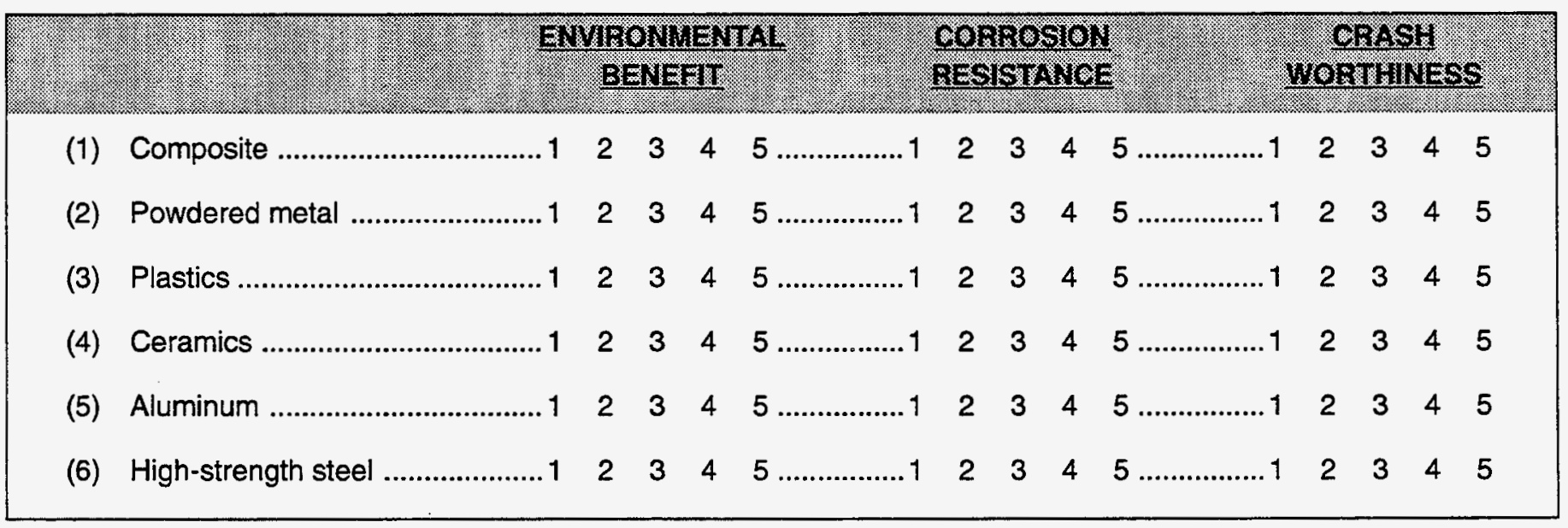

(1) Composite $\begin{array}{lllll}.1 & 2 & 3 & 4 & 5\end{array}$ $\begin{array}{lllll}1 & 2 & 3 & 4 & 5\end{array}$ $\begin{array}{lllll}.1 & 2 & 3 & 4 & 5\end{array}$

(2) Powdered metal $\begin{array}{lllll}1 & 2 & 3 & 4 & 5\end{array}$ $\begin{array}{lllll}1 & 2 & 3 & 4 & 5\end{array}$ $\begin{array}{lllll}1 & 2 & 3 & 4 & 5\end{array}$

(3) Plastics $\begin{array}{lllll}1 & 2 & 3 & 4 & 5\end{array}$ $\begin{array}{lllll}1 & 2 & 3 & 4 & 5\end{array}$ $\begin{array}{lllll}1 & 2 & 3 & 4 & 5\end{array}$

(4) Ceramics $\begin{array}{lllll}1 & 2 & 3 & 4 & 5\end{array}$ 12.345 $\begin{array}{lllll}1 & 2 & 3 & 4 & 5\end{array}$

(5) Aluminum $\begin{array}{lllll}1 & 2 & 3 & 4 & 5\end{array}$ $\begin{array}{lllll}1 & 2 & 3 & 4 & 5\end{array}$ $\begin{array}{lllll}1 & 2 & 3 & 4 & 5\end{array}$

(6) High-strength steel

$\begin{array}{lllll}.1 & 2 & 3 & 4 & 5\end{array}$ $\begin{array}{lllll}. .1 & 2 & 3 & 4 & 5\end{array}$ $\begin{array}{lllll}. .1 & 2 & 3 & 4 & 5\end{array}$

\begin{tabular}{|c|c|c|c|c|c|c|}
\hline & $=18$ & ST STrem & sulys mim & MEAT & & \\
\hline 2 & mentert: & reoproston & 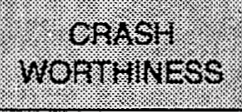 & 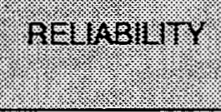 & DURAEIIIT: & $\frac{\mathrm{coss}}{\mathrm{er} F}$ \\
\hline (1) Composite & 2.98 & 4.49 & 4.05 & 3.70 & 4.04 & 2.59 \\
\hline (2) Powdered metal & 3.19 & 2.86 & 2.81 & 3.44 & 3.35 & 3.10 \\
\hline (3) Plastics & 3.12 & 4.66 & 2.97 & 3.59 & 3.61 & 3.96 \\
\hline (4) Ceramics & 3.39 & 4.69 & 2.31 & 3.09 & 3.26 & 2.42 \\
\hline (5) Aluminum & 3.90 & 3.49 & 3.69 & 4.13 & 3.95 & 3.65 \\
\hline $\begin{array}{l}\text { (6) High-strength } \\
\text { steel }\end{array}$ & 3.76 & 2.60 & 4.57 & 4.58 & 4.27 & 4.24 \\
\hline
\end{tabular}




\section{COMPONENTS - Combustion Engines for Hybrids}

(E) The five engine types given below may all be used in hybrid electric vehicles after appropriate modification and optimization. Please rank these five from 1 (least) to 5 (most) with respect to technological maturity, suitability, and cost effectiveness in each of the three future years shown.

YOUR SECOND STAGE RESPONSE
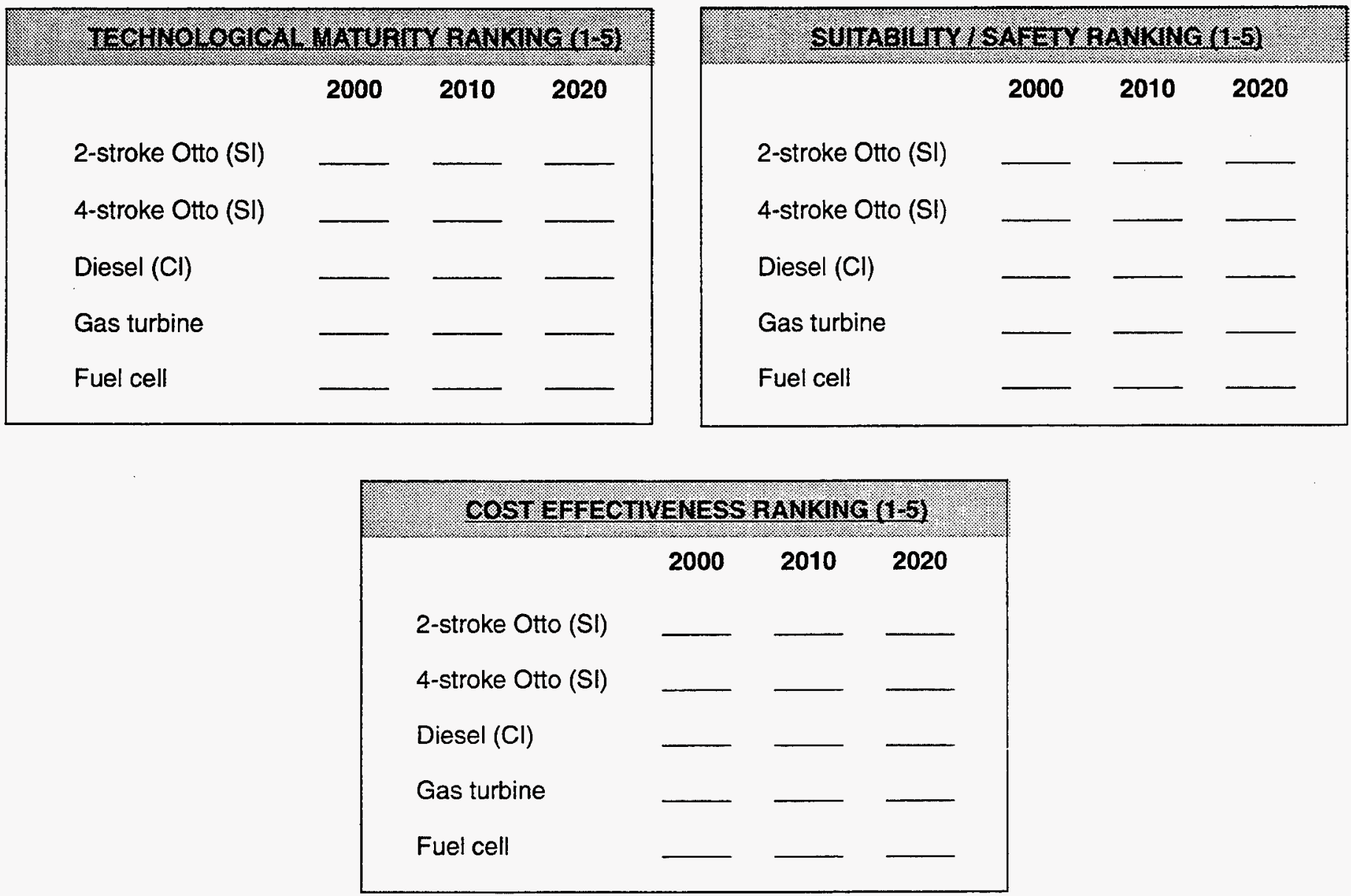

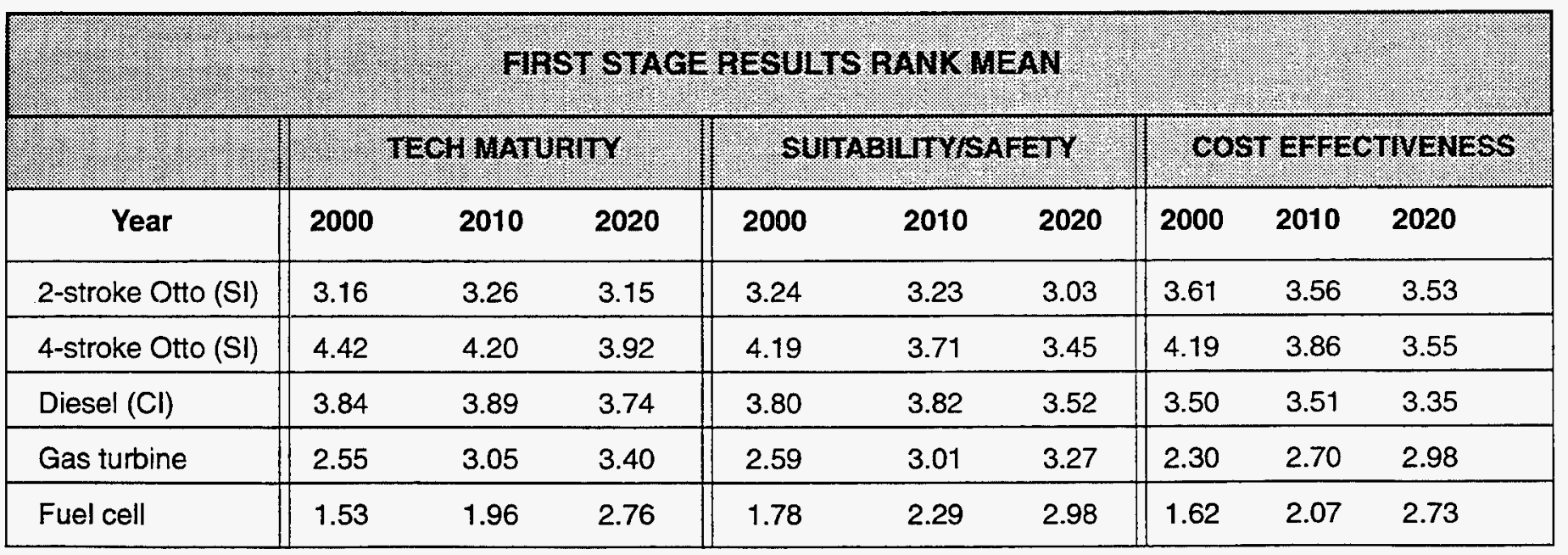




\section{COMPONENTS - Advanced Concepts}

(F) Could high technologies be modified in order to benefit electric vehicle applications? What are the advanced technologies most likely to be both available and useful for EV and HEV application in the years 2000, 2010, and 2020? For each year please rank the five candidate technologies below for, respectively, (a) viability and (b) cost in each of these years, using a scale of 1 (weakest technological candidate; excessive cost) to 5 (strongest technological candidate; most reasonable cost).

\section{YOUR SECOND STAGE RESPONSE}
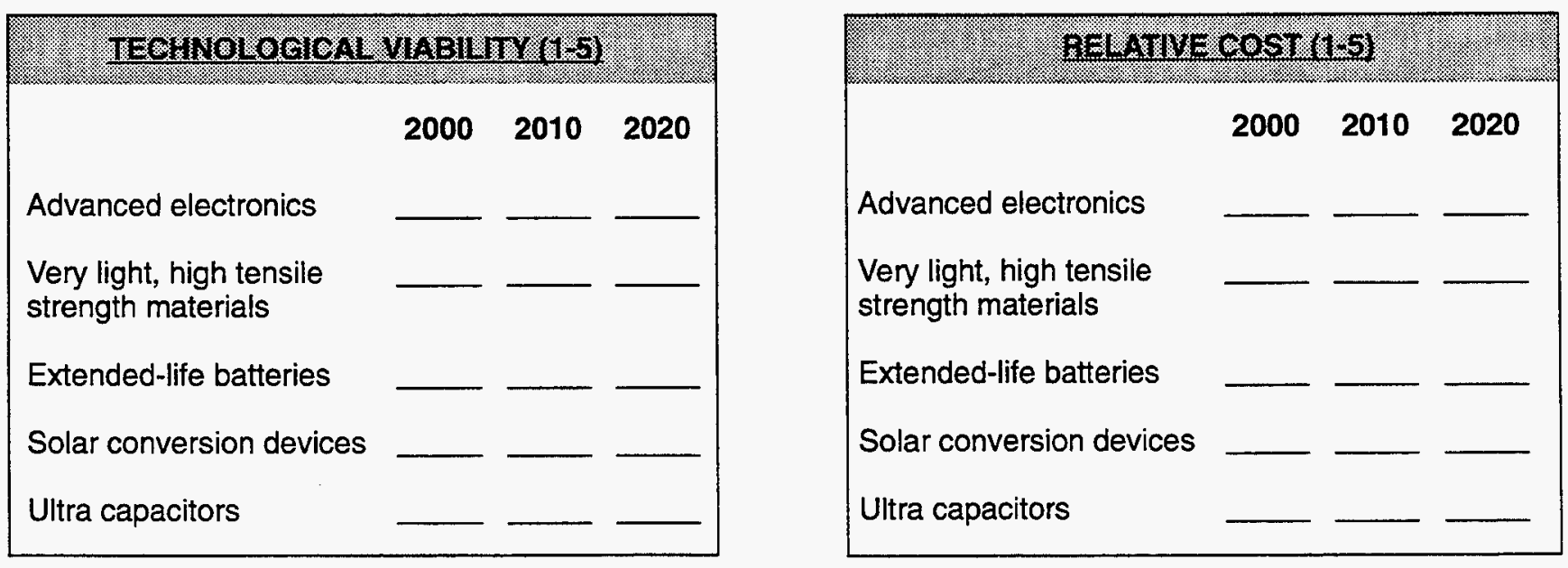

\begin{tabular}{|c|c|c|c|c|c|c|c|c|}
\hline \multicolumn{9}{|c|}{ FIRST STAGE RESUITSRAIK MEAN } \\
\hline & \multicolumn{4}{|c|}{ 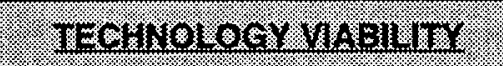 } & \multicolumn{4}{|c|}{ GE $A T H=$ DOST } \\
\hline hedr & 1995 & 2000 & 2010 & 2020 & 1995 & 2800 & 28.10 & 2020 \\
\hline Advanced electronics & 4.11 & 4.13 & 4.08 & 4.02 & 3.95 & 4.12 & 4.19 & 4.17 \\
\hline $\begin{array}{l}\text { Very light, high } \\
\text { tensile strength mat. }\end{array}$ & 3.47 & 3.61 & 3.66 & 3.62 & 3.29 & 3.33 & 3.38 & 3.38 \\
\hline Extended-life batteries & 2.8 & 3.14 & 3.50 & 3.68 & 2.67 & 2.98 & 3.24 & 3.33 \\
\hline Solar conversion devices & 1.78 & 1.86 & 2.10 & 2.26 & 1.89 & 2.03 & 2.20 & 2.31 \\
\hline Ultra capacitors & 1.97 & 2.30 & 2.62 & 2.93 & 2.02 & 2.19 & 2.47 & 2.69 \\
\hline
\end{tabular}




\section{SYSTEM IMPACTS - Air Pollution}

(A) Please indicate whether you agree or disagree with the following statements.

YOUR SECOND STAGE RESPONSE

AGREE DISAGREE

(1) Electricity used by EVs and HEVs will be generated predominantly

$\square$

from coal.

(2) If (1) is true, total emissions of carbon dioxide and, possibly,

.$\square$

of oxides of nitrogen and sulfur will increase.

(3) Most electricity used by EVs and HEVs will be generated . from natural gas and other low-carbon-per-kW fuels.

(4) Nuclear power will play an important role in . electricity generation for EVs.

(5) Any increases in power plant emissions due to EV use .0 will be offset at the local level by decreases in on-road emissions.

(6) Most EV charging will use overnight base load capacity, . resulting in little net increase in daytime power plant emissions.

(7) EVs will be environmentally beneficial due to displacement of emissions from urban areas to remote power plants and from daytime to nighttime.

(8) EVs will help reduce urban ozone levels due to displacement of gasoline combustion and storage by fuels and/or energy

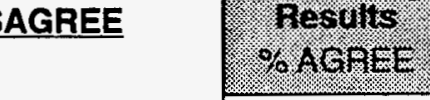

Fits: Stage

51

59

43

47

71

77 production techniques with lower ozone-forming potential.

\section{SYSTEM IMPACTS - Global Warming}

(B) Please indicate whether you agree or disagree with the following statements on global warming.

\section{AGREE DISAGREE}

(1) EVs and HEVs will reduce global warming potential by 2020 even if these vehicles have a market share of only 33 percent.

(2) The complexity of global warming as a scientific issue requires that many more studies must be undertaken betore key policy decisions are made.

(3) Mitigation of global warming potential could have significant socio-economic benefits.

(4) Global warming has been unmasked as such an unimportant issue that future decisions about transportation policy should not be required to consider it.

(5) Policies with significant implications for global warming potential

First Stage Results \%. वGREE will be implemented by governments no later than year 2000 . 


\section{SYSTEM IMPACTS - Nuclear Energy}

(C) Europe and Asia have both made a strong commitment to nuclear power, concluding that, in general, only nuclear power can provide both sufficiently high energy efficiency and low air pollution at reasonable cost. In the U.S., attitudes about the necessity for nuclear power are far more equivocal. Please rank the six following possible causes for this difference in the U.S. position using a scale of 1 (strongest disagreement) to 6 (strongest agreement).

\section{YOUR SECOND STAGE RESPONSE}

\section{RANK 1-6}

Relative abundance of coal in the U.S.

Relative abundance of natural gas in the U.S.

Perceived superiority of U.S. fossil fuel power plant technology

Continued availability in the U.S. of remote areas for building non-nuclear

power plants which disperse pollution from tall stacks

Negative public opinion due to accidents or near accidents in U.S.

Lack of perception or education about the relative costs and environmental benefits of nuclear, fossil, and renewable energy plant technologies,

tirst Stage Results TINU VIEAUV including costs of residuals disposal

\section{SYSTEM IMPACTS - Market Success Factors}

(D) Please rate the following based on your perception of actions required in order to improve the chances of successful EV/HEV commercialization in the 1990s. Use a scale of 1 (strongest disagreement) to 5 (strongest agreement).

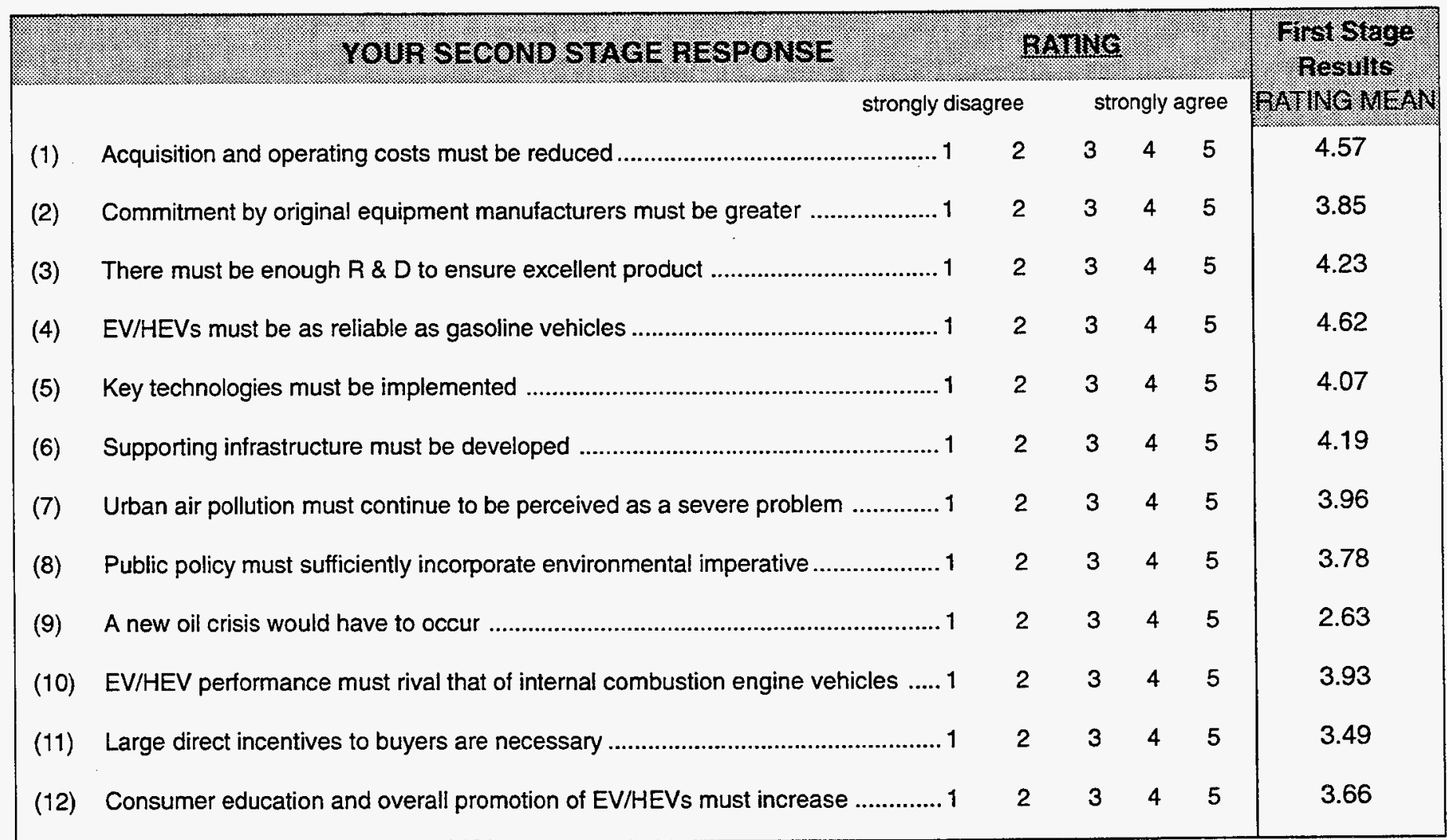


127

APPENDIX B:

COMPARISON OF STAGE 1 AND STAGE 2 QUESTIONNAIRES 


\section{APPENDIX B}

\section{COMPARISON OF STAGE 1 AND STAGE 2 QUESTIONNAIRES}

\section{Stage 1 Questionnaire}

The layout of the Stage 1 questionnaire was as follows:

I. Vehicles
A. Basic characteristics of electric passenger vehicles (EVs)
B. Basic characteristics of hybrid electric passenger vehicles (HEVs)
C. Amenities
D. Research and development needs
E. Hybrids
F. Cost ratios
G. Fuel and maintenance cost ratios
H. Obstacles to commercialization
I. Market penetration

II. Components
A. Battery characteristics
B. Environmental impact
C. Motors
D. Advanced materials
E. Combustion engines for hybrids
F. Advanced concepts

III. System Impacts
A. Air pollution
B. Global warming
C. Nuclear energy
D. Market success factors

Stage 2 Questionnaire

The layout of the Stage 2 questionnaire was essentially the same as the Stage 1 except that question $G$ in section one had three parts (as shown below) instead of just one.

I. Vehicles

G. Fuel and maintenance cost ratios

Part 1 - provide fuel and maintenance cost ratios

Part 2 - provide fuel economy ratios

Part 3 - provide HEV fuel type 
APPENDIX C:

DETAILED RESULTS OF STAGE 2 
132 


\section{Electric/Hybrid Vehicle Study}

Second Stage Results 
If you have a specific concept of the likely market(s) for electric vehicles in the U.S. transportation system (for example, commercial fleet vehicle only, commuter car, "city car," rental/lease vehicle only) please indicate what that market or markets will be before proceeding with the questionnaire:

\section{VEHICLES - Basic Characteristics of Electric Passenger Vehicles (EVs)}

(A) Please rate below the importance of these vehicular attributes from 1 (not important) to 10 (most important), based on your assessment of the most likely EV market as entered above, and also identify on the accompanying charts the most realistic specifications and characteristics of EVs for each of the years 2000, 2010, and 2020.

YOUR SECOND STAGE RESPONSE

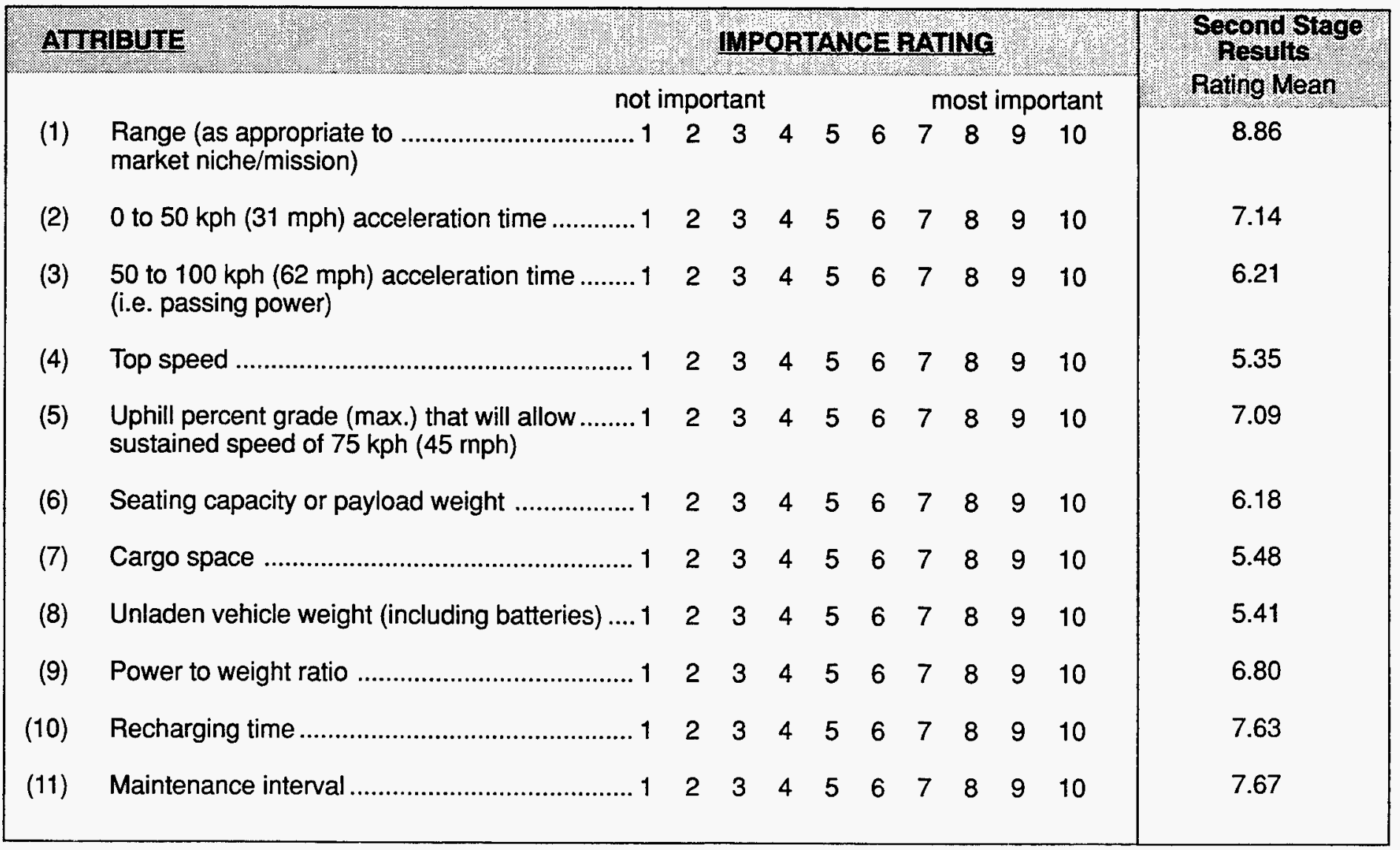


Please mark appropriate box for EVs for each projection year.

YOUR SECOND STAGE RESPONSE

\begin{tabular}{|c|c|c|c|}
\hline KM (MI.) & 2000 & 2010 & 2020 \\
\hline $650(404)$ & & & \\
\hline $450(280)$ & & & \\
\hline $350(217)$ & & & \\
\hline $250(155)$ & & & \\
\hline $150(93)$ & & & \\
\hline
\end{tabular}

| TOP SPEEB
\begin{tabular}{|c|c|c|c|} 
KPH (MPH) & 2000 & 2010 & 2020 \\
\hline $190(118)$ & & & \\
\hline $150(93)$ & & & \\
\hline $130(81)$ & & & \\
\hline $110(68)$ & & & \\
\hline $90(56)$ & & & \\
\hline
\end{tabular}

\begin{tabular}{|c|c|c|c|}
\hline \multicolumn{5}{|c|}{ ACCELERATONO 50 KPH $(31 \mathrm{MPH})$} \\
\hline SEC. & 2000 & 2010 & 2020 \\
\hline 11 & & & \\
\hline 9 & & & \\
\hline 7 & & & \\
\hline 5 & & & \\
\hline 3 & & & \\
\hline
\end{tabular}

\begin{tabular}{|c|c|c|c|}
\hline MAX. UPHII GRADE FOR SUSTAINED \\
\hline \% GRADE & 2000 & 2010 & 2020 \\
\hline 11 & & & \\
\hline 7 & & & \\
\hline 5 & & & \\
\hline 3 & & & \\
\hline 1 & & & \\
\hline
\end{tabular}

\begin{tabular}{|c|c|c|c|}
\hline \multicolumn{5}{|c|}{ ACCELERATION 50-100 KPH (62 MPH) } \\
\hline SEC. & 2000 & 2010 & 2020 \\
\hline 14 & & & \\
\hline 12 & & & \\
\hline 10 & & & \\
\hline 8 & & & \\
\hline 6 & & & \\
\hline
\end{tabular}

\begin{tabular}{|c|c|c|c|}
\hline 0.3 & SEATINGCAPACITY \\
\hline PERSONS & 2000 & 2010 & 2020 \\
\hline 6 & & & \\
\hline 5 & & & \\
\hline 4 & & & \\
\hline 3 & & & \\
\hline 2 & & & \\
\hline
\end{tabular}

If you disagree with the range of values provided along the $y$-axis for any of these characteristics, please supplement or replace them by entering your preferred values in the appropriate cells.

\begin{tabular}{|c|c|c|c|}
\hline \multicolumn{4}{|c|}{ SECOND STAGE RESULTS MEAN } \\
\hline YEAR & 2000 & 2010 & 2020 \\
\hline Range, Km & 179 & 270 & 358 \\
\hline $0-50 \mathrm{KPH}, \mathrm{Sec}$ & 7.40 & 5.80 & 5.20 \\
\hline $50-100 \mathrm{KPH}, \mathrm{Sec}$ & 11.56 & 9.89 & 9.19 \\
\hline Top Speed, KPH & 117 & 131 & 141 \\
\hline Up Hill, \% & 5.03 & 6.75 & 7.84 \\
\hline Seating, Person & 3.41 & 4.08 & 4.64 \\
\hline
\end{tabular}


Please mark appropriate box for EVs for each projection year.

YOUR SECOND STAGE RESPONSE

\begin{tabular}{|c|c|c|c|}
\hline \multicolumn{4}{|c|}{ CaFGo space } \\
\hline LITERS (ft3) & 2000 & 2010 & 2020 \\
\hline $600(21)$ & & & \\
\hline $400(14)$ & & & \\
\hline $300(11)$ & & & \\
\hline $200(7)$ & & & \\
\hline $100(4)$ & & & \\
\hline
\end{tabular}

\begin{tabular}{|c|c|c|c|}
\hline \multicolumn{4}{|c|}{ RECHARGING (REFUELING) TIME } \\
\hline MINUTES & 2000 & 2010 & 2020 \\
\hline 300 & & & \\
\hline 120 & & & \\
\hline 30 & & & \\
\hline 10 & & & \\
\hline 5 & & & \\
\hline
\end{tabular}

\begin{tabular}{|c|c|c|c|}
\hline \multicolumn{4}{|c|}{ CURBWEIGHT } \\
\hline KG (LB) & 2000 & 2010 & 2020 \\
\hline $1800(3968)$ & & & \\
\hline $1400(3086)$ & & & \\
\hline $1200(2646)$ & & & \\
\hline $1000(2205)$ & & & \\
\hline $800(1764)$ & & & \\
\hline
\end{tabular}

\begin{tabular}{|c|c|c|c|}
\hline . MAINTENANCEINTERVAL \\
\hline KM (MI) & 2000 & 2010 & 2020 \\
\hline $75000(46603)$ & & & \\
\hline $50000(31069)$ & & & \\
\hline $30000(18641)$ & & & \\
\hline $15000(9321)$ & & & \\
\hline $5000(3107)$ & & & \\
\hline
\end{tabular}

\begin{tabular}{|c|c|c|c|}
\hline & POWER RATING & \\
\hline kW (hp) & 2000 & 2010 & 2020 \\
\hline $150(201)$ & & & \\
\hline $110(148)$ & & & \\
\hline $90(121)$ & & & \\
\hline $70(94)$ & & & \\
\hline $50(67)$ & & & \\
\hline
\end{tabular}

If you disagree with the range of values provided along the $y$-axis for any of these characteristics, please supplement or replace them by entering your preferred values in the appropriate cells.

\begin{tabular}{|c|c|c|c|}
\hline \multicolumn{4}{|c|}{ SECOND STAGE RESULTS MEAN } \\
\hline YEAR & 2000 & 2010 & 2020 \\
\hline Cargo, Liter & 216 & 289 & 345 \\
\hline Curb Weight, Kg & 1538 & 1351 & 1222 \\
\hline Power, Kw & 66.7 & 86.1 & 99.2 \\
\hline Recharging, Min & 233 & 141 & 85 \\
\hline Maintenance, Km & 20322 & 33589 & 47694 \\
\hline
\end{tabular}


If you have a specific concept of the likely market(s) for hybrid electric vehicles in the U.S. transportation system (for example, commercial fleet vehicle only, commuter car, "city car", rental/lease vehicle only) please indicate what that market or markets will be before proceeding:

\section{VEHICLES - Basic Characteristics of Hybrid Electric Passenger Vehicles (HEVs)}

(B) Please rate below the importance of these vehicular attributes from 1 (not important) to 10 (most important), based on your assessment of the most likely HEV market(s), and also identify on the accompanying charts the most realistic specifications and characteristics of HEVs (battery plus engine) for each of years 2000, 2010, and 2020.

YOUR SECOND STAGE RESPONSE

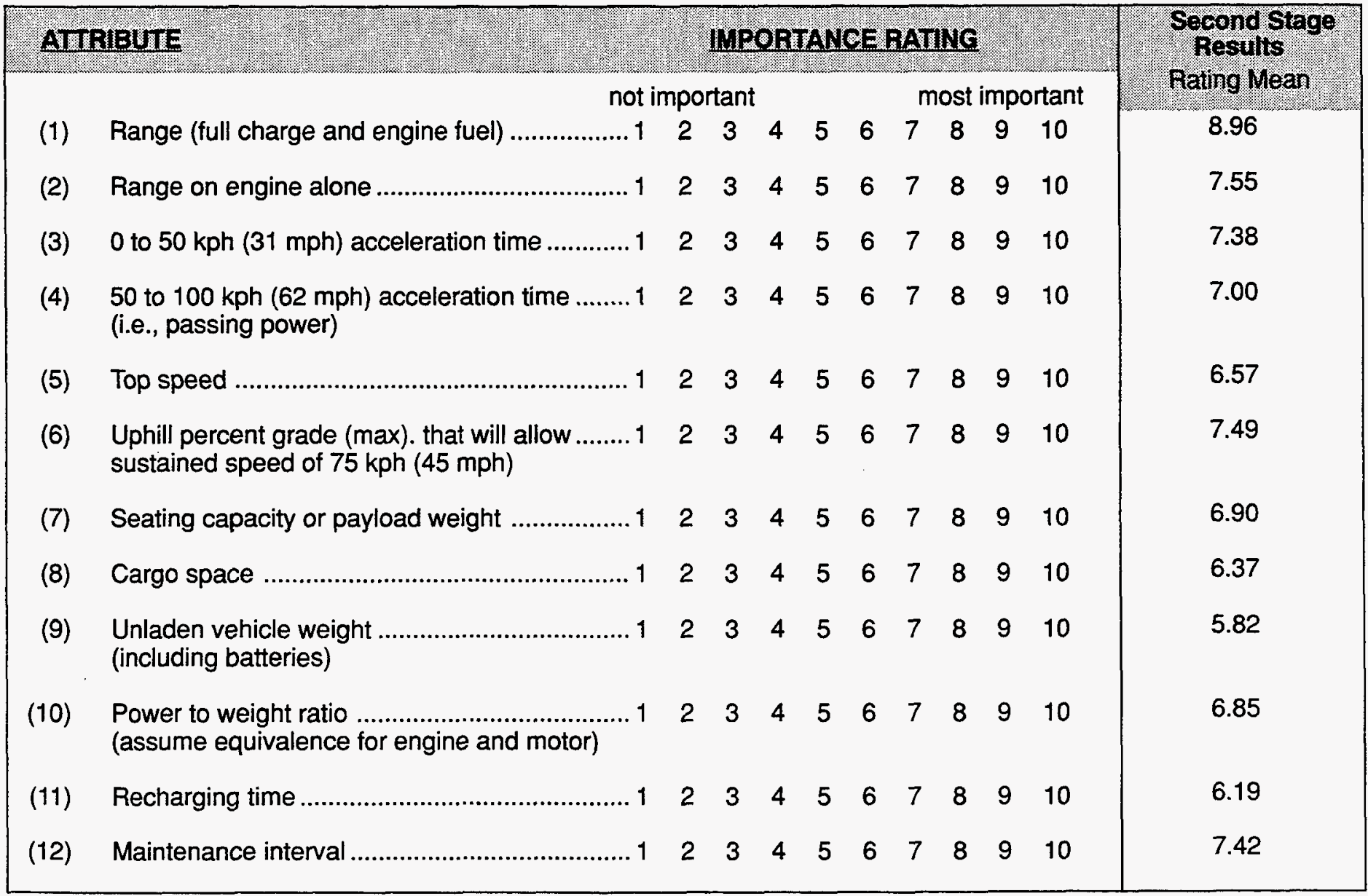


Please mark appropriate box for $\mathrm{HEVs}$ for each projection year.

\section{YOUR SECOND STAGE RESPONSE}

\begin{tabular}{|c|c|c|c|}
\hline Ty & RANGE \\
\hline KM (MI.) & 2000 & 2010 & 2020 \\
\hline $650(404)$ & & & \\
\hline $450(280)$ & & & \\
\hline $350(217)$ & & & \\
\hline $250(155)$ & & & \\
\hline $150(93)$ & & & \\
\hline
\end{tabular}

\begin{tabular}{|c|c|c|c|}
\hline \multicolumn{4}{|c|}{ ACCELLRATION, 50-100 KPH (62 MPH } \\
\hline & & 9 & 48 \\
\hline SEC. & 2000 & 2010 & 2020 \\
\hline 14 & & & \\
\hline 12 & & & \\
\hline 10 & & & \\
\hline 8 & & & \\
\hline 6 & & & \\
\hline
\end{tabular}

\begin{tabular}{|}
\hline RANGE OFENGINEALONE \\
\hline KM (MI.) & 2000 & 2010 & 2020 \\
\hline $300(186)$ & & & \\
\hline $200(124)$ & & & \\
\hline $150(93)$ & & & \\
\hline $100(62)$ & & & \\
\hline $50(31)$ & & & \\
\hline
\end{tabular}

\begin{tabular}{|c|c|c|c|}
\hline TOP SPEED & . \\
\hline KPH (MPH) & 2000 & 2010 & 2020 \\
\hline $190(118)$ & & & \\
\hline $150(93)$ & & & \\
\hline $130(81)$ & & & \\
\hline $110(68)$ & & & \\
\hline $90(56)$ & & & \\
\hline
\end{tabular}

\begin{tabular}{|c|c|c|c|}
\hline \multicolumn{4}{|c|}{ ACCEIERATION. $0-50 \mathrm{KPH}(31 \mathrm{MPH})$} \\
\hline SEC. & 2000 & 2010 & 2020 \\
\hline 11 & & & \\
\hline 9 & & & \\
\hline 7 & & & \\
\hline 5 & & & \\
\hline 3 & & & \\
\hline
\end{tabular}

\begin{tabular}{|}
\begin{tabular}{|c|c|c|c|}
\hline MAX UPHILL GRADE FOR SUSTAINED \\
\hline $\begin{array}{c}\text { M TS KPH (45 MPHI SPEED } \\
\text { \% GRADE }\end{array}$ & 2000 & 2010 & 2020 \\
\hline 11 & & & \\
\hline 7 & & & \\
\hline 5 & & & \\
\hline 3 & & & \\
\hline 1 & & & \\
\hline
\end{tabular}
\end{tabular}

If you disagree with the range of values provided along the $y$-axis for any of these characteristics, please supplement or replace them by entering your preferred values in the appropriate cells.

\begin{tabular}{|c|c|c|c|}
\hline \multicolumn{4}{|c|}{ SECOND STAGE RESULTS MEAN } \\
\hline YEAR & 2000 & 2010 & 2020 \\
\hline Range, Km & 353 & 469 & 527 \\
\hline Engine Range, Km & 215 & 257 & 281 \\
\hline $0-50 \mathrm{KPH}, \mathrm{Sec}$ & 6.95 & 5.46 & 4.70 \\
\hline $50-100 \mathrm{KPH}, \mathrm{Sec}$ & 10.75 & 9.10 & 8.23 \\
\hline Top Speed, KPH & 125 & 139 & 147 \\
\hline Up Hill, \% & 5.88 & 7.77 & 9.32 \\
\hline
\end{tabular}


Please mark appropriate box for HEVs for each projection year.

\section{YOUR SECOND STAGE RESPONSE}

\begin{tabular}{|c|c|c|c|}
\hline \multicolumn{4}{|c|}{ SEATING CAPACIM } \\
\hline PERSONS & 2000 & 2010 & 2020 \\
\hline 6 & & & \\
\hline 5 & & & \\
\hline 4 & & & \\
\hline 3 & & & \\
\hline 2 & & & \\
\hline
\end{tabular}

\begin{tabular}{|c|c|c|c|}
\hline POWEARATING & \\
kW (hp) & 2000 & 2010 & 2020 \\
\hline $150(201)$ & & & \\
\hline $110(148)$ & & & \\
\hline $90(121)$ & & & \\
\hline $70(94)$ & & & \\
\hline $50(67)$ & & & \\
\hline
\end{tabular}

\begin{tabular}{|c|c|c|c|}
\hline & CARGO SPACE & \\
LITERS (ft3) & 2000 & 2010 & 2020 \\
\hline $600(21)$ & & & \\
\hline $400(14)$ & & & \\
\hline $300(11)$ & & & \\
\hline $200(7)$ & & & \\
\hline $100(4)$ & & & \\
\hline
\end{tabular}

\begin{tabular}{|c|c|c|c|}
\hline \multicolumn{4}{|c|}{ RECHARGING (REFUEINGI TME } \\
\hline MINUTES & 2000 & 2010 & 2020 \\
\hline 300 & & & \\
\hline 120 & & & \\
\hline 30 & & & \\
\hline 10 & & & \\
\hline 5 & & & \\
\hline
\end{tabular}

\begin{tabular}{|c|c|c|c|}
\hline & CURB WEICHT \\
\hline KG (LB) & 2000 & 2010 & 2020 \\
\hline $1800(3968)$ & & & \\
\hline $1400(3086)$ & & & \\
\hline $1200(2646)$ & & & \\
\hline $1000(2205)$ & & & \\
\hline $800(1764)$ & & & \\
\hline
\end{tabular}

\begin{tabular}{|c|c|c|c|}
\hline MAITENANCE INIERVAL & \\
\hline KM (MI) & 2000 & 2010 & 2020 \\
\hline $75000(46603)$ & & & \\
\hline $50000(31069)$ & & & \\
\hline $30000(18641)$ & & & \\
\hline $15000(9321)$ & & & \\
\hline $5000(3107)$ & & & \\
\hline
\end{tabular}

If you disagree with the range of values provided along the $y$-axis for any of these characteristics, please supplement or replace them by entering your preferred values in the appropriate cells.

\begin{tabular}{|c|c|c|c|}
\hline \multicolumn{4}{|c|}{ SECOND STAGE RESULTS MEAN } \\
\hline YEAR & 2000 & 2010 & 2020 \\
\hline Seating, Person & 3.85 & 4.50 & 4.96 \\
\hline Cargo, Liter & 244 & 317 & 367 \\
\hline Curb Weight, Kg & 1556 & 1382 & 1265 \\
\hline Power, kW & 79.6 & 99.1 & 108.6 \\
\hline Recharging, Min & 144 & 62 & 45 \\
\hline Maintenance, KM & 17181 & 28464 & 38127 \\
\hline
\end{tabular}




\section{VEHICLES - Amenities}

(C) Cars often do not succeed in the marketplace without additional amenities for occupant comfort and aesthetics. If applied to EVs and HEVs, some of these component amenities may have to be re-designed or even newly-developed. In your view, how important are the following amenities to the eventual success of EVs and HEVs? Please rank from 1 (least important) to 5 (most important).

\section{SECOND STAGE RESULTS RANK MEAN}

\section{RANK 1-5}

\subsection{Air conditioning}

4.53 Compartment heating and window defrost (to comfort level in 5 minutes)

2.25 Power auxiliaries (windows, doors, seats, brakes, steering)

2.47 Audio entertainment

3.24 Premium safety equipment (i.e., air bags, anti-lock brakes)

\section{VEHICLES - Research and Development Needs}

(D) Battery (energy density, operating temperature, materials) and energy storage technology (ultracapacitors, flywheels); vehicular technology (body, chassis, steering and suspension); and component technology (motor, drive train, and regenerative or mechanical braking) are the three major concerns in R \& D aimed at commercialization of EVs and HEVs. In your opinion, which areas of concern will require the greatest share of $R \& D$ before these vehicles can be successfully marketed? Please rank the three areas from 1 (least important) to 3 (most important).

SECOND STAGE RESULTS RANK MEAN

RANK 1-3

2.85 Battery/Energy storage technology

1.31 Vehicular technology

1.90 Component technologies 


\section{VEHICLES - Hybrids}

(E) Hybrid electric vehicles (HEVs) have been considered an alternative to gasoline passenger vehicles because they may combine the best aspects of internal combustion (IC) engine-powered and battery-powered propulsion. Please indicate with an " $x$ " whether you agree or disagree with the following statements about HEVs. Assume that the IC engine is fueled by either gasoline or a non-petroleum fuel; if your answer would differ based on what the IC engine fuel is, please so indicate.

\section{YOUR SECOND STAGE RESPONSE AGREE DISAGREE}

(1) HEVs will be commercialized as a viable alternative to gasoline vehicles in the intermediate term (2000-2005)
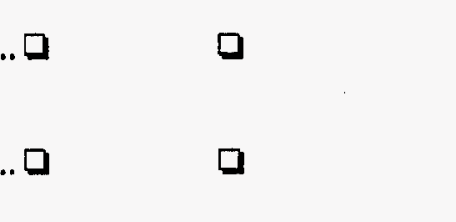

(3) HEVs will never be a viable alternative

HEVs will be commercialized as a viable alternative
to gasoline vehicles in the longer term (2005-2020) $\square$

(4) Most components needed by HEVs are market-ready today ...........

(5) New $R$ \& D requirements for HEVs are minimal .

(6) Operating range of HEVs will be extended by more than $150 \mathrm{~km}$ (93 miles) compared to EVs

\begin{tabular}{|c|}
\hline $\begin{array}{c}\text { Second Stage } \\
\text { Resilts }\end{array}$ \\
\% Agree \\
47 \\
83 \\
8 \\
27 \\
15 \\
94 \\
88 \\
23 \\
98 \\
98 \\
\end{tabular}

(7) Component manufacturing and servicing infrastructure for HEVs is lacking....

(8) HEVs will cost less than EVs when commercialized

(9) HEVs could meet U.S. Tier II emissions standards if required for MY2004 and later automobiles

\section{ㅁ.} $\square$

Performance of HEVs can be improved.

(11) Hybrid vehicles will not need electricity from the grid. 


\section{VEHICLES - Cost Ratios}

(F) Using a conventional gasoline-fueled compact 4-door sedan as the baseline [1993 US $\$ 15000$ as index value (1.0)], please provide your estimate of the purchase price ratio for each of the five types of vehicles listed below in each of 3 future years. The cost of the initial battery pack should be included but not the replacement battery cost in your estimate.

\section{SECOND STAGE RESULTS MEAN \\ YEAR $2000 \quad 2010 \quad 2020$}

(1) Conventional (piston) engines ................................. $\quad \underline{1.26} \quad \underline{1.60} \quad \underline{2.02}$

(2) Electric .............................................................. $\quad \underline{2.29} \quad \underline{2.31 \quad \underline{2.38}}$

(3) Hybrid with conventional (piston) engine .................... $\quad \underline{2.47} \quad \underline{2.44} \quad \underline{2.54}$

(4) Hybrid with gas turbine ............................................ $3.27 \quad \underline{3.04} \quad \underline{3.07}$

(5) Hybrid with fuel cell ................................................ $\quad \underline{5.15} \quad \underline{4.36} \quad \underline{3.98}$

Please describe below how you arrived at these values (a list of assumptions about the type and size of battery pack that you assume for vehicles $2-5$ would be very helpful) 


\section{VEHICLES - Fuel and Maintenance Cost Ratios}

(G) Part 1 - Using a conventional gasoline-fueled mid-size sedan with fuel and maintenance cost of 1993 US $\$ 0.18 / \mathrm{km}$ $(\$ 0.29 / \mathrm{mile})$ as the baseline, please provide your estimate of the fuel and maintenance cost ratio for each of the five types of vehicles listed below in each of 3 future years. Do not include replacement cost for the propulsion battery pack in your estimate.

\section{SECOND STAGE RESULTS MEAN \\ YEAR $2000 \quad 2010 \quad 2020$}

(1) Conventional (piston) engines …............................. $1.19 \quad \underline{1.47}$

(2) Electric ................................................................ $1.41 \quad 1.43 \quad 1.54$

(3) Hybrid with conventional (piston) engine .................. $1.56 \quad 1.63 \quad \underline{1.88}$

(4) Hybrid with gas turbine ......................................... $\quad \underline{2.00 \quad 1.96} \quad \underline{2.08}$

(5) Hybrid with fuel cell ........................................... $\underline{2.66} \quad \underline{2.27} \quad \underline{2.35}$

Please describe below how you arrived at these values 


\section{VEHICLES - Fuel and Maintenance Cost Ratios}

(G) Part 2 - Using a conventional gasoline-fueled mid-size sedan with an estimated year 2000 fuel economy of 30 miles/ gallon $(12.75 \mathrm{~km} / \mathrm{L})$ as the baseline, please provide your estimate of the fuel economy ratio for each of the 5 types of vehicles listed below for each of the 3 future years.

\begin{tabular}{llll}
\multicolumn{3}{c}{ SECOND STAGE RESULTS MEAN } \\
YEAR & 2000 & 2010 & 2020 \\
& $\frac{1.00}{1.41}$ & $\frac{1.09}{1.54}$ & $\frac{1.16}{1.67}$ \\
& $\frac{1.18}{1.29}$ & $\frac{1.40}{1.52}$ \\
$\ldots \ldots \ldots \ldots \ldots . . .$. & $\frac{1.22}{1.40}$ & $\underline{1.59}$
\end{tabular}

(G) Part 3 - Please indicate the type of fuel that you have assumed for the three types of hybrid electric vehicles in each of 3 future years.

(1) Hybrid with conventional (piston) engine

(2) Hybrid with gas turbine

(3) Hybrid with fuel cell

YEAR $2000 \quad 2010 \quad 2020$

\begin{tabular}{|c|c|c|c|c|c|c|c|c|c|}
\hline \multirow[b]{2}{*}{ Fuel Type } & \multicolumn{3}{|c|}{ HEV/ICE } & \multicolumn{3}{|c|}{ HEV / Turbine } & \multicolumn{3}{|c|}{ HEV / Fuel Cell } \\
\hline & 2000 & 2010 & 2020 & 2000 & 2010 & 2020 & 2000 & 2010 & 2020 \\
\hline alcohol & & & & 1 & 1 & 1 & 2 & 3 & 3 \\
\hline methanol & 1 & 1 & 2 & 1 & 1 & 1 & 13 & 15 & 13 \\
\hline meth.,distil., or NG & & & & & & & 1 & 1 & 1 \\
\hline natural gas & & 3 & 3 & 3 & 5 & 4 & 2 & 3 & 1 \\
\hline CNG & & 5 & 6 & 8 & 11 & 10 & 4 & 5 & 3 \\
\hline LNG & & & & & & & 1 & 1 & 1 \\
\hline NG or hydrogen & & & & & & & 1 & 1 & 1 \\
\hline LPG or CNG & & 1 & 1 & & 1 & 1 & & & \\
\hline diesel & 4 & 5 & 4 & 5 & 6 & 6 & & & \\
\hline diesel \#2 & 1 & 2 & 1 & 1 & 1 & 1 & & & \\
\hline diesel or mid. distl. & & 1 & 1 & & & & & & \\
\hline jet fuel (JP4) & & & & 5 & 5 & 6 & & & \\
\hline jet fuel (JP8) & & & & 1 & 1 & 1 & & & \\
\hline kerosene & & & & 8 & 9 & 7 & & & \\
\hline diesel or kerosene & & & & 1 & 1 & 1 & & & \\
\hline diesel, JP4, or kerosene & & & & 1 & 1 & 1 & & & 1 \\
\hline fuel oil or kerosene & & & & 1 & 1 & 1 & & & \\
\hline fuel oil & & & & 3 & 2 & 2 & & & \\
\hline hydrogen & & & 1 & 1 & 1 & 2 & 20 & 20 & 24 \\
\hline hydrogen-air & & & & & & & & & 1 \\
\hline hydrogen-oxygen & & & & & & & 2 & 2 & 2 \\
\hline gasoline & 52 & 38 & 36 & 12 & 10 & 10 & 2 & 2 & 2 \\
\hline RFG & 5 & 4 & 4 & 1 & & & & & \\
\hline gas / alcohol & & 2 & 1 & & & & & & \\
\hline gas / coal & 1 & 1 & 1 & & & & & & \\
\hline methane & & & & 2 & 1 & 1 & 2 & 2 & 2 \\
\hline biofuel & & & & & & 1 & & & \\
\hline carbon & & & & & & & & & 1 \\
\hline electricity & & & & & & & 1 & 1 & 1 \\
\hline synfuel & & & 2 & & & 1 & & & \\
\hline propane & & & & & & & & & 1 \\
\hline No. of responses & 64 & 63 & 63 & 55 & 58 & 58 & 51 & 56 & 57 \\
\hline No response (blank) & 29 & 30 & 30 & 38 & 35 & 35 & 42 & 37 & 36 \\
\hline Total Population & 93 & 93 & 93 & 93 & 93 & 93 & 93 & 93 & 93 \\
\hline
\end{tabular}




\section{VEHICLES - Obstacles to Commercialization}

(H) Recent studies have estimated that EVs and HEVs could cost significantly more than their gasoline counterparts. Please rank from 1 (least important) to 6 (most important) the following six issues according to your belief in their potential to be obstacles to $\mathrm{EV}$ and $\mathrm{HEV}$ commercialization; use cost as the primary criterion.

\begin{tabular}{|c|c|c|}
\hline$\frac{\text { EVs }}{\text { RANK } 1-6}$ & $\begin{array}{l}\text { HEVs } \\
\text { RANK 1 - } 6\end{array}$ & \\
\hline$\underline{2.15}$ & 1.93 & Materials scarcity \\
\hline 4.77 & $\underline{4.75}$ & $\begin{array}{l}\text { Cost and complexities in manufacture of battery and drivetrain } \\
\text { needed to produce an attractive vehicle }\end{array}$ \\
\hline$\underline{5.09}$ & 4.99 & Sales volume too low for economical production \\
\hline$\underline{2.66}$ & $\underline{2.86}$ & Inadequate government R \& D support \\
\hline 3.16 & 3.22 & $\begin{array}{l}\text { Insufficient Corporate Average Fuel Economy (CAFE) credits to } \\
\text { offset costs of R \& D and vehicles }\end{array}$ \\
\hline$\underline{3.42}$ & $\underline{3.41}$ & $\begin{array}{l}\text { Failure of life cycle costing to include intangible environmental } \\
\text { benefits needed to offset } R \& D \text { and vehicle costs }\end{array}$ \\
\hline
\end{tabular}




\section{VEHICLES - Market Penetration}

(I) Please estimate the market (U.S.) share in percent for each of the six vehicle types listed below in each of three future years. Make sure the shares total to $100 \%$ in each column. Estimate the share of new light duty vehicle (passenger cars and light trucks) sales.

SECOND STAGE RESULTS MEAN NORMALIZED

YEAR $\quad 2000 \quad 2010 \quad 2020$

(1) Conventional (piston) engines ................................. $\quad \underline{97.12} \quad \underline{89.71} \quad \underline{77.55}$

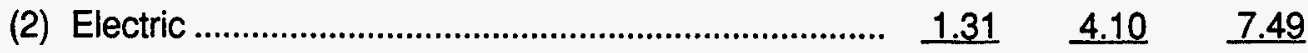

(3) Hybrid with conventional (piston) engine ..................... $1.14 \quad \underline{4.09} \quad \underline{7.91}$

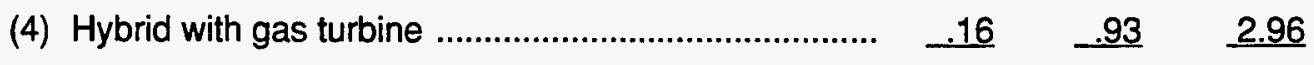

(5) Hybrid with fuel cell ................................................. $\quad .16 \quad \begin{array}{llll}.71 & 2.96\end{array}$

(6) Other technology not named above please stipulate)

$.11 \quad .46 \quad 1.13$

TOTALS $100 \% \quad 100 \% \quad 100 \%$ 


\section{COMPONENTS - Battery Characteristics}

(A) Battery technology is important to both electric and hybrid electric vehicles (EVs and HEVs). For each of the years 2000,2010 , and 2020 , please estimate achievable characteristics of as many of the ten types of batteries listed in the next page with which you are familiar. Please feel free to ask your colleagues to assist you in responding to this question.

\section{SECOND STAGE RESULTS MEAN}

Please provide your estimate of battery characteristics using the same units as the current batteries.

\begin{tabular}{|c|c|c|c|c|c|c|c|c|c|c|c|c|c|c|c|}
\hline $\begin{array}{l}\text { BATTERY } \\
\text { ChARACTERISTICS: }\end{array}$ & \multicolumn{3}{|c|}{$\begin{array}{l}\text { SPECIFIC } \\
\text { ENERGY }\end{array}$} & \multicolumn{3}{|c|}{$\begin{array}{l}\text { SPECIFIC } \\
\text { POWER AT } 50 \% \\
\text { DEPTH OF } \\
\text { BISCHARGE } \\
\text { (DOD) }\end{array}$} & \multicolumn{3}{|c|}{$\begin{array}{l}\text { grey- } \\
\text { MFE }\end{array}$} & \multicolumn{3}{|c|}{ 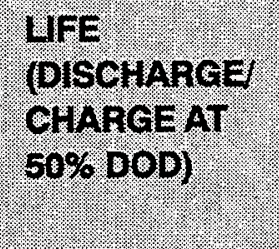 } & \multicolumn{3}{|c|}{$\begin{array}{l}\text { INITAL } \\
\text { Cost }\end{array}$} \\
\hline $\begin{array}{l}\text { Current lead acid } \\
\text { Current nickel cadmium } \\
\text { Current sodium sulfur }\end{array}$ & \multicolumn{3}{|c|}{$30 \mathrm{Wr}$} & \multicolumn{3}{|c|}{$\begin{array}{l}80 \mathrm{~W} / \mathrm{kg} \\
175 \\
130\end{array}$} & \multicolumn{3}{|c|}{$\begin{array}{l}3 \text { Years } \\
5 \\
4\end{array}$} & \multicolumn{3}{|c|}{$\begin{array}{l}500 \text { Cycles } \\
1000 \\
700\end{array}$} & \multicolumn{3}{|c|}{$\begin{array}{l}\text { US } \$ 200 / K W h \\
700 \\
400\end{array}$} \\
\hline YEAR & 용 & 웅 & 옹 & ᄋ & 웅 & ్ㅗํ & ᄋ & 웅 & 尺्ญ & ষ্ণ & 웅 & ్ㅗ & 융 & 웅 & 尺్ \\
\hline Lead acid & 40 & 44 & 48 & 155 & 190 & 214 & 3.43 & 4.37 & 4.43 & 611 & 740 & 872 & 185 & 179 & 184 \\
\hline Lithium iron disulfide & 97 & 116 & 138 & 167 & 209 & 269 & 3.48 & 4.62 & 5.72 & 519 & 698 & 884 & 853 & 664 & 622 \\
\hline Lithium polymer & 110 & 144 & 172 & 136 & 167 & 193 & 4.79 & 7.22 & 8.19 & 577 & 876 & 1185 & 592 & 406 & 296 \\
\hline Nickel cadmium & 57 & 60 & 62 & 189 & 199 & 209 & 5.74 & 6.61 & 7.84 & 1255 & 1428 & 1546 & 575 & 517 & 492 \\
\hline Nickel iron & 51 & 55 & 58 & 125 & 140 & 152 & 8.34 & 9.12 & 9.75 & 1055 & 1294 & 1545 & 529 & 482 & 448 \\
\hline Nickel metal hydride & 73 & 83 & 89 & 165 & 184 & 203 & 4.63 & 5.99 & 6.65 & 969 & 1177 & 1312 & 569 & 426 & 382 \\
\hline Nickel zinc & 61 & 68 & 74 & 171 & 192 & 214 & 3.08 & 4.17 & 4.78 & 427 & 570 & 716 & 654 & 587 & 548 \\
\hline Sodium sulfur & 95 & 102 & 107 & 144 & 153 & 160 & 4.23 & 5.36 & 5.26 & 683 & 829 & 910 & 392 & 339 & 318 \\
\hline Zinc air & 116 & 137 & 146 & 91 & 108 & 122 & 3.76 & 4.93 & 5.33 & 428 & 568 & 735 & 483 & 387 & 339 \\
\hline Zinc bromide & 69 & 75 & 79 & 94 & 110 & 124 & 3.19 & 4.22 & 4.96 & 560 & 704 & 840 & 667 & 576 & 523 \\
\hline
\end{tabular}




\section{COMPONENTS - Environmental Impact}

(B) The weight of vehicular propulsion battery modules will be in the hundreds of kilograms, or as much as one-third of vehicle curb weight, indicating a significant materials disposal problem at the end of the module's life. How would you rate the following battery types with respect to their (a) recyclability and (b) overall environmental impact with respect to residuals of manufacture, use, and disposal? Please use a scale of 1 (least recyclable, most negative environmental impact) to 10 (most recyclable, least negative environmental impact).

YOUR SECOND STAGE RESPONSE

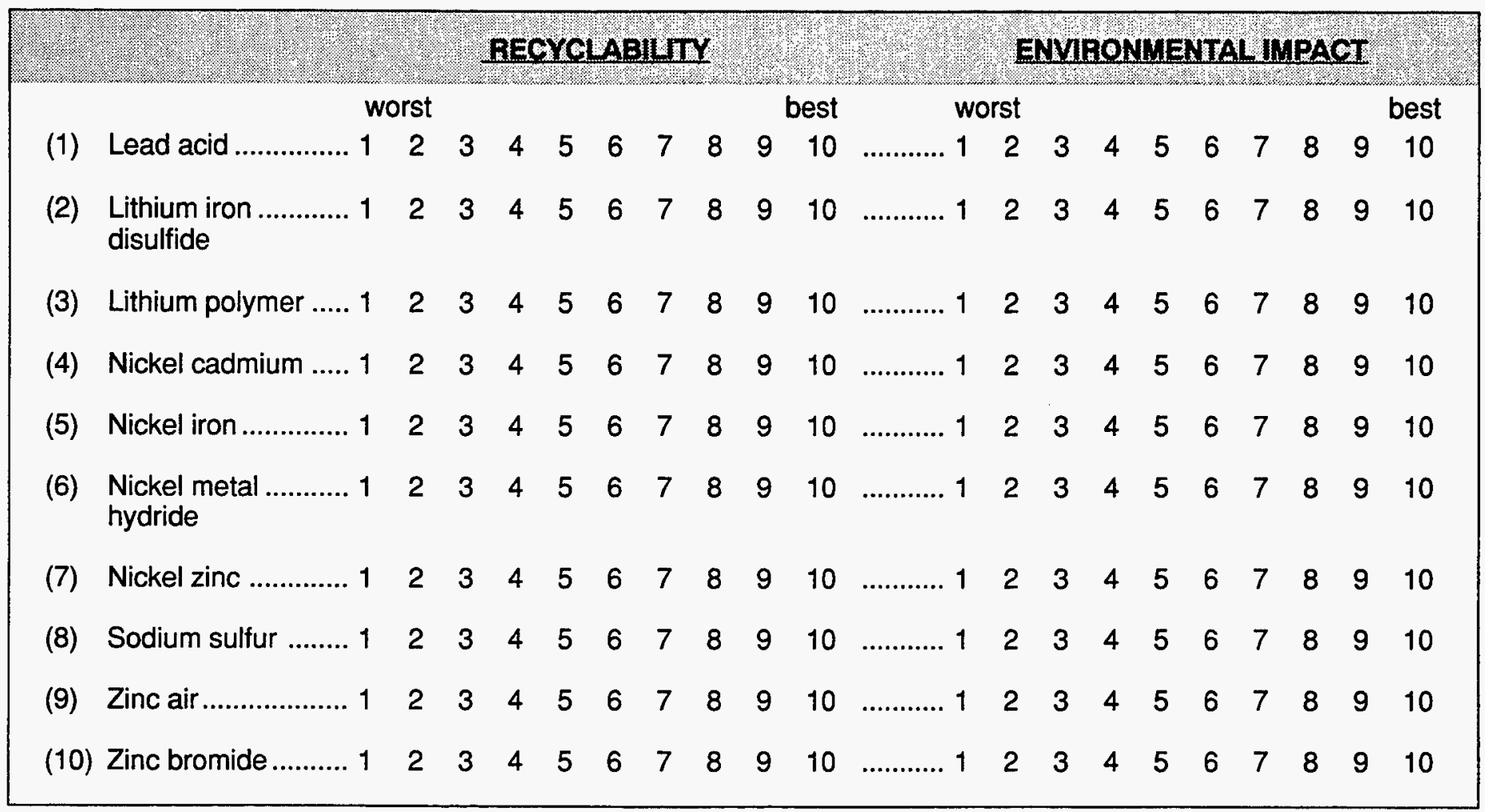

SECOND STAGE RESULTS RATING MEAN

\begin{tabular}{|lcc|}
\hline & RECYCLABILTY & ENVIRONMENTAL MPACT \\
\hline (1) Lead acid & 8.62 & 6.53 \\
(2) Lithium iron disulfide & 5.91 & 6.32 \\
(3) Lithium polymer & 5.93 & 7.02 \\
(4) Nickel cadmium & 6.22 & 4.25 \\
(5) Nickel iron & 6.62 & 6.38 \\
(6) Nickel metal hydride & 7.38 & 7.16 \\
(7) Nickel zinc & 6.45 & 6.39 \\
(8) Sodium sulfur & 6.10 & 6.34 \\
(9) Zinc air & 7.02 & 7.48 \\
(10) Zinc bromide & 4.57 & 3.98 \\
\hline
\end{tabular}




\section{COMPONENTS - Motors}

(C) The match between motor technology and propulsion battery system will be of great importance to the ultimate success of EVs and HEVs. Three candidate motor technology types are given below. For each of the projection years shown, please indicate your ranking of these three candidates from 1 (least likely) to 3 (most likely) with respect to your estimate of technological maturity and appropriateness of motor/battery system match in that year. Also please give your estimate of what each of these systems will cost, using as your index value (1.0) the cost of a 1993 DC motor and assuming amortization of necessary research, development, and demonstration. Assume equal production volumes for all candidates.

SECOND STAGE RESULTS RANK MEAN

\begin{tabular}{|c|c|c|c|}
\hline \multicolumn{4}{|c|}{ 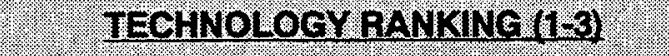 } \\
\hline & 2000 & 2010 & 2020 \\
\hline Direct current & 1.92 & 1.55 & 1.46 \\
\hline AC induction & $\underline{2.34}$ & $\underline{2.44}$ & $\underline{2.51}$ \\
\hline DC brushless & 1.79 & $\underline{2.11}$ & $\underline{2.14}$ \\
\hline
\end{tabular}

\section{SECOND STAGE RESULTS RANK MEAN}

\begin{tabular}{|lllll|}
\hline \multicolumn{4}{c}{ COST RATIO TO } & \multicolumn{3}{c|}{ 1993 DC MOTOR } \\
& 2000 & 2010 & 2020 \\
Direct current & $\underline{1.17}$ & $\underline{1.32}$ & $\underline{1.45}$ \\
AC induction & $\underline{1.74}$ & $\underline{1.50}$ & $\underline{1.42}$ \\
DC brushless & $\underline{2.45}$ & $\underline{1.99}$ & $\underline{1.68}$ \\
\hline
\end{tabular}

Please describe how you developed the cost ratios 


\section{COMPONENTS - Advanced Materials}

(D) Electric and hybrid vehicle design goals include low vehicle weight without sacrifice in occupant safety. Advanced materials may be good candidates for helping to achieve these goals, and EV production may in turn stimulate development and accelerate commercialization of advanced materials. A selection of materials likely to be used in EV/HEV production applications is given below. Please rate each with respect to the attributes shown, using a scale of 1 (poor performance on this attribute) to 5 (excellent performance on this attribute).

YOUR SECOND STAGE RESPONSE

\begin{tabular}{|c|c|c|c|c|c|c|c|c|c|c|c|c|c|}
\hline \multirow[b]{2}{*}{ (1) } & \multirow[b]{2}{*}{ 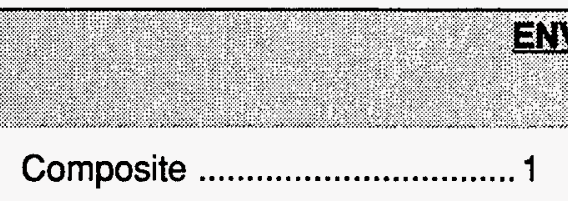 } & \multicolumn{3}{|c|}{$\begin{array}{l}\text { IMRONMENTA } \\
\text { BENEFIT }\end{array}$} & \multicolumn{4}{|c|}{$\begin{array}{l}\text { CORROSION } \\
\text { RESISTANCE }\end{array}$} & \multicolumn{5}{|c|}{$\begin{array}{c}\text { CRASH } \\
\text { WORTHINESS }\end{array}$} \\
\hline & & 2 & 3 & 4 & $5 \ldots \ldots \ldots \ldots . .1$ & 2 & 3 & 4 & $5 \ldots \ldots \ldots . .1$ & 2 & 3 & 4 & 5 \\
\hline (2) & Powdered metal ........................... 1 & 2 & 3 & 4 & $5 \ldots \ldots \ldots \ldots \ldots . .1$ & 2 & 3 & 4 & $5 \ldots \ldots \ldots \ldots \ldots . .1$ & 2 & 3 & 4 & 5 \\
\hline (3) & Plastics ...... & 2 & 3 & 4 & $5 \ldots \ldots \ldots \ldots \ldots \ldots$ & 2 & 3 & 4 & $5 \ldots \ldots \ldots \ldots \ldots . .1$ & 2 & 3 & 4 & 5 \\
\hline (4) & 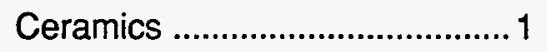 & 2 & 3 & 4 & $5 \ldots \ldots \ldots \ldots \ldots . .1$ & 2 & 3 & 4 & $5 \ldots \ldots \ldots \ldots \ldots . .1$ & 2 & 3 & 4 & 5 \\
\hline (5) & 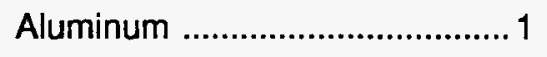 & 2 & 3 & 4 & 5 & 2 & 3 & 4 & $5 \ldots \ldots \ldots \ldots \ldots \ldots \ldots$ & 2 & 3 & 4 & 5 \\
\hline (6) & High-strength steel ....................... & 2 & 3 & 4 & $5 \ldots \ldots \ldots \ldots \ldots . . .1$ & 2 & 3 & 4 & $5 \ldots \ldots \ldots \ldots \ldots . . .1$ & 2 & 3 & 4 & 5 \\
\hline
\end{tabular}

\section{RELIABILITY}

(1) Composite

(2) Powdered metal

(3) Plastics

(4) Ceramics

(5) Aluminum

(6) High-strength steel

\begin{abstract}
$\begin{array}{llll}2 & 3 & 4 & 5\end{array}$
\end{abstract}
$\begin{array}{llll}2 & 3 & 4 & 5\end{array}$

$\begin{array}{llll}2 & 3 & 4 & 5\end{array}$

$\begin{array}{llll}2 & 3 & 4 & 5\end{array}$

$\begin{array}{llll}2 & 3 & 4 & 5\end{array}$

$\begin{array}{llll}2 & 3 & 4 & 5\end{array}$

\section{DURABILTTY}

COST EFFECTIVENESS

\section{SECOND STAGE RESULTS RATING MEAN}

\begin{tabular}{|l|c|c|c|c|c|c|}
\hline & $\begin{array}{c}\text { ENV } \\
\text { BENEFIT }\end{array}$ & $\begin{array}{c}\text { CORROSION } \\
\text { RESISTANCE }\end{array}$ & $\begin{array}{c}\text { CRASH } \\
\text { WORTHINESS }\end{array}$ & RELIABILITY & DURABILITY & $\begin{array}{c}\text { COST } \\
\text { EFF }\end{array}$ \\
\hline (1) Composite & 2.97 & 4.57 & 3.85 & 3.64 & 3.89 & 2.76 \\
\hline (2) Powdered metal & 3.11 & 2.97 & 2.85 & 3.39 & 3.32 & 2.99 \\
\hline (3) Plastics & 3.14 & 4.65 & 3.09 & 3.55 & 3.54 & 4.00 \\
\hline (4) Ceramics & 3.43 & 4.53 & 2.32 & 2.92 & 3.37 & 2.47 \\
\hline (5) Aluminum & 3.66 & 3.59 & 3.88 & 4.14 & 4.07 & 3.68 \\
\hline $\begin{array}{l}\text { (6) High-strength } \\
\text { steel }\end{array}$ & 3.70 & 2.71 & 4.51 & 4.76 & 4.29 & 4.45 \\
\hline
\end{tabular}




\section{COMPONENTS - Combustion Engines for Hybrids}

(E) The five engine types given below may all be used in hybrid electric vehicles after appropriate modification and optimization. Please rank these five from 1 (least) to 5 (most) with respect to technological maturity, suitability, and cost effectiveness in each of the three future years shown.

\section{SECOND STAGE RESULTS RANK MEAN}

\begin{tabular}{|llll|}
\hline \multicolumn{4}{|c|}{ TECHNOLOGICAL MATURITY RANKING (1-5) } \\
\hline & 2000 & 2010 & 2020 \\
2-stroke Otto (SI) & $\underline{3.15}$ & $\underline{3.03}$ & $\underline{3.03}$ \\
4-stroke Otto (SI) & $\underline{4.67}$ & $\underline{4.44}$ & $\underline{4.18}$ \\
Diesel (CI) & $\underline{3.86}$ & $\underline{4.01}$ & $\underline{3.91}$ \\
Gas turbine & $\underline{2.18}$ & $\underline{2.58}$ & $\underline{3.11}$ \\
Fuel cell & $\underline{1.18}$ & $\underline{1.47}$ & $\underline{1.90}$ \\
\hline
\end{tabular}

\begin{tabular}{|c|c|c|c|}
\hline \multicolumn{4}{|c|}{ 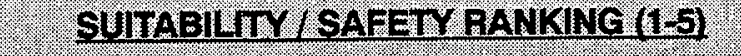 } \\
\hline & 2000 & 2010 & 2020 \\
\hline 2-stroke Otto (SI) & $\underline{2.94}$ & $\underline{2.69}$ & $\underline{2.67}$ \\
\hline 4-stroke Otto (SI) & $\underline{4.51}$ & $\underline{4.11}$ & $\underline{3.66}$ \\
\hline Diesel (Cl) & $\underline{3.82}$ & $\underline{3.93}$ & $\underline{3.83}$ \\
\hline Gas turbine & $\underline{2.35}$ & 2.84 & $\underline{3.15}$ \\
\hline Fuel cell & 1.39 & 1.87 & $\underline{2.49}$ \\
\hline
\end{tabular}

\begin{tabular}{|llll|}
\hline \multicolumn{4}{|c|}{ COST EFFECTINENESS RANKING $(1-5)$} \\
\hline & 2000 & 2010 & 2020 \\
2-stroke Otto (SI) & $\underline{3.28}$ & $\underline{3.36}$ & $\underline{3.33}$ \\
4-stroke Otto (SI) & $\underline{4.71}$ & $\underline{4.41}$ & $\underline{3.87}$ \\
Diesel (CI) & $\underline{3.59}$ & $\underline{3.57}$ & $\underline{3.49}$ \\
Gas turbine & $\underline{2.17}$ & $\underline{2.42}$ & $\underline{2.67}$ \\
Fuel cell & $\underline{1.23}$ & $\underline{1.39}$ & $\underline{1.93}$ \\
\hline
\end{tabular}




\section{COMPONENTS - Advanced Concepts}

(F) Could high technologies be modified in order to benefit electric vehicle applications? What are the advanced technologies most likely to be both available and useful for EV and HEV application in the years 2000, 2010, and 2020? For each year please rank the five candidate technologies below for, respectively, (a) viability and (b) cost in each of these years, using a scale of 1 (weakest technological candidate; excessive cost) to 5 (strongest technological candidate; most reasonable cost).

SECOND STAGE RESULTS RANK MEAN

\begin{tabular}{|llll|}
\hline \multicolumn{4}{|c|}{ TECHNOLOGICAL VIABILM } \\
\hline & 2000 & 2010 & 2020 \\
Advanced electronics & $\underline{4.48}$ & $\underline{4.38}$ & $\underline{4.39}$ \\
$\begin{array}{l}\text { Very light, high tensile } \\
\text { strength materials }\end{array}$ & $\underline{3.63}$ & $\underline{3.73}$ & $\underline{3.71}$ \\
$\begin{array}{l}\text { Extended-life batteries } \\
\text { Solar conversion devices }\end{array}$ & $\underline{3.12}$ & $\underline{3.37}$ & $\underline{3.62}$ \\
Ultra capacitors & $\underline{1.83}$ & $\underline{2.12}$ & $\underline{1.65}$ \\
\hline
\end{tabular}

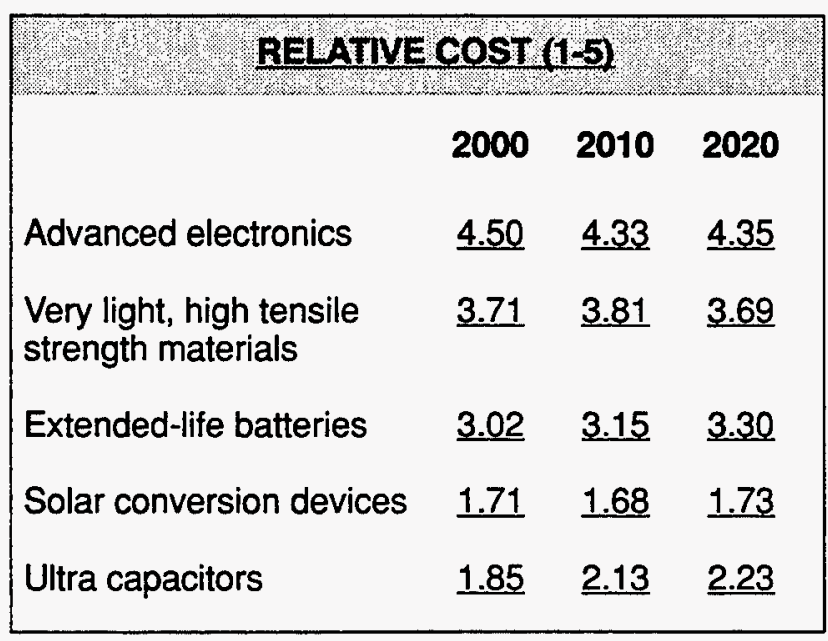




\section{SYSTEM IMPACTS - Air Pollution}

(A) Please indicate whether you agree or disagree with the following statements.

YOUR SECOND STAGE RESPONSE

AGREE DISAGREE

(1) Electricity used by EVs and HEVs will be generated predominantly

口 from coal.

(2) If (1) is true, total emissions of carbon dioxide and, possibly, of oxides of nitrogen and sulfur will increase.

(3) Most electricity used by EVs and HEVs will be generated . from natural gas and other low-carbon-per-kW fuels.

(4) Nuclear power will play an important role in electricity generation for EVs.

(5) Any increases in power plant emissions due to EV use will be offset at the local level by decreases in on-road emissions.

(6) Most EV charging will use overnight base load capacity, resulting in little net increase in daytime power plant emissions.

(7) EVs will be environmentally beneficial due to displacement of emissions from urban areas to remote power plants and from daytime to nighttime.

(8) EVs will help reduce urban ozone levels due to displacement of gasoline combustion and storage by fuels and/or energy

\begin{tabular}{|c|}
$\begin{array}{c}\text { Socond Stage } \\
\text { Results } \\
\text { \% AGREE }\end{array}$ \\
49 \\
71 \\
47 \\
40 \\
87 \\
92 \\
93
\end{tabular}
production techniques with lower ozone-forming potential.

(B) Please indicate whether you agree or disagree with the following statements on global warming.

\section{YOUR SECOND STAGE RESPONSE AGREE DISAGREE}

(1) EVs and HEVs will reduce global warming potential by 2020 even if these vehicles have a market share of only 33 percent.

(2) The complexity of global warming as a scientific issue requires that many more studies must be undertaken before key policy decisions are made.

(3) Mitigation of global warming potential could have significant socio-economic benefits.

(4) Global warming has been unmasked as such an unimportant issue that future decisions about transportation policy should not be required to consider it.

(5) Policies with significant implications for global warming potential will be implemented by governments no later than year 2000 .

\begin{tabular}{|c|}
\hline $\begin{array}{c}\text { Second Stage } \\
\text { Results } \\
\% \text { A GREE }\end{array}$ \\
44 \\
84 \\
81 \\
16 \\
\end{tabular}




\section{SYSTEM IMPACTS - Nuclear Energy}

(C) Europe and Asia have both made a strong commitment to nuclear power, concluding that, in general, only nuclear power can provide both sufficiently high energy efficiency and low air pollution at reasonable cost. In the U.S., attitudes about the necessity for nuclear power are far more equivocal. Please rank the six following possible causes for this difference in the U.S. position using a scale of 1 (strongest disagreement) to 6 (strongest agreement).

\section{RANK 1 - 6}

\section{YOUR SECOND STAGE RESPONSE}

Second Stage Results RANK MEAN

Relative abundance of coal in the U.S.

Relative abundance of natural gas in the U.S.

Perceived superiority of U.S. fossil fuel power plant technology

Continued availability in the U.S. of remote areas for building non-nuclear power plants which disperse pollution from tall stacks

Negative public opinion due to accidents or near accidents in U.S.

Lack of perception or education about the relative costs and environmental benefits of nuclear, fossil, and renewable energy plant technologies, including costs of residuals disposal

\section{SYSTEM IMPACTS - Market Success Factors}

(D) Please rate the following based on your perception of actions required in order to improve the chances of successful EV/HEV commercialization in the 1990s. Use a scale of 1 (strongest disagreement) to 5 (strongest agreement).

\section{YOUR SECOND STAGE RESPONSE}

\section{RATING} strongly disagree strongly agree

(1) Acquisition and operating costs must be reduced

(2) Commitment by original equipment manufacturers must be greater

(3) There must be enough $R$ \& $D$ to ensure excellent product

(4) EV/HEVs must be as reliable as gasoline vehicles

(5) Key technologies must be implemented

(6) Supporting infrastructure must be developed

(7) Urban air pollution must continue to be perceived as a severe problem

(8) Public policy must sufficiently incorporate environmental imperative

(9) A new oil crisis would have to occur
EV/HEV performance must rival that of internal combustion engine vehicles .....1 1

Large direct incentives to buyers are necessary . .1

$\begin{array}{llll}2 & 3 & 4 & 5 \\ 2 & 3 & 4 & 5 \\ 2 & 3 & 4 & 5 \\ 2 & 3 & 4 & 5 \\ 2 & 3 & 4 & 5 \\ 2 & 3 & 4 & 5 \\ 2 & 3 & 4 & 5 \\ 2 & 3 & 4 & 5 \\ 2 & 3 & 4 & 5 \\ 2 & 3 & 4 & 5 \\ 2 & 3 & 4 & 5 \\ 2 & 3 & 4 & 5\end{array}$

Second Stage Results RATING MEAN

4.78

3.82

4.26

4.62

4.04

4.12

4.10

3.83

2.58 


\section{DISTRIBUTION FOR ANL/ESD-36}

\section{Internal}

ANL Publications and Record Services Dept.

A. Vyas (341)

F. Bennett

R. Weeks

L. Welko

\section{External}

U.S. Department of Energy Office of Scientific and Technical Information (2)

Manager, U.S. Department of Energy Chicago Field Office ANL-E Libraries

ANL-W Library 


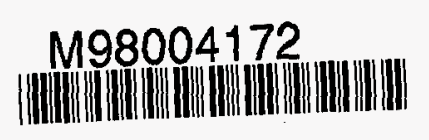

Report Number (14) ANL/ESD--36

Publ. Date (11) $\frac{1997 / 2}{D O E / E E, X F}$
Sponsor Code (18)
UC Category (19) 